\title{
GEOGRAFIA DA MORTALIDADE NO TRÂNSITO NO BRASIL
}

Dissertação apresentada à Escola de Engenharia de São Carlos, da Universidade de São Paulo, como parte dos requisitos para a obtenção do título de Mestre em Ciências, Programa de Pós-graduação em Engenharia de Transportes. Área de concentração: Planejamento e operações de Sistema de Transportes

Orientador: Prof. Titular Antonio Clóvis Pinto Ferraz 
AUTORIZO A REPRODUÇÃO E DIVULGAÇÃO TOTAL OU PARCIAL DESTE TRABALHO, POR QUALQUER MEIO CONVENCIONAL OU ELETRÔNICO, PARA FINS DE ESTUDO E PESQUISA, DESDE QUE CITADA A FONTE.

Ficha catalográfica preparada pela Seção de Tratamento da Informação do Serviço de Biblioteca - EESC/USP

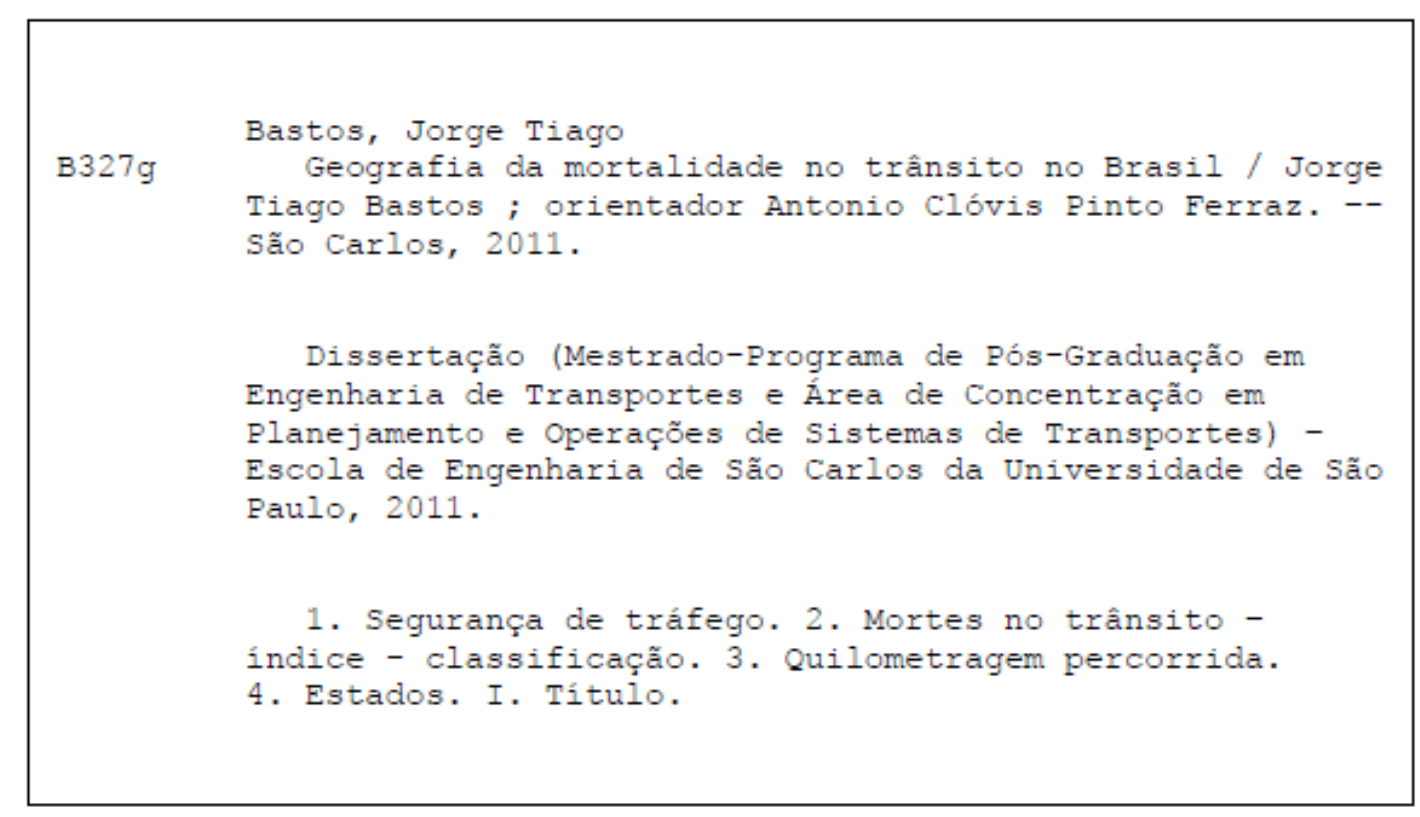




\section{FOLHA DE JULGAMENTO}

Candidato(a): Engenheiro JORGE TIAGO BASTOS.

Dissertação defendida e julgada em 07/02/2011 perante a Comissão Julgadora:

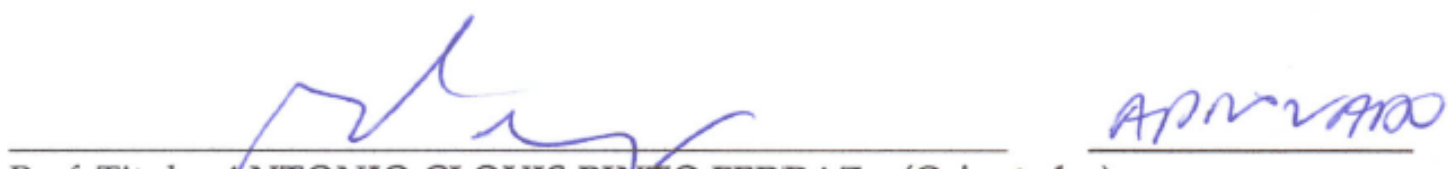

Prof. Titular ANTONIO CLOVIS PIXYTO FERRAZ - (Orientador)

(Escola de Engenharia de São Carlos/USP)

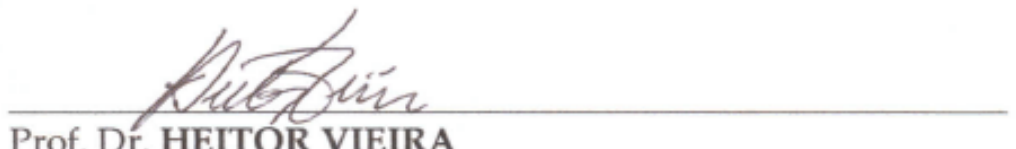

qPror4do

(Universidade Federal do Rio Grande/FURG)

Pelasabrombosa.

APROVADO

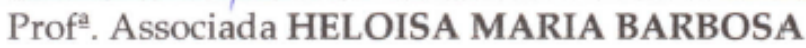

(Universidade Federal de Minas Gerais/UFMG)

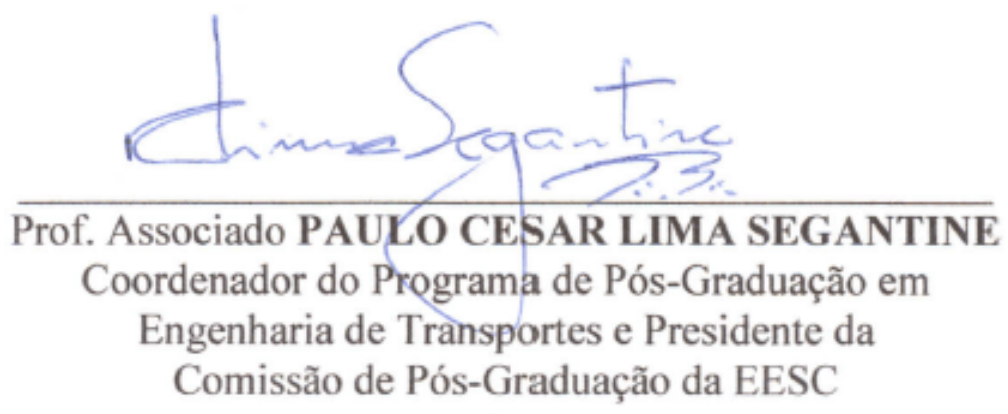





\section{DEDICATÓRIA}

Aos meus pais, Jorge e Lizete,

e irmãos, Fernando e Ianaê.

Pela compreensão e apoio em

todos os momentos. 



\section{AGRADECIMENTOS}

Ao Prof. Dr. Antonio Clóvis Pinto Ferraz (Coca), pela orientação, amizade e experiência transmitida.

A Prof ${ }^{\mathrm{a}}$. Dr ${ }^{\mathrm{a}}$. Bárbara Stolte Bezerra, pelo imprescindível apoio.

Aos colegas e amigos da pós-graduação - em especial Madalena Ribeiro, Isabela Fornaciari e Luciana Spigolon - pela convivência diária, além de Gustavo Riente, Victor Alves, Cândido Andrade, Joicy Poloni, Magaly Romão e Marcelo Mancini.

Aos amigos de longa data, que acompanham minha trajetória e torcem por mim.

Aos amigos e revisores Karina Camargo e Osvaldo Arruti.

A Deise Barboza Schiavon Segalla, pelo fornecimento de dados de frota de veículos da ANFAVEA/SINDIPEÇAS.

A todos os professores e funcionários do Departamento de Transportes da EESC-USP.

A CAPES, pela bolsa de estudos concedida. 

BASTOS, J. T. Geografia da mortalidade no trânsito no Brasil. São Carlos, 2010, 146 p. Dissertação (Mestrado) - Escola de Engenharia de São Carlos, Universidade de São Paulo.

Neste trabalho é estimado o valor do índice de mortes por quilômetro percorrido pela frota de veículos rodoviários no Brasil e em cada estado da federação nos anos de 2004 a 2008. Para determinar os valores da quilometragem anual média dos veículos - parâmetro necessário para estimativa do índice de mortes por veículo-quilômetro - desenvolveu-se um método apropriado tomando como referência a quantidade de combustível vendida pelas distribuidoras em cada estado. Os estados foram classificados em relação a todos os índices associados à mortalidade viária, assim como analisadas as relações entre o índice de mortes por quilômetro e o nível de desenvolvimento econômico dos estados. Constata-se que a situação da mortalidade no trânsito é um grave problema nacional, sobretudo nos estados mais pobres, onde os índices de mortes por veículo-quilômetro atingem números extremamente elevados. $\mathrm{O}$ fato positivo é que os números apontam para uma redução contínua do índice de mortes por quilômetro, que passou de 68,26 para 55,87 mortes por bilhão de quilômetros no país entre 2004 e 2008 (queda de 18,15\%). Isso se deve ao aumento da quilometragem percorrida, função do aumento da frota, do crescimento econômico e de certa estabilização do número de mortes; este último em decorrência de ações em âmbito nacional implementadas pelo governo federal, bem como de ações específicas levadas a efeito em alguns estados.

Palavras - Chave: Segurança de Tráfego. Mortes no trânsito - índice - classificação. Quilometragem percorrida. Estados. 

BASTOS, J. T. Geography of traffic fatalities in Brazil. São Carlos, 2010, 146 p. Dissertação (Mestrado) - Escola de Engenharia de São Carlos, Universidade de São Paulo.

This research estimated the value of the rate of deaths per kilometer traveled by the road vehicles fleet in Brazil and in each of the states of the federation, in the years 2004 to 2008. To determine the values of the average annual distance traveled by vehicles - parameter needed to estimate the rate of deaths per vehicle-kilometers - an appropriate methodology has been developed with reference on the amount of fuel sold by distributors in every state. The states were ranked according to all indexes associated with road fatalities, and the relationship between the rate of deaths per kilometer and the level of economic development of states, expressed by the motorization rate and the GDP per capita, is analyzed. It appears that the situation of traffic mortality is a serious national problem, especially in the poorest states, where the rate of deaths per vehicle-km reaches very high figures. The positive fact is that the numbers point to a continued reduction in the rate of deaths per kilometer, which decreased from 68.26 to 55.87 deaths per billion $\mathrm{km}$ in the country between 2004 and 2008 (a decrease of $18.15 \%$ ). This is due to the increase on the distance traveled, a result of the increased fleet and economic growth, and also of some stabilization in the number of deaths; being the last a consequence of nationwide actions implemented by the federal government, and also of specific actions carried out in some states.

Keywords: Traffic safety. Traffic fatalities indexes and ranking. Distance traveled. States. 



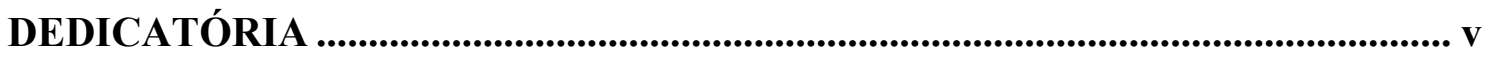

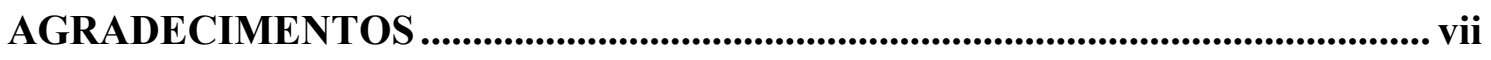

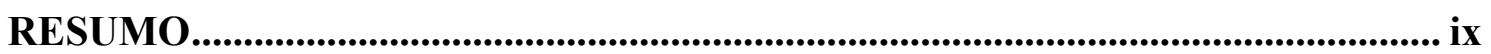

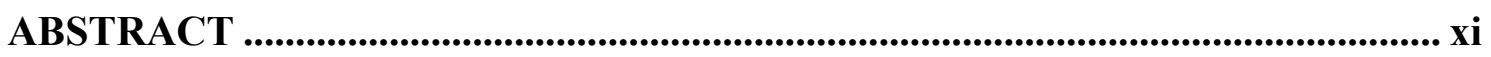

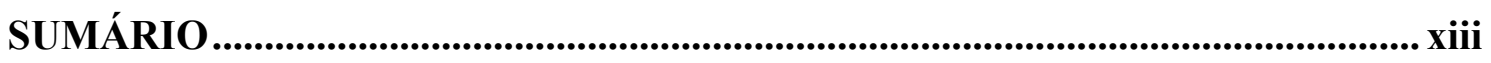

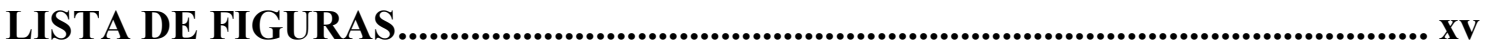

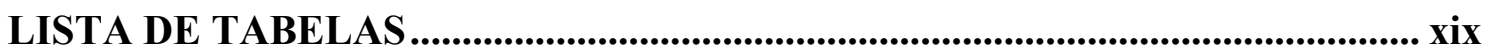

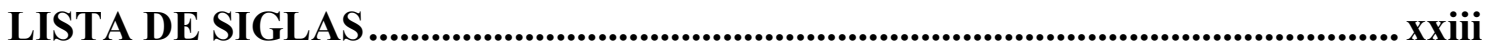

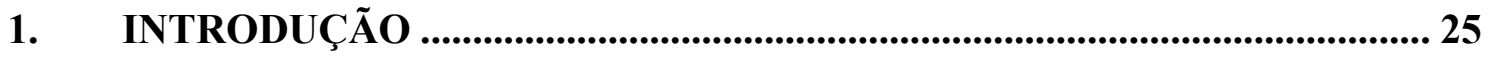

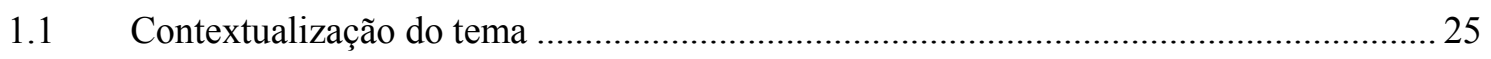

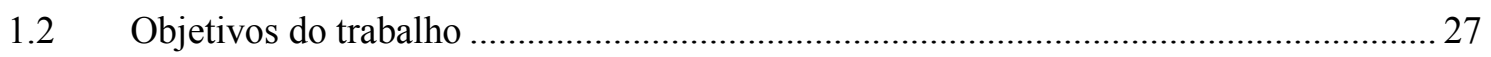

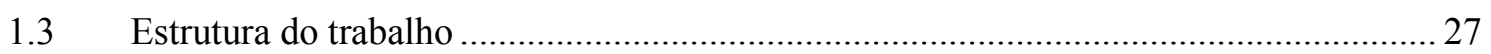



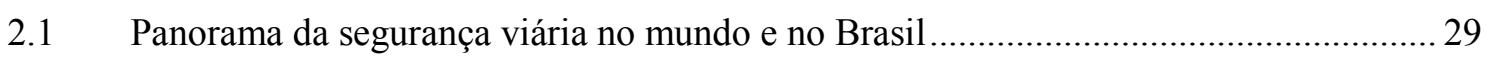

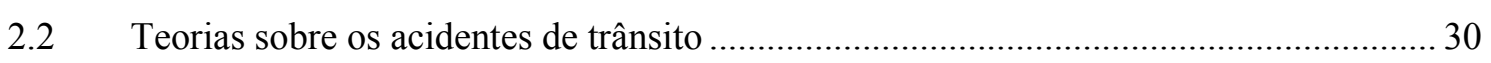

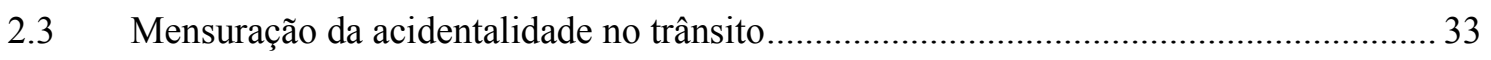

2.4 Acidentalidade no trânsito e desenvolvimento econômico e social .................................. 37

2.5 A exposição ao trânsito e o risco de acidentes ..................................................................... 37

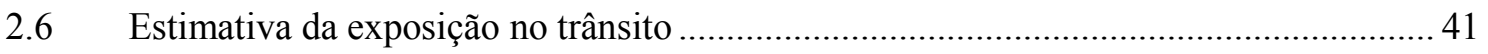

3. FONTES DE DADOS PARA A MENSURAÇÃO DA MORTALIDADE NO

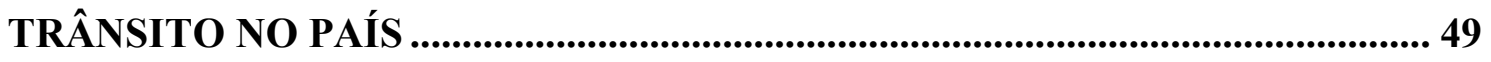

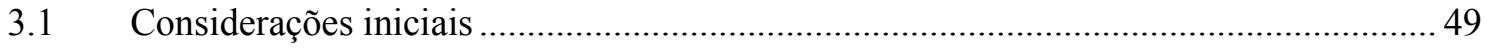

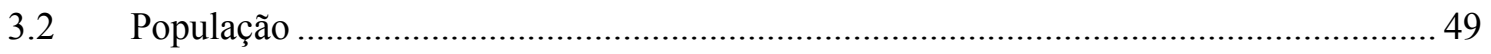

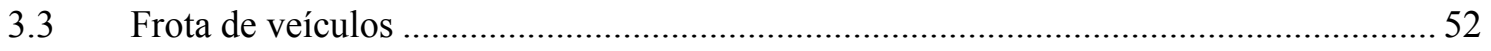

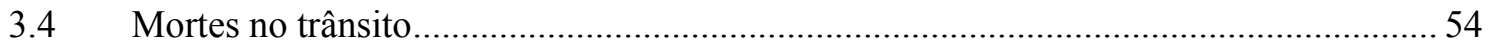

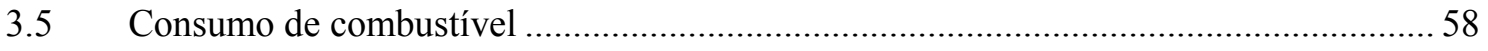

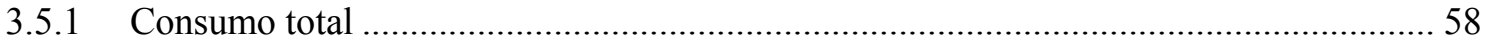

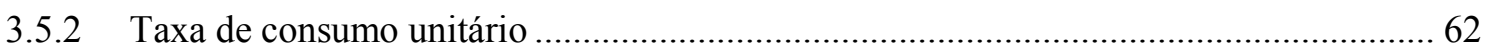

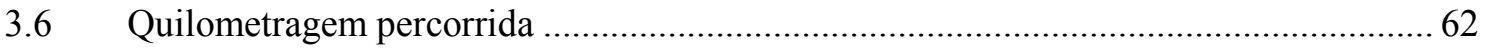


4. MÉTODO DE CÁLCULO DO ÍNDICE DE MORTES POR QUILÔMETRO ......................................................................................................65



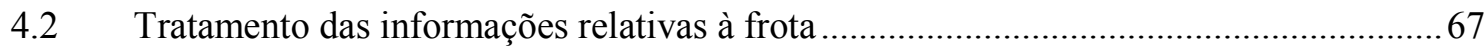

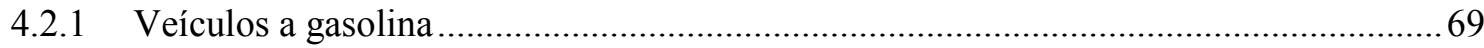

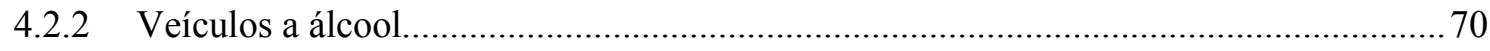

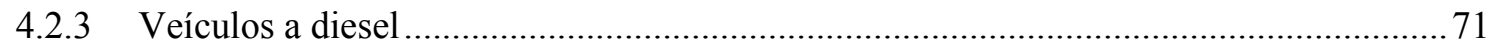

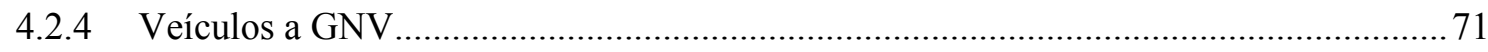

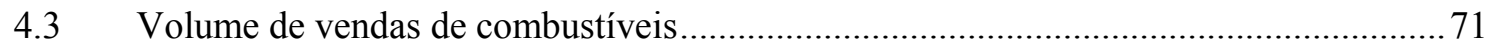



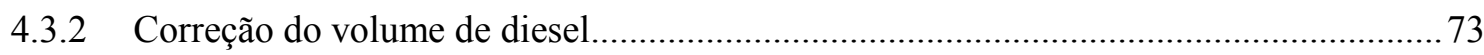





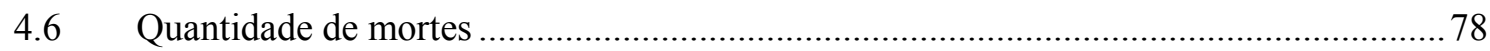

4.7 Índice de mortes por veículo.quilômetro percorrido .......................................................79

5. VALORES OBTIDOS E ANÁLISE DOS RESULTADOS ............................81

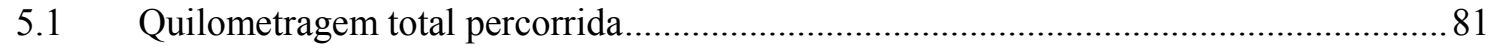

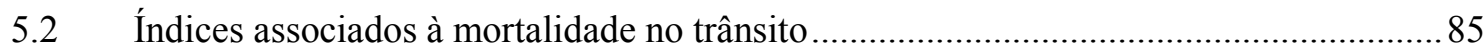

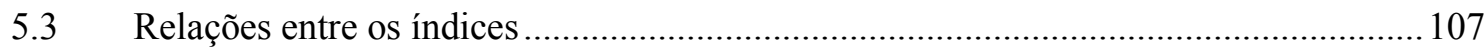

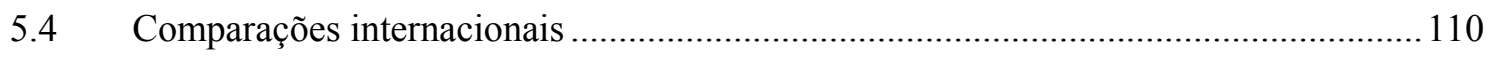

6. CONCLUSÕES E RECOMENDAÇÕES ......................................................113

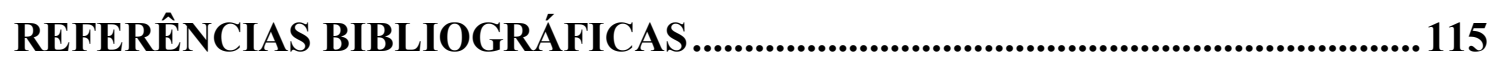

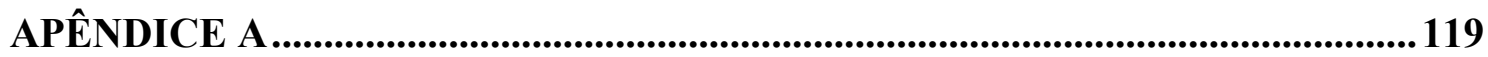

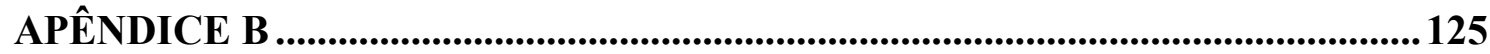

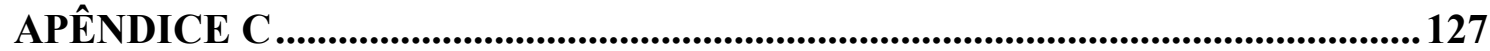



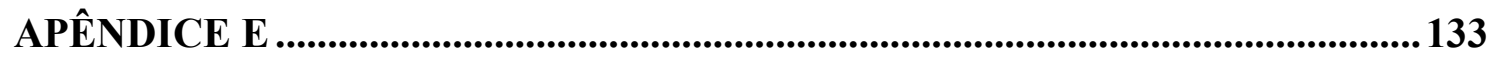

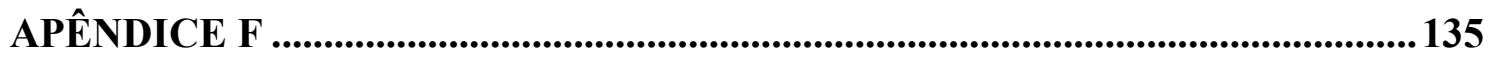



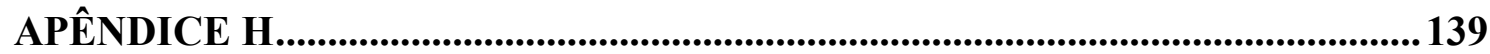

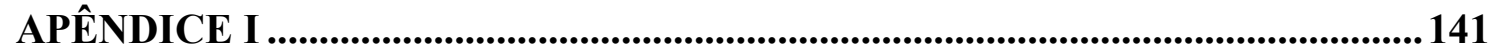

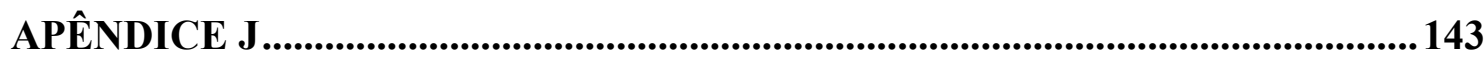

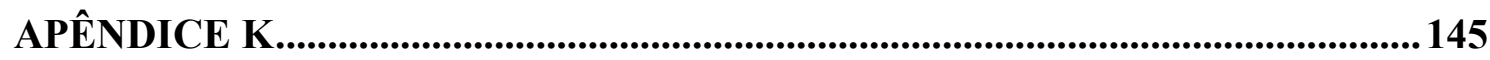

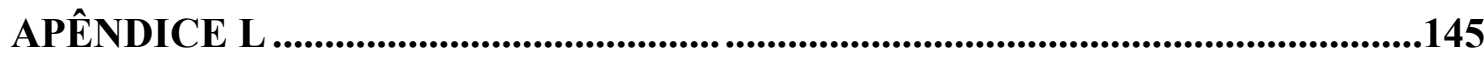




\section{LISTA DE FIGURAS}

Figura 2.1 - Taxa de mortes para cada 100.000 habitantes...................................................34

Figura 2.2 - Taxa de mortes para cada 100.000 veículos.......................................................34

Figura 2.3 - Comparação das taxas de mortes por população e frota de veículos....................35

Figura 2.4 - Curva típica do desenvolvimento da motorização..............................................36 nos países industrializados

Figura 2.5 - Taxa de mortes por bilhão de veículos x km no ano de 2006 .36



Figura 3. 2 - Distribuição da quilometragem média anual $(\mathrm{em} \mathrm{km})$....................................63 de acordo com a idade do veículo

Figura 4. 1- Fluxograma das informações usadas para o cálculo do .66 índice de mortes por veículo x quilômetro

Figura 4. 2- Classificação da frota - compatibilização dos dados do. .68 DENATRAN para ANFAVEA/SINDIPEÇAS

Figura 5.1 - Variação da quilometragem média anual no Brasil. 83 no período $2004-2008$

Figura 5.2 - Variação da quilometragem média anual no Brasil. .83 no período $2004-2008$

Figura 5.3 - Quilometragem média anual x Índice de motorização. . .84

Figura 5.4 - Quilometragem total x PIB per capita no país...............................................84

Figura 5.5- Mapa temático do índice de mortes por quilômetro percorrido em 2004.............93

Figura 5.6- Mapa temático do índice de mortes por quilômetro percorrido em 2005............94

Figura 5.7- Mapa temático do índice de mortes por quilômetro percorrido em 2006............94

Figura 5.8- Mapa temático do índice de mortes por quilômetro percorrido em 2007............95

Figura 5.9- Mapa temático do índice de mortes por quilômetro percorrido em 2008.............95 
Figura 5.10- Índice de mortes por bilhão de quilômetros, por 100mil.

habitantes, por 100mil veículos e índice de motorização

no Brasil no período 2004-2008

Figura 5.11- Índice de mortes por bilhão de quilômetros no Acre

.97 no período 2004-2008

Figura 5.12- Índice de mortes por bilhão de quilômetros em Alagoas .97 no período 2004-2008

Figura 5.13- Índice de mortes por bilhão de quilômetros no Amapá. .98 no período 2004-2008

Figura 5.14- Índice de mortes por bilhão de quilômetros no Amazonas. .98 no período 2004-2008

Figura 5.15- Índice de mortes por bilhão de quilômetros na Bahia. . .98 no período 2004-2008

Figura 5.16- Índice de mortes por bilhão de quilômetros no Ceará. . .99 no período 2004-2008

Figura 5.17- Índice de mortes por bilhão de quilômetros no Distrito Federal .99 no período 2004-2008

Figura 5.18- Índice de mortes por bilhão de quilômetros no Espírito Santo .99 no período 2004-2008

Figura 5.19- Índice de mortes por bilhão de quilômetros em Goiás. 100 no período 2004-2008

Figura 5.20- Índice de mortes por bilhão de quilômetros no Maranhão. 100 no período 2004-2008

Figura 5.21- Índice de mortes por bilhão de quilômetros no Mato Grosso .100 no período 2004-2008

Figura 5.22- Índice de mortes por bilhão de quilômetros no Mato Grosso do Sul. no período 2004-2008

Figura 5.23- Índice de mortes por bilhão de quilômetros em Minas Gerais. 101 no período 2004-2008

Figura 5.24- Índice de mortes por bilhão de quilômetros no Pará. no período 2004-2008

Figura 5.25- Índice de mortes por bilhão de quilômetros na Paraíba 102 no período 2004-2008 
Figura 5.26- Índice de mortes por bilhão de quilômetros no Paraná. no período 2004-2008

Figura 5.27- Índice de mortes por bilhão de quilômetros em Pernambuco. 102 no período 2004-2008

Figura 5.28- Índice de mortes por bilhão de quilômetros no Piauí 103 no período 2004-2008

Figura 5.29- Índice de mortes por bilhão de quilômetros no Rio de Janeiro. 103 no período $2004-2008$

Figura 5.30- Índice de mortes por bilhão de quilômetros no Rio Grande do Norte. 103 no período 2004-2008

Figura 5.31- Índice de mortes por bilhão de quilômetros no Rio Grande do Sul 104 no período 2004-2008

Figura 5.32- Índice de mortes por bilhão de quilômetros em Rondônia. 104 no período 2004-2008

Figura 5.33- Índice de mortes por bilhão de quilômetros em Roraima. 104 no período 2004-2008

Figura 5.34- Índice de mortes por bilhão de quilômetros em Santa Catarina 105 no período 2004-2008

Figura 5.35- Índice de mortes por bilhão de quilômetros em São Paulo no período 2004-2008

Figura 5.36- Índice de mortes por bilhão de quilômetros em Sergipe. 105 no período 2004-2008

Figura 5.37- Índice de mortes por bilhão de quilômetros em Tocantins. .106 no período 2004-2008

Figura 5.38- Análise da evolução dos índices em relação à redução média nacional 107

Figura 5.39- Relação entre o índice de mortes/bilhão de km e o índice de. 108 mortes/100 mil veículos (2008)

Figura 5.40- Relação entre o índice de motorização e o PIB per capita em 2007. 108

Figura 5.41- Relação entre o índice de mortes por bilhão de quilômetros. 109 e o índice de motorização em 2008

Figura 5.42- Relação entre o índice de mortes por bilhão de quilômetros. .109 e o PIB per capita em 2007 
Figura 5.43- Comparação da quilometragem média anual no Brasil...................................110 e em outros países

Figura 5.44- Comparação do índice de mortes por bilhão de quilômetros............................111 no Brasil (2008) e em outros países (2009) 


\section{LISTA DE TABELAS}

Tabela 3.1 - População brasileira no período 2004-2008 (habitantes) ..................................50

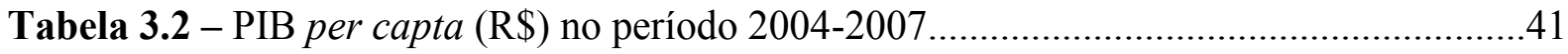

Tabela 3.3 - Frota de veículos no período 2004-2008, segundo o DENATRAN...................52

Tabela 3.4 - Agrupamento dos códigos para acidentes de transporte, segundo......................55 a CID-10

Tabela 3.5 - Categorias do agrupamento V01-V09 .55 (pedestre traumatizado em acidente de transporte)

Tabela 3.6 - Categorias do agrupamento V10 -V19 .55 (ciclista traumatizado em acidente de transporte)

Tabela 3.7 - Categorias do agrupamento V20 -V29. .56 (motociclista traumatizado em acidente de transporte)

Tabela 3.8 - Categorias do agrupamento V30 -V39 .56 (ocupante de triciclo motorizado traumatizado em acidente de transporte)

Tabela 3.9 - Categorias do agrupamento V40 - V49. .56 (ocupante de automóvel traumatizado em acidente de transporte)

Tabela 3.10 - Categorias do agrupamento V50 -V59. .57 (ocupante de caminhonete traumatizado em acidente de transporte)

Tabela 3.11 - Categorias do agrupamento V60 -V69. .57 (ocupante de veículo de transporte pesado traumatizado em acidente de transporte)

Tabela 3.12 - Categorias do agrupamento V70 -V79. (ocupante de ônibus traumatizado em acidente de transporte)

Tabela 3.13 - Categorias do agrupamento V80 -V89. .58 (outros acidentes de transporte terrestre)

Tabela 3.14 - Consumo setorial de óleo diesel no Brasil entre 2004 e 2008. .60

Tabela 3.15 - Consumo setorial de álcool hidratado no Brasil entre 2004 e 2008. .61

Tabela 3.16 - Consumo setorial de gasolina no Brasil entre 2004 e 2008 .61 
Tabela 3.17 - Preço médio (R\$/litro) do álcool e da gasolina no Brasil. 61 no período 2004-2008

Tabela 3.18 - Quilometragem anual para ônibus (2004) .64

Tabela 3.19 - Quilometragem anual para caminhões (2004) .64

Tabela 3.20 - Quilometragem anual para veículos leves (2004) .64

Tabela 4.1 - Fatores de correção aplicados ao volume de álcool............................................72

Tabela 4.2 - Taxa média de consumo dos veículos a gasolina $(\mathrm{km} / \mathrm{l})$...................................74

Tabela 4.3 - Taxa média de consumo dos veículos a álcool $(\mathrm{km} / \mathrm{l})$......................................74

Tabela 4.4 - Taxa média de consumo dos veículos a diesel $(\mathrm{km} / \mathrm{l})$......................................75

Tabela 4.5 - Dados de morte excluídos do estudo....................................................................

Tabela 5.1 - Quilometragens médias anuais correspondentes ao ano de 2008......................81

Tabela 5.2 - Índices associados à mortalidade no trânsito para o ano de 2004 ........................85

Tabela 5.3 - Índices associados à mortalidade no trânsito para o ano de 2005 .......................87

Tabela 5.4 - Índices associados à mortalidade no trânsito para o ano de 2006.......................88

Tabela 5.5 - Índices associados à mortalidade no trânsito para o ano de 2007.......................90

Tabela 5.6 - Índices associados à mortalidade no trânsito para o ano de 2008........................91

Tabela 5.7 - Classificação dos estados nos Grupos A, B, C e D.............................................96

Tabela 5.8 - Classificação dos estados nos Grupos A, B e C.................................................106

Tabela A.1 - Frota de veículos motorizados por categoria segundo o.................................119 DENATRAN em 2004

Tabela A.2 - Frota de veículos motorizados por categoria segundo o. 120 DENATRAN em 2005

Tabela A.3 - Frota de veículos motorizados por categoria segundo o. .121 DENATRAN em 2006

Tabela A.4 - Frota de veículos motorizados por categoria segundo o. 122 DENATRAN em 2007

Tabela A.5 - Frota de veículos motorizados por categoria segundo o. 123 DENATRAN em 2008 
Tabela B.1 - Frota nacional de veículos leves por categoria e tipo de combustível segundo ANFAVEA/SINDIPEÇAS

Tabela B.2 - Frota nacional de motocicletas por cilindrada segundo 125 ANFAVEA/SINDIPEÇAS

Tabela B.3 - Frota nacional de caminhões por categoria 125 segundo ANFAVEA/SINDIPEÇAS

Tabela B.4 - Frota nacional de ônibus por categoria segundo ANFAVEA/SINDIPEÇAS

Tabela C.1 - Frota de veículos convertidos para o uso do GNV no período 2004-2008. 127

Tabela D.1 - Volume de gasolina comercializado, por estado, no período 2004-2008 (1)....129

Tabela D.2 - Volume de álcool comercializado, por estado, no período 2004-2008 (1).......130

Tabela D.3 - Volume de óleo diesel comercializado, por estado, no período. 131 2004-2008 (1)

Tabela D.4 - Volume de GNV comercializado, por estado, no período 2004-2008 $\left(\mathrm{m}^{3}\right) \ldots . .132$

Tabela E.1 - Preços do álcool e gasolina no período 2004-2008

Tabela F.1 - Volume de álcool corrigido, por estado, no período 2004-2008 (1) 135

Tabela G.1 - Fator de correção 7 do óleo diesel (uso agropecuário)......

Tabela H.1 - Fator de correção 8 do óleo diesel (uso ferroviário).

Tabela I.1 - Fator de correção 9 do óleo diesel (uso aquaviário).

Tabela J.1 - Volume de óleo diesel corrigido, por estado, no período 2004-2008 (1) 143

Tabela K.1- Valores de $k$ 145 
Tabela L.2- Quilometragens médias anuais correspondentes ao ano de $2004 \ldots \ldots \ldots \ldots \ldots \ldots \ldots . . . . .147$

Tabela L.2- Quilometragens médias anuais correspondentes ao ano de 2005.....................148

Tabela L.3- Quilometragens médias anuais correspondentes ao ano de 2006....................149

Tabela L.4- Quilometragens médias anuais correspondentes ao ano de 2007 ....................150 


\section{LISTA DE SIGLAS}

ABRAMET Associação Brasileira de Medicina de Tráfego

ANFAVEA Associação Nacional dos Fabricantes de Veículos Automotores

ANP Agência Nacional do Petróleo Gás Natural e Biocombustíveis

CID Classificação Internacional de Doenças

DALY Disability-Adjust Life Year

DATASUS Departamento de Informática do Sistema Único de Saúde

DENATRAN Departamento Nacional de Trânsito

DETRAN Departamento Estadual de Trânsito

DPVAT Danos Pessoais Causados por Veículos Automotores de Via Terrestre

FENASEG Federação Nacional das Empresas de Seguros Privado

GNV Gás Natural Veicular

IBGE Instituto Brasileiro de Geografia e Estatística

IRTAD International Road Traffic and Accident Database

OMS Organização Mundial da Saúde

PIB Produto Interno Bruto

SINDIPEÇAS Sindicato Nacional da Indústria de Componentes para Veículos

Automotores

SUS S Sistema Único de Saúde

VDMA Volume Médio Diário Anual

WBCSD World Business Council for Sustainable Development 



\section{INTRODUÇÃO}

\subsection{Contextualização do tema}

A mensuração (quantificação) da acidentalidade no trânsito é de fundamental importância para a avaliação objetiva da segurança viária. Somente com valores numéricos é possível comparar a situação da acidentalidade em diferentes locais (países, estados, municípios etc.), bem como em um mesmo espaço geográfico em diferentes épocas - o que é imprescindível na avaliação de ações voltadas para a redução dos acidentes, mortes e feridos no trânsito.

Os valores referentes à acidentalidade podem ser absolutos ou relativos (neste caso por meio de índices/taxas), normalmente referidos ao período de um ano.

Os índices mais comumente usados para caracterizar a acidentalidade num espaço geográfico têm como base de referência a população e a frota de veículos motorizados. Seguem observações a respeito desses índices:

O índice de mortes por habitante mede o impacto negativo da acidentalidade viária na sociedade. Essa taxa permite comparar o risco de morte no trânsito com os riscos advindos de outras causas (tipos de doença, catástrofes, homicídios, acidentes no trabalho, etc.). $\mathrm{O}$ conhecimento dos riscos de morte associados às diversas causas constitui informação relevante para a definição de prioridades na política de saúde pública. Esse índice também permite comparar o impacto da acidentalidade viária na sociedade entre distintos países, estados, municípios ou cidades, bem como as situações do mesmo espaço geográfico em diferentes anos, o que constitui informação útil para avaliar o desempenho de diferentes políticas de segurança no trânsito, bem como para identificar fatores de êxito ou de insucesso. (FERRAZ; RAIA JÚNIOR; BEZERRA, 2008 p. 64)

O índice de mortes por veículo mede o risco de uma pessoa morrer ao viajar por transporte rodoviário em um país, estado, município, etc. Esse índice é o mais indicado para comparar a segurança no trânsito entre diferentes espaços geográficos, pois o índice de mortes por habitante é altamente impactado pela taxa de motorização: quanto maior a taxa de motorização (que guarda estreita relação como grau de exposição ao trânsito) maior o número de mortes no trânsito. A comparação dos índices de mortes entre distintos espaços geográficos, bem como as situações do mesmo espaço em diferentes anos, constitui informação valiosa para avaliar o desempenho de diferentes políticas de segurança no trânsito, bem como para identificar fatores de êxito ou de insucesso. A desagregação desse índice por tipo de veículo, permite medir o risco relativo de morrer ao viajar por um ou outro tipo de veículo. (FERRAZ; RAIA JÚNIOR; BEZERRA, 2008 p. 65) 
O índice de mortes por veículo é simples de ser obtido e expressa razoavelmente bem o risco de morrer ao viajar por transporte rodoviário. Contudo, o índice mais apropriado para avaliar a segurança no trânsito é o índice de mortes em relação à quantidade de tráfego expressa em veículos x quilômetros (quilometragem total percorrida pela frota de veículos) - que representa uma medida da efetiva exposição no trânsito.

A quilometragem total anual percorrida pela frota de veículos é estimada pelo produto da frota total e da quilometragem média anual dos veículos, obtida por amostragem, sendo o cálculo normalmente desagregado por tipo de veículo. Esses cálculos podem, inclusive, ser realizados por modo de transporte, incluindo o modo a pé.

Também importante para análises no âmbito da segurança é o índice de motorização, como observado a seguir:

O índice de motorização, que corresponde à taxa de veículos por habitante, retrata, em grande medida, o nível de desenvolvimento econômico-social de um país, estado, município, região, etc. Sendo o veículo automotor (carro, motocicleta, etc.) um bem de consumo desejado pela maioria da população, a quantidade de veículos em relação à população expressa o quanto as pessoas estão podendo satisfazer esse desejo - o que, evidentemente, guarda relação direta com a renda per capita e a distribuição da renda na sociedade (valores que expressam o grau de desenvolvimento econômico e social). (FERRAZ; RAIA JÚNIOR; BEZERRA, 2008 p. 65)

No Brasil, a mensuração da segurança no trânsito é expressa por intermédio dos índices de mortes por habitante ou por veículo, pois não há séries temporais oficiais com valores da quilometragem média anual ou total da frota rodoviária (MINISTÉRIO DA CIÊNCIA E TECNOLOGIA, 2006). Nesse sentido, há a necessidade da adoção de um método para estimar a quilometragem percorrida, pois o conhecimento desse parâmetro seria de extremo interesse para a elaboração de um diagnóstico mais preciso da mortalidade no trânsito do país, bem como para a definição de políticas públicas (planos de ações) mais adequadas para a redução das mortes no trânsito. 


\subsection{Objetivos do trabalho}

O objetivo principal deste trabalho de pesquisa é estimar o índice de mortes em relação à exposição real (quilometragem percorrida) no país e nos estados nos anos de 2004, 2005, 2006, 2007 e 2008, bem como inferir conclusões relevantes a partir dos valores obtidos.

Também é objetivo deste trabalho obter as seguintes informações:

- $\quad$ Número absoluto de mortes e índices de mortes por habitante e por veículo no país e nos estados, em todos os anos citados;

- $\quad$ Estabelecer uma classificação (ranking) dos estados no tocante aos seguintes parâmetros: número absoluto de mortes, índice de mortes por habitante, índice de mortes por veículo e índice de mortes por quilômetro percorrido, bem como analisar os resultados;

- $\quad$ Registrar, para cada estado, a evolução dos valores do índice de mortes por quilômetro nos anos de 2004 a 2008, assim como analisar os resultados obtidos;

- Avaliar a relação entre a taxa de motorização e o Produto Interno Bruto - PIB per capita (valores que expressam o nível de desenvolvimento econômico e social) e os diversos índices de mortalidade no trânsito, bem como analisar os resultados;

\subsection{Estrutura do trabalho}

No Capítulo 1 é contextualizado o tema do trabalho, são colocados os objetivos da pesquisa e é apresentada a forma como o trabalho encontra-se desenvolvido.

O Capítulo 2 contém uma revisão bibliográfica, a qual contempla os conceitos que nortearam o desenvolvimento da pesquisa.

No Capítulo 3 são relacionadas as fontes de informações usadas para a mensuração da segurança no trânsito no Brasil, bem como comentados alguns aspetos pertinentes.

No Capítulo 4 é descrita a metodologia utilizada no trabalho.

No Capítulo 5 são apresentados os valores obtidos e analisados os resultados.

No Capítulo 6 são tecidas algumas considerações relevantes no contexto do trabalho. 



\section{REVISÃO BIBLIOGRÁFICA}

\subsection{Panorama da segurança viária no mundo e no Brasil}

De acordo com a OMS - Organização Mundial da Saúde (2009) morrem mais de 1,2 milhão de pessoas por ano devido a acidentes de trânsito no mundo, além de um número entre 20 e 50 milhões de vítimas com traumatismos não fatais, muitos com seqüelas graves definitivas que impedem uma vida normal. Mais de 90\% dessas vítimas fatais vivem em países de renda baixa ou média, apesar de os mesmos concentrarem apenas $48 \%$ dos veículos do mundo.

Uma avaliação mais adequada do impacto negativo dos acidentes de trânsito para a sociedade deve ser feita com base no indicador de saúde DALY (Disability-Adjust Life Year), que combina o número de anos perdidos devido à morte prematura e o número de anos vividos com incapacidade (ponderado conforme o tipo de incapacidade). Sob a ótica deste indicador, no ano de 1990, os acidentes de trânsito estavam classificados em $9^{\circ}$ lugar, representando 2,6\% do total. Em 2020, a previsão é que os acidentes de trânsito passem a ocupar a $3^{\mathrm{a}}$ posição, representando $5,1 \%$ do total. Considerando apenas os países com desenvolvimento médio ou baixo, os acidentes passarão a ocupar, em 2020, a $2^{a}$ posição, perdendo apenas para cardiopatia. (FERRAZ; RAIA JÚNIOR; BEZERRA, 2008)

Em 2008, houve em torno de 36 mil mortes em decorrência dos acidentes de trânsito no Brasil (MINISTÉRIO DA SAÚDE, 2010). Isso representa um custo estimado de 31,42 bilhões de reais, correspondente a aproximadamente $1,23 \%$ do PIB brasileiro no mesmo ano. Considerando a relação entre as taxas de mortalidade por veículo automotor no Brasil e nas nações desenvolvidas, observa-se que o risco de morte em acidente de trânsito é entre cinco e dez vezes maior no Brasil. (FERRAZ, RAIA JÚNIOR, BEZERRA, 2008)

Esses números, que expressam a gravidade do problema da acidentalidade viária no mundo, em particular no Brasil, mostram a grande importância da realização de estudos acerca do tema e da implementação de ações voltadas para o aumento da segurança no trânsito. 


\subsection{Teorias sobre os acidentes de trânsito}

Há cerca de 100 anos, quando o problema dos acidentes passou a preocupar a sociedade, muitas teorias começaram a ser formuladas na tentativa de explicar o porquê desses eventos. A seguir estão resumidas as principais teorias que emergiram na tentativa de entender a questão da acidentalidade no trânsito, com base em Elvik et al. (2009).

Ao final do século XIX os acidentes eram entendidos como eventos puramente aleatórios, sobre os quais o ser humano não teria nenhum controle. Essa visão foi confrontada durante a Primeira Guerra Mundial por um modelo baseado na suposição de diferentes tendências iniciais para o acidente (teoria da propensão). Esse ponto de vista foi predominante nas pesquisas sobre segurança viária de 1920 a 1950. Entretanto, essa teoria foi enfraquecida pela constatação de que a maioria dos acidentes envolvia condutores comuns.

Em razão do insucesso das teorias anteriores, surgiu o argumento de que a prevenção dos acidentes é apenas possível com a identificação das suas reais causas. Por intermédio dessa abordagem, concluiu-se que os acidentes têm, geralmente, mais de uma causa, e que raramente é possível identificar alguma delas como mais decisiva que as outras. Complementarmente, descobriu-se que fatores humanos contribuíam para a maioria dos acidentes.

A visão fortemente focada nos erros humanos, nos anos 50, levou a uma ênfase equivocada em tentar mudar o comportamento humano como a única ação para combater os acidentes de trânsito. Contudo, logo foi percebido que esses esforços tiveram apenas um modesto sucesso, pois seria necessário descobrir o porquê dos erros humanos - fato que levou a formulação de um novo tipo de teoria dos acidentes de trânsito.

A teoria do sistema (ou teoria epidemiológica) emergiu na década de 50 e tornou-se popular nos anos 60 e 70, sendo a mais bem sucedida das teorias. A proposição básica da teoria dos sistemas é que os acidentes são resultados de desajustes na interação entre as várias partes de sistemas complexos. De acordo com essa teoria, os erros seriam cometidos devido ao projeto inadequado do sistema (não condizente com as capacidades humanas). A teoria dos sistemas tenta encontrar a solução para o problema dos acidentes modificando os componentes técnicos do sistema de transporte, principalmente aqueles relacionados à engenharia de segurança e à engenharia veicular. 
Há também teorias comportamentais, cuja ideia básica é que a avaliação e a aceitação do risco humano são determinantes muito importantes do número de acidentes. Mais especificamente, a teoria homeostática do risco, de Gerald Wilde (em destaque desde 1980), propõe que cada sociedade tem o número de acidentes que "quer" ter e que a única forma de reduzir esse número é mudando o nível de segurança desejado.

As seguintes principais conclusões podem ser inferidas a partir dessas teorias:

- Todas as teorias propostas contêm algum elemento de verdade;

- Nenhuma das teorias fornece uma explicação científica completa para os acidentes;

- Praticamente todas as teorias foram propostas como meios de reduzir os acidentes, sem considerar a curiosidade intelectual.

Apesar de nenhuma teoria ter sido eleita pela comunidade científica como ideal para explicar completamente os acidentes, algumas parecem desfrutar de maior popularidade no meio científico, como a que considera o acidente uma variável aleatória. Isso porque, apesar de os acidentes resultarem de escolhas humanas e de aspectos comportamentais, se pudessem ser antecipados, provavelmente não ocorreriam. Dessa forma, o melhor que se espera é a previsão de seu número aproximado. (ELVIK et al., 2009; FRIDSTROM et al., 1995)

A contagem de acidentes em um dado local geralmente apresenta uma variação bastante acentuada e aparentemente aleatória de um período para outro. Por outro lado, em dados geograficamente muito agregados de acidentes, como para um país inteiro, por exemplo, observa-se uma considerável estabilidade nos valores. (FRIDSTROM et al., 1995)

O número esperado de acidentes é o número médio de acidentes que provavelmente ocorrerá num determinado período de tempo, mantidos constantes o nível de exposição e todos os outros fatores de risco. Por isso, o valor verdadeiro para o número esperado de acidentes não pode ser observado diretamente, mas estimado. O método mais comum para tal é estudar uma grande diversidade de unidades, que variam quanto a características capazes de influenciar no número esperado de acidentes. Em análises estatísticas, tenta-se determinar a quantidade de variações sistemáticas na contagem de acidentes e identificar os fatores capazes de produzilas. (ELVIK et al., 2009)

Todavia, na busca de explicações para os acidentes e de formas de prevê-los é importante distinguir variações sistemáticas e aleatórias nos números de acidentes. Variações sistemáticas são as variações verdadeiras na contagem de acidentes (variação do número esperado de 
acidentes). Variações aleatórias são aquelas observadas entre a contagem e o número esperado de acidentes. (ELVIK et al., 2009; EVANS, 2004)

De acordo com Elvik et al. (2009), dois grupos de fatores são responsáveis por gerar variações sistemáticas no número de acidentes: a quantidade de tráfego (exposição) e os fatores de risco (fatores que afetam a probabilidade de acidentes sob uma dada exposição). É claro que, além disso, estão o nível de ocupação dos veículos e outros fatores que podem influenciar mais diretamente no número de vítimas por acidentes.

Hauer (1997) atribui as variações sistemáticas no número de acidentes às mudanças ocorridas em quatro fatores:

- Tráfego, tempo, comportamento do usuário da via, frota de automóvel e muitos outros fatores que mudam autonomamente ao longo do tempo;

- Demais ações para aumentar a segurança, que podem ter ocorrido simultaneamente ao tratamento de interesse;

- A contagem de acidentes, que pode ter mudado devido a ajustes do limite de reportabilidade;

- A proporção de acidentes registrados, que também pode ter mudado com o tempo.

Já as variações puramente aleatórias no número de acidentes são geralmente modeladas pela lei de probabilidade de Poisson. A distribuição de probabilidades de Poisson é um tipo de distribuição binomial para números excessivamente grandes de tentativas, que, quanto maiores, menor é a probabilidade de fracasso. Portanto, essa lei aplica-se ao estudo de eventos raros, tratando de sua ocorrência, ou não, durante determinado período. Tais eventos devem ser independentes (o sucesso de um não deve afetar a probabilidade de sucesso de outro). Analogamente, para a aplicação dessa lei à segurança viária, uma suposição básica deve ser feita: os acidentes são eventos estatisticamente independentes, ou seja, a ocorrência de um não afeta a probabilidade da ocorrência de outro acidente. (Elvik et al, 2009)

A Equação 2.1 descreve a função de probabilidade de Poisson, a qual fornece o valor de probabilidade de " $\mathrm{x}$ " erros para " $\mathrm{N}$ " tentativas (exposição), dado um número esperado de erros " $\lambda$ " em determinado período.

$P(X=x)=\frac{\lambda^{x} \cdot e^{-\lambda}}{x !}$ 
$\mathrm{Na}$ terminologia da pesquisa de acidentes (FRIDSTROM et al., 1995; ELVIK; ERKE; CHRISTENSEN, 2009), tem-se:

$\lambda$ : número esperado de acidentes;

$\mathrm{x}$ : taxa de acidentes para a qual a probabilidade está sendo calculada;

e: base do logaritmo natural $(\mathrm{e}=2,71828 \ldots)$

A distribuição de Poisson possui uma característica peculiar bastante interessante para a área da segurança: sua variância é igual à média (valor esperado $\lambda$ ). Isso possibilita que, conhecendo o valor esperado, saiba-se também, teoricamente, qual a variação aleatória esperada em torno desse valor. (FRIDSTROM et al., 1995)

\subsection{Mensuração da acidentalidade no trânsito}

A mensuração da acidentalidade no trânsito permite a comparação da situação da acidentalidade em diferentes locais ou num mesmo espaço geográfico em diferentes épocas. Tais valores podem ser absolutos ou relativos, sendo que os índices em relação à população e à frota são os mais usados para caracterizar a acidentalidade em determinado local.

Praticamente qualquer quantidade medida em segurança acaba sendo uma taxa porque os dados quase sempre estão relacionados a algum indicador da exposição ao risco. É importante especificar claramente qual a taxa usada e como ela se relaciona ao problema tratado. (EVANS, 2004)

Elvik et al. (2009) e Thagesen (1996) chamam a relação do número de mortes com a população de risco para a saúde, pois possibilita a comparação com o risco de outras causas de morte (mortes/100.000 habitantes). A relação do número de mortes com a quantidade de transporte é tratada pelos autores como risco de tráfego, justamente por indicar o quão seguro é trafegar por determinado local (geralmente mortes/1.000.000.000 de quilômetros viajados). $\mathrm{Na}$ ausência de dados de fluxo, o risco do tráfego é determinado por meio da frota registrada (mortes/100.000 veículos).

Na Figura 2.1 são apresentados os valores do índice de mortes por habitante no trânsito em alguns países e, na Figura 2.2, valores do índice de mortes por veículo. 


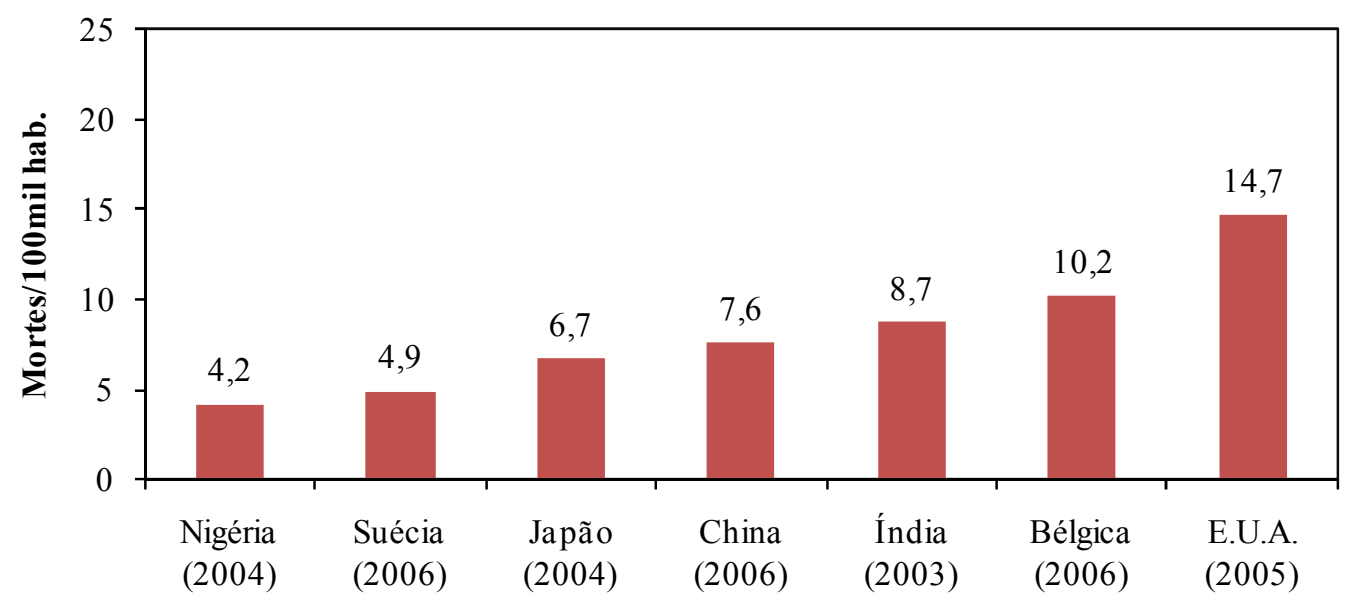

Figura 2. 1 - Taxa de mortes para cada 100.000 habitantes (Fonte: Elvik et al., 2009, adaptado)

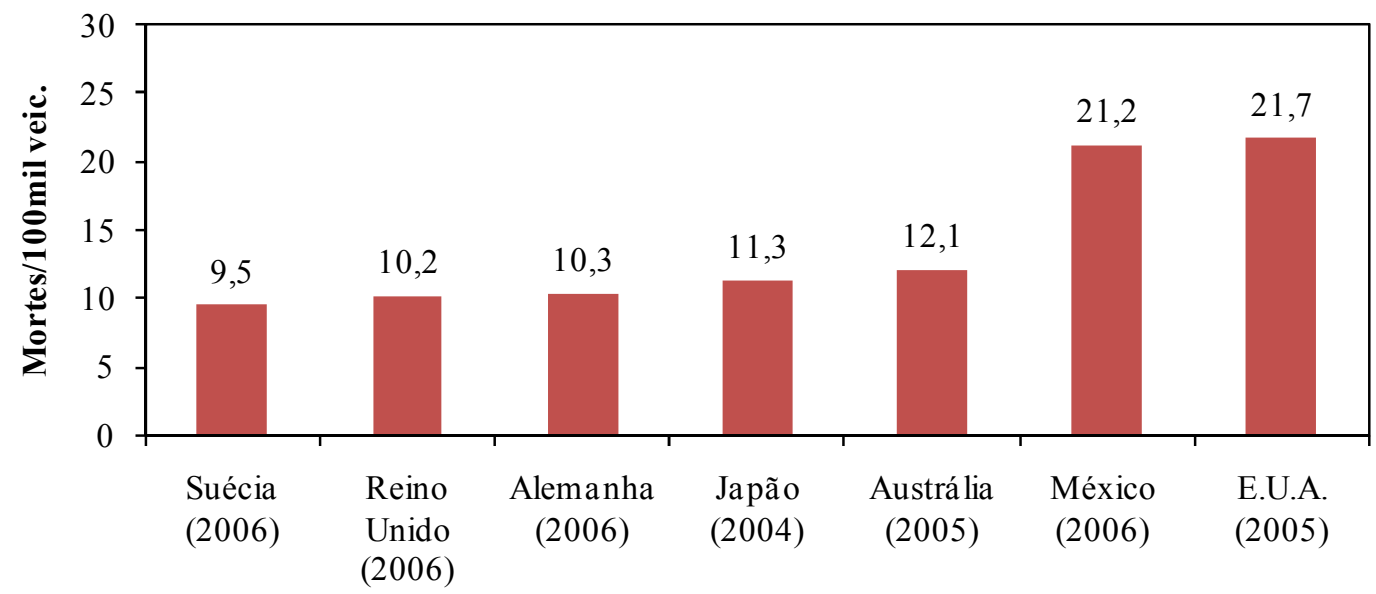

Figura 2. 2 - Taxa de mortes para cada 100.000 veículos (Fonte: Elvik et al., 2009, adaptado)

A interpretação dos valores do índice de mortes por habitante deve ser feita com muito cuidado, sob pena de levar a conclusões equivocadas. Por exemplo, na Figura 2.1 nota-se que a taxa da Nigéria é menor do que a da Suécia e do Japão sugerindo que a segurança viária é melhor naquele país. Essa distorção da realidade deve-se, sobretudo, à baixa taxa de motorização da Nigéria - um país muito pobre. Também deve ter contribuído para o valor baixo da referida taxa, o sub-registro de mortes no trânsito - fato comum nos países pouco desenvolvidos. A mesma explicação vale para o fato da China e da Índia apresentarem taxas menores que a Bélgica e os Estados Unidos.

Algo semelhante, porém com um menor nível de distorção, pode ocorrer quando da comparação do índice de mortes por veículo automotor registrado. Por exemplo, na Figura 2.2 observa-se que a taxa do México é ligeiramente menor do que o dos Estados Unidos. Essa 
distorção deve-se ao fato de que nos Estados Unidos é maior a quilometragem média anual percorrida por veículo, em razão da maior renda da população.

Os índices de mortes por 100.000 veículos para Índia, Bangladesh e Vietnã são, respectivamente, 740, 1250 e 1788 - valores exageradamente elevados que refletem uma população muito grande exposta a um tráfego motorizado pequeno (em relação à população), porém desordenado. Além disso, conta para esses números um grande sub-registro de veículos e a precariedade dos cuidados médicos com as vítimas de acidentes.

Dessa forma, o uso do número de habitantes como medida da exposição tende a resultar em uma posição mais favorável para países com menores taxas de motorização. De maneira oposta, a taxa que leva em conta a frota acaba por resultar em números alarmantes para países com baixas taxas de motorização. A Figura 2.3 mostra a relação entre essas duas abordagens para países em diferentes estágios de desenvolvimento.

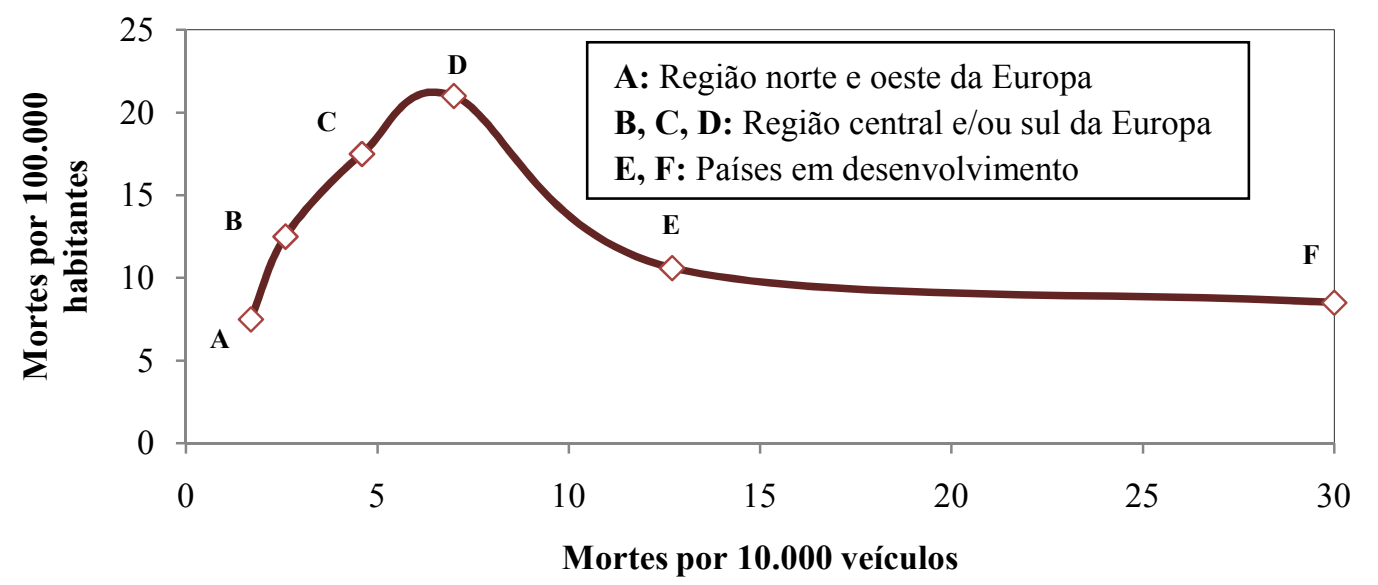

Figura 2. 3 - Comparação das taxas de mortes por população e frota de veículos

Devido ao grau de motorização ser considerado como um indicador do nível de desenvolvimento, muitas vezes, as questões da segurança acabam ficando em segundo plano quando o índice de motorização é baixo, pois o interesse prioritário da nação é o desenvolvimento econômico. Isso aconteceu com a maioria dos países desenvolvidos algumas décadas atrás e vem acontecendo nos países em desenvolvimento. Em razão disso, a taxa de motorização tende a apresentar um formato de desenvolvimento semelhante a uma curva em S, conforme indicado na Figura 2.4.

Esse desenvolvimento pode apresentar interrupções temporárias devido a dificuldades econômicas, mas o padrão indicado parece ser típico. Os três estágios de motorização mostrados na Figura 2.4 podem ser caracterizados como (THAGESEN, 1996): 
- Estágio I - Desenvolvimento: o crescimento econômico tem prioridade e a preocupação com a segurança no trânsito é pequena (50-100 veículos para cada 1.000 habitantes);

- Estágio II - Explosão: a preocupação com a segurança é crescente (300-400 veículos para cada 1.000 habitantes);

- Estágio III - Saturação: a preocupação com a segurança é grande (mais de 400 veículos para cada 1.000 habitantes).

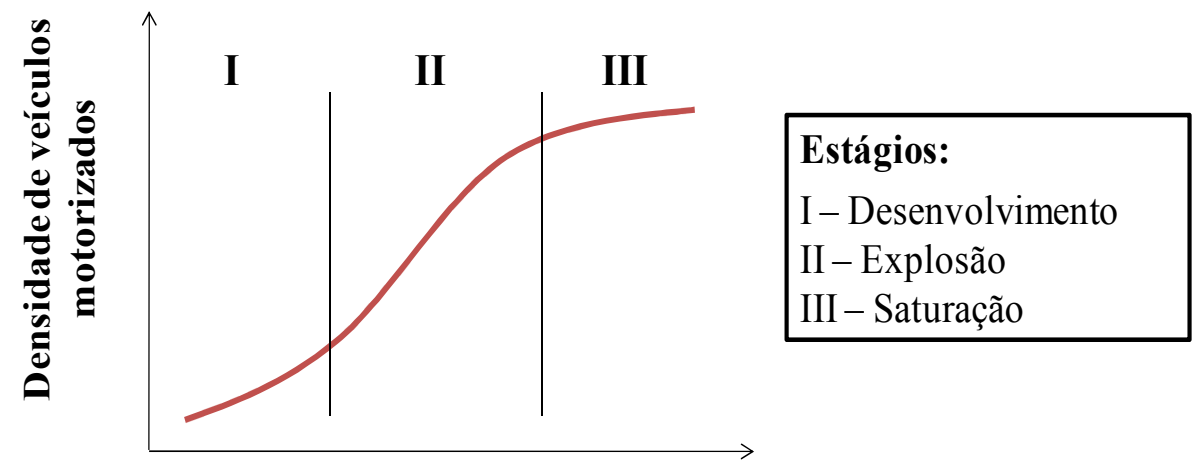

\section{Tempo}

Figura 2. 4 - Curva típica do desenvolvimento da motorização nos países industrializados (Fonte: Thagesen, 1996, adaptado)

No entanto, como já referido no Capítulo 1, o índice mais adequado para a avaliação da segurança no trânsito é aquele que considera a exposição real expressa em veículos $\mathrm{x}$ quilômetros percorridos, ou seja, o número de mortes em relação à quilometragem total percorrida pela frota de veículos. Na Figura 2.5 são mostrados os valores desse índice para alguns países.

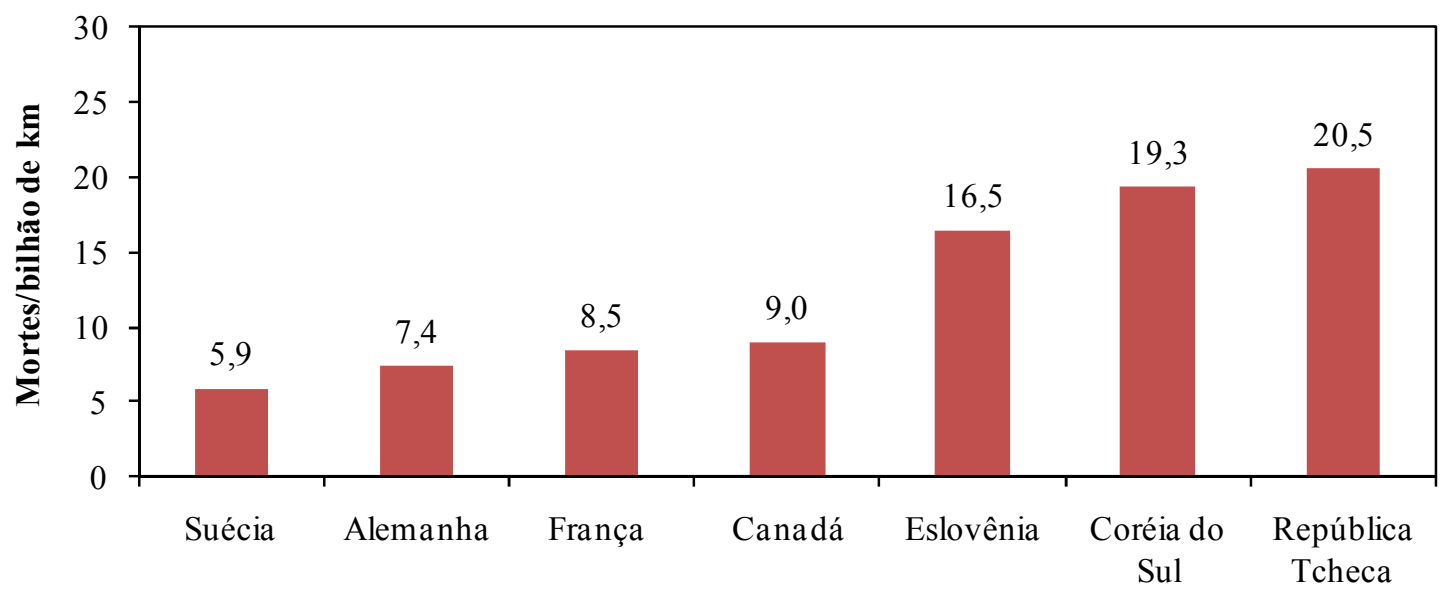

Figura 2. 5 - Taxa de mortes por bilhão de veículos x km no ano de 2006 (Fonte: Elvik et al., 2009, adaptado) 


\subsection{Acidentalidade no trânsito e desenvolvimento econômico e social}

De acordo com Ferraz, Raia Júnior e Bezerra (2008), a maior segurança no trânsito dos países desenvolvidos deve-se aos seguintes principais fatores:

- Legislação e punição mais severas;

- Maior conhecimento e respeito às leis de trânsito;

- Melhor treinamento de condutores e pedestres;

- Melhor sistema de estatísticas de acidentes.

Também podem existir diferenças significativas nos índices de acidentes de trânsito em diferentes regiões de um mesmo país, como, aliás, ocorre no Brasil, em razão de diferentes níveis de desenvolvimento econômico, social e cultural.

O confronto de valores relativos à segurança no trânsito com indicadores socioeconômicos, como o PIB per capita e a taxa de motorização, mostra que há uma relação entre o nível de segurança e o grau de desenvolvimento de uma sociedade.

A falta de preocupação com a acidentalidade no trânsito nos países pouco desenvolvidos é atribuída à existência de problemas mais graves e a escassez de recursos - numa certa semelhança com a teoria das necessidades humanas de Maslow (sintetizadas graficamente através de cincos camadas distintas em uma pirâmide, com a camada mais baixa representando as necessidades vitais para a sobrevivência, as camadas posteriores associadas a distintas necessidades em ordem de importância e a camada mais alta reunindo as necessidades espirituais). (FERRAZ; RAIA JÚNIOR; BEZERRA, 2008)

\subsection{A exposição ao trânsito e o risco de acidentes}

Não há uma definição de exposição comum para todas as áreas, pois isso depende da natureza do tema em questão (EVANS, 2004). Em transportes, exposição é a quantidade de transporte realizada em um dado sistema de transportes (HERMANS; WETS; VAN DEN BOSSCHE, 2006). Numa definição mais específica, aplicada à área da segurança no trânsito, segundo 
Elvik et al. (2009), exposição expressa a quantidade de atividade na qual há a possibilidade da ocorrência de um acidente de trânsito.

A influência de outros fatores associados à exposição ocorre indiretamente, de modo a afetar a quantidade de acidentes. Isso significa que, apesar de haver uma relação entre exposição e número de acidentes, essa relação é complexa, pois depende de outros aspectos incorporados nessa exposição, como por exemplo, a forma de condução (mais ou menos agressiva), o modo de transporte usado e o gênero (EVANS, 2004).

Numa visão mais abrangente, pode-se ainda dizer que a ocorrência de acidentes, além da exposição ao trânsito, depende do binômio legislação/fiscalização e de um grande número de fatores associados a componentes físicos do sistema de trânsito: o ser humano, o veículo e a via/ambiente (FERRAZ; RAIA JÚNIOR; BEZERRA, 2008).

Portanto, no processo que desencadeia um acidente de trânsito, além da presença do fator exposição, há a participação de outros fatores de risco que contribuem para o aumento da probabilidade da ocorrência de acidentes. Em um estudo sobre os mecanismos de detecção de fatores de risco, Elvik (2006) propôs quatro "leis" para investigações de causa de acidentes:

- Lei universal do aprendizado - a habilidade de detectar e controlar perigos no trânsito aumenta uniformemente com o aumento da quantidade de viagens;

- Lei dos eventos raros - quanto mais raro de ser encontrado um fator de risco, maior é o seu efeito na taxa de acidentes;

- Lei da complexidade - quanto mais informações por unidade de tempo um usuário da via tiver que processar, maior se torna a probabilidade de cometer um erro;

- Lei da capacidade cognitiva - quanto mais perto dos limites da capacidade cognitiva o condutor estiver, maior é o risco da ocorrência de acidentes.

A exposição poder ser medida de várias formas: contagens de tráfego, pesquisas de hábitos de viagem e estimativas indiretas de exposição (HERMANS; WETS; VAN DEN BOSSCHE, 2006).

As duas medidas de exposição mais comumente usadas em pesquisas de segurança viária são a quantidade de tráfego (veículos x quilômetros percorridos) e o volume de veículos (por exemplo, no caso de interseções).

Apesar da inquestionável importância do conhecimento da quantidade de tráfego para o estudo da segurança viária, devido ao fato de apenas os valores médios ou totais serem usados 
nas análises, essa medida é ainda considerada como uma medida sumária de exposição. Tal atribuição se deve à dificuldade de estimar com precisão a forma da relação entre exposição e o número de acidentes por meio de valores médios para a exposição, já que essa relação não é linear (ELVIK; ERKE; CHRISTENSEN, 2009).

Pignataro (1973) já discutia essa não linearidade. Em um estudo de acidentes rodoviários constatou-se que a taxa de acidentes aumenta com o crescimento do volume de veículos, atingindo um máximo para vias com um volume de 8.000 a 9.000 veículos/dia (para rodovias de pista simples). No entanto, um tráfego mais intenso reduziria a taxa de acidentes devido ao congestionamento. Em concordância com esses resultados, há outro estudo que relaciona a taxa de acidentes ao volume horário em rodovias da Califórnia: os acidentes aumentam com o volume, atingindo um valor máximo em torno de 650 veículos/hora.

Nos países desenvolvidos, a quantidade de tráfego expressa em veículo-quilômetro (quilometragem total percorrida) é uma medida amplamente coletada pela maioria das agências que tratam da segurança viária, o que acabou difundindo seu uso em razão da fácil disponibilidade nesses países. Contudo, análises de ocorrência de acidentes baseadas na quilometragem total percorrida, sob o ponto de vista teórico ainda são uma forma agregada e cumulativa de abordar dados quando a frequência de acidentes é calculada pela agregação de dados de um período de tempo (anos ou meses) e locais (seções de via) específicos (GOLOB; RECKER; ALVAREZ, 2004).

No mesmo sentido, Mensah e Hauer (1998) consideram o número de veículos x quilômetros como uma média que engloba condições muito diferentes, que por sua vez podem envolver diferentes níveis de risco: dia e noite, tempo bom ou ruim, pista seca ou escorregadia, entre outros.

Como nos países em desenvolvimento raramente existe uma medida ou estimativa da quantidade de tráfego, o número registrado de veículos motorizados é geralmente usado como uma medida da atividade de tráfego (exposição no trânsito). Tal suposição baseia-se nos dados de países desenvolvidos, nos quais o uso de veículos motorizados mostrou-se bastante estável ao longo do tempo.

Essa idéia motivou tentativas de estimar o número de mortes no trânsito a partir da frota motorizada e do número de habitantes de um país. Dentro desse contexto, a hipótese de Smeed é a mais conhecida, sendo expressa pela Equação 2.2 (THAGESEN, 1996): 
$F=k \cdot M^{0,33} \cdot I^{0,67}$

Em que,

$F$ : número de mortes em determinado ano;

I: número de habitantes;

$M$ : número de veículos motorizados;

$k$ : constante.

A hipótese de Smeed descreve diferenças nos níveis de risco (do tráfego e da saúde) entre países como consequência de diferentes níveis de motorização. Entretanto, tal hipótese parece funcionar apenas em países com menores níveis de motorização, e não para níveis maiores. A ideia básica de que as mortes crescem com a frota de veículos motorizados, mas não proporcionalmente a ela, reflete o fato de que com o crescimento da motorização, a segurança de tráfego se torna uma preocupação crescente como sugerido no Estágio II do modelo da Figura 2.4.

Essa preocupação desencadeia ações que reduzem a taxa de mortes. Em termos gerais: se a elevada aquisição de veículos (motorização) gera mais acidentes, por outro lado, a preocupação social cria ações corretivas em diferentes sentidos. Ações corretivas como a educação do usuário da via ou melhor manutenção dos veículos têm resultados lentos, mas apresentam efeitos satisfatórios em longo prazo. Portanto, são considerados elementos de um processo de maturidade social no qual a sociedade lentamente se ajusta às condições de motorização do tráfego.

A partir dessa constatação, emerge uma hipótese alternativa: o tempo, por si só, pode ser uma variável muito útil na análise do risco no sistema de trânsito. Dessa forma, a OECD (Organização para a Cooperação e o Desenvolvimento Econômico) sugere que em vez de estudar as taxas de mortes como uma função da motorização, uma relação muito mais simples surge quando o risco de acidentes ou mortes no trânsito é estudado ao longo do tempo. Em uma escala semi-logarítmica, as curvas da relação são aproximadamente lineares e seguem a Equação 2.3:

$F / M=k \cdot e^{((t-T) \cdot \ln a)}=k \cdot a^{(t-T)}$

Em que,

$F$ : número de mortes no ano " $\mathrm{t}$ ";

$M$ : número de veículos motorizados no ano " $\mathrm{t}$ ”; 
$a$ : redução relativa anual da taxa de mortes "F/M";

$k$ e $T$ : constantes, tal que se o ano inicial é “T”, então " $\mathrm{k}$ ” é a taxa de mortes no ano "T". Exemplificando, se o risco do sistema de tráfego em 1950 era 0,01 e se o risco em qualquer ano é 95\% do risco do ano anterior, então tem-se a Equação 2.4:

$F / M=0,01 \cdot e^{((t-1950) \cdot \ln 0,95)}=0,01 \cdot 0,95(t-1950)$

De acordo com esse modelo, há uma melhoria constante da segurança no trânsito, independente do nível de motorização do país, mas pelo fato de a sociedade ter começado a se envolver em atividades de segurança. Tais políticas agiriam ao longo do tempo, sem depender do grau de motorização.

Contudo, esse modelo, ao contrário do anterior, não se aplica bem para países em desenvolvimento, onde o risco parece ser mais ou menos constante ao longo do tempo. Isso significa que as mortes crescem de forma diretamente proporcional ao número de veículos motorizados, conforme sugeria o modelo anterior de Smeed. Essa tendência foi também verificada para alguns países industrializados (por exemplo, Reino Unido e Dinamarca) há muitos anos, quando a motorização era baixa.

Em conclusão, segundo Thagesen (1996), juntando as observações das duas hipóteses e a classificação de Sicking, tem-se:

- Durante o Estágio I (motorização em desenvolvimento) o risco ao sistema de tráfego é constante ao longo do tempo, e;

- Durante o Estágio II (motorização em explosão) o risco ao sistema de tráfego é uma função exponencialmente decrescente ao longo do tempo.

\subsection{Estimativa da exposição no trânsito}

A medida de exposição mais amplamente aceita no âmbito da segurança viária é, como visto, a quilometragem percorrida pelos veículos motorizados, ou seja, a quantidade de tráfego expressa em veículos x quilômetros percorridos.

Em uma seção de via, essa medida baseia-se no fluxo de veículos em circulação, geralmente expresso pelo VDMA - Volume Diário Médio Anual. O VDMA representa simplesmente o 
fluxo de veículos ao longo de uma seção da via em um dia médio do ano. Seu cálculo é baseado em dados de dois tipos de contagens: contagens automatizadas permanentes e contagens de curto período. O ideal é que se combinem essas duas medidas para se obter uma estimativa do VDMA para uma rede viária maior (LEDUC, 2008).

A quilometragem média percorrida é considerada como um indicador da demanda de tráfego, sendo usada para indicar o nível de mobilidade e os padrões de viagem. A estimativa da quilometragem total percorrida não é tão direta como no caso do fluxo de tráfego. Existem, basicamente, quatro métodos para determinar esse parâmetro:

- Leitura de odômetros - nas inspeções regulares, a quilometragem média percorrida é determinada e depois multiplicada pelo número de veículos. Esse método é principalmente usado na Holanda, Dinamarca, Letônia e Suíça.

- Contagens de tráfego - para um trecho considerado, a quilometragem total percorrida é calculada pela multiplicação do VDMA pelo comprimento do trecho (em quilômetros). Esse cálculo pode ser feito separadamente para cada tipo de veículo e depois somado para resultar em uma distância total. É o principal método usado na Bélgica, Finlândia, Estônia, Hungria, República Tcheca, Polônia, Eslováquia, Eslovênia, Reino Unido, Suécia e Estados Unidos.

- Pesquisa com condutores - um questionário é enviado anualmente para milhares de residências com um ou mais veículos, contendo perguntas acerca do número de quilômetros dirigidos em cada veículo durante o ano, bem como do consumo unitário.

- Consumo de combustível - a quantidade de tráfego (quilometragem percorrida) é estimada a partir de informações sobre consumo global de combustível (litros/ano) e o consumo unitário (km/l). Esse método é usado na França, Áustria e Portugal.

Segundo Leduc (2008), os métodos para o levantamento de dados que permitem medir ou estimar os volumes de tráfego podem ser classificados como tecnologias de sensoriamento remoto e tecnologias para obtenção de dados in-situ.

No caso das tecnologias de sensoriamento remoto, os dados obtidos de veículos em circulação baseiam-se na coleta de informações do tráfego real por meio da localização do veículo via telefone móvel ou GPS (Sistema de Posicionamento Global) em qualquer ponto da rede viária. Cada veículo é equipado com um telefone móvel ou GPS que atua como um sensor para a rede viária. Dados como a localização do veículo, velocidade e sentido de viagem são enviados remotamente para uma central de processamento. Após coletadas e extraídas, as 
informações úteis (situação do tráfego, rotas alternativas etc.) podem ser redistribuídas para os condutores nas vias.

As tecnologias in-situ são aquelas em que o tráfego é medido por meio de detectores localizados ao longo da via ou nos veículos, podendo geralmente ser divididas em duas categorias: métodos intrusivos e não intrusivos. Os métodos intrusivos consistem basicamente na coleta de dados através de sensores dispostos ao longo da via ou nela instalados, que podem ser:

- Tubos pneumáticos: tubos de borracha colocados perpendicularmente ao sentido de tráfego para detectar veículos por meio de mudanças de pressão produzidas quando o pneu passa sobre o tubo. O pulso de ar resultante da passagem é gravado e processado pelo contador localizado na lateral da via.

- Sensores piezoelétricos: os sensores são colocados em uma ranhura na superfície da via monitorada, perpendicularmente ao sentido do tráfego. A deformação mecânica do material piezoelétrico modifica a densidade da carga da superfície do material, de modo a produzir uma diferença de potencial entre os eletrodos.

- Loops magnéticos: são embutidos nas vias formando um quadrado que gera um campo magnético. A informação é transmitida para um dispositivo de contagem localizado na lateral da via.

Por outro lado, os métodos não intrusivos são aqueles baseados em observações remotas, tais como:

- Contagens manuais: método mais tradicional, no qual observadores treinados coletam dados que não podem ser obtidos eficientemente nas contagens automáticas, como taxa de ocupação do veículo, contagem de pedestres e classificação de veículos.

- Infravermelho passivo e ativo: a presença, a velocidade e o tipo de veículo são detectados com base na energia infravermelha radiante na área de detecção.

- Magnética passiva: sensores magnéticos são fixados abaixo ou no topo do leito da via, os quais realizam contagens classificatórias e medições de velocidade. Entretanto, há dificuldades de operação quando o espaçamento entre os veículos é muito pequeno.

- Radar de micro-ondas: detecta veículos em movimento e suas velocidades, bem como realiza a contagem classificatória, não sendo afetado por condições climáticas.

- Ultrassônico e acústico passivo: emitem ondas sonoras para detectar veículos, medindo o tempo para que o sinal retorne ao dispositivo. Os sensores ultrassônicos são 
colocados sobre a via e podem ser afetados por temperatura ou mau tempo. Os dispositivos acústicos passivos são dispostos ao longo da lateral da via e podem coletar o fluxo, velocidade e classificar os dados.

- Detecção de imagem de vídeo: câmeras de vídeo gravam o número de veículos, seus tipos e velocidades por meio de diferentes técnicas de vídeo.

Conforme já comentado, a quantidade de tráfego é estimada por meio da combinação de técnicas diretas (pesquisas de viagem e contagens de tráfego) e métodos indiretos, para os quais dados de vendas de combustível e taxas unitárias de consumo de combustível para uma determinada frota são usados, conforme descrevem os exemplos a seguir, baseados em Thomas (2005).

$\mathrm{Na}$ Alemanha, as quilometragens percorridas em veículos a gasolina e a diesel são estimadas separadamente, usando um procedimento comum. Periodicamente esse procedimento é recalibrado por censos de tráfego em todo o país.

Na França e na Noruega, um procedimento parecido é usado para o mesmo tipo de estimativa. Cinco classes de veículos a gasolina são consideradas: mopeds, motocicletas, ônibus, caminhões e automóveis. Pesquisas periódicas são realizadas para estimar a distância anual média viajada $(\mathrm{km} /$ veículo) e o consumo médio de combustível $(1 / \mathrm{km})$ para as quatro primeiras classes. Os valores calculados são combinados com os dados de frota veicular para estimar a quantidade total de combustível consumido por essas quatro classes. Essa informação é combinada com as estimativas do consumo médio por quilômetro e do número de automóveis para calcular a quilometragem total percorrida pelos automóveis.

Um procedimento similar é usado para estimar a distância viajada em veículos a diesel. Seis classes de veículos a diesel são adotadas: automóveis, ônibus, semi-trailers, tratores agrícolas, veículos especiais e de construção e caminhões. Pesquisas periódicas são empreendidas para estimar a distância média anual percorrida e o consumo médio de combustível por quilômetro para as cinco primeiras classes. Subtraindo do consumo total de diesel o diesel consumido pelas cinco primeiras classes e por atividades não relacionadas ao transporte, tem-se o diesel consumido pelos caminhões. O número total de caminhões x quilômetros é calculado usando o número total de caminhões, o consumo total de diesel pelos caminhões e uma estimativa do consumo médio por quilômetro. 
Tal tipo de estimativa exige que várias suposições simplificadoras sejam adotadas. A principal delas é a de que a quilometragem viajada está diretamente relacionada às vendas de combustível, podendo por elas ser representada. No entanto, essa suposição ignora o efeito da crescente tendência de eficiência energética de automóveis e caminhões. Essa fragilidade pode ser o maior obstáculo para a análise de séries temporais, já que é sabido que os veículos novos são mais eficientes energeticamente que aqueles produzidos há vários anos.

Numa iniciativa da União Europeia na criação de modelos para o tráfego e segurança (COST 329 Action), em 2001, foi desenvolvido um método para estimar o volume de tráfego de países para os quais esse dado não existia, por meio da frota de veículos e do consumo de combustível. Tal modelo baseou-se em informações de países nos quais o volume de tráfego é conhecido, fazendo apenas alguns ajustes nos modelos matemáticos de acordo com o país. $\mathrm{O}$ procedimento se mostrou útil principalmente para alguns países do leste e sul da Europa. Portugal, por exemplo, teve seu volume de tráfego estimado de 1980 até 2000. (CARDOSO, 2005)

Duas hipóteses foram o ponto de partida para esse método:

- Os totais de diesel e de gasolina vendidos (para atividades de transporte rodoviário) são usados para a produção de volume de tráfego;

- Países com níveis comparáveis de desenvolvimento e com grande interação econômica possuem algumas similaridades quanto às taxas de consumo de combustível dos veículos.

Dados de sete países europeus foram coletados e usados para quantificar essas similaridades por meio de análise estatística. Assumiu-se, portanto, que há uma tendência comum no tempo para a taxa de consumo de combustível. Além disso, em cada país base (aqueles com os volumes de tráfego conhecidos), a quilometragem anual média viajada por quantidade de combustível vendido é relacionada a um fator específico para cada país. Dessa forma, diferenças entre as taxas de consumo para cada combustível, ano e país base são capturadas por fatores específicos. Também se considera que há um fator comum que relaciona as taxas de consumo da gasolina e do diesel.

As Equações 2.5 e 2.6 mostram o formato geral do modelo:

$T V_{i t}=a_{i} \cdot f_{t} \cdot\left(G A S_{i t}+k_{i t} \cdot D I S_{i t}\right)$ 
$k_{i t}=\frac{k_{t r u c k} \cdot t_{r u c k}+k_{\text {car }} \cdot \text { car }_{i t}}{\text { truck }_{i t}+\text { car }_{i t}}$

$k_{\text {car }}=1 \quad k_{\text {truck }}=0,25$

Nas quais,

$\mathrm{TV}_{\mathrm{it}}$ : volume de tráfego no país "ii", durante o ano " $\mathrm{t}$ ”;

$a_{i}$ : fator do país;

$f t$ : tendência comum para a taxa de consumo do combustível;

$k_{i t}$ : fator comum, que relaciona as taxas de consumo do diesel e da gasolina, no país "i", durante o ano " $\mathrm{t}$ ";

$\mathrm{GAS}_{\mathrm{it}}$ : vendas de gasolina no país "i”", durante o ano " $\mathrm{t}$ ";

$\mathrm{DIS}_{\mathrm{it}}$ : vendas de diesel no país " $\mathrm{i}$ ", durante o ano " $\mathrm{t}$ ";

car $_{i t}$ : frota de automóveis no país "i”" no ano " $t$ ";

truck $k_{i t}$ : frota de caminhões e ônibus no país "i”" no ano "t".

O fator " $a$ ” é principalmente influenciado por características gerais de cada país, como a composição da frota, características da rede viária e a atividade de transporte rodoviário em geral; sendo que foi ajustado para cada país base usando regressão linear. A variável " $f_{t}$ " reflete a evolução da taxa de consumo de combustível em todos os países base.

Apesar do uso bem sucedido desse modelo em Portugal, a generalização do método para outros países deve ser precedida de pesquisas para verificar a aplicabilidade das duas hipóteses básicas mencionadas. Diferenças em características básicas da frota de veículos (tipo, idade, distribuição, manutenção etc.) ou em características importantes da rede viária (geometria, pavimento, sistemas de gerência etc.) podem existir. Isso requer o ajuste de novos parâmetros às equações básicas.

O uso de dados de vendas de combustíveis está ainda acompanhado de algumas ressalvas que diminuem a precisão dos resultados. A primeira delas diz respeito ao fato de que nem todo o combustível vendido em determinado ano foi necessariamente consumido naquele ano, por exemplo, o combustível vendido em 2007 pode ter sido usado em 2008, assim como o combustível vendido em 2006 pode ter sido usado em 2007. A outra, importante quando da segregação da informação por unidades da federação, refere-se ao fato de que o combustível vendido em um local pode ter sido consumido em outro. 
Há ainda outros aspectos que podem diminuir a robustez das informações de vendas de combustível:

- Possibilidade de comércio clandestino de combustíveis;

- Abastecimentos realizados em países vizinhos em zonas de fronteira, em razão do custo mais baixo do combustível. 



\section{FONTES DE DADOS PARA A MENSURAÇÃO DA MORTALIDADE NO TRÂNSITO NO PAÍS}

\subsection{Considerações iniciais}

O último ano considerado no presente estudo foi 2008, pois é o último ano em que se tem disponível o número de mortes definitivo (de acordo com o Ministério da Saúde).

Entretanto, nas análises que consideraram o PIB per capita dos estados, o ano de 2007 foi o último ano tratado em razão de não se terem disponíveis esses valores para 2008.

\subsection{População}

Os dados demográficos, incluindo as populações (número de habitantes) e parâmetros socioeconômicos, podem ser obtidos junto ao IBGE - Instituto Brasileiro de Geografia e Estatística, do Ministério do Planejamento Orçamento e Gestão (2010).

Na Tabela 3.1 estão relacionados os valores de população do país e dos diversos estados, no período 2004-2008. 
Tabela 3. 1 - População brasileira no período 2004-2008 (habitantes)

\begin{tabular}{|c|c|c|c|c|c|}
\hline Unidade da federação & 2004 & 2005 & 2006 & 2007 & 2008 \\
\hline Brasil & 179.108.134 & 184.184 .074 & 186.770 .613 & 189.335.191 & 189.612 .814 \\
\hline Região Norte & 14.064 .278 & 14.698 .834 & 15.022 .071 & 15.342 .561 & 15.142 .684 \\
\hline Acre & 614.205 & 669.737 & 686.650 & 703.447 & 680.073 \\
\hline Amapá & 553.100 & 594.577 & 615.724 & 636.652 & 613.164 \\
\hline Amazonas & 3.100 .136 & 3.232 .319 & 3.311 .046 & 3.389 .081 & 3.341 .096 \\
\hline Pará & 6.695 .940 & 6.970 .591 & 7.110 .462 & 7.249 .184 & 7.321 .493 \\
\hline Rondônia & 1.479 .940 & 1.534 .584 & 1.562 .406 & 1.590 .027 & 1.493 .566 \\
\hline Roraima & 367.701 & 391.318 & 403.340 & 415.281 & 412.783 \\
\hline Tocantins & 1.253 .256 & 1.305 .708 & 1.332 .443 & 1.358 .889 & 1.280 .509 \\
\hline Região Nordeste & 49.862.741 & 51.018 .983 & 51.609 .036 & 52.193.847 & 53.088.499 \\
\hline Alagoas & 2.947 .717 & 3.015 .901 & 3.050 .649 & 3.085 .053 & 3.127 .557 \\
\hline Bahia & 13.552 .649 & 13.815 .260 & 13.950 .125 & 14.083 .771 & 14.502 .575 \\
\hline Ceará & 7.862 .067 & 8.097 .290 & 8.217 .140 & 8.335 .849 & 8.450 .527 \\
\hline Maranhão & 5.943 .807 & 6.103 .338 & 6.184 .543 & 6.265 .102 & 6.305 .539 \\
\hline Paraíba & 3.542 .167 & 3.595 .849 & 3.623 .198 & 3.650 .180 & 3.742 .606 \\
\hline Pernambuco & 8.238 .849 & 8.413 .601 & 8.502 .602 & 8.590 .868 & 8.734 .194 \\
\hline Piauí & 2.949 .133 & 3.006 .886 & 3.036 .271 & 3.065 .488 & 3.119 .697 \\
\hline Rio Grande do Norte & 2.923 .287 & 3.003 .040 & 3.043 .740 & 3.084 .106 & 3.106 .430 \\
\hline Sergipe & 1.903 .065 & 1.967 .818 & 2.000 .768 & 2.033 .430 & 1.999 .374 \\
\hline Região Sudeste & 76.333.625 & 78.472.036 & 79.561.023 & 80.641.101 & 80.187.717 \\
\hline Espírito Santo & 3.298 .541 & 3.408 .360 & 3.464 .280 & 3.519 .712 & 3.453 .648 \\
\hline Minas Gerais & 18.762 .405 & 19.237 .434 & 19.479 .262 & 19.719 .285 & 19.850 .072 \\
\hline Rio de Janeiro & 15.033 .317 & 15.383 .422 & 15.561 .720 & 15.738 .536 & 15.872 .362 \\
\hline São Paulo & 39.239 .362 & 40.442 .820 & 41.055 .761 & 41.663 .568 & 41.011 .635 \\
\hline Região Sul & 26.315.184 & 26.973.432 & 27.308.919 & 27.641.501 & 27.497.970 \\
\hline Paraná & 10.015 .425 & 10.261 .840 & 10.387 .408 & 10.511 .933 & 10.590 .169 \\
\hline Rio Grande do Sul & 10.613 .256 & 10.845 .002 & 10.963 .216 & 11.080 .317 & 10.855 .214 \\
\hline Santa Catarina & 5.686 .503 & 5.866 .590 & 5.958 .295 & 6.049 .251 & 6.052 .587 \\
\hline Região Centro-Oeste & 12.532.306 & 13.020 .789 & 13.269 .564 & 13.516.181 & 13.695 .944 \\
\hline Distrito Federal & 2.233 .614 & 2.333 .109 & 2.383 .784 & 2.434 .033 & 2.557 .158 \\
\hline Goiás & 5.402 .335 & 5.619 .919 & 5.730 .762 & 5.840 .650 & 5.844 .996 \\
\hline Mato Grosso & 2.697 .717 & 2.803 .272 & 2.857 .024 & 2.910 .255 & 2.957 .732 \\
\hline Mato Grosso do Sul & 2.198 .640 & 2.264 .489 & 2.297 .994 & 2.331 .243 & 2.336 .058 \\
\hline
\end{tabular}

(Fonte: IBGE - Estimativas populacionais para o Tribunal de Contas da União - TCU)

Na Tabela 3.2 estão indicados os valores do Produto Interno Bruto por habitante (PIB per capita), nos anos de 2004 a 2007 (os valores de 2008 não estão disponíveis). 
Tabela 3. 2 - PIB per capita $(\mathrm{R} \$)$ no período 2004-2007

\begin{tabular}{|c|c|c|c|c|}
\hline Unidade da federação & 2004 & 2005 & 2006 & 2007 \\
\hline Brasil & $10.692,19$ & $11.658,10$ & $12.686,60$ & $14.464,73$ \\
\hline Norte & $6.679,93$ & $7.241,49$ & $7.987,81$ & $9.134,62$ \\
\hline Acre & $6.251,21$ & $6.693,56$ & $7.040,86$ & $8.789,49$ \\
\hline Amapá & $7.026,17$ & $7.334,93$ & $8.542,94$ & $10.253,74$ \\
\hline Amazonas & $9.657,97$ & $10.318,30$ & $11.826,21$ & $13.042,83$ \\
\hline Pará & $5.191,52$ & $5.612,32$ & $6.240,05$ & $7.006,81$ \\
\hline Rondônia & $7.208,59$ & $8.395,74$ & $8.389,21$ & $10.319,98$ \\
\hline Roraima & $7.360,85$ & $8.124,58$ & $9.074,35$ & $10.534,08$ \\
\hline Tocantins & $6.555,94$ & $6.939,37$ & $7.208,34$ & $8.920,73$ \\
\hline Nordeste & $4.898,99$ & $5.498,83$ & $6.028,09$ & $6.748,81$ \\
\hline Alagoas & $4.324,35$ & $4.688,25$ & $5.162,19$ & $5.858,37$ \\
\hline Bahia & $5.780,06$ & $6.581,04$ & $6.918,97$ & $7.787,40$ \\
\hline Ceará & $4.621,82$ & $5.055,43$ & $5.634,97$ & $6.149,03$ \\
\hline Maranhão & $3.587,90$ & $4.150,95$ & $4.627,71$ & $5.165,23$ \\
\hline Paraíba & $4.209,90$ & $4.691,09$ & $5.506,52$ & $6.097,04$ \\
\hline Pernambuco & $5.287,29$ & $5.933,46$ & $6.526,63$ & $7.336,78$ \\
\hline Piauí & $3.297,24$ & $3.701,24$ & $4.211,87$ & $4.661,56$ \\
\hline Rio Grande do Norte & $5.259,92$ & $5.950,38$ & $6.753,04$ & $7.607,01$ \\
\hline Sergipe & $6.289,39$ & $6.823,61$ & $7.559,35$ & $8.711,70$ \\
\hline Sudeste & $14.009,42$ & $15.468,74$ & $16.911,70$ & $19.277,26$ \\
\hline Espírito Santo & $11.997,94$ & $13.854,91$ & $15.234,76$ & $18.002,92$ \\
\hline Minas Gerais & $9.335,97$ & $10.013,76$ & $11.024,70$ & $12.519,40$ \\
\hline Rio de Janeiro & $14.663,82$ & $16.057,40$ & $17.692,59$ & $19.245,08$ \\
\hline São Paulo & $16.157,79$ & $17.975,61$ & $19.550,37$ & $22.667,25$ \\
\hline Sul & $12.676,91$ & $13.205,97$ & $14.156,15$ & $16.564,00$ \\
\hline Paraná & $12.079,83$ & $12.344,44$ & $13.151,98$ & $15.711,20$ \\
\hline Rio Grande do Sul & $12.850,07$ & $13.298,02$ & $14.304,83$ & $16.688,74$ \\
\hline Santa Catarina & $13.403,29$ & $14.542,79$ & $15.633,20$ & $17.834,00$ \\
\hline Centro-Oeste & $13.845,69$ & $14.605,73$ & $15.545,74$ & $17.844,46$ \\
\hline Distrito Federal & $30.991,50$ & $34.514,74$ & $37.599,28$ & $40.696,08$ \\
\hline Goiás & $8.718,01$ & $8.992,02$ & $9.956,30$ & $11.547,68$ \\
\hline Mato Grosso & $13.444,59$ & $13.365,06$ & $12.340,79$ & $14.953,58$ \\
\hline Mato Grosso do Sul & $9.461,22$ & $9.561,12$ & $10.592,44$ & $12.411,18$ \\
\hline
\end{tabular}

(Fonte: IBGE, em parceria com os Órgãos Estaduais de Estatística, Secretarias Estaduais de Governo) 


\subsection{Frota de veículos}

Os dados da frota nacional de veículos podem ser obtidos junto ao DENATRAN Departamento Nacional de Trânsito, do Ministério das Cidades (2010).

Os dados podem ser filtrados de acordo com o ano ou mês de interesse, região do país, estado, município, ano de fabricação e tipo do veículo, conforme a seguinte classificação: automóvel, bonde, caminhão, caminhão trator, caminhonete, camioneta, chassi plataforma, ciclomotor, microônibus, motocicleta, motoneta, ônibus, quadriciclo, reboque, semirreboque, side-car, outros, trator esteira, trator rodas, triciclo e utilitário.

Os valores publicados pelo DENATRAN são obtidos por meio do somatório dos dados de cadastramento oriundos do DETRAN (Departamento Estadual de Trânsito) de cada estado. Todavia, o cálculo não considera uma parcela de sucateamento (devido a acidentes e roubo) e tampouco as transferências interestaduais (gerando dupla contagem), o que tende a resultar em dados superestimados. (INFOPETRO, 2010)

Na Tabela 3.3 é compilada a frota de veículos brasileira no período 2004-2008, de acordo com o DENATRAN (2010). Os dados segregados por categoria de veículo podem ser verificados no Apêndice A.

Tabela 3. 3 - Frota de veículos no período 2004-2008, segundo o DENATRAN

\begin{tabular}{cccccc}
\hline \multirow{2}{*}{ Unidades da Federação } & \multicolumn{5}{c}{ Frota } \\
\cline { 2 - 6 } & $\mathbf{2 0 0 4}$ & $\mathbf{2 0 0 5}$ & $\mathbf{2 0 0 6}$ & $\mathbf{2 0 0 7}$ & $\mathbf{2 0 0 8}$ \\
\hline Brasil & $\mathbf{3 8 . 2 7 0 . 6 2 8 0}$ & $\mathbf{4 1 . 0 3 5 . 1 2 1}$ & $\mathbf{4 4 . 2 6 8 . 2 7 8}$ & $\mathbf{4 8 . 4 5 3 . 8 9 9}$ & $\mathbf{5 3 . 2 0 6 . 1 7 4}$ \\
\hline Região Norte & $\mathbf{1 . 3 0 2 . 2 6 9}$ & $\mathbf{1 . 4 6 9 . 9 1 2}$ & $\mathbf{1 . 6 5 9 . 2 3 1}$ & $\mathbf{1 . 8 8 1 . 9 5 3}$ & $\mathbf{2 . 1 5 4 . 2 8 0}$ \\
\hline Acre & 64.655 & 72.086 & 81.508 & 93.934 & 109.604 \\
Amapá & 48.437 & 56.015 & 64.963 & 74.556 & 85.704 \\
Amazonas & 265.606 & 299.721 & 333.198 & 371.025 & 415.774 \\
Pará & 433.383 & 487.780 & 543.272 & 622.157 & 722.269 \\
Rondônia & 259.473 & 288.956 & 320.426 & 361.783 & 418.033 \\
Roraima & 58.557 & 63.763 & 71.271 & 83.699 & 96.124 \\
Tocantins & 172.158 & 201.591 & 244.593 & 274.799 & 306.772 \\
\hline Região Nordeste & $\mathbf{4 . 7 4 6 . 8 2 2}$ & $\mathbf{5 . 1 7 7 . 5 6 2}$ & $\mathbf{5 . 7 0 5 . 1 6 6}$ & $\mathbf{6 . 3 9 8 . 8 8 3}$ & $\mathbf{7 . 2 1 4 . 8 3 0}$ \\
\hline Alagoas & 230.119 & 249.606 & 272.474 & 301.497 & 335.568 \\
Bahia & 1.153 .051 & 1.268 .702 & 1.399 .112 & 1.563 .195 & 1.766 .774 \\
Ceará & 880.375 & 950.233 & 1.042 .449 & 1.165 .708 & 1.302 .108 \\
Maranhão & 314.130 & 358.135 & 407.705 & 476.486 & 556.961 \\
& & & & & Continua
\end{tabular}


Conclusão

\begin{tabular}{cccccc}
\hline Unidades da Federação & $\mathbf{2 0 0 4}$ & & $\mathbf{2 0 0 4}$ & & $\mathbf{2 0 0 4}$ \\
\hline Paraíba & 346.547 & 376.059 & 416.173 & 472.465 & 538.242 \\
Pernambuco & 967.664 & 1.036 .195 & 1.123 .353 & 1.239 .508 & 1.378 .903 \\
Piauí & 262.676 & 292.702 & 330.838 & 375.274 & 432.671 \\
Rio Grande do Norte & 367.274 & 403.790 & 450.342 & 514.137 & 579.979 \\
Sergipe & 224.986 & 242.140 & 262.720 & 290.613 & 323.624 \\
\hline Região Sudeste & $\mathbf{2 0 . 7 7 4 . 8 9 1}$ & $\mathbf{2 2 . 0 6 5 . 4 3 7}$ & $\mathbf{2 3 . 6 6 4 . 1 5 5}$ & $\mathbf{2 5 . 7 2 8 . 4 0 8}$ & $\mathbf{2 8 . 0 3 5 . 2 1 3}$ \\
\hline Espírito Santo & 672.446 & 731.384 & 805.049 & 906.439 & 1.022 .071 \\
Minas Gerais & 4.031 .451 & 4.320 .622 & 4.680 .296 & 5.146 .635 & 5.700 .994 \\
Rio de Janeiro & 3.002 .624 & 3.152 .302 & 3.324 .350 & 3.564 .556 & 3.838 .207 \\
São Paulo & 13.068 .370 & 13.861 .129 & 14.854 .460 & 16.110 .778 & 17.473 .941 \\
\hline Região Sul & $\mathbf{8 . 2 7 2 . 2 6 9}$ & $\mathbf{8 . 8 8 4 . 0 9 2}$ & $\mathbf{9 . 5 1 1 . 4 2 8}$ & $\mathbf{1 0 . 3 0 6 . 7 8 9}$ & $\mathbf{1 1 . 1 7 6 . 7 2 4}$ \\
\hline Paraná & 3.118 .501 & 3.366 .148 & 3.611 .097 & 3.939 .569 & 4.301 .003 \\
Rio Grande do Sul & 3.161 .333 & 3.343 .251 & 3.533 .971 & 3.773 .633 & 4.054 .573 \\
Santa Catarina & 1.992 .435 & 2.174 .693 & 2.366 .360 & 2.593 .587 & 2.821 .148 \\
\hline Região Centro-Oeste & $\mathbf{3 . 1 7 4 . 3 7 7}$ & $\mathbf{3 . 4 3 8 . 1 1 8}$ & $\mathbf{3 . 7 2 8 . 2 9 8}$ & $\mathbf{4 . 1 3 7 . 8 6 6}$ & $\mathbf{4 . 6 2 5 . 1 2 7}$ \\
\hline Distrito Federal & 764.274 & 810.583 & 874.233 & 955.939 & 1.038 .243 \\
Goiás & 1.280 .968 & 1.388 .620 & 1.512 .961 & 1.693 .779 & 1.906 .778 \\
Mato Grosso & 581.692 & 644.623 & 699.158 & 782.071 & 900.311 \\
Mato Grosso do Sul & 547.443 & 594.292 & 641.946 & 706.077 & 779.795 \\
\hline & & & & &
\end{tabular}

Por outro lado, também há dados relativos à frota de veículos provenientes de outras fontes, como a ANFAVEA (Associação Nacional dos Fabricantes de Veículos Automotores) e o SINDIPEÇAS (Sindicato Nacional da Indústria de Componentes para Veículos Automotores), cujos valores diferem dos do DENATRAN por considerarem o histórico de vendas e a probabilidade de sucateamento. (BORBA, 2008)

Segundo Segalla (2010), no levantamento de frota do SINDIPEÇAS os veículos somente são considerados sucateados quando sofrem acidentes com perda total ou por roubo sem recuperação, sendo essa taxa de $1,5 \%$ ao ano para automóveis e comerciais leves e de 1,0\% para caminhões e ônibus, já que nesse último caso é mais raro haver roubo sem recuperação do veículo.

Os dados de frota nacional classificados por tipo de combustível, fornecidos pela ANFAVEA/SINDIPEÇAS (2010) podem ser consultados no Apêndice B. A frota de veículos a GNV por estado encontra-se no Apêndice C. 


\subsection{Mortes no trânsito}

As informações sobre mortes no trânsito podem ser obtidas em três fontes: DENATRAN, FENASEG (Federação Nacional das Empresas de Seguros Privado) e DATASUS Departamento de Informática do SUS (Sistema Único de Saúde).

Os dados do DENATRAN baseiam-se nos boletins de ocorrência da Polícia Militar, que registram as mortes ocorridas no local e, algumas vezes, aquelas ocorridas logo após o acidente. Portanto, não contemplam as mortes de feridos ocorridas, geralmente em hospitais, nos dias que seguem ao acidente.

Os dados do FENASEG correspondem às indenizações pagas nos casos de morte, invalidez permanente e reembolso de despesas médicas, cobertas pelo seguro de Danos Pessoais Causados por Veículos Automotores de Via Terrestre - DPVAT.

O DATASUS, do Ministério da Saúde, por meio do Sistema de Informações sobre Mortalidade (SIM), é um sistema gerido pelo Departamento de Análise de Situação de Saúde (da Secretaria de Vigilância em Saúde), em conjunto com as Secretarias Estaduais e Municipais de Saúde. O procedimento começa com a coleta das Declarações de Óbito dos cartórios, realizado pelas Secretarias de Saúde, que inserem esses dados no SIM. A informação primordial é, portanto, a causa básica do óbito, a qual é codificada pelo médico atestante, segundo regras estabelecidas pela OMS. (MINISTÉRIO DA SAÚDE, 2010)

Neste trabalho foram utilizados os dados do DATASUS, que considera o total de mortes, tenham essas ocorrido no local do acidente, no transporte ao hospital ou no hospital. Essas informações são consideradas bastante confiáveis pela comunidade científica do país.. No sistema DATASUS, a causa morte é especificada de acordo com a Classificação Internacional de Doenças (CID), cuja décima revisão (CID-10) entrou em vigor no Brasil em 1996 (ver Tabela 3.4). 
Tabela 3. 4 - Agrupamento dos códigos para acidentes de transporte, segundo a CID-10

\begin{tabular}{cl}
\hline Código & Especificação \\
\hline V01-V09 & Pedestre traumatizado em acidente de transporte \\
V10-V19 & Ciclista traumatizado em acidente de transporte \\
V20-V29 & Motociclista traumatizado em acidente de transporte \\
V30-V39 & Ocupante de triciclo motorizado traumatizado em acidente de transporte \\
V40-V49 & Ocupante automóvel traumatizado em acidente de transporte \\
V50-V59 & Ocupante de caminhonete traumatizado em acidente de transporte \\
V60-V69 & Ocupante de veículo de transporte pesado traumatizado em acidente de transporte \\
V70-V79 & Ocupante de onibus traumatizado em acidente de transporte \\
V80-V89 & Outros acidentes de transporte terrestre \\
V90-V94 & Acidentes de transporte por água \\
V95-V97 & Acidentes de transporte aéreo espacial \\
V98-V99 & Outros acidentes de transporte não especificados \\
\hline
\end{tabular}

Cada agrupamento divide-se em algumas categorias, conforme mostram as Tabelas 3.5 a 3.13 (MINISTÉRIO DA SAÚDE, 2010). Os agrupamentos V90-V94, V95-V97 e V98-V99 não foram detalhados por não serem de interesse da presente pesquisa.

Tabela 3. 5- Categorias do agrupamento V01-V09 (pedestre traumatizado em acidente de transporte)

\begin{tabular}{cl}
\hline Código & Especificação \\
\hline V01 & Pedestre traumatizado em colisão com um veículo a pedal \\
V02 & Pedestre traumatizado em colisão com um veículo a motor de duas ou três rodas \\
V03 & Pedestre traumatizado em colisão com um automóvel (carro), "pick up" ou caminhonete \\
V04 & Pedestre traumatizado em colisão com um veículo de transporte pesado ou com um ônibus \\
V05 & Pedestre traumatizado em colisão com trem (comboio) ou um veículo ferroviário \\
V06 & Pedestre traumatizado em colisão com outro veículo não-motorizado \\
V09 & Pedestre traumatizado em outros acidentes de transporte e em acidentes de transporte não \\
\hline
\end{tabular}

Tabela 3. 6- Categorias do agrupamento V10 -V19 (ciclista traumatizado em acidente de transporte)

\begin{tabular}{cl}
\hline Código & Especificação \\
\hline V10 & Ciclista traumatizado em colisão com um pedestre ou um animal \\
V11 & Ciclista traumatizado em colisão com outro veículo a pedal \\
V12 & Ciclista traumatizado em colisão com um veículo a motor de duas ou três rodas \\
V13 & Ciclista traumatizado em colisão com um automóvel, "pick up" ou caminhonete \\
V14 & Ciclista traumatizado em colisão com um veículo de transporte pesado ou um ônibus \\
V15 & Ciclista traumatizado em colisão com um trem ou um veículo ferroviário \\
V16 & Ciclista traumatizado em colisão com outro veículo não-motorizado \\
V17 & Ciclista traumatizado em colisão com um objeto fixo ou parado \\
V18 & Ciclista traumatizado em um acidente de transporte sem colisão \\
V19 & Ciclista traumatizado em outros acidentes de transporte e em acidentes de transporte não \\
\hline
\end{tabular}


Tabela 3. 7- Categorias do agrupamento V20 -V29 (motociclista traumatizado em acidente de transporte)

\begin{tabular}{cl}
\hline Código & Especificação \\
\hline V20 & Motociclista traumatizado em colisão com um pedestre ou um animal \\
V21 & Motociclista traumatizado em colisão com um veículo a pedal \\
V22 & Motociclista traumatizado em colisão com um veículo a motor de duas ou três rodas \\
V23 & Motociclista traumatizado em colisão com um automóvel (carro), "pick up" ou \\
V24 & Motociclista traumatizado em colisão com um veículo de transporte pesado ou um ônibus \\
V25 & Motociclista traumatizado em colisão com um trem ou um veículo ferroviário \\
V26 & Motociclista traumatizado em colisão com outro veículo não-motorizado \\
V27 & Motociclista traumatizado em colisão com um objeto fixo ou parado \\
V28 & Motociclista traumatizado em um acidente de transporte sem colisão \\
V29 & Motociclista traumatizado em outros acidentes de transporte e em acidentes de transporte \\
\hline
\end{tabular}

Tabela 3. 8- Categorias do agrupamento V30 -V39 (ocupante de triciclo motorizado traumatizado em acidente de transporte)

\begin{tabular}{cl}
\hline Código & Especificação \\
\hline V30 & $\begin{array}{l}\text { Ocupante de um triciclo motorizado traumatizado em colisão com um pedestre ou um animal } \\
\text { V31 }\end{array}$ \\
Ocupante de um triciclo motorizado traumatizado em colisão com um veículo a pedal \\
V32 & $\begin{array}{l}\text { Ocupante de um triciclo motorizado traumatizado em colisão com outro veículo a motor de } \\
\text { duas ou três rodas }\end{array}$ \\
V33 & $\begin{array}{l}\text { Ocupante de um triciclo motorizado traumatizado em colisão com um automóvel, "pick up" } \\
\text { ou caminhonete }\end{array}$ \\
V34 & $\begin{array}{l}\text { Ocupante de um triciclo motorizado traumatizado em colisão com um veículo de transporte } \\
\text { pesado ou um ônibus }\end{array}$ \\
V35 & $\begin{array}{l}\text { Ocupante de um triciclo motorizado traumatizado em colisão com um trem (comboio) ou um } \\
\text { veículo ferroviário }\end{array}$ \\
V36 & $\begin{array}{l}\text { Ocupante de um triciclo motorizado traumatizado em colisão com outro veículo não- } \\
\text { motorizado }\end{array}$ \\
V37 & $\begin{array}{l}\text { Ocupante de um triciclo motorizado traumatizado em colisão com um objeto fixo ou parado } \\
\text { V38upante de um triciclo motorizado traumatizado em um acidente de transporte sem colisão }\end{array}$ \\
V39 & $\begin{array}{l}\text { Ocupante de um triciclo motorizado traumatizado em outros acidentes de transporte e em } \\
\text { acidentes de transporte não especificados }\end{array}$ \\
\hline
\end{tabular}

Tabela 3. 9- Categorias do agrupamento V40 -V49 (ocupante de automóvel traumatizado em acidente de transporte)

\begin{tabular}{|c|c|}
\hline Código & Especificação \\
\hline V40 & Ocupante de um automóvel traumatizado em colisão com um pedestre ou um animal \\
\hline V41 & Ocupante de um automóvel traumatizado em colisão com um veículo a pedal \\
\hline V42 & $\begin{array}{l}\text { Ocupante de um automóvel traumatizado em colisão com outro veículo a motor de duas ou três } \\
\text { rodas }\end{array}$ \\
\hline V43 & $\begin{array}{l}\text { Ocupante de um automóvel traumatizado em colisão com um automóvel, "pick up" ou } \\
\text { caminhonete }\end{array}$ \\
\hline V44 & $\begin{array}{l}\text { Ocupante de um automóvel traumatizado em colisão com um veículo de transporte pesado ou } \\
\text { um ônibus }\end{array}$ \\
\hline V45 & $\begin{array}{l}\text { Ocupante de um automóvel traumatizado em colisão com um trem (comboio) ou um veículo } \\
\text { ferroviário }\end{array}$ \\
\hline V46 & Ocupante de um automóvel traumatizado em colisão com outro veículo não-motorizado \\
\hline V47 & Ocupante de um automóvel traumatizado em colisão com um objeto fixo ou parado \\
\hline V48 & Ocupante de um automóvel traumatizado em um acidente de transporte sem colisão \\
\hline V49 & $\begin{array}{l}\text { Ocupante de um automóvel traumatizado em outros acidentes de transporte e em acidentes de } \\
\text { transporte não especificados }\end{array}$ \\
\hline
\end{tabular}


Tabela 3. 10 - Categorias do agrupamento V50 -V59 (ocupante de caminhonete traumatizado em acidente de transporte)

\begin{tabular}{|c|c|}
\hline Código & Especificação \\
\hline V50 & Ocupante de uma caminhonete traumatizado em colisão com um pedestre ou um animal \\
\hline V51 & Ocupante de uma caminhonete traumatizado em colisão com um veículo a pedal \\
\hline V52 & $\begin{array}{l}\text { Ocupante de uma caminhonete traumatizado em colisão com veículo a motor de duas ou três } \\
\text { rodas }\end{array}$ \\
\hline V53 & $\begin{array}{l}\text { Ocupante de uma caminhonete traumatizado em colisão com um automóvel (carro) ou uma } \\
\text { caminhoneta }\end{array}$ \\
\hline V54 & $\begin{array}{l}\text { Ocupante de uma caminhonete traumatizado em colisão com um veículo de transporte pesado } \\
\text { ou um ônibus }\end{array}$ \\
\hline V55 & $\begin{array}{l}\text { Ocupante de uma caminhonete traumatizado em colisão com um trem (comboio) ou veículo } \\
\text { ferroviário }\end{array}$ \\
\hline V56 & Ocupante de uma caminhonete traumatizado em colisão com outro veículo não-motorizado \\
\hline V57 & Ocupante de uma caminhonete traumatizado em colisão com um objeto fixo ou parado \\
\hline V58 & Ocupante de uma caminhonete traumatizado em um acidente de transporte sem colisão \\
\hline V59 & $\begin{array}{l}\text { Ocupante de uma caminhonete traumatizado em outros acidentes de transporte e em acidentes } \\
\text { de transporte não especificados }\end{array}$ \\
\hline
\end{tabular}

Tabela 3. 11 - Categorias do agrupamento V60 -V69 (ocupante de veículo de transporte pesado traumatizado em acidente de transporte)

\begin{tabular}{cl}
\hline Código & Especificação \\
\hline V60 & $\begin{array}{l}\text { Ocupante de um veículo de transporte pesado traumatizado em colisão com um pedestre ou } \\
\text { um animal }\end{array}$ \\
V61 & $\begin{array}{l}\text { Ocupante de um veículo de transporte pesado traumatizado em colisão com um veículo a } \\
\text { pedal }\end{array}$ \\
V62 & $\begin{array}{l}\text { Ocupante de um veículo de transporte pesado traumatizado em colisão com um veículo a } \\
\text { motor de duas ou três rodas }\end{array}$ \\
V63 & $\begin{array}{l}\text { Ocupante de um veículo de transporte pesado traumatizado em colisão com um automóvel } \\
\text { (carro) ou uma caminhonete }\end{array}$ \\
V64 & $\begin{array}{l}\text { Ocupante de um veículo de transporte pesado traumatizado em colisão com um outro veículo } \\
\text { de transporte pesado ou um ônibus }\end{array}$ \\
V65 & $\begin{array}{l}\text { Ocupante de um veículo de transporte pesado traumatizado em colisão com um trem } \\
\text { (comboio) ou um veículo ferroviário }\end{array}$ \\
V66 & $\begin{array}{l}\text { Ocupante de um veículo de transporte pesado traumatizado em colisão com um outro veículo } \\
\text { não-motorizado } \\
\text { Ocupante de um veículo de transporte pesado traumatizado em colisão com um objeto fixo } \\
\text { ou parado } \\
\text { Ocupante de um veículo de transporte pesado traumatizado em um acidente de transporte sem } \\
\text { colisão }\end{array}$ \\
V66 & $\begin{array}{l}\text { Ocupante de um veículo de transporte pesado traumatizado em outros acidentes de transporte } \\
\text { não especificados }\end{array}$ \\
\hline
\end{tabular}

Tabela 3. 12 - Categorias do agrupamento V70 -V79 (ocupante de ônibus traumatizado em acidente de transporte)

\begin{tabular}{|c|c|}
\hline Código & Especificação \\
\hline V70 & Ocupante de um ônibus traumatizado em colisão com um pedestre ou um animal \\
\hline V71 & Ocupante de um ônibus traumatizado em colisão com um veículo a pedal \\
\hline V72 & $\begin{array}{l}\text { Ocupante de um ônibus traumatizado em colisão com um outro veículo a motor de duas } \\
\text { ou três rodas }\end{array}$ \\
\hline V73 & $\begin{array}{l}\text { Ocupante de um ônibus traumatizado em colisão com um automóvel (carro) ou uma } \\
\text { caminhonete }\end{array}$ \\
\hline V74 & $\begin{array}{l}\text { Ocupante de um ônibus traumatizado em colisão com um veículo de transporte pesado } \\
\text { ou um ônibus }\end{array}$ \\
\hline V75 & $\begin{array}{l}\text { Ocupante de um ônibus traumatizado em colisão com um trem (comboio) ou um veículo } \\
\text { ferroviário }\end{array}$ \\
\hline V76 & Ocupante de um ônibus traumatizado em colisão com outro veículo não-motorizado \\
\hline
\end{tabular}




\begin{tabular}{|c|c|}
\hline Onclusã & \\
\hline Código & Especificação \\
\hline V77 & Ocupante de um ônibus traumatizado em colisão com um objeto fixo ou parado \\
\hline V78 & Ocupante de um ônibus traumatizado em um acidente de transporte sem colisão \\
\hline V79 & $\begin{array}{l}\text { Ocupante de um ônibus traumatizado em outros acidentes de transporte e em acidentes } \\
\text { de transporte não especificados }\end{array}$ \\
\hline
\end{tabular}

Tabela 3. 13 - Categorias do agrupamento V80 -V89 (outros acidentes de transporte terrestre)

\begin{tabular}{cl}
\hline Código & Especificação \\
\hline V80 & $\begin{array}{l}\text { Pessoa montada em animal ou ocupante de um veículo a tração animal traumatizado em um } \\
\text { acidente de transporte }\end{array}$ \\
V81 & $\begin{array}{l}\text { Ocupante de um trem (comboio) ou um veículo ferroviário traumatizado em um acidente de } \\
\text { transporte }\end{array}$ \\
V82 & $\begin{array}{l}\text { Ocupante de um bonde (carro elétrico) traumatizado em um acidente de transporte } \\
\text { Ocupante de um veículo especial a motor usado principalmente em áreas industriais } \\
\text { V83 }\end{array}$ \\
traumatizado em um acidente de transporte \\
V84 $\begin{array}{l}\text { Ocupante de um veículo especial a motor de uso essencialmente agrícola traumatizado em } \\
\text { um acidente de transporte }\end{array}$ \\
V85 & $\begin{array}{l}\text { Ocupante de um veículo a motor especial de construções traumatizado em um acidente de } \\
\text { tansporte }\end{array}$ \\
Ocupante de um veículo especial para qualquer terreno ou de outro veículo a motor \\
projetado essencialmente para uso não em via pública, traumatizado em um acidente de \\
transporte \\
Acidente de trânsito de tipo especificado, mas sendo desconhecido o modo de transporte da \\
vítima
\end{tabular}

\subsection{Consumo de combustível}

\subsubsection{Consumo total}

Os tipos de combustíveis mais utilizados pela frota brasileira de veículos são o óleo diesel, o álcool hidratado, a gasolina tipo "C” e, nos últimos anos o Gás Natural Veicular - GNV. Abaixo seguem algumas especificações sobre os tipos de combustíveis, conforme a Agência Nacional do Petróleo Gás Natural e Biocombustíveis (ANP) do Ministério de Minas e Energia (2004):

- Etanol - combustível usado nos motores de ciclo Otto no setor de transporte rodoviário, também chamado de álcool etílico;

- Álcool Etílico Anidro Combustível - destinado aos distribuidores para mistura com a gasolina A para formulação da gasolina C (que é a comercializada nas bombas); 
- Álcool Etílico Hidratado Combustível - combustível usado em motores de ignição por centelha (Ciclo Otto), em substituição à Gasolina $\mathrm{C}$, ou seja, é o álcool que é comercializado nas bombas;

- Gasolina A - é a gasolina sem a adição de álcool, como sai da refinaria;

- Gasolina C - é aquela constituída de gasolina A e álcool etílico anidro combustível (é a gasolina que sai de bomba de combustível);

- GNV (Gás Natural Veicular) - mistura combustível gasosa proveniente do gás natural e biogás, destinada ao uso veicular;

- Óleo Diesel - derivado da destilação do petróleo bruto constituído basicamente por hidrocarbonetos.

Em termos de volumes comercializados, o óleo diesel e a gasolina lideram o mercado brasileiro. Já a participação do álcool voltou a crescer devido à inserção dos veículos bicombustíveis no mercado. A Figura 3.1 mostra a evolução das vendas de combustíveis no mercado interno, no período de 2004 a 2008. Os valores de vendas para cada unidade da federação podem ser encontrados no Apêndice D.

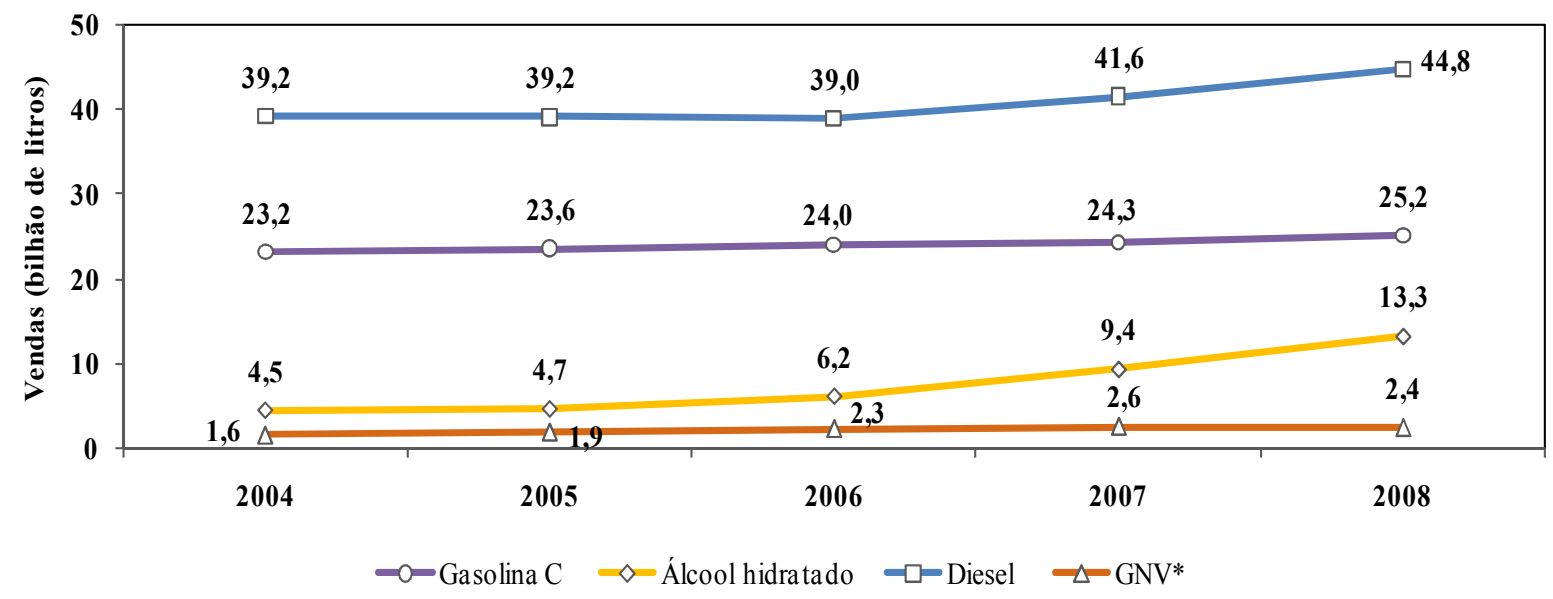

Figura 3. 1 - Vendas de combustíveis no Brasil (Fonte: Ministério de Minas e Energia, 2010; PETROBRAS, 2010; *Unidade do GNV: bilhões de $\mathrm{m}^{3}$ )

Apesar da grande maioria dos volumes de combustíveis comercializados serem destinados ao transporte rodoviário, há ainda outros usos dependendo do tipo de combustível.

No caso do óleo diesel, segundo o Ministério de Minas e Energia (2009), o mercado é dividido em sete segmentos de consumo:

- Transformação (geração de eletricidade);

- Setor energético; 
- Comercial;

- Público;

- Agropecuário;

- Transportes;

- Industrial;

Evidentemente, apenas o volume de diesel destinado às atividades de transporte rodoviário são de interesse da pesquisa. A Tabela 3.14 mostra os volumes consumidos de óleo diesel em cada um desses setores para os anos de 2004-2008. Conforme pode ser observado, as atividades de transporte rodoviário são responsáveis pela maior parcela do óleo diesel consumida no país $(75,69 \%)$, seguidas pelo setor agropecuário $(14,02 \%)$.

Tabela 3. 14 - Consumo setorial de óleo diesel no Brasil entre 2004 e 2008

\begin{tabular}{|c|c|c|c|c|c|c|}
\hline \multirow{2}{*}{ Segmentos de consumo } & \multicolumn{5}{|c|}{ Volume consumido $\left(\mathrm{mil} \mathrm{m}^{3}\right)$} & \multirow{2}{*}{$\begin{array}{l}\text { Percentual } \\
\text { médio }\end{array}$} \\
\hline & 2004 & 2005 & 2006 & 2007 & 2008 & \\
\hline Transformação* & 2.166 & 2.235 & 1.910 & 1.704 & 2.215 & $4,86 \%$ \\
\hline Setor energético & 174 & 186 & 109 & 155 & 179 & $0,38 \%$ \\
\hline Comercial & 121 & 63 & 64 & 66 & 69 & $0,18 \%$ \\
\hline Público & 147 & 101 & 108 & 111 & 113 & $0,28 \%$ \\
\hline Agropecuário & 5.621 & 5.583 & 5.660 & 6.013 & 6.704 & $14,02 \%$ \\
\hline Transporte rodoviário & 30.588 & 30.429 & 30.889 & 32.714 & 34.977 & $75,69 \%$ \\
\hline Transporte ferroviário & 657 & 665 & 654 & 686 & 739 & $1,61 \%$ \\
\hline Transporte hidroviário & 371 & 375 & 419 & 481 & 489 & $1,01 \%$ \\
\hline Industrial & 832 & 786 & 786 & 855 & 884 & $1,97 \%$ \\
\hline Total & 40.677 & 40.423 & 40.599 & 42.785 & 46.369 & $100,00 \%$ \\
\hline
\end{tabular}

No caso do álcool hidratado, também segundo o Ministério de Minas e Energia (2009), o mercado brasileiro se divide em dois segmentos de consumo:

- Consumo final não-energético;

- Transporte rodoviário.

A Tabela 3.15 mostra os volumes consumidos de álcool hidratado em cada um desses setores para os anos de 2004-2008. De acordo com os dados da Tabela 3.15, as atividades de 
transporte rodoviário são responsáveis pela maior parcela do álcool hidratado consumida no Brasil (90,96\%).

Tabela 3. 15 - Consumo setorial de álcool hidratado no Brasil entre 2004 e 2008

\begin{tabular}{ccccccc}
\hline \multirow{2}{*}{ Segmentos de consumo } & \multicolumn{5}{c}{ Volume consumido $\left(\mathbf{m i l ~ m}^{\mathbf{3}}\right)$} & \multirow{2}{*}{$\begin{array}{c}\text { Percentual } \\
\text { médio }\end{array}$} \\
\cline { 2 - 6 } & $\mathbf{2 0 0 4}$ & $\mathbf{2 0 0 5}$ & $\mathbf{2 0 0 6}$ & $\mathbf{2 0 0 7}$ & $\mathbf{2 0 0 8}$ & \\
\hline Consumo não-energético & 865 & 558 & 920 & 398 & 913 & $9,04 \%$ \\
Transporte rodoviário & 4.835 & 5.656 & 7.095 & 10.366 & 14.667 & $90,96 \%$ \\
\hline Total & $\mathbf{5 . 7 0 0}$ & $\mathbf{6 . 2 1 4}$ & $\mathbf{8 . 0 1 5}$ & $\mathbf{1 0 . 7 6 4}$ & $\mathbf{1 5 . 5 8 0}$ & $\mathbf{1 0 0 , 0 0 \%}$ \\
\hline
\end{tabular}

(Fonte: ANP, Ministério de Minas e Energia, 2009)

Quanto à gasolina, a divisão do mercado é a seguinte:

- Transporte rodoviário;

- Transporte aéreo.

A Tabela 3.16 mostra os volumes consumidos de gasolina em cada um desses setores para os anos de 2004-2008. De acordo com os dados da Tabela 3.16, as atividades de transporte rodoviário são responsáveis pela maior parcela da gasolina consumida no Brasil $(99,65 \%)$.

Tabela 3. 16 - Consumo setorial de gasolina no Brasil entre 2004 e 2008

\begin{tabular}{ccccccc}
\hline \multirow{2}{*}{ Segmentos de consumo } & \multicolumn{5}{c}{ Volume consumido $\left(\mathbf{m i l ~ m}^{\mathbf{3}}\right)$} & \multirow{2}{*}{$\begin{array}{c}\text { Percentual } \\
\text { médio }\end{array}$} \\
\cline { 2 - 6 } & $\mathbf{2 0 0 4}$ & $\mathbf{2 0 0 5}$ & $\mathbf{2 0 0 6}$ & $\mathbf{2 0 0 7}$ & $\mathbf{2 0 0 8}$ & \\
\hline Transporte rodoviário & 17.672 & 17.712 & 18.824 & 18.627 & 18.942 & $99,65 \%$ \\
Transporte aéreo & 61 & 56 & 71 & 73 & 61 & $0,35 \%$ \\
\hline Total & $\mathbf{1 7 . 7 3 3}$ & $\mathbf{1 7 . 7 6 8}$ & $\mathbf{1 8 . 8 9 5}$ & $\mathbf{1 8 . 7 0 0}$ & $\mathbf{1 9 . 0 0 3}$ & $\mathbf{1 0 0 , 0 0 \%}$ \\
\hline (Fonte: ANP, Ministério de Minas e Energia, 2009) & &
\end{tabular}

Outro aspecto do mercado de combustíveis brasileiro relevante para a pesquisa é a possibilidade de uso do álcool ou da gasolina nos veículos bicombustíveis. Devido à escolha de qual combustível usar ser guiada principalmente pelo custo, cabe aqui uma análise dos preços médios do litro do álcool e da gasolina em cada estado no período de análise.

A Tabela 3.17 mostra os preços médios desses dois combustíveis de 2004-2008 no país.

Tabela 3. 17 - Preço médio (R \$/litro) do álcool e da gasolina no Brasil no período 2004-2008

\begin{tabular}{ccccccccccc}
\hline Combustível & \multicolumn{4}{c}{ Álcool } & \multicolumn{4}{c}{ Gasolina } \\
\hline Ano & $\mathbf{2 0 0 4}$ & $\mathbf{2 0 0 5}$ & $\mathbf{2 0 0 6}$ & $\mathbf{2 0 0 7}$ & $\mathbf{2 0 0 8}$ & $\mathbf{2 0 0 4}$ & $\mathbf{2 0 0 5}$ & $\mathbf{2 0 0 6}$ & $\mathbf{2 0 0 7}$ & $\mathbf{2 0 0 8}$ \\
\hline Brasil & 1,21 & 1,38 & 1,68 & 1,49 & 1,48 & 2,08 & 2,31 & 2,54 & 2,50 & 2,50 \\
\hline
\end{tabular}

(Fonte: ANP, Ministério de Minas e Energia, 2010) 
No Apêndice E podem ser encontrados os preços médios do álcool e da gasolina para cada unidade da federação.

\subsubsection{Taxa de consumo unitário}

A taxa de consumo de combustível é dada pela quilometragem percorrida com 1litro ou $1 \mathrm{~m}^{3}$ (no caso do GNV) de combustível. A disponibilidade dessa informação varia de acordo com a categoria de veículo.

Para os automóveis e comerciais leves, podem-se encontrar valores medidos da taxa de consumo provenientes de testes realizados pelo INMETRO, para o Programa Brasileiro de Etiquetagem Veicular, sob a responsabilidade do CONPET - Programa Nacional de Racionalização do Uso dos Derivados do Petróleo e do Gás Natural, situado dentro do Ministério de Minas e Energia (2010b). Entretanto, apenas alguns modelos de veículos (os mais populares) foram testados, de modo que para a obtenção de outros valores de taxas, exige-se a coleta em outras fontes, como o Autoesporte (2010) e demais sítios especializados da internet.

As motocicletas podem ter seus dados de consumo consultados em sítios especializados da internet (MOTO ESPORTE, 2010).

Para a estimativa da taxa de consumo de combustível de caminhões e ônibus, podem ser utilizados os estudos sobre emissões veiculares do Ministério do Meio Ambiente (2010) como base. Tais estudos, por sua vez, baseiam-se em informações da ANFAVEA e de empresas do setor.

A taxa de consumo dos veículos a GNV pode ser consultada em GASNET (2010).

\subsection{Quilometragem percorrida}

Alguns estudos brasileiros, principalmente aqueles voltados para questões ambientais de análises de emissões veiculares, já realizaram estimativas globais das quilometragens anuais percorridas pela frota nacional. Os resultados desses trabalhos são apresentados a seguir. 


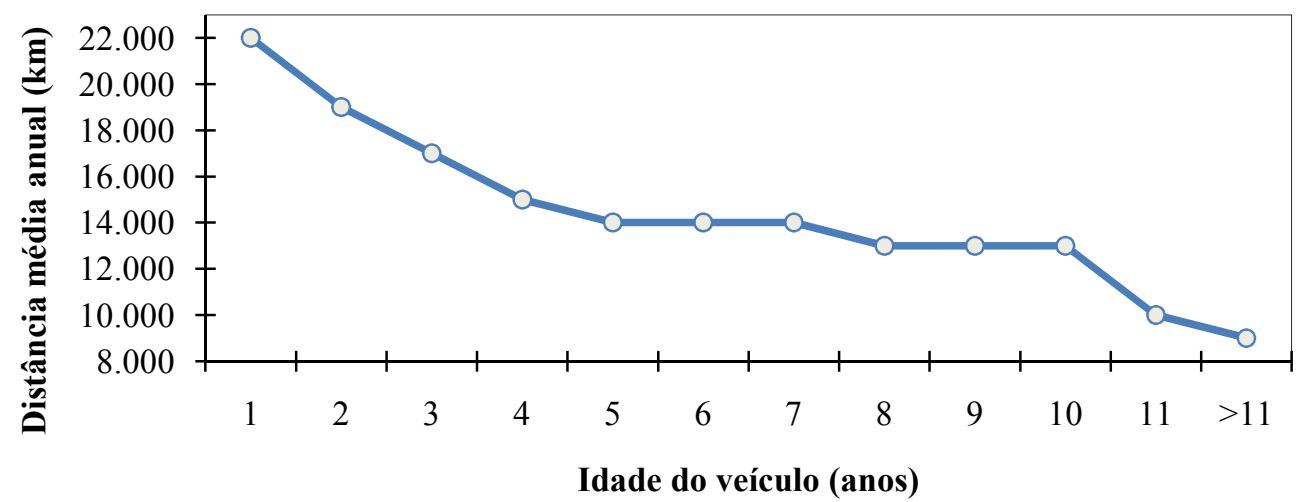

Figura 3. 2 - Distribuição da quilometragem média anual $(\mathrm{em} \mathrm{km})$ de acordo com a idade do veículo (Fonte: Azuaga, 2000)

A CETESB - Companhia Ambiental do Estado de São Paulo, em um estudo para a Região Metropolitana de São Paulo, determinou as quilometragens médias anuais percorridas por veículos leves, encontrando uma relação entre a idade e a quilometragem anual. A distribuição da quilometragem média anual pela idade do veículo se dá conforme a Figura 3.2, adaptada de Azuaga (2000).

Isso ocorre porque os proprietários de veículos mais novos, em geral, são aqueles que possuem maior disponibilidade de renda para o consumo de combustível, além de apresentarem um comportamento de menor elasticidade-preço da demanda. Já os proprietários de veículos mais antigos geralmente possuem um nível menor de renda, destinando uma parcela menor ao consumo de combustíveis, além de apresentar um comportamento mais sensível às variações de preços dos combustíveis. (SCHAEFFER; SZKLO, 2007)

Estimativas elaboradas por Azuaga (2000), para o ano de 1998, chegaram a uma quilometragem média nacional de $14.472 \mathrm{~km}$ anuais para automóveis, 14.661 para comerciais leves. Borba (2008), em estudo mais detalhado, propôs uma metodologia para a regionalização do mercado de combustíveis no Brasil, obtendo ao longo de sua pesquisa, estimativas regionais (e individualmente para os estados da região sudeste) da quilometragem média percorrida por ano para os diferentes modos de transporte, conforme apresentado nas Tabelas 3.18 a 3.20. 
Tabela 3. 18 - Quilometragem anual para ônibus (2004)

\begin{tabular}{ccccccccc}
\hline \multirow{2}{*}{$\begin{array}{c}\text { Tipo de } \\
\text { onibus }\end{array}$} & \multicolumn{4}{c}{ Regiões } & \multicolumn{4}{c}{ Estados do Sudeste } \\
\cline { 2 - 9 } & $\mathbf{N}$ & NE & CO & S & SP & RJ & MG & ES \\
\hline Urbano & 87.051 & 73.850 & 51.810 & 58.695 & 55.740 & 76.092 & 54.834 & 69.714 \\
Interurbano & 113.364 & 113.364 & 113.364 & 113.364 & 113.364 & 113.364 & 113.364 & 113.364 \\
Micro-ônibus & 43.871 & 37.444 & 26.714 & 30.066 & 28.627 & 38.535 & 28.186 & 35.430 \\
\hline (Fonte: Borba, 2008) & & & & & & &
\end{tabular}

Tabela 3. 19 - Quilometragem anual para caminhões (2004)

\begin{tabular}{ccccccccc}
\hline \multirow{2}{*}{$\begin{array}{c}\text { Tipo de } \\
\text { caminhão }\end{array}$} & \multicolumn{4}{c}{ Regiões } & \multicolumn{4}{c}{ Estados do Sudeste } \\
\cline { 2 - 9 } & NE & CO & S & SP & RJ & MG & ES \\
\hline Grande & 123.132 & 51.274 & 90.144 & 47.945 & 43.580 & 34.728 & 65.687 & 31.271 \\
Pequeno & 61.566 & 25.637 & 45.072 & 23.972 & 21.790 & 17.364 & 32.844 & 15.635 \\
\hline (Fonte: Borba, 2008) & & & & & & &
\end{tabular}

Tabela 3. 20 - Quilometragem anual para veículos leves (2004)

\begin{tabular}{ccccccccc}
\hline \multirow{2}{*}{$\begin{array}{c}\text { Tipo de } \\
\text { veículo leve }\end{array}$} & \multicolumn{4}{c}{ Regiões } & \multicolumn{4}{c}{ Estados do Sudeste } \\
\cline { 2 - 9 } & $\mathbf{N}$ & $\mathbf{N E}$ & $\mathbf{C O}$ & $\mathbf{S}$ & SP & RJ & MG & ES \\
\hline Leves (total) & 16.596 & 12.622 & 11.779 & 9.231 & 8.405 & 8.747 & 9.950 & 10.380 \\
Urbano & 12.687 & 9.603 & 9.898 & 7.516 & 7.316 & 7.717 & 8.149 & 8.385 \\
Interurbano & 3.909 & 3.019 & 1.881 & 1.715 & 1.090 & 1.031 & 1.801 & 1.994 \\
\hline (Fonte: Borba, 2008) & & & & & & &
\end{tabular}

Nota-se que cada região, assim como cada unidade da federação da Região Sudeste, apresenta valores significativamente distintos, resultado de características sociais e econômicas específicas de cada região ou estado, que afetam os padrões de viagens. Isso sugere a adoção de modelos individualizados para a estimativa de dados dessa natureza, levando a resultados mais precisos e verossímeis.

Vieira (1999), por meio de dados de vendas de combustíveis, entrevistas com condutores profissionais do transporte rodoviário sobre as taxas de consumo e dados de frota; realizou uma estimativa para o ano de 1996 de $10.437 \mathrm{~km}$ rodados por veículo (o equivalente a 7 viagens casa-trabalho-casa por semana de $20 \mathrm{~km}$ e mais $310 \mathrm{~km}$ mensais em viagens de lazer). O total de quilômetros percorridos naquele ano (1996) de 285 bilhões é compatível com os níveis de movimentos registrados na antiga Alemanha Ocidental ou no Japão em meados dos anos 70 . 


\section{MÉTODO DE CÁLCULO DO ÍNDICE DE MORTES POR QUILÔMETRO}

\subsection{Considerações iniciais}

A estimativa da quilometragem total percorrida (quantidade de tráfego expressa em veículos $\mathrm{x}$ quilômetros) com base no consumo de combustível, para compor o índice de mortes por quilômetro, deve levar em conta uma série de particularidades da frota, dos tipos de combustíveis disponíveis no mercado e das atividades de transporte de uma forma geral. Devido à grande variedade de veículos motorizados existentes (quanto a tipo, idade, combustível usado etc.) e às várias opções de combustíveis disponíveis no mercado (esses com diferentes taxas de consumo), a tarefa de realizar tal estimativa para o país e os estados exige uma coleta de dados extensa e minuciosa.

Basicamente, as seguintes informações são necessárias:

- Frota de veículos motorizados - informação desagregada por tipo de veículo, tipo de combustível usado e estado em que o veículo está registrado;

- Vendas de combustíveis - informação desagregada por tipo de combustível e unidade da federação;

- Taxa de consumo de combustível - informação que depende do tipo de veículo e do tipo de combustível usado para fornecer uma taxa de consumo unitário que relaciona a quantidade de quilômetros percorridos com 1 litro de combustível.

O método desenvolvido para ser usado neste trabalho compreendeu as seguintes seis etapas: tratamento dos dados de frota, tratamento dos dados de vendas de combustíveis, estimativa das taxas de consumo de combustível, estimativa da quilometragem percorrida, levantamento da quantidade de mortes e determinação do índice de mortes por veículo.km percorrido.

Na Figura 4.1 encontra-se o fluxograma com a estrutura do método desenvolvido para ser empregado neste trabalho. 




Figura 4. 1- Fluxograma das informações usadas para o cálculo do índice de mortes por veículo x quilômetro 
Todas as informações necessárias para os cálculos da pesquisa foram devidamente armazenadas em uma planilha em Microsoft Office Excel, sendo que as diversas abas (cada qual contendo determinado tipo de informação) foram vinculadas. Isso possibilitou a observação da variação do índice de mortes por quilômetro mediante a alteração de qualquer variável levada em consideração.

\subsection{Tratamento das informações relativas à frota}

A primeira informação coletada foi relativa à frota de cada tipo de veículo, de acordo com dados provenientes do Ministério das Cidades (2010) e ANFAVEA/SINDIPEÇAS (2010), para os veículos a gasolina, álcool e diesel, e do GASNET (2010), para os veículos movidos a GNV.

Foram usadas diferentes fontes para obtenção dos dados de frota, visto que cada uma apresentou vantagem sob pontos de vista distintos. Os valores fornecidos pelo DENATRAN apresentam-se segregados em categorias de veículos convenientes para o estudo e estão distribuídos por unidade da federação. A ANFAVEA/SINDIPEÇAS apresenta valores nacionais (sem divisão por unidade da federação), porém com um detalhamento ainda maior das categorias de veículos, discriminando inclusive o tipo de combustível de cada modelo.

Dessa forma, como cada uma das fontes de frota possui vantagens quanto à forma de organização dos dados, optou-se por usar uma base mista de frota. Essa base consiste nos números absolutos de veículos apresentados pelo DENATRAN, porém emprega a distribuição dos tipos de combustíveis de acordo com os percentuais da frota da ANFAVEA/SINDIPEÇAS. Essa escolha foi baseada, principalmente, no fato de a frota do DENATRAN estar distribuída entre os estados brasileiros e ser o dado mais amplamente aceito para pesquisas em transportes.

De acordo com dados do DENATRAN, os tipos de veículos estão desagregados em 21 categorias, das quais apenas 10 foram utilizadas. Foram excluídas da análise, por não apresentarem influência significativa no estudo, as seguintes categorias: bonde, chassiplataforma, reboque, semi-reboque, ciclomotor, triciclo, quadriciclo, side-car, trator esteira, trator rodas e outros (aqueles que não se enquadra em nenhuma definição estabelecida). 
Como as informações sobre o tipo de frota do DENATRAN não estavam agregadas da mesma forma que as informações da ANFAVEA/SINDIPEÇAS, a classificação da frota do DENATRAN foi compatibilizada com a usada pela ANFAVEA/SINDIPEÇAS, conforme apresentado na Figura 4.2.

\begin{tabular}{|c|c|c|}
\hline $\begin{array}{l}\text { Categorias } \\
\text { principais }\end{array}$ & $\begin{array}{l}\text { Categorias } \\
\text { DENATRAN }\end{array}$ & $\begin{array}{c}\text { Categorias } \\
\text { ANFAVEA/SINDIPEÇAS }\end{array}$ \\
\hline Automóvel & Automóvel & 18 subcategorias \\
\hline \multirow{3}{*}{ Comercial leve } & Caminhonete & \multirow{3}{*}{14 subcategorias } \\
\hline & Camioneta & \\
\hline & Utilitário & \\
\hline \multirow{3}{*}{ Caminhão } & \multirow{2}{*}{ Caminhão } & Leve \\
\hline & & Médio \\
\hline & Caminhão-trator & Pesado \\
\hline \multirow{3}{*}{ Ônibus } & Microônibus & Microônibus \\
\hline & \multirow{2}{*}{ Ônibus } & Rodoviário \\
\hline & & Urbano \\
\hline \multirow{4}{*}{ Motocicleta } & Motoneta & Até $115 \mathrm{CC}$ \\
\hline & \multirow{3}{*}{ Motocicleta } & Entre 116 e $250 \mathrm{CC}$ \\
\hline & & Entre 251 e $500 \mathrm{CC}$ \\
\hline & & Mais que $500 \mathrm{CC}$ \\
\hline
\end{tabular}

Figura 4.2- Classificação da frota - compatibilização dos dados do DENATRAN para ANFAVEA/SINDIPEÇAS

Tal compatibilização dos valores de frota do DENATRAN e da ANFAVEA/SINDIPEÇAS possibilitou a estimativa da frota, por estado, de cada categoria de veículo, segundo cada tipo de combustível. Isso fez com que as particularidades da frota de cada unidade da federação pudessem ser consideradas.

Nos subitens seguintes são relatados os procedimentos de cálculo para o tratamento dos dados de frota. O detalhamento está dividido de acordo com o tipo de combustível utilizado na seguinte ordem: veículos a gasolina, veículos a álcool, veículos a diesel e veículos a GNV. 


\subsubsection{Veículos a gasolina}

A frota de veículos a gasolina em circulação (de acordo com ANFAVEA/SINDIPEÇAS) é composta pelas seguintes categorias: automóveis, comerciais leves, motocicletas, caminhões e ônibus. Nesta pesquisa, os caminhões e ônibus movidos à gasolina foram contabilizados como caminhões/ônibus a diesel, em razão de representarem parcela pouco significativa, bem menor que $1 \%$ do total em ambas as categorias.

Conforme mostrado na Figura 4.2, os automóveis estão divididos em 18 subcategorias e os comerciais leves em $14^{1}$, para as quais foram adotadas taxas de consumo de combustível (em $\mathrm{km} / 1$ ) conforme especificado no item 3.5.2.

A frota total é resultado da soma de todas as subcategorias, descontada a frota a GNV (no caso dos automóveis ${ }^{2}$ ) e acrescido um percentual de veículos bicombustíveis que usam gasolina. A parcela de veículos bicombustíveis acrescida varia de acordo com o estado e com o ano, visto que a preferência do abastecimento com gasolina ou álcool depende do preço do litro de cada um desses combustíveis.

Os preços médios do álcool e da gasolina no período 2004-2008 foram usados como base para classificar os veículos flex em veículo a álcool ou a gasolina (conforme Apêndice E). Nos estados onde o preço da gasolina era menor que 1,43 vezes o preço do álcool, considerou-se todos os veículos bicombustíveis como sendo a gasolina. Caso contrário, acrescentou-se apenas 5\% dos veículos bicombustíveis à frota de veículos à gasolina (devido a uma parcela de usuários com comportamento inelástico em relação ao preço dos dois combustíveis premissa adotada neste trabalho).

A frota de motocicletas divulgada pela ANFAVEA/SINDIPEÇAS apresenta a especificação da cilindrada de cada veículo, o que possibilitou a divisão nas quatro subcategorias apresentadas na Figura 4.2. Na compatibilização com a frota fornecida pelo DENATRAN, as motocicletas de até $115 \mathrm{CC}$ correspondem às motonetas. As outras três subcategorias somadas correspondem à categoria de motocicletas do DENATRAN.

\footnotetext{
${ }^{1}$ Subcategorias de automóveis a gasolina: cupe/conversível, cupe/conversível/sedan, esportivo, hachback médio, hatchback pequeno, hatchback popular, hatchback/sedan, minivan, sedan grande, sedan médio, sedan pequeno, sedan popular, sedan/SW, sedan/SW/conversível, sedan/SW/cupe, SW, SW popular e utilitário.

Subcategorias de comerciais leves a gasolina: furgão grande, furgão pequeno, furgão popular, jeep, pickup grande, pickup média, pickup pequena, pickup popular, SW, utilitário esportivo, utilitário/esportivo/popular e van.

${ }^{2}$ Considerou-se que a conversão para o GNV foi feita unicamente por proprietários de automóveis movidos exclusivamente a gasolina.
} 


\subsubsection{Veículos a álcool}

A frota circulante de veículos a álcool, de acordo com ANFAVEA/SINDIPEÇAS, é composta pelas seguintes categorias: automóveis, comerciais leves e caminhões. Todavia, os caminhões que usam o álcool como combustível foram contabilizados como caminhões a diesel, pois representam um percentual muito pequeno do total dessa frota (bem menor que $1 \%$ ).

De forma similar ao considerado no caso dos veículos leves a gasolina, a frota total de veículos leves a álcool é resultado da soma de todas as subcategorias, acrescido um percentual de veículos bicombustíveis que usam álcool. Essa parcela corresponde a 95\% dos veículos bicombustíveis quando o preço médio do litro do álcool era menor que 0,70 vezes o preço do litro da gasolina.

A adoção de um mesmo percentual de veículos leves a álcool para todos os estados brasileiros leva à superestimação da quilometragem percorrida pelos veículos a álcool nos locais onde a aquisição desse tipo de veículo é mais comum (e a participação desses veículos na frota é maior), como, por exemplo, na Região Sudeste. Por outro lado, a distância percorrida pelos veículos a álcool é subestimada nos locais onde a venda de veículos a álcool é proporcionalmente menor, como, por exemplo, na Região Norte, devido ao uso do álcool não ser economicamente tão atrativo quanto no Sudeste.

Em vista disso, há necessidade de ajustar a participação dos veículos a álcool na frota de cada unidade da federação por meio de outro procedimento. Tal ajuste levou em consideração a razão entre o volume total de álcool e a frota de veículos leves em cada estado (em litros de álcool por veículo leve) em relação à média nacional de:

- 168 1/veículo leve em 2004;

- 186 1/veículo leve em 2005;

- 220 1/veículo leve em 2006;

- 299 1/veículo leve em 2007;

- 393 1/veículo leve em 2008.

Por exemplo, se no ano de 2008 a razão entre o volume total de álcool comercializado e a frota de veículos leves no Amapá é de 59 1/veículo leve, a frota de veículos leves a álcool do Amapá deve ser corrigida pela multiplicação por $59 \div 393=0,15$; o que significa uma redução 
de $85 \%$ na frota de veículos a álcool estimada. Tomando como exemplo contrário o estado de São Paulo, com uma razão de 596 1/veículo leve em 2008, o fator de correção usado deve ser $596 \div 393=1,52$; o que sugere o aumento de $52 \%$ da frota de veículos a álcool em São Paulo.

Logicamente, esses veículos subtraídos ou somados à frota usuária de álcool, devem ser adicionados ou retirados, respectivamente, da frota de veículos leves usuária de gasolina.

\subsubsection{Veículos a diesel}

A frota de veículos a diesel em circulação (ANFAVEA/SINDIEÇAS) é composta pelas seguintes categorias: automóveis, comerciais leves, caminhões e ônibus. Conforme já foi mencionado, os caminhões e ônibus movidos a gasolina e a álcool foram incorporados à frota a diesel desses veículos. Acredita-se que essa consideração seja razoável, já que desde 1985 mais de $95 \%$ dos caminhões e $100 \%$ dos ônibus vendidos no país são a diesel (ANFAVEA, 2006).

\subsubsection{Veículos a GNV}

Com o objetivo de simplificar os cálculos, considerou-se que a frota de veículos a GNV constitui-se apenas de uma categoria única (automóveis). Assim, o número de veículos adaptados para o uso do gás foi subtraído da frota de automóveis a gasolina. O número de conversões baseou-se em GASNET (2010) e pode ser visualizado no Apêndice C.

\subsection{Volume de vendas de combustíveis}

Os volumes totais de combustíveis vendidos, por ano e unidade da federação estão disponíveis no Apêndice D. 
A soma dos volumes estaduais de vendas de álcool e diesel fornecidos pela ANP não conferem com os valores nacionais de consumo fornecido no Balanço Energético Nacional dos anos de 2004-2008 para esses combustíveis, já que há uma diferença entre volume vendido e o efetivamente consumido em cada ano. Em razão disso, foram aplicados fatores de correção (que multiplicam o volume total) em relação ao valor nacional, obviamente de forma proporcional à quantidade de vendas em cada unidade da federação.

Além disso, no caso do álcool e do diesel deve-se ressaltar que os dados de vendas divulgados incluem volumes destinados a outras atividades e não apenas a quantidade de combustível destinada ao transporte rodoviário, havendo, portanto, a necessidade de correção dos valores. Os fatores de correção devido ao ajuste ao valor nacional e devido a outras atividades que não o transporte rodoviário são abordados nos subitens 4.3.1 e 4.3.2.

Para o volume de gasolina essa correção não foi necessária, já que a soma dos valores estaduais excedia o valor nacional, optando-se por usar o maior valor. Além disso, os dados da ANP já separavam o volume de gasolina $\mathrm{C}$ e gasolina de aviação, não havendo a necessidade dessa correção.

\subsubsection{Correção do volume de álcool}

Os volumes de álcool foram corrigidos de acordo com os seguintes dois fatores (cujos valores estão na Tabela 4.1):

- Fator de correção 1 - em relação ao valor nacional;

- Fator de correção 2 - em relação ao consumo final não energético.

Tabela 4. 1 - Fatores de correção aplicados ao volume de álcool

\begin{tabular}{cccccc}
\hline Tipo de correção & \multicolumn{5}{c}{ Fatores de correção para o álcool hidratado } \\
\cline { 2 - 6 } & $\mathbf{2 0 0 4}$ & $\mathbf{2 0 0 5}$ & $\mathbf{2 0 0 6}$ & $\mathbf{2 0 0 7}$ & $\mathbf{2 0 0 8}$ \\
\hline Ajuste ao valor nacional & 1,263 & 1,331 & 1,296 & 1,149 & 1,172 \\
Consumo final não energético & 0,848 & 0,910 & 0,885 & 0,963 & 0,941 \\
\hline Correção final (Fator 1 x Fator 2) & $\mathbf{1 , 0 7 1}$ & $\mathbf{1 , 2 1 1}$ & $\mathbf{1 , 1 4 7}$ & $\mathbf{1 , 1 0 6}$ & $\mathbf{1 , 1 0 3}$ \\
\hline
\end{tabular}

Os volumes de álcool corrigidos podem ser consultados no Apêndice F. 


\subsubsection{Correção do volume de diesel}

Os volumes de óleo diesel foram corrigidos de acordo com nove fatores:

- Fator de correção 1 - em relação ao valor nacional;

- Fator de correção 2 - óleo diesel para transformação;

- Fator de correção 3 - óleo diesel usado no setor energético;

- Fator de correção 4 - óleo diesel destinado à atividade comercial;

- Fator de correção 5 - óleo diesel destinado ao setor público;

- Fator de correção 6 - óleo diesel destinado ao setor industrial;

- Fator de correção 7 - óleo diesel destinado ao setor agropecuário;

- Fator de correção 8 - óleo diesel destinado ao transporte ferroviário;

- Fator de correção 9 - óleo diesel destinado ao transporte hidroviário.

O produto dos fatores de correção 1 ao 6 resulta em um multiplicador final de 0,948; 0,945; 0,963; 0,959 e 0,957 para o volume de diesel nos anos de 2004, 2005, 2006, 2007 e 2008, respectivamente.

O fator de correção 7, referente ao óleo diesel destinado ao setor agropecuário, baseou-se nos volumes de diesel consumidos pelos estabelecimentos agropecuários de cada unidade da federação, conforme percentuais relativos ao Censo Agropecuário do ano de 2006, elaborado pelo IBGE, situado no Ministério do Planejamento Orçamento e Gestão (2006). O fator de correção 7 usado para cada estado pode ser observado no Apêndice G.

O fator de correção 8, cujo os valores podem ser consultados no Apêndice $\mathrm{H}$, correspondente ao desconto devido ao diesel usado no transporte ferroviário, foi calculado com base nas informações sobre consumo de óleo diesel por estrada de ferro disponibilizadas no Anuário Estatístico dos Transportes Terrestres, contendo informações relativas ao período de 2004 a 2008 (MINSTÉRIO DOS TRANSPORTES, 2009). Adotou-se o critério da extensão (em km) de malha ferroviária contida em cada estado para determinar a parcela de óleo diesel correspondente a cada unidade da federação.

Finalmente, no cálculo do fator de correção 9, para a estimativa do volume de óleo diesel destinado ao transporte aquaviário em cada estado, usou-se a extensão da malha hidroviária principal navegável de cada estado para distribuir as parcelas de óleo diesel usados para o 
transporte aquaviário. Esse procedimento foi usado pela falta de dados disponíveis para estimar o volume de diesel usado em transporte aquaviário individualmente em cada estado. Os valores do fator de correção 9 por ano e unidade da federação estão disponíveis no Apêndice I.

Os volumes de óleo diesel corrigidos podem ser visualizados no Apêndice J.

\subsection{Consumo unitário de combustível}

Usou-se uma taxa de consumo de combustível de um único modelo de veículo para cada subcategoria (por exemplo, hatchback pequeno, sedan médio, pickup grande etc.), o qual serviu como veículo representante da categoria, baseando-se na suposição de que não há grandes variações no consumo unitário entre veículos pertencentes à mesma subcategoria.

A taxa de consumo para cada categoria de veículo é resultado da ponderação levando em consideração a frota de cada subcategoria. Os valores da taxa de consumo para todas as categorias de veículos por tipo de combustível podem ser observados nas Tabela 4.2 a 4.4.

Tabela 4. 2 - Taxa média de consumo dos veículos a gasolina $(\mathrm{km} / \mathrm{l})$

\begin{tabular}{cccccc}
\hline \multirow{2}{*}{ Categorias } & \multicolumn{5}{c}{ Gasolina (km/l) } \\
\cline { 2 - 6 } & $\mathbf{2 0 0 4}$ & $\mathbf{2 0 0 5}$ & $\mathbf{2 0 0 6}$ & $\mathbf{2 0 0 7}$ & $\mathbf{2 0 0 8}$ \\
\hline Automóveis* & 10,90 & 10,90 & 10,90 & 10,89 & 10,88 \\
Comerciais leves* & 9,85 & 9,83 & 9,83 & 9,80 & 9,72 \\
Motocicleta $\leq 115$ CC** & 40,00 & 40,00 & 40,00 & 40,00 & 40,00 \\
Motocicleta $>115$ e $\leq 250 C C^{* *}$ & 30,00 & 30,00 & 30,00 & 30,00 & 30,00 \\
Motocicleta $>250$ e $\leq 500 C C^{* *}$ & 20,00 & 20,00 & 20,00 & 20,00 & 20,00 \\
Motocicleta $>500 C C^{* *}$ & 10,00 & 10,00 & 10,00 & 10,00 & 10,00 \\
\hline *Fonte: CONPET (2010); AUTOESPORTE (2010) & & & & \\
**Fonte: MOTOESPORTE (2010) & & & & & \\
\end{tabular}

$\underline{\text { Tabela 4. } 3 \text { - Taxa média de consumo dos veículos a álcool }(\mathrm{km} / \mathrm{l})}$

\begin{tabular}{cccccc}
\hline \multirow{2}{*}{ Categorias } & \multicolumn{5}{c}{ Álcool (km/l) } \\
\cline { 2 - 6 } & $\mathbf{2 0 0 4}$ & $\mathbf{2 0 0 5}$ & $\mathbf{2 0 0 6}$ & $\mathbf{2 0 0 7}$ & $\mathbf{2 0 0 8}$ \\
\hline Automóveis & 6,95 & 6,95 & 6,95 & 6,95 & 6,95 \\
Comerciais leves & 6,72 & 6,72 & 6,72 & 6,72 & 6,72 \\
\hline Fonte: CONPET (2010); AUTOESPORTE (2010)
\end{tabular}


Tabela 4. 4 - Taxa média de consumo dos veículos a diesel $(\mathrm{km} / \mathrm{l})$

\begin{tabular}{cccccc}
\hline \multirow{2}{*}{ Categorias } & \multicolumn{5}{c}{ Diesel (km/l) } \\
\cline { 2 - 6 } & $\mathbf{2 0 0 4}$ & $\mathbf{2 0 0 5}$ & $\mathbf{2 0 0 6}$ & $\mathbf{2 0 0 7}$ & $\mathbf{2 0 0 8}$ \\
\hline Automóveis* & 10,00 & 10,00 & 10,00 & 10,00 & 10,00 \\
Comerciais leves* & 9,10 & 9,10 & 9,10 & 9,10 & 9,10 \\
Caminhão leve** & 6,86 & 6,86 & 6,86 & 6,86 & 6,86 \\
Caminhão médio** & 5,61 & 5,61 & 5,61 & 5,61 & 5,61 \\
Caminhão pesado** & 3,10 & 3,10 & 3,10 & 3,10 & 3,10 \\
Microônibus** & 4,70 & 4,70 & 4,70 & 4,70 & 4,70 \\
Ônibus rodoviário** & 3,00 & 3,00 & 3,00 & 3,00 & 3,00 \\
Onnibus urbano** & 2,37 & 2,37 & 2,37 & 2,37 & 2,37 \\
\hline *Fonte: AUTOESPORTE (2010) \\
**Fonte: Ministério do Meio Ambiente - MMA (2010)
\end{tabular}

A taxa de consumo dos veículos a GNV, de 13,80km/m³ , foi baseada em GASNET (2010b).

\subsection{Quilometragem total percorrida}

Para o cálculo da quilometragem total percorrida é necessário, inicialmente, estimar o percentual de combustível destinado a cada categoria de veículo.

Para estimar o percentual do volume total de gasolina comercializado correspondente às categorias de veículos leves (automóveis e comerciais leves) e motocicletas foram usados valores da quilometragem anual média obtidos em pesquisas anteriormente realizadas.

No caso dos veículos leves a gasolina (automóveis e comerciais leves) foram usados os valores calculados por Borba (2008) relacionados na Tabela 3.18 do Capítulo 3.

No caso das motocicletas foram usadas as estimativas de WBCSD - World Business Council for Sustainable Development (2004) e VIEIRA et al. (2008) acerca da quilometragem média anual viajada por motocicletas.

Disponíveis esses valores, as taxas médias de consumo e a frota de cada categoria procedeu-se o cálculo do volume de gasolina consumido. Dessa forma, pôde-se obter a parcela de cada categoria de veículo no consumo total de gasolina. Finalmente, o volume total calculado foi normalizado em relação ao valor de volume fornecido pela ANP. 
A distribuição do volume de álcool seguiu a mesma proporção da frota de automóveis e comerciais leves, já que esse combustível é apenas usado por essas categorias de veículos.

No caso GNV todo o volume é consumido por automóveis, não havendo necessidade de distribuição do mesmo entre as categorias de veículos.

Por fim, no caso do óleo diesel, seguiu-se o mesmo procedimento adotado para a divisão do volume de gasolina consumido por cada categoria veicular, baseando-se, no entanto, apenas nas estimativas de Borba (2008), cujos valores estão indicados nas Tabelas 3.18 e 3.19 do Capítulo 3.

Entretanto, em alguns estados o volume de óleo diesel estimado $\left(V_{d, \text { calc }}\right)$ resultou muito aquém do volume oficial declarado pela ANP $\left(V_{A N P}\right)$, este último já corrigido de acordo com os nove fatores de correção citados no Item 4.3.2, de modo que o fator $k$ da Equação 4.1 resultou muito pequeno. Isso sugere que processo de correção dos volumes adotado não foi suficiente para contemplar as particularidades de cada estado. Os valores do fator de correção $\mathrm{k}$ podem ser consultados no Apêndice J.

$V_{d, \text { calc }}=k \cdot V_{A N P}$

Tal discrepância ocorreu principalmente nos estados da Região Norte, com destaque para o Amapá, onde o volume de diesel estimado foi $29 \%$ do valor da ANP. Provavelmente, ainda uma parcela considerável do óleo diesel vendido no Amapá (assim como em outros estados) seja destinada a outras atividades que não o transporte rodoviário. No caso particular do Amapá, pode haver ainda uma forte influência da Guiana Francesa (fronteira oeste do Amapá), cuja moeda é o Euro, o que torna o combustível brasileiro barato, de modo a estimular a compra por condutores do país vizinho, aumentando o volume oficial de diesel vendido no Amapá.

Em razão disso, admitiu-se como aceitável uma variação até 30\% menor que o volume oficial declarado pela ANP (fator $k \geq 0,70$ ). Para variações maiores, o volume de óleo diesel foi recorrigido de acordo com os seguintes fatores:

- Se $0,60 \leq k<0,70$, foi adotado $k=0,70$;

- $\operatorname{Se} 0,50 \leq k<0,60$, foi adotado $k=0,60$;

- $\operatorname{Se} k<0,50$, foi adotado $k=0,50$. 
Por outro lado, apesar de ocorrer com menor frequência, quando o volume de diesel estimado excedia o volume declarado pela ANP, admitiu-se como aceitável a mesma variação de até $30 \%$ em relação ao volume oficial declarado pela ANP (fator $k \leq 1,30$ ). Para variações maiores, o volume de óleo diesel foi recorrigido de acordo com os seguintes fatores:

- $\quad$ Se $1,30<k \leq 1,40$, foi adotado $k=1,30$;

- Se $1,40<k \leq 1,50$, adotado $k=1,40$;

- $\quad$ Se $k>1,50$, foi adotado $k=1,50$.

Um exemplo disso (fator $\mathrm{k}>1,30$ ) ocorreu no estado de Roraima, provavelmente influenciado pela fronteira com a Venezuela, onde o preço dos combustíveis derivados do petróleo é significativamente menor. Isso estimula o abastecimento da frota brasileira no país vizinho ou mesmo o comércio clandestino.

Influências desse tipo, em estados com pequenas frotas, como é o caso de Roraima (influência da Venezuela) e do Amapá (influência da Guiana Francesa) são capazes de alterar significativamente as estimativas realizadas no presente trabalho, o que justifica as correções realizadas. Se os valores discrepantes fossem mantidos, a exposição (em veículos.km) seria superestimada ou subestimada, dependendo do estado, levando a distorções nos valores do índice de mortes por quilômetro.

Disponíveis todos os valores mencionados, o cálculo da quilometragem percorrida para cada veículo por tipo de combustível é realizado por intermédio da Equação 4.2:

$Q_{i j k}=F_{i j k} \cdot T_{i j} \cdot p_{j i} \cdot V_{j k}$

Em que,

$Q_{i k j}$; Quilometragem viajada (em veículo.km) pelo veículo “i”, usando combustível “j”, no ano " $k$ ";

$F_{i j k}:$ Frota do veículo " $i$ ", usando combustível " $j ”$, no ano " $k$ ”;

$T_{i j k}$ :Taxa de consumo de combustível do veículo “ $i$ ”, usando combustível “j”, no ano " $k$ ";

$p_{i j k}:$ Parcela do combustível “j” usada pelo veículo "i”, no ano " $\mathrm{k}$ ”;

$V_{j k}$ :Vendas do combustível " $j$ ", no ano " $k$ ".

Dessa forma, a quilometragem total percorrida pela frota é dada pela Equação 4.3: 
$Q_{k}=\sum_{i=1}^{16} Q_{i j k}$

Na qual,

$Q_{k}$ : Quilometragem total viajada (em veículo.km) pelo no ano " $k$ ";

$Q_{i j k}$ : Quilometragem (em veículo.km) viajada pelo veículo “ $i ”$, usando combustível "j", no ano " $k$ ".

\subsection{Quantidade de mortes}

Foram coletadas informações, por estado, de ocorrência do óbito, sendo que os dados estão distribuídos conforme já descrito no Capítulo 3. Alguns dados de morte foram excluídos da análise por sua ocorrência não ser determinada por atividade de transporte rodoviário motorizado. A Tabela 4.5 contém os códigos e a descrição dos dados de morte não considerados na presente pesquisa.

Tabela 4. 5 - Dados de morte excluídos do estudo

\begin{tabular}{|c|c|}
\hline Código & Especificação \\
\hline V01 & Pedestre traumatizado em colisão com um veículo a pedal \\
\hline V05 & Pedestre traumatizado em colisão com trem (comboio) ou um veículo ferroviário \\
\hline V06 & Pedestre traumatizado em colisão com outro veículo não-motorizado \\
\hline V10 & Ciclista traumatizado em colisão com um pedestre ou um animal \\
\hline V11 & Ciclista traumatizado em colisão com outro veículo a pedal \\
\hline V15 & Ciclista traumatizado em colisão com um trem ou um veículo ferroviário \\
\hline V16 & Ciclista traumatizado em colisão com outro veículo não-motorizado \\
\hline V17 & Ciclista traumatizado em colisão com um objeto fixo ou parado \\
\hline V81 & $\begin{array}{l}\text { Ocupante de um trem (comboio) ou um veículo ferroviário traumatizado em um acidente } \\
\text { de transporte }\end{array}$ \\
\hline V82 & Ocupante de um bonde (carro elétrico) traumatizado em um acidente de transporte \\
\hline V83 & $\begin{array}{l}\text { Ocupante de um veículo especial a motor usado principalmente em áreas industriais } \\
\text { traumatizado em um acidente de transporte }\end{array}$ \\
\hline V84 & $\begin{array}{l}\text { Ocupante de um veículo especial a motor de uso essencialmente agrícola traumatizado em } \\
\text { um acidente de transporte }\end{array}$ \\
\hline V85 & $\begin{array}{l}\text { Ocupante de um veículo a motor especial de construções traumatizado em um acidente de } \\
\text { transporte }\end{array}$ \\
\hline V86 & $\begin{array}{l}\text { Ocupante de um veículo especial para qualquer terreno ou de outro veículo a motor } \\
\text { projetado essencialmente para uso não em via pública, traumatizado em um acidente de } \\
\text { transporte }\end{array}$ \\
\hline V88 & $\begin{array}{l}\text { Acidente não-de-trânsito de tipo especificado, mas sendo desconhecido o modo de } \\
\text { transporte da vítima }\end{array}$ \\
\hline
\end{tabular}




\section{7 Índice de mortes por veículo.quilômetro percorrido}

Disponíveis as informações referentes aos itens anteriores, o índice de mortes por bilhão de veículo.km percorrido é determinado por intermédio da Equação 4.4:

$I M_{i k}=10^{9} \cdot M_{i k} / Q_{i k}$

Em que,

$I M_{i k}$ : Índice de mortes (por bilhão de veículo.km) do modo " $i$ " no ano " $k$ ";

$M_{i k}$ : Número de mortes no modo " $i$ " no ano " $k$ ";

$Q_{i j k}$ : Quilometragem (em veículo.km) viajada no modo " $i$ " no ano " $k$ ". 



\section{VALORES OBTIDOS E ANÁLISE DOS RESULTADOS}

\subsection{Quilometragem total percorrida}

Na Tabela 5.1 estão relacionadas as quilometragens médias anuais percorridas, por tipo de veículo e global, no país e nos diversos estados correspondentes ao ano de 2008. Também está indicada nessa tabela a posição relativa de cada estado no tocante ao valor global, seguindo a seguinte lógica: maior quilometragem - $1^{\mathrm{a}}$ posição e menor quilometragem - $27^{\mathrm{a}}$ posição. Os valores correspondentes aos anos de 2004 a 2007 encontram-se no Apêndice L.

Tabela 5.1- Quilometragens médias anuais correspondentes ao ano de 2008

\begin{tabular}{|c|c|c|c|c|c|}
\hline $\begin{array}{c}\text { Grandes Regiões e } \\
\text { Unidades da Federação }\end{array}$ & $\begin{array}{l}\text { Todos os } \\
\text { veículos }\end{array}$ & $\begin{array}{l}\text { Veículo } \\
\text { leve }\end{array}$ & Motocicleta & Caminhão & Ônibus \\
\hline Brasil & $\begin{array}{c}12.680 \\
\left(20^{\circ}-21^{\circ}\right)\end{array}$ & $\begin{array}{c}9.869 \\
\left(20^{\circ}-21^{\circ}\right)\end{array}$ & $\begin{array}{c}13.604 \\
\left(10^{\circ}-11^{\circ}\right)\end{array}$ & $\begin{array}{c}39.950 \\
\left(12^{\circ}-13^{\circ}\right)\end{array}$ & $\begin{array}{c}61.131 \\
\left(18^{\circ}-19^{\circ}\right)\end{array}$ \\
\hline Norte & 18.353 & 14.431 & 11.732 & 95.572 & 92.376 \\
\hline Acre & $\begin{array}{c}16.035 \\
\left(7^{\circ}\right)\end{array}$ & $\begin{array}{c}13.022 \\
\left(9^{\circ}\right)\end{array}$ & $\begin{array}{c}10.910 \\
\left(26^{\circ}\right)\end{array}$ & $\begin{array}{c}95.259 \\
\left(4^{\circ}\right)\end{array}$ & $\begin{array}{c}98.543 \\
\left(3^{\circ}\right)\end{array}$ \\
\hline Amapá & $\begin{array}{c}20.525 \\
\left(1^{\circ}\right)\end{array}$ & $\begin{array}{c}16.091 \\
\left(1^{\circ}\right)\end{array}$ & $\begin{array}{c}14.464 \\
\left(7^{\circ}\right)\end{array}$ & $\begin{array}{c}132.406 \\
\left(1^{\circ}\right)\end{array}$ & $\begin{array}{c}129.701 \\
\left(1^{\circ}\right)\end{array}$ \\
\hline Amazonas & $\begin{array}{c}18.788 \\
\left(3^{\circ}\right)\end{array}$ & $\begin{array}{c}15.542 \\
\left(2^{\circ}\right)\end{array}$ & $\begin{array}{c}13.353 \\
\left(11^{\circ}\right)\end{array}$ & $\begin{array}{c}82.722 \\
\left(6^{\circ}\right)\end{array}$ & $\begin{array}{c}80.838 \\
\left(6^{\circ}\right)\end{array}$ \\
\hline Pará & $\begin{array}{c}20.063 \\
\left(2^{\circ}\right)\end{array}$ & $\begin{array}{c}14.636 \\
\left(3^{\circ}\right)\end{array}$ & $\begin{array}{c}12.972 \\
\left(15^{\circ}\right)\end{array}$ & $\begin{array}{c}102.789 \\
\left(2^{\circ}\right)\end{array}$ & $\begin{array}{c}99.350 \\
\left(2^{\circ}\right)\end{array}$ \\
\hline Rondônia & $\begin{array}{c}16.845 \\
\left(6^{\circ}\right)\end{array}$ & $\begin{array}{c}11.588 \\
\left(13^{\circ}\right)\end{array}$ & $\begin{array}{c}11.580 \\
\left(23^{\circ}\right)\end{array}$ & $\begin{array}{c}95.512 \\
\left(3^{\circ}\right)\end{array}$ & $\begin{array}{c}96.997 \\
\left(4^{\circ}\right)\end{array}$ \\
\hline Roraima & $\begin{array}{c}14.148 \\
\left(13^{\circ}\right)\end{array}$ & $\begin{array}{c}12.432 \\
\left(11^{\circ}\right)\end{array}$ & $\begin{array}{c}10.934 \\
\left(25^{\circ}\right)\end{array}$ & $\begin{array}{c}73.657 \\
\left(7^{\circ}\right)\end{array}$ & $\begin{array}{c}69.296 \\
\left(13^{\circ}\right)\end{array}$ \\
\hline Tocantins & $\begin{array}{c}18.662 \\
\left(4^{\circ}\right)\end{array}$ & $\begin{array}{c}13.702 \\
\left(4^{\circ}\right)\end{array}$ & $\begin{array}{c}12.237 \\
\left(18^{\circ}\right)\end{array}$ & $\begin{array}{c}91.845 \\
\left(5^{\circ}\right) \\
\end{array}$ & $\begin{array}{c}84.053 \\
\left(5^{\circ}\right)\end{array}$ \\
\hline Nordeste & 14.312 & 11.759 & 13.818 & 34.637 & 66.804 \\
\hline Alagoas & $\begin{array}{c}14.712 \\
\left(12^{\circ}\right)\end{array}$ & $\begin{array}{c}12.723 \\
\left(10^{\circ}\right)\end{array}$ & $\begin{array}{c}14.106 \\
\left(9^{\circ}\right)\end{array}$ & $\begin{array}{c}28.629 \\
\left(25^{\circ}\right)\end{array}$ & $\begin{array}{c}51.882 \\
\left(24^{\circ}\right)\end{array}$ \\
\hline Bahia & $\begin{array}{c}15.548 \\
\left(8^{\circ}\right)\end{array}$ & $\begin{array}{l}12.117 \\
\left(12^{\circ}\right)\end{array}$ & $\begin{array}{c}15.985 \\
\left(4^{\circ}\right)\end{array}$ & $\begin{array}{l}35.346 \\
\left(17^{\circ}\right)\end{array}$ & $\begin{array}{c}68.608 \\
\left(15^{\circ}\right)\end{array}$ \\
\hline Ceará & $\begin{array}{c}12.659 \\
\left(21^{\circ}\right)\end{array}$ & $\begin{array}{c}9.953 \\
\left(20^{\circ}\right)\end{array}$ & $\begin{array}{c}12.845 \\
\left(17^{\circ}\right)\end{array}$ & $\begin{array}{l}33.760 \\
\left(21^{\circ}\right)\end{array}$ & $\begin{array}{c}65.283 \\
\left(16^{\circ}\right)\end{array}$ \\
\hline Maranhão & $\begin{array}{c}17.017 \\
\left(5^{\circ}\right)\end{array}$ & $\begin{array}{c}13.567 \\
\left(6^{\circ}\right)\end{array}$ & $\begin{array}{c}17.292 \\
\left(2^{\circ}\right)\end{array}$ & $\begin{array}{c}36.107 \\
\left(16^{\circ}\right)\end{array}$ & $\begin{array}{c}72.185 \\
\left(9^{\circ}\right)\end{array}$ \\
\hline
\end{tabular}




\begin{tabular}{|c|c|c|c|c|c|}
\hline $\begin{array}{c}\text { Grandes Regiões e } \\
\text { Unidades da Federação }\end{array}$ & $\begin{array}{l}\text { Todos os } \\
\text { veículos }\end{array}$ & $\begin{array}{l}\text { Veículo } \\
\text { leve }\end{array}$ & Motocicleta & Caminhão & Ônibus \\
\hline Paraíba & $\begin{array}{c}15.020 \\
\left(11^{\circ}\right)\end{array}$ & $\begin{array}{c}13.658 \\
\left(5^{\circ}\right)\end{array}$ & $\begin{array}{c}12.986 \\
\left(14^{\circ}\right)\end{array}$ & $\begin{array}{c}38.190 \\
\left(13^{\circ}\right)\end{array}$ & $\begin{array}{c}75.345 \\
\left(7^{\circ}\right)\end{array}$ \\
\hline Pernambuco & $\begin{array}{c}13.200 \\
\left(19^{\circ}\right)\end{array}$ & $\begin{array}{c}10.511 \\
\left(19^{\circ}\right)\end{array}$ & $\begin{array}{c}13.116 \\
\left(13^{\circ}\right)\end{array}$ & $\begin{array}{c}33.259 \\
\left(22^{\circ}\right)\end{array}$ & $\begin{array}{c}62.333 \\
\left(18^{\circ}\right)\end{array}$ \\
\hline Piauí & $\begin{array}{c}13.122 \\
\left(20^{\circ}\right)\end{array}$ & $\begin{array}{c}11.087 \\
\left(16^{\circ}\right)\end{array}$ & $\begin{array}{c}12.170 \\
\left(19^{\circ}\right)\end{array}$ & $\begin{array}{c}34.438 \\
\left(18^{\circ}\right)\end{array}$ & $\begin{array}{c}69.360 \\
\left(12^{\circ}\right)\end{array}$ \\
\hline Rio Grande do Norte & $\begin{array}{c}13.966 \\
\left(14^{\circ}\right)\end{array}$ & $\begin{array}{c}13.090 \\
\left(8^{\circ}\right)\end{array}$ & $\begin{array}{c}11.314 \\
\left(24^{\circ}\right)\end{array}$ & $\begin{array}{c}36.437 \\
\left(15^{\circ}\right)\end{array}$ & $\begin{array}{c}68.797 \\
\left(14^{\circ}\right)\end{array}$ \\
\hline Sergipe & $\begin{array}{c}15.351 \\
\left(10^{\circ}\right)\end{array}$ & $\begin{array}{c}13.256 \\
\left(7^{\circ}\right)\end{array}$ & $\begin{array}{c}12.947 \\
\left(16^{\circ}\right)\end{array}$ & $\begin{array}{c}36.919 \\
\left(14^{\circ}\right)\end{array}$ & $\begin{array}{c}73.399 \\
\left(8^{\circ}\right)\end{array}$ \\
\hline Sudeste & 12.326 & 9.827 & 14.472 & 35.192 & 60.381 \\
\hline Espírito Santo & $\begin{array}{c}12.310 \\
\left(22^{\circ}\right)\end{array}$ & $\begin{array}{c}9.036 \\
\left(23^{\circ}\right)\end{array}$ & $\begin{array}{c}14.355 \\
\left(8^{\circ}\right)\end{array}$ & $\begin{array}{l}23.295 \\
\left(27^{\circ}\right)\end{array}$ & $\begin{array}{c}71.759 \\
\left(11^{\circ}\right)\end{array}$ \\
\hline Minas Gerais & $\begin{array}{c}13.321 \\
\left(18^{\circ}\right)\end{array}$ & $\begin{array}{c}8.928 \\
\left(24^{\circ}\right)\end{array}$ & $\begin{array}{c}15.389 \\
\left(5^{\circ}\right)\end{array}$ & $\begin{array}{c}52.182 \\
\left(12^{\circ}\right)\end{array}$ & $\begin{array}{c}63.095 \\
\left(17^{\circ}\right)\end{array}$ \\
\hline Rio de Janeiro & $\begin{array}{c}13.517 \\
\left(16^{\circ}\right)\end{array}$ & $\begin{array}{c}11.193 \\
\left(15^{\circ}\right)\end{array}$ & $\begin{array}{c}18.167 \\
\left(1^{\circ}\right)\end{array}$ & $\begin{array}{c}25.425 \\
\left(26^{\circ}\right)\end{array}$ & $\begin{array}{c}71.947 \\
\left(10^{\circ}\right)\end{array}$ \\
\hline São Paulo & $\begin{array}{c}11.746 \\
\left(25^{\circ}\right)\end{array}$ & $\begin{array}{l}9.796 \\
\left(21^{\circ}\right) \\
\end{array}$ & $\begin{array}{c}13.487 \\
\left(10^{\circ}\right)\end{array}$ & $\begin{array}{c}31.161 \\
\left(24^{\circ}\right)\end{array}$ & $\begin{array}{c}54.609 \\
\left(23^{\circ}\right)\end{array}$ \\
\hline Sul & 11.145 & 7.971 & 14.205 & 33.432 & 56.198 \\
\hline Paraná & $\begin{array}{c}10.601 \\
\left(27^{\circ}\right)\end{array}$ & $\begin{array}{l}7.688 \\
\left(27^{\circ}\right)\end{array}$ & $\begin{array}{c}11.962 \\
\left(21^{\circ}\right)\end{array}$ & $\begin{array}{c}34.034 \\
\left(20^{\circ}\right)\end{array}$ & $\begin{array}{c}57.323 \\
\left(20^{\circ}\right)\end{array}$ \\
\hline Rio Grande do Sul & $\begin{array}{c}11.191 \\
\left(26^{\circ}\right)\end{array}$ & $\begin{array}{l}7.796 \\
\left(26^{\circ}\right)\end{array}$ & $\begin{array}{c}16.072 \\
\left(3^{\circ}\right)\end{array}$ & $\begin{array}{c}32.216 \\
\left(23^{\circ}\right)\end{array}$ & $\begin{array}{c}54.937 \\
\left(22^{\circ}\right)\end{array}$ \\
\hline Santa Catarina & $\begin{array}{c}11.939 \\
\left(24^{\circ}\right)\end{array}$ & $\begin{array}{c}8.666 \\
\left(25^{\circ}\right)\end{array}$ & $\begin{array}{c}15.059 \\
\left(6^{\circ}\right)\end{array}$ & $\begin{array}{c}34.166 \\
\left(19^{\circ}\right)\end{array}$ & $\begin{array}{c}56.074 \\
\left(21^{\circ}\right)\end{array}$ \\
\hline Centro-Oeste & 13.704 & 10.681 & 11.899 & 59.924 & 50.944 \\
\hline Distrito Federal & $\begin{array}{c}12.143 \\
\left(23^{\circ}\right)\end{array}$ & $\begin{array}{c}10.684 \\
\left(18^{\circ}\right)\end{array}$ & $\begin{array}{c}13.213 \\
\left(12^{\circ}\right)\end{array}$ & $\begin{array}{c}53.959 \\
\left(11^{\circ}\right)\end{array}$ & $\begin{array}{c}44.809 \\
\left(27^{\circ}\right)\end{array}$ \\
\hline Goiás & $\begin{array}{c}13.713 \\
\left(15^{\circ}\right)\end{array}$ & $\begin{array}{c}10.820 \\
\left(17^{\circ}\right)\end{array}$ & $\begin{array}{c}12.123 \\
\left(20^{\circ}\right)\end{array}$ & $\begin{array}{c}55.268 \\
\left(10^{\circ}\right)\end{array}$ & $\begin{array}{c}48.723 \\
\left(26^{\circ}\right)\end{array}$ \\
\hline Mato Grosso & $\begin{array}{c}15.455 \\
\left(9^{\circ}\right)\end{array}$ & $\begin{array}{c}11.485 \\
\left(14^{\circ}\right)\end{array}$ & $\begin{array}{c}10.618 \\
\left(27^{\circ}\right)\end{array}$ & $\begin{array}{c}70.795 \\
\left(8^{\circ}\right)\end{array}$ & $\begin{array}{c}59.786 \\
\left(19^{\circ}\right)\end{array}$ \\
\hline Mato Grosso do Sul & $\begin{array}{c}13.504 \\
\left(17^{\circ}\right)\end{array}$ & $\begin{array}{c}9.722 \\
\left(22^{\circ}\right)\end{array}$ & $\begin{array}{c}11.769 \\
\left(22^{\circ}\right)\end{array}$ & $\begin{array}{c}58.446 \\
\left(9^{\circ}\right)\end{array}$ & $\begin{array}{c}51.150 \\
\left(25^{\circ}\right)\end{array}$ \\
\hline
\end{tabular}

Na Figura 5.1 pode ser observada a variação da quilometragem anual média no país considerando toda a frota de 2004 a 2008. 


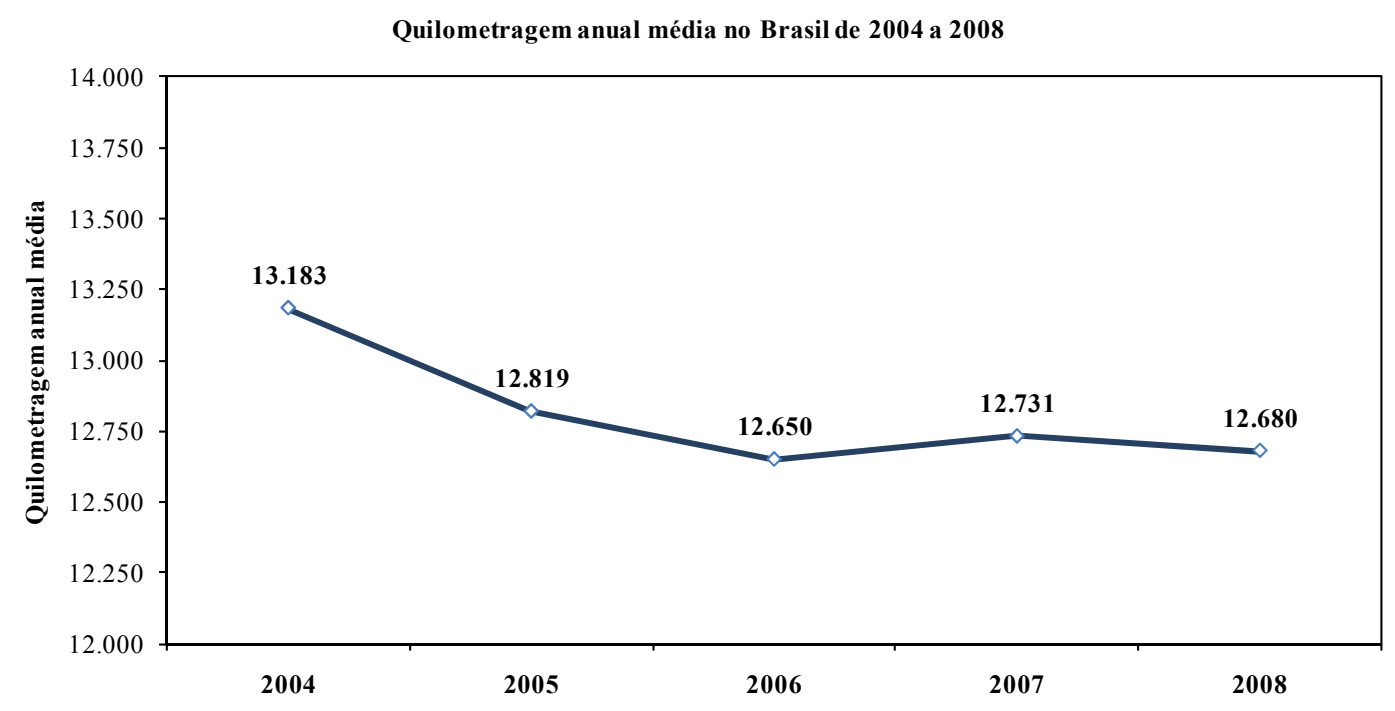

Figura 5.1 - Variação da quilometragem média anual no Brasil no período 2004 - 2008

Na Figura 5.2 é mostrada a variação da quilometragem anual média no país por categoria de veículo de 2004 a 2008.

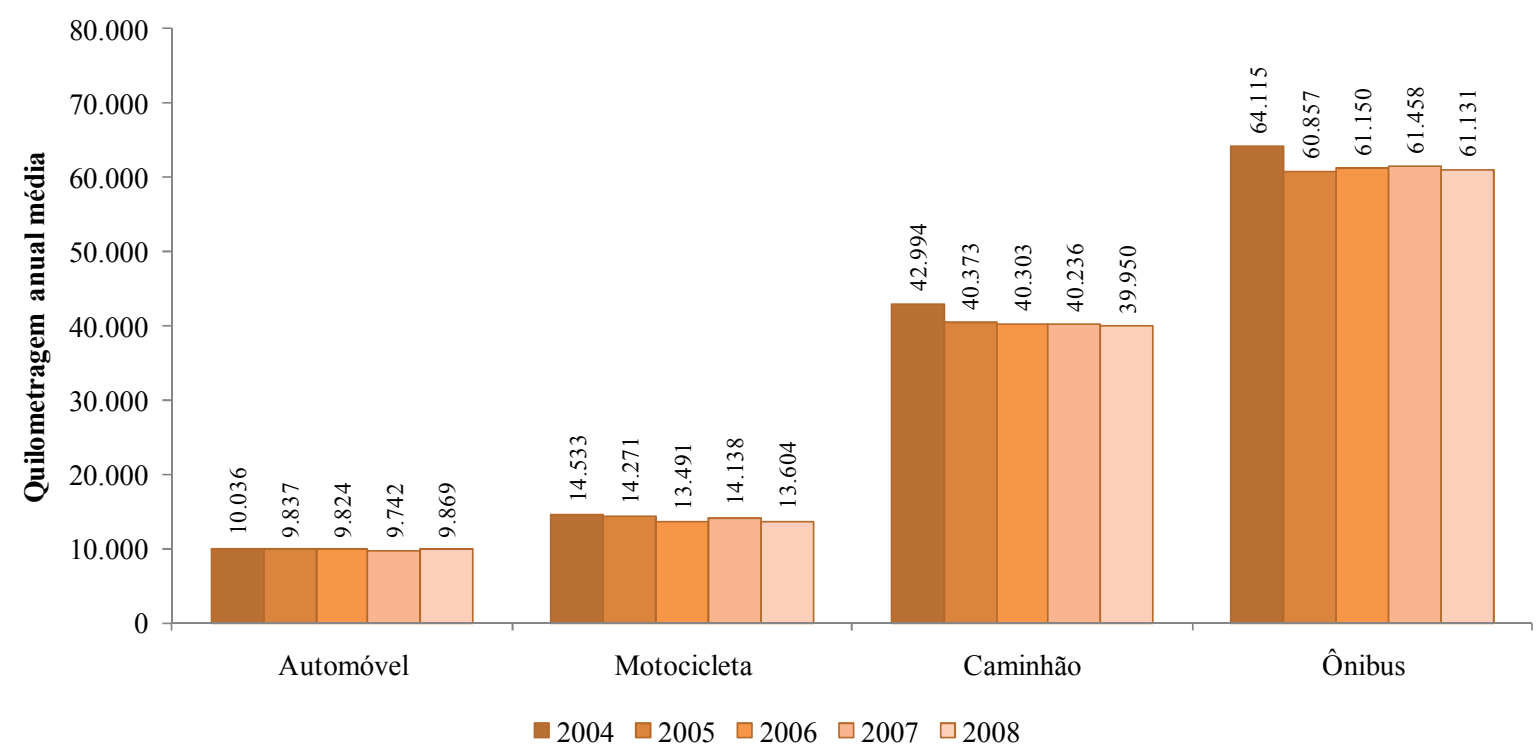

Figura 5.2 - Variação da quilometragem média anual no Brasil no período 2004 - 2008

No gráfico da Figura 5.3 está presente a relação entre a quilometragem anual média global e o índice de motorização para o ano de 2008. 


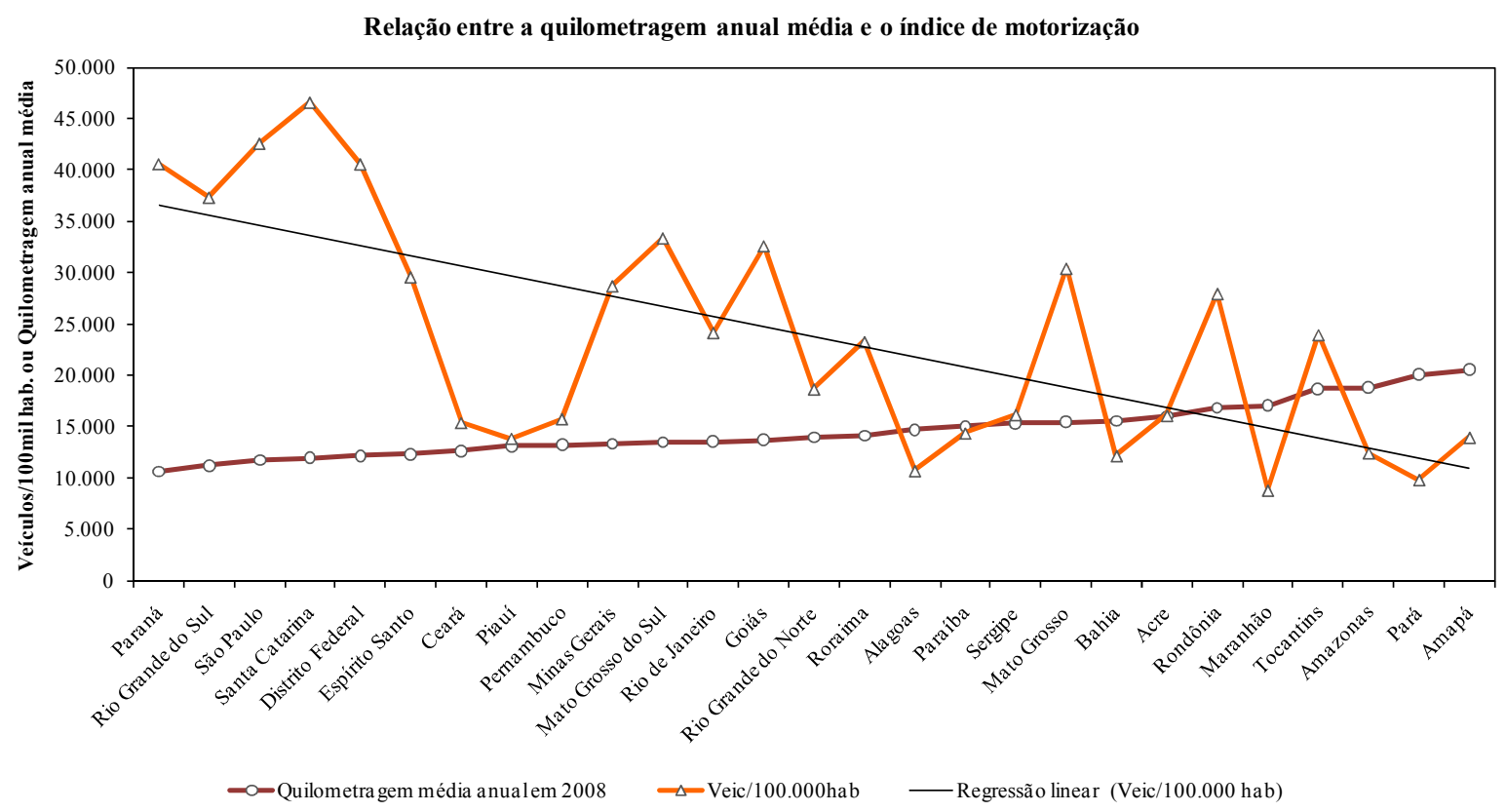

Figura 5.3 - Quilometragem média anual x Índice de motorização

Como se pode constatar, há tendência de aumento da quilometragem anual média com a diminuição do índice de motorização nos estados, muito provavelmente pelo fato de que nos estados mais ricos (com maior índice de motorização) mais pessoas compram veículos motorizados para o uso em viagens urbanas de curta distância.

Na Figura 5.4 é mostrada a relação entre a quilometragem total no país e o PIB per capita nos anos de 2004 a 2007, de modo que o crescimento do PIB parece ser acompanhado por um aumento da quilometragem total.

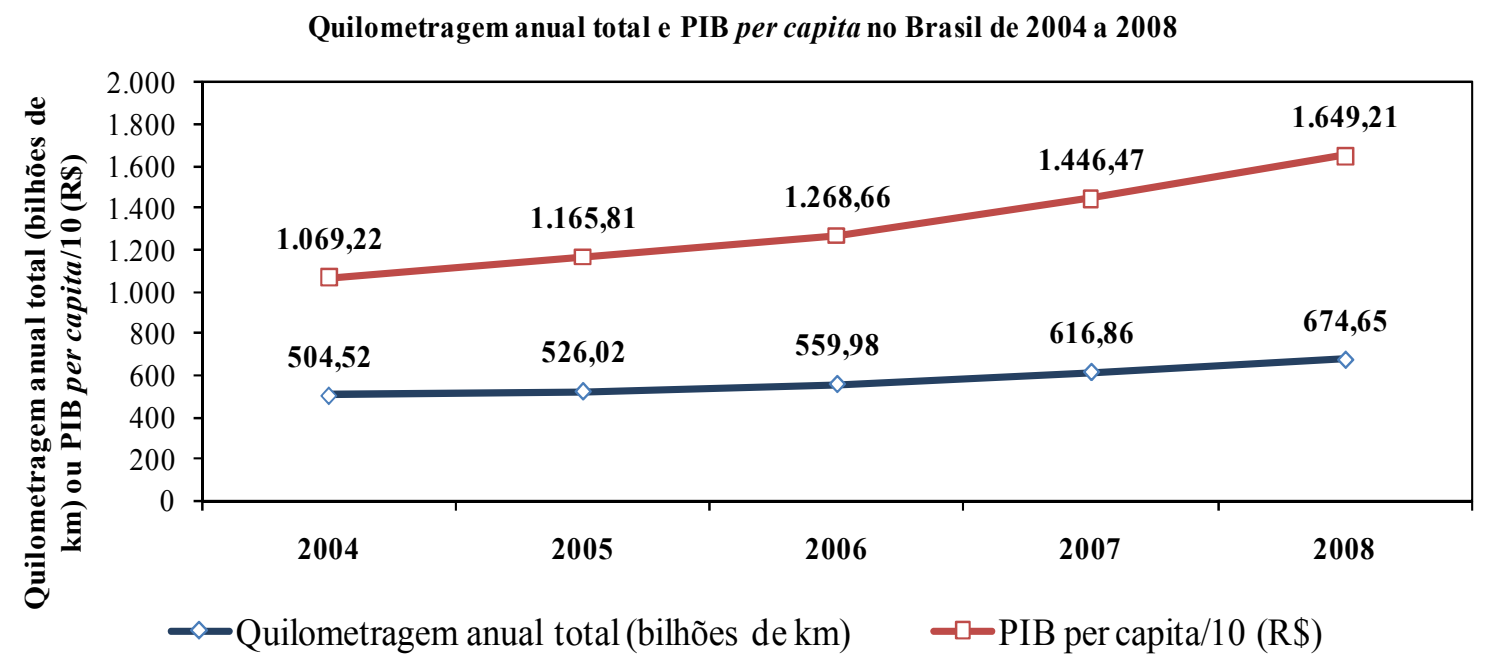

Figura 5.4 - Quilometragem total x PIB per capita no país 


\section{$5.2 \quad$ Índices associados à mortalidade no trânsito}

Nas Tabelas 5.2 a 5.6 são compilados, respectivamente para os anos de 2004, 2005, 2006, 2007 e 2008, os valores dos seguintes parâmetros: número de mortes, índice de mortes por habitante, índice de mortes por veículo, índice de mortes por quilômetro percorrido e índice de motorização. Também está indicada nas tabelas a posição relativa de cada estado na classificação geral, seguindo a seguinte lógica: melhor situação - $1^{\text {a }}$ posição e pior situação $27^{\mathrm{a}}$ posição, sendo que os estados estão ordenados de acordo com o índice de mortes $/ \mathrm{km}$.

Tabela 5. 2 - Índices associados à mortalidade no trânsito para o ano de 2004

\begin{tabular}{|c|c|c|c|c|c|}
\hline Estados & Mortes & Mortes/100mil hab & Mortes/100mil veíc & Mortes $/ \mathbf{1 0}^{\mathbf{9}} \mathrm{km}$ & Veíc/hab \\
\hline \multirow{2}{*}{ São Paulo } & 6.875 & 17,52 & 52,61 & 45,98 & 0,33 \\
\hline & $\left(27^{\circ}\right)$ & $\left(8^{\circ}\right)$ & $\left(1^{\circ}\right)$ & $\left(1^{\circ}\right)$ & $\left(3^{\circ}\right)$ \\
\hline \multirow{2}{*}{ Rio Grande do Sul } & 2.041 & 19,23 & 64,56 & 52,27 & 0,30 \\
\hline & $\left(23^{\circ}\right)$ & $\left(14^{\circ}\right)$ & $\left(2^{\circ}\right)$ & $\left(2^{\circ}\right)$ & $\left(5^{\circ}\right)$ \\
\hline \multirow{2}{*}{ Distrito Federal } & 580 & 25,97 & 75,89 & 56,38 & 0,34 \\
\hline & $\left(11^{\mathrm{o}}\right)$ & $\left(20^{\circ}\right)$ & $\left(3^{\circ}\right)$ & $\left(3^{\circ}\right)$ & $\left(2^{\circ}\right)$ \\
\hline \multirow{2}{*}{ Minas Gerais } & 3.288 & 17,52 & 81,56 & 61,54 & 0,21 \\
\hline & $\left(26^{\circ}\right)$ & $\left(9^{\circ}\right)$ & $\left(4^{\circ}\right)$ & $\left(4^{\circ}\right)$ & $\left(9^{\circ}\right)$ \\
\hline \multirow{2}{*}{ Amazonas } & 352 & 11,35 & 132,53 & 63,17 & 0,09 \\
\hline & $\left(5^{\circ}\right)$ & $\left(2^{\circ}\right)$ & $\left(16^{\circ}\right)$ & $\left(5^{\circ}\right)$ & $\left(23^{\circ}\right)$ \\
\hline \multirow{2}{*}{ Santa Catarina } & 1.779 & 31,28 & 89,29 & 63,67 & 0,35 \\
\hline & $\left(22^{\circ}\right)$ & $\left(24^{\circ}\right)$ & $\left(5^{\circ}\right)$ & $\left(6^{\circ}\right)$ & $\left(1^{\circ}\right)$ \\
\hline \multirow{2}{*}{ Bahia } & 1.300 & 9,59 & 112,74 & 65,59 & 0,09 \\
\hline & $\left(18^{\circ}\right)$ & $\left(1^{\circ}\right)$ & $\left(8^{\circ}\right)$ & $\left(7^{\circ}\right)$ & $\left(24^{\circ}\right)$ \\
\hline \multirow{2}{*}{ Rio de Janeiro } & 2.833 & 18,84 & 94,35 & 70,46 & 0,20 \\
\hline & $\left(24^{\circ}\right)$ & $\left(11^{\circ}\right)$ & $\left(6^{\circ}\right)$ & $\left(8^{\circ}\right)$ & $\left(11^{\circ}\right)$ \\
\hline \multirow{2}{*}{ Rondônia } & 340 & 22,97 & 131,03 & 71,96 & 0,18 \\
\hline & $\left(4^{\circ}\right)$ & $\left(18^{\circ}\right)$ & $\left(15^{\circ}\right)$ & $\left(9^{\circ}\right)$ & $\left(12^{\circ}\right)$ \\
\hline \multirow{2}{*}{ Roraima } & 70 & 19,04 & 119,54 & 73,10 & 0,16 \\
\hline & $\left(1^{\circ}\right)$ & $\left(13^{\circ}\right)$ & $\left(10^{\circ}\right)$ & $\left(10^{\circ}\right)$ & $\left(13^{\circ}\right)$ \\
\hline \multirow{2}{*}{ Rio Grande do Norte } & 427 & 14,61 & 116,26 & 73,63 & 0,13 \\
\hline & $\left(6^{\circ}\right)$ & $\left(6^{\circ}\right)$ & $\left(9^{\circ}\right)$ & $\left(11^{\circ}\right)$ & $\left(15^{\circ}\right)$ \\
\hline \multirow{2}{*}{ Acre } & 83 & 13,51 & 128,37 & 74,66 & 0,11 \\
\hline & $\left(2^{\circ}\right)$ & $\left(5^{\circ}\right)$ & $\left(14^{\circ}\right)$ & $\left(12^{\circ}\right)$ & $\left(19^{\circ}\right)$ \\
\hline \multirow{2}{*}{ Goiás } & 1.559 & 28,86 & 121,70 & 76,00 & 0,24 \\
\hline & $\left(20^{\circ}\right)$ & $\left(22^{\circ}\right)$ & $\left(11^{\circ}\right)$ & $\left(13^{\circ}\right)$ & $\left(7^{\circ}\right)$ \\
\hline \multirow{2}{*}{ Mato Grosso do Sul } & 688 & 31,29 & 125,68 & 81,87 & 0,25 \\
\hline & $\left(13^{\circ}\right)$ & $\left(25^{\circ}\right)$ & $\left(12^{\circ}\right)$ & $\left(14^{\circ}\right)$ & $\left(6^{\circ}\right)$ \\
\hline
\end{tabular}


Conclusão

\begin{tabular}{|c|c|c|c|c|c|}
\hline Estados & Mortes & Mortes/100mil hab & Mortes/100mil veíc & Mortes $/ 10^{9} \mathrm{~km}$ & Veíc/hab \\
\hline \multirow{2}{*}{ Mato Grosso } & 904 & 33,51 & 155,41 & 85,18 & 0,22 \\
\hline & $\left(17^{\circ}\right)$ & $\left(26^{\circ}\right)$ & $\left(18^{\circ}\right)$ & $\left(15^{\circ}\right)$ & $\left(8^{\circ}\right)$ \\
\hline \multirow{2}{*}{ Paraná } & 3.059 & 30,54 & 98,09 & 85,77 & 0,31 \\
\hline & $\left(25^{\circ}\right)$ & $\left(23^{\circ}\right)$ & $\left(7^{\circ}\right)$ & $\left(16^{\circ}\right)$ & $\left(4^{\circ}\right)$ \\
\hline \multirow{2}{*}{ Espírito Santo } & 859 & 26,04 & 127,74 & 93,77 & 0,20 \\
\hline & $\left(16^{\circ}\right)$ & $\left(21^{\mathrm{o}}\right)$ & $\left(13^{\circ}\right)$ & $\left(17^{\circ}\right)$ & $\left(10^{\circ}\right)$ \\
\hline \multirow{2}{*}{ Amapá } & 117 & 21,15 & 241,55 & 95,71 & 0,09 \\
\hline & $\left(3^{\circ}\right)$ & $\left(17^{\circ}\right)$ & $\left(25^{\circ}\right)$ & $\left(18^{\circ}\right)$ & $\left(22^{\circ}\right)$ \\
\hline \multirow{2}{*}{ Pará } & 850 & 12,69 & 196,13 & 97,48 & 0,06 \\
\hline & $\left(15^{\circ}\right)$ & $\left(4^{\circ}\right)$ & $\left(21^{\circ}\right)$ & $\left(19^{\circ}\right)$ & $\left(26^{\circ}\right)$ \\
\hline \multirow{2}{*}{ Pernambuco } & 1.388 & 16,85 & 143,44 & 103,47 & 0,12 \\
\hline & $\left(19^{\circ}\right)$ & $\left(7^{\circ}\right)$ & $\left(17^{\circ}\right)$ & $\left(20^{\circ}\right)$ & $\left(17^{\circ}\right)$ \\
\hline \multirow{2}{*}{ Paraíba } & 629 & 17,76 & 181,50 & 104,79 & 0,10 \\
\hline & $\left(12^{\circ}\right)$ & $\left(10^{\circ}\right)$ & $\left(19^{\circ}\right)$ & $\left(21^{\circ}\right)$ & $\left(20^{\circ}\right)$ \\
\hline \multirow{2}{*}{ Tocantins } & 455 & 36,31 & 264,29 & 112,45 & 0,14 \\
\hline & $\left(8^{\circ}\right)$ & $\left(27^{\circ}\right)$ & $\left(27^{\circ}\right)$ & $\left(22^{o}\right)$ & $\left(14^{\mathrm{o}}\right)$ \\
\hline \multirow{2}{*}{ Sergipe } & 447 & 23,49 & 198,68 & 121,21 & 0,12 \\
\hline & $\left(7^{\circ}\right)$ & $\left(19^{\circ}\right)$ & $\left(22^{\circ}\right)$ & $\left(23^{\circ}\right)$ & $\left(16^{\circ}\right)$ \\
\hline \multirow{2}{*}{ Maranhão } & 738 & 12,42 & 234,93 & 127,75 & 0,05 \\
\hline & $\left(14^{\mathrm{o}}\right)$ & $\left(3^{\circ}\right)$ & $\left(24^{\mathrm{o}}\right)$ & $\left(24^{\mathrm{o}}\right)$ & $\left(27^{\circ}\right)$ \\
\hline \multirow{2}{*}{ Ceará } & 1.640 & 20,86 & 186,28 & 146,71 & 0,11 \\
\hline & $\left(21^{\mathrm{o}}\right)$ & $\left(16^{\circ}\right)$ & $\left(20^{\circ}\right)$ & $\left(25^{\circ}\right)$ & $\left(18^{\circ}\right)$ \\
\hline \multirow{2}{*}{ Alagoas } & 561 & 19,03 & 243,79 & 147,17 & 0,08 \\
\hline & $\left(9^{\circ}\right)$ & $\left(12^{\circ}\right)$ & $\left(26^{\circ}\right)$ & $\left(26^{\circ}\right)$ & $\left(25^{\circ}\right)$ \\
\hline \multirow{2}{*}{ Piauí } & 576 & 19,53 & 219,28 & 154,11 & 0,09 \\
\hline & $\left(10^{\circ}\right)$ & $\left(15^{\circ}\right)$ & $\left(23^{\circ}\right)$ & $\left(27^{\circ}\right)$ & $\left(21^{\mathrm{o}}\right)$ \\
\hline \multirow{2}{*}{ Brasil } & \multirow{2}{*}{34.438} & 19,23 & 89,99 & 68,26 & 0,21 \\
\hline & & $\left(14^{o}\right)^{*}$ & $\left(5^{o}-6^{o}\right)^{*}$ & $\left(7^{o}-8^{o}\right)^{*}$ & $\left(9^{o}\right)^{*}$ \\
\hline
\end{tabular}

*Posição hipotética do Brasil na classificação estadual 
Tabela 5. 3 - Índices associados à mortalidade no trânsito para o ano de 2005

\begin{tabular}{|c|c|c|c|c|c|}
\hline Estados & Mortes & Mortes/100mil hab & Mortes/100mil veíc & Mortes $/ 10^{9} \mathrm{~km}$ & Veíc/hab \\
\hline \multirow{2}{*}{ São Paulo } & 6.993 & 17,29 & 50,45 & 45,55 & 0,34 \\
\hline & $\left(27^{\circ}\right)$ & $\left(8^{\circ}\right)$ & $\left(1^{\circ}\right)$ & $\left(1^{\circ}\right)$ & $\left(3^{\circ}\right)$ \\
\hline \multirow{2}{*}{ Rio Grande do Sul } & 1.970 & 18,17 & 58,92 & 52,83 & 0,31 \\
\hline & $\left(23^{\circ}\right)$ & $\left(12^{\circ}\right)$ & $\left(2^{\circ}\right)$ & $\left(2^{\circ}\right)$ & $\left(5^{\circ}\right)$ \\
\hline \multirow{2}{*}{ Minas Gerais } & 3.381 & 17,58 & 78,25 & 56,38 & 0,22 \\
\hline & $\left(26^{\circ}\right)$ & $\left(9^{\circ}\right)$ & $\left(4^{\circ}\right)$ & $\left(3^{\circ}\right)$ & $\left(9^{\circ}\right)$ \\
\hline \multirow{2}{*}{ Distrito Federal } & 600 & 25,72 & 74,02 & 56,93 & 0,35 \\
\hline & $\left(10^{\circ}\right)$ & $\left(20^{\circ}\right)$ & $\left(3^{\circ}\right)$ & $\left(4^{\circ}\right)$ & $\left(2^{\circ}\right)$ \\
\hline \multirow{2}{*}{ Amazonas } & 381 & 11,79 & 127,12 & 62,88 & 0,09 \\
\hline & $\left(6^{\circ}\right)$ & $\left(1^{\circ}\right)$ & $\left(13^{\circ}\right)$ & $\left(5^{\circ}\right)$ & $\left(23^{\circ}\right)$ \\
\hline \multirow{2}{*}{ Santa Catarina } & 1.845 & 31,45 & 84,84 & 64,30 & 0,37 \\
\hline & $\left(22^{\circ}\right)$ & $\left(26^{\circ}\right)$ & $\left(5^{\circ}\right)$ & $\left(6^{\circ}\right)$ & $\left(1^{\circ}\right)$ \\
\hline \multirow{2}{*}{ Rio de Janeiro } & 2.854 & 18,55 & 90,54 & 67,78 & 0,20 \\
\hline & $\left(24^{\circ}\right)$ & $\left(13^{\circ}\right)$ & $\left(7^{\circ}\right)$ & $\left(7^{\circ}\right)$ & $\left(11^{\circ}\right)$ \\
\hline \multirow{2}{*}{ Rondônia } & 335 & 21,83 & 115,93 & 67,89 & 0,19 \\
\hline & $\left(4^{\circ}\right)$ & $\left(18^{\circ}\right)$ & $\left(10^{\circ}\right)$ & $\left(8^{\circ}\right)$ & $\left(12^{\circ}\right)$ \\
\hline \multirow{2}{*}{ Rio Grande do Norte } & 450 & 14,98 & 111,44 & 68,88 & 0,13 \\
\hline & $\left(8^{\circ}\right)$ & $\left(6^{\circ}\right)$ & $\left(9^{\circ}\right)$ & $\left(9^{\circ}\right)$ & $\left(15^{\circ}\right)$ \\
\hline \multirow{2}{*}{ Mato Grosso } & 859 & 30,64 & 133,26 & 72,49 & 0,23 \\
\hline & $\left(14^{\circ}\right)$ & $\left(25^{\circ}\right)$ & $\left(15^{\circ}\right)$ & $\left(10^{\circ}\right)$ & $\left(8^{\circ}\right)$ \\
\hline \multirow{2}{*}{ Paraná } & 2.944 & 28,69 & 87,46 & 73,71 & 0,33 \\
\hline & $\left(25^{\circ}\right)$ & $\left(24^{\circ}\right)$ & $\left(6^{\circ}\right)$ & $\left(11^{\circ}\right)$ & $\left(4^{\circ}\right)$ \\
\hline \multirow{2}{*}{ Goiás } & 1.492 & 26,55 & 107,44 & 77,12 & 0,25 \\
\hline & $\left(19^{\circ}\right)$ & $\left(21^{\circ}\right)$ & $\left(8^{\circ}\right)$ & $\left(12^{\circ}\right)$ & $\left(7^{\circ}\right)$ \\
\hline \multirow{2}{*}{ Acre } & 95 & 14,18 & 131,79 & 81,06 & 0,11 \\
\hline & $\left(1^{\circ}\right)$ & $\left(4^{\circ}\right)$ & $\left(14^{\circ}\right)$ & $\left(13^{\circ}\right)$ & $\left(19^{\circ}\right)$ \\
\hline \multirow{2}{*}{ Amapá } & 108 & 18,16 & 192,81 & 81,48 & 0,09 \\
\hline & $\left(3^{\circ}\right)$ & $\left(11^{\circ}\right)$ & $\left(23^{\circ}\right)$ & $\left(14^{\circ}\right)$ & $\left(22^{\circ}\right)$ \\
\hline \multirow{2}{*}{ Bahia } & 1.771 & 12,82 & 139,59 & 86,27 & 0,09 \\
\hline & $\left(21^{\circ}\right)$ & $\left(2^{\circ}\right)$ & $\left(17^{\circ}\right)$ & $\left(15^{\circ}\right)$ & $\left(24^{\circ}\right)$ \\
\hline \multirow{2}{*}{ Espírito Santo } & 864 & 25,35 & 118,13 & 90,13 & 0,21 \\
\hline & $\left(15^{\circ}\right)$ & $\left(19^{\circ}\right)$ & $\left(11^{\circ}\right)$ & $\left(16^{\circ}\right)$ & $\left(10^{\circ}\right)$ \\
\hline \multirow{2}{*}{ Mato Grosso do Sul } & 727 & 32,10 & 122,33 & 91,60 & 0,26 \\
\hline & $\left(13^{\circ}\right)$ & $\left(27^{\circ}\right)$ & $\left(12^{\circ}\right)$ & $\left(17^{\circ}\right)$ & $\left(6^{\circ}\right)$ \\
\hline \multirow{2}{*}{ Tocantins } & 362 & 27,72 & 179,57 & 95,32 & 0,15 \\
\hline & $\left(5^{\circ}\right)$ & $\left(23^{\circ}\right)$ & $\left(22^{\circ}\right)$ & $\left(18^{\circ}\right)$ & $\left(14^{\circ}\right)$ \\
\hline \multirow{2}{*}{ Pará } & 958 & 13,74 & 196,40 & 99,35 & 0,07 \\
\hline & $\left(17^{\circ}\right)$ & $\left(3^{\circ}\right)$ & $\left(24^{\circ}\right)$ & $\left(19^{\circ}\right)$ & $\left(26^{\circ}\right)$ \\
\hline \multirow{2}{*}{ Pernambuco } & 1.407 & 16,72 & 135,79 & 100,11 & 0,12 \\
\hline & $\left(18^{\circ}\right)$ & $\left(7^{\circ}\right)$ & $\left(16^{\circ}\right)$ & $\left(20^{\circ}\right)$ & $\left(16^{\circ}\right)$ \\
\hline \multirow{2}{*}{ Sergipe } & 382 & 19,41 & 157,76 & 100,13 & 0,12 \\
\hline & $\left(7^{\circ}\right)$ & $\left(14^{\circ}\right)$ & $\left(18^{\circ}\right)$ & $\left(21^{\circ}\right)$ & $\left(17^{\circ}\right)$ \\
\hline
\end{tabular}


Conclusão

\begin{tabular}{cccccc}
\hline Estados & Mortes & Mortes/100mil hab & Mortes/100mil veíc & Mortes/10 $\mathbf{~ k m ~}$ & Veíc/hab \\
\hline \multirow{2}{*}{ Paraíba } & 638 & 17,74 & 169,65 & 104,64 & 0,10 \\
& $\left(12^{\circ}\right)$ & $\left(10^{\circ}\right)$ & $\left(20^{\circ}\right)$ & $\left(22^{\circ}\right)$ & $\left(20^{\circ}\right)$ \\
Roraima & 104 & 26,58 & 163,10 & 106,31 & 0,16 \\
& $\left(2^{\circ}\right)$ & $\left(22^{\circ}\right)$ & $\left(19^{\circ}\right)$ & $\left(23^{\circ}\right)$ & $\left(13^{\circ}\right)$ \\
Maranhão & 879 & 14,40 & 245,44 & 143,30 & 0,06 \\
& $\left(16^{\circ}\right)$ & $\left(5^{\circ}\right)$ & $\left(27^{\circ}\right)$ & $\left(24^{\circ}\right)$ & $\left(27^{\circ}\right)$ \\
Ceará & 1.698 & 20,97 & 178,69 & 144,99 & 0,12 \\
& $\left(20^{\circ}\right)$ & $\left(16^{\circ}\right)$ & $\left(21^{\circ}\right)$ & $\left(25^{\circ}\right)$ & $\left(18^{\circ}\right)$ \\
Alagoas & 592 & 19,63 & 237,17 & 146,88 & 0,08 \\
& $\left(9^{\circ}\right)$ & $\left(15^{\circ}\right)$ & $\left(26^{\circ}\right)$ & $\left(26^{\circ}\right)$ & $\left(25^{\circ}\right)$ \\
Piauí & 636 & 21,15 & 217,29 & 162,45 & 0,10 \\
& $\left(11^{\circ}\right)$ & $\left(17^{\circ}\right)$ & $\left(25^{\circ}\right)$ & $\left(27^{\circ}\right)$ & $\left(21^{\circ}\right)$ \\
\hline \multirow{2}{*}{ Brasil } & 35.325 & 19,18 & 86,08 & 67,16 & 0,22 \\
& & $\left(13^{\circ}-14^{\circ}\right)^{*}$ & $\left(5^{\circ}-6^{\circ}\right)^{*}$ & $\left(6^{\circ}-7^{\circ}\right)^{*}$ & $\left(9^{\circ}\right)^{*}$ \\
\hline
\end{tabular}

*Posição hipotética do Brasil na classificação estadual

Tabela 5. 4 - Índices associados à mortalidade no trânsito para o ano de 2006

\begin{tabular}{|c|c|c|c|c|c|}
\hline Estados & Mortes & Mortes/100mil hab & Mortes/100mil veíc & Mortes $/ \mathbf{1 0}^{\mathbf{9}} \mathrm{km}$ & $\begin{array}{l}\text { Veíc/ } \\
\text { hab }\end{array}$ \\
\hline \multirow{2}{*}{ São Paulo } & 6.960 & 16,95 & 46,85 & 41,24 & 0,36 \\
\hline & $\left(27^{\circ}\right)$ & $\left(8^{\circ}\right)$ & $\left(1^{\circ}\right)$ & $\left(1^{\circ}\right)$ & $\left(3^{\circ}\right)$ \\
\hline \multirow{2}{*}{ Rio Grande do Sul } & 1.885 & 17,19 & 53,34 & 49,94 & 0,32 \\
\hline & $\left(22^{\circ}\right)$ & $\left(9^{\circ}\right)$ & $\left(2^{\circ}\right)$ & $\left(2^{\circ}\right)$ & $\left(5^{\circ}\right)$ \\
\hline \multirow{2}{*}{ Distrito Federal } & 567 & 23,79 & 64,86 & 52,13 & 0,37 \\
\hline & $\left(9^{\circ}\right)$ & $\left(17^{\circ}\right)$ & $\left(3^{\circ}\right)$ & $\left(3^{\circ}\right)$ & $\left(2^{\circ}\right)$ \\
\hline \multirow{2}{*}{ Minas Gerais } & 3.638 & 18,68 & 77,73 & 58,48 & 0,24 \\
\hline & $\left(26^{\circ}\right)$ & $\left(11^{\circ}\right)$ & $\left(4^{\mathrm{o}}\right)$ & $\left(4^{\circ}\right)$ & $\left(9^{\circ}\right)$ \\
\hline \multirow{2}{*}{ Acre } & 79 & 11,51 & 96,92 & 61,30 & 0,12 \\
\hline & $\left(1^{\circ}\right)$ & $\left(1^{\circ}\right)$ & $\left(9^{\circ}\right)$ & $\left(5^{\circ}\right)$ & $\left(19^{\circ}\right)$ \\
\hline \multirow{2}{*}{ Amazonas } & 420 & 12,68 & 126,05 & 62,31 & 0,10 \\
\hline & $\left(7^{\circ}\right)$ & $\left(3^{\circ}\right)$ & $\left(15^{\circ}\right)$ & $\left(6^{\circ}\right)$ & $\left(23^{\circ}\right)$ \\
\hline \multirow{2}{*}{ Santa Catarina } & 1.928 & 32,36 & 81,48 & 62,38 & 0,40 \\
\hline & $\left(23^{\circ}\right)$ & $\left(27^{\circ}\right)$ & $\left(6^{\circ}\right)$ & $\left(7^{\circ}\right)$ & $\left(1^{\circ}\right)$ \\
\hline \multirow{2}{*}{ Goiás } & 1.377 & 24,03 & 91,01 & 66,75 & 0,26 \\
\hline & $\left(18^{\circ}\right)$ & $\left(18^{\circ}\right)$ & $\left(8^{\circ}\right)$ & $\left(8^{\circ}\right)$ & $\left(7^{\circ}\right)$ \\
\hline \multirow{2}{*}{ Rondônia } & 408 & 26,11 & 127,33 & 68,05 & 0,21 \\
\hline & $\left(6^{\circ}\right)$ & $\left(20^{\circ}\right)$ & $\left(16^{\circ}\right)$ & $\left(9^{\circ}\right)$ & $\left(12^{\circ}\right)$ \\
\hline \multirow{2}{*}{ Rio de Janeiro } & 3.011 & 19,35 & 90,57 & 68,46 & 0,21 \\
\hline & $\left(25^{\circ}\right)$ & $\left(15^{\circ}\right)$ & $\left(7^{\circ}\right)$ & $\left(10^{\circ}\right)$ & $\left(11^{\circ}\right)$ \\
\hline \multirow{2}{*}{ Rio Grande do Norte } & 482 & 15,84 & 107,03 & 70,19 & 0,15 \\
\hline & $\left(8^{\circ}\right)$ & $\left(6^{\circ}\right)$ & $\left(11^{\circ}\right)$ & $\left(11^{\circ}\right)$ & $\left(15^{\circ}\right)$ \\
\hline
\end{tabular}


Conclusão

\begin{tabular}{|c|c|c|c|c|c|}
\hline Estados & Mortes & Mortes/100mil hab & Mortes/100mil veíc & Mortes $/ 10^{9} \mathbf{k m}$ & Veíc/hab \\
\hline \multirow{2}{*}{ Bahia } & 1.732 & 12,42 & 123,79 & 71,95 & 0,10 \\
\hline & $\left(21^{\circ}\right)$ & $\left(2^{\circ}\right)$ & $\left(14^{\circ}\right)$ & $\left(12^{\circ}\right)$ & $\left(24^{\circ}\right)$ \\
\hline \multirow{2}{*}{ Paraná } & 2.900 & 27,92 & 80,31 & 74,83 & 0,35 \\
\hline & $\left(24^{\circ}\right)$ & $\left(24^{\circ}\right)$ & $\left(5^{\circ}\right)$ & $\left(13^{\circ}\right)$ & $\left(4^{\circ}\right)$ \\
\hline \multirow{2}{*}{ Mato Grosso } & 844 & 29,54 & 120,72 & 75,66 & 0,24 \\
\hline & $\left(15^{\circ}\right)$ & $\left(26^{\circ}\right)$ & $\left(13^{\circ}\right)$ & $\left(14^{\circ}\right)$ & $\left(8^{\circ}\right)$ \\
\hline \multirow{2}{*}{ Mato Grosso do Sul } & 672 & 29,24 & 104,68 & 79,46 & 0,28 \\
\hline & $\left(11^{\circ}\right)$ & $\left(25^{\circ}\right)$ & $\left(10^{\circ}\right)$ & $\left(15^{\circ}\right)$ & $\left(6^{\circ}\right)$ \\
\hline \multirow{2}{*}{ Amapá } & 117 & 19,00 & 180,10 & 83,36 & 0,11 \\
\hline & $\left(3^{\circ}\right)$ & $\left(13^{\circ}\right)$ & $\left(23^{\circ}\right)$ & $\left(16^{\circ}\right)$ & $\left(22^{\circ}\right)$ \\
\hline \multirow{2}{*}{ Espírito Santo } & 928 & 26,79 & 115,27 & 89,05 & 0,23 \\
\hline & $\left(16^{\circ}\right)$ & $\left(22^{\circ}\right)$ & $\left(12^{\circ}\right)$ & $\left(17^{\circ}\right)$ & $\left(10^{\circ}\right)$ \\
\hline \multirow{2}{*}{ Tocantins } & 350 & 26,27 & 143,09 & 90,35 & 0,18 \\
\hline & $\left(4^{\circ}\right)$ & $\left(21^{\circ}\right)$ & $\left(19^{\circ}\right)$ & $\left(18^{\circ}\right)$ & $\left(13^{\circ}\right)$ \\
\hline \multirow{2}{*}{ Sergipe } & 372 & 18,59 & 141,60 & 91,80 & 0,13 \\
\hline & $\left(5^{\circ}\right)$ & $\left(10^{\circ}\right)$ & $\left(18^{\circ}\right)$ & $\left(19^{\circ}\right)$ & $\left(17^{\circ}\right)$ \\
\hline \multirow{2}{*}{ Pernambuco } & 1.433 & 16,85 & 127,56 & 96,45 & 0,13 \\
\hline & $\left(19^{\circ}\right)$ & $\left(7^{\circ}\right)$ & $\left(17^{\circ}\right)$ & $\left(20^{\circ}\right)$ & $\left(16^{\circ}\right)$ \\
\hline \multirow{2}{*}{ Pará } & 1.001 & 14,08 & 184,25 & 96,92 & 0,08 \\
\hline & $\left(17^{\circ}\right)$ & $\left(5^{\circ}\right)$ & $\left(24^{\circ}\right)$ & $\left(21^{\circ}\right)$ & $\left(26^{\circ}\right)$ \\
\hline \multirow{2}{*}{ Roraima } & 110 & 27,27 & 154,34 & 102,64 & 0,18 \\
\hline & $\left(2^{\circ}\right)$ & $\left(23^{\circ}\right)$ & $\left(20^{\circ}\right)$ & $\left(22^{\circ}\right)$ & $\left(14^{\circ}\right)$ \\
\hline \multirow{2}{*}{ Paraíba } & 693 & 19,13 & 166,52 & 107,25 & 0,11 \\
\hline & $\left(12^{\circ}\right)$ & $\left(14^{\circ}\right)$ & $\left(22^{\circ}\right)$ & $\left(23^{\circ}\right)$ & $\left(20^{\circ}\right)$ \\
\hline \multirow{2}{*}{ Maranhão } & 814 & 13,16 & 199,65 & 123,96 & 0,07 \\
\hline & $\left(14^{\circ}\right)$ & $\left(4^{\circ}\right)$ & $\left(25^{\circ}\right)$ & $\left(24^{\circ}\right)$ & $\left(27^{\circ}\right)$ \\
\hline \multirow{2}{*}{ Ceará } & 1.651 & 20,09 & 158,38 & 127,80 & 0,13 \\
\hline & $\left(20^{\circ}\right)$ & $\left(16^{\circ}\right)$ & $\left(21^{\circ}\right)$ & $\left(25^{\circ}\right)$ & $\left(18^{\circ}\right)$ \\
\hline \multirow{2}{*}{ Alagoas } & 574 & 18,82 & 210,66 & 136,01 & 0,09 \\
\hline & $\left(10^{\circ}\right)$ & $\left(12^{\circ}\right)$ & $\left(26^{\circ}\right)$ & $\left(26^{\circ}\right)$ & $\left(25^{\circ}\right)$ \\
\hline \multirow{2}{*}{ Piauí } & 771 & 25,39 & 233,04 & 158,40 & 0,11 \\
\hline & $\left(13^{\circ}\right)$ & $\left(19^{\circ}\right)$ & $\left(27^{\circ}\right)$ & $\left(27^{\circ}\right)$ & $\left(21^{\circ}\right)$ \\
\hline \multirow[t]{2}{*}{ Brasil } & 35.717 & 19,12 & 80,68 & 63,78 & 0,24 \\
\hline & 35.117 & $\left(13^{\circ}-14^{o}\right)^{*}$ & $\left(5^{\circ}-6^{\circ}\right)^{*}$ & $\left(7^{\circ}-8^{\circ}\right)^{*}$ & $\left(10^{\circ}-11^{\circ}\right)^{*}$ \\
\hline
\end{tabular}

*Posição hipotética do Brasil na classificação estadual 
Tabela 5.5 - Índices associados à mortalidade no trânsito para o ano de 2007

\begin{tabular}{|c|c|c|c|c|c|}
\hline Estados & Mortes & Mortes/100mil hab & Mortes/100mil veic & Mortes $/ \mathbf{1 0}^{\mathbf{9}} \mathrm{km}$ & Veíc/hab \\
\hline \multirow{2}{*}{ São Paulo } & 7.249 & 17,40 & 44,99 & 38,28 & 0,39 \\
\hline & $\left(27^{\mathrm{o}}\right)$ & $\left(11^{\mathrm{o}}\right)$ & $\left(1^{\circ}\right)$ & $\left(1^{\mathrm{o}}\right)$ & $\left(3^{\circ}\right)$ \\
\hline \multirow{2}{*}{ Rio Grande do Sul } & 1.874 & 16,91 & 49,66 & 45,53 & 0,34 \\
\hline & $\left(21^{\mathrm{o}}\right)$ & $\left(10^{\circ}\right)$ & $\left(2^{\circ}\right)$ & $\left(2^{\circ}\right)$ & $\left(5^{\circ}\right)$ \\
\hline \multirow{2}{*}{ Amazonas } & 360 & 10,62 & 97,03 & 51,17 & 0,11 \\
\hline & $\left(5^{\circ}\right)$ & $\left(1^{\circ}\right)$ & $\left(11^{\circ}\right)$ & $\left(3^{\circ}\right)$ & $\left(24^{\circ}\right)$ \\
\hline \multirow{2}{*}{ Distrito Federal } & 620 & 25,47 & 64,86 & 53,47 & 0,39 \\
\hline & $\left(9^{\circ}\right)$ & $\left(20^{\circ}\right)$ & $\left(3^{\circ}\right)$ & $\left(4^{\circ}\right)$ & $\left(2^{\circ}\right)$ \\
\hline \multirow{2}{*}{ Minas Gerais } & 3.764 & 19,09 & 73,14 & 53,36 & 0,26 \\
\hline & $\left(26^{\circ}\right)$ & $\left(13^{\circ}\right)$ & $\left(5^{\circ}\right)$ & $\left(5^{\circ}\right)$ & $\left(9^{\circ}\right)$ \\
\hline \multirow{2}{*}{ Rio de Janeiro } & 2.652 & 16,85 & 74,40 & 54,52 & 0,23 \\
\hline & $\left(24^{\circ}\right)$ & $\left(9^{\circ}\right)$ & $\left(6^{\circ}\right)$ & $\left(6^{\circ}\right)$ & $\left(12^{\circ}\right)$ \\
\hline \multirow{2}{*}{ Rondônia } & 354 & 22,26 & 97,85 & 57,74 & 0,23 \\
\hline & $\left(4^{\circ}\right)$ & $\left(17^{\circ}\right)$ & $\left(12^{\circ}\right)$ & $\left(7^{\circ}\right)$ & $\left(11^{\circ}\right)$ \\
\hline \multirow{2}{*}{ Santa Catarina } & 1.890 & 31,24 & 72,87 & 60,55 & 0,43 \\
\hline & $\left(22^{\circ}\right)$ & $\left(25^{\circ}\right)$ & $\left(4^{\circ}\right)$ & $\left(8^{\circ}\right)$ & $\left(1^{\circ}\right)$ \\
\hline \multirow{2}{*}{$\begin{array}{l}\text { Rio Grande do } \\
\text { Norte }\end{array}$} & 470 & 15,24 & 91,42 & 61,16 & 0,17 \\
\hline & $\left(8^{\circ}\right)$ & $\left(5^{\circ}\right)$ & $\left(9^{\circ}\right)$ & $\left(9^{\circ}\right)$ & $\left(15^{\circ}\right)$ \\
\hline \multirow{2}{*}{ Goiás } & 1.411 & 24,16 & 83,30 & 61,42 & 0,29 \\
\hline & $\left(18^{\circ}\right)$ & $\left(18^{\circ}\right)$ & $\left(8^{\circ}\right)$ & $\left(10^{\circ}\right)$ & $\left(7^{\circ}\right)$ \\
\hline \multirow{2}{*}{ Amapá } & 99 & 15,55 & 132,79 & 62,97 & 0,12 \\
\hline & $\left(2^{o}\right)$ & $\left(6^{\circ}\right)$ & $\left(18^{\circ}\right)$ & $\left(11^{\circ}\right)$ & $\left(22^{\circ}\right)$ \\
\hline \multirow{2}{*}{ Acre } & 98 & 13,93 & 104,33 & 63,46 & 0,13 \\
\hline & $\left(1^{\circ}\right)$ & $\left(3^{\circ}\right)$ & $\left(13^{\circ}\right)$ & $\left(12^{\circ}\right)$ & $\left(19^{\circ}\right)$ \\
\hline \multirow{2}{*}{ Mato Grosso do Sul } & 678 & 29,08 & 96,02 & 72,56 & 0,30 \\
\hline & $\left(11^{\circ}\right)$ & $\left(21^{\circ}\right)$ & $\left(10^{\circ}\right)$ & $\left(13^{\circ}\right)$ & $\left(6^{\circ}\right)$ \\
\hline \multirow{2}{*}{ Paraná } & 3.127 & 29,75 & 79,37 & 74,59 & 0,37 \\
\hline & $\left(25^{\circ}\right)$ & $\left(23^{\circ}\right)$ & $\left(7^{\circ}\right)$ & $\left(14^{\circ}\right)$ & $\left(4^{\circ}\right)$ \\
\hline \multirow{2}{*}{ Bahia } & 1.927 & 13,68 & 123,27 & 75,14 & 0,11 \\
\hline & $\left(23^{\circ}\right)$ & $\left(2^{\circ}\right)$ & $\left(17^{\circ}\right)$ & $\left(15^{\circ}\right)$ & $\left(23^{\circ}\right)$ \\
\hline \multirow{2}{*}{ Mato Grosso } & 887 & 30,48 & 113,42 & 75,27 & 0,27 \\
\hline & $\left(14^{\circ}\right)$ & $\left(24^{\circ}\right)$ & $\left(14^{\circ}\right)$ & $\left(16^{\circ}\right)$ & $\left(8^{\circ}\right)$ \\
\hline \multirow{2}{*}{ Tocantins } & 427 & 31,42 & 155,39 & 86,39 & 0,20 \\
\hline & $\left(6^{\circ}\right)$ & $\left(26^{\circ}\right)$ & $\left(22^{\circ}\right)$ & $\left(17^{\circ}\right)$ & $\left(13^{\circ}\right)$ \\
\hline \multirow{2}{*}{ Espírito Santo } & 1.034 & 29,38 & 114,07 & 90,49 & 0,26 \\
\hline & $\left(16^{\circ}\right)$ & $\left(22^{\circ}\right)$ & $\left(15^{\circ}\right)$ & $\left(18^{\circ}\right)$ & $\left(10^{\circ}\right)$ \\
\hline \multirow{2}{*}{ Pernambuco } & 1.416 & 16,48 & 114,24 & 90,81 & 0,14 \\
\hline & $\left(19^{\circ}\right)$ & $\left(8^{\circ}\right)$ & $\left(16^{\circ}\right)$ & $\left(19^{\circ}\right)$ & $\left(16^{\circ}\right)$ \\
\hline \multirow{2}{*}{ Pará } & 1.058 & 14,59 & 170,05 & 91,45 & 0,09 \\
\hline & $\left(17^{\circ}\right)$ & $\left(4^{\circ}\right)$ & $\left(24^{\circ}\right)$ & $\left(20^{\circ}\right)$ & $\left(26^{\circ}\right)$ \\
\hline \multirow{3}{*}{ Paraíba } & 695 & 19,04 & 147,10 & 93,98 & 0,13 \\
\hline & $\left(12^{\circ}\right)$ & $\left(12^{\circ}\right)$ & $\left(20^{\circ}\right)$ & $\left(21^{\circ}\right)$ & $\left(20^{\circ}\right)$ \\
\hline & & & & & Continua \\
\hline
\end{tabular}


Conclusão

\begin{tabular}{cccccc}
\hline Estados & Mortes & Mortes/100mil hab & Mortes/100mil veíc & Mortes/109 $\mathbf{k m}$ & Veíc/hab \\
\hline \multirow{2}{*}{ Sergipe } & 436 & 21,44 & 150,03 & 97,46 & 0,14 \\
& $\left(7^{\circ}\right)$ & $\left(16^{\circ}\right)$ & $\left(21^{\circ}\right)$ & $\left(22^{\circ}\right)$ & $\left(17^{\circ}\right)$ \\
\multirow{3}{*}{ Ceará } & 1.668 & 20,01 & 143,09 & 116,75 & 0,14 \\
& $\left(20^{\circ}\right)$ & $\left(14^{\circ}\right)$ & $\left(19^{\circ}\right)$ & $\left(23^{\circ}\right)$ & $\left(18^{\circ}\right)$ \\
\multirow{3}{*}{ Roraima } & 142 & 34,19 & 169,66 & 122,62 & 0,20 \\
& $\left(3^{\circ}\right)$ & $\left(27^{\circ}\right)$ & $\left(23^{\circ}\right)$ & $\left(24^{\circ}\right)$ & $\left(14^{\circ}\right)$ \\
Maranhão & 985 & 15,72 & 206,72 & 127,49 & 0,08 \\
& $\left(15^{\circ}\right)$ & $\left(7^{\circ}\right)$ & $\left(26^{\circ}\right)$ & $\left(25^{\circ}\right)$ & $\left(27^{\circ}\right)$ \\
\multirow{3}{*}{ Alagoas } & 660 & 21,39 & 218,91 & 147,32 & 0,10 \\
& $\left(10^{\circ}\right)$ & $\left(15^{\circ}\right)$ & $\left(27^{\circ}\right)$ & $\left(26^{\circ}\right)$ & $\left(25^{\circ}\right)$ \\
\multirow{2}{*}{ Piauí } & 772 & 25,18 & 205,72 & 147,89 & 0,12 \\
& $\left(13^{\circ}\right)$ & $\left(19^{\circ}\right)$ & $\left(25^{\circ}\right)$ & $\left(27^{\circ}\right)$ & $\left(21^{\circ}\right)$ \\
\hline \multirow{2}{*}{ Brasil } & 36.753 & 19,41 & 75,85 & 59,58 & 0,26 \\
& & $\left(13^{\circ}-14^{\circ}\right)^{*}$ & $\left(6^{\circ}-7^{\circ}\right)^{*}$ & $\left(7^{\circ}-8^{\circ}\right)^{*}$ & $\left(9^{\circ}-10^{\circ}\right)^{*}$ \\
\hline
\end{tabular}

*Posição hipotética do Brasil na classificação estadual

Tabela 5. 6 - Índices associados à mortalidade no trânsito para o ano de 2008

\begin{tabular}{cccccc}
\hline Estados & Mortes & Mortes/100mil hab & Mortes/100mil veic & Mortes/10 $\mathbf{k m}$ & Veíc/hab \\
\hline \multirow{2}{*}{ São Paulo } & 7.349 & 17,92 & 42,06 & 35,81 & 0,43 \\
& $\left(27^{\circ}\right)$ & $\left(10^{\circ}\right)$ & $\left(1^{\circ}\right)$ & $\left(1^{\circ}\right)$ & $\left(2^{\circ}\right)$ \\
Rio Grande do Sul & 1.969 & 18,14 & 48,56 & 43,40 & 0,37 \\
& $\left(23^{\circ}\right)$ & $\left(11^{\circ}\right)$ & $\left(2^{\circ}\right)$ & $\left(2^{\circ}\right)$ & $\left(5^{\circ}\right)$ \\
Amazonas & 375 & 11,22 & 90,19 & 48,01 & 0,12 \\
& $\left(4^{\circ}\right)$ & $\left(1^{\circ}\right)$ & $\left(11^{\circ}\right)$ & $\left(3^{\circ}\right)$ & $\left(23^{\circ}\right)$ \\
Distrito Federal & 610 & 22,85 & 58,75 & 48,38 & 0,41 \\
& $\left(10^{\circ}\right)$ & $\left(17^{\circ}\right)$ & $\left(3^{\circ}\right)$ & $(4)$ & $\left(4^{\circ}\right)$ \\
Rio de Janeiro & 2.573 & 16,21 & 67,04 & 49,60 & 0,24 \\
& $\left(24^{\circ}\right)$ & $\left(6^{\circ}\right)$ & $\left(5^{\circ}\right)$ & $\left(5^{\circ}\right)$ & $\left(12^{\circ}\right)$ \\
Amapá & 90 & 14,68 & 105,01 & 51,16 & 0,14 \\
& $\left(1^{\circ}\right)$ & $\left(4^{\circ}\right)$ & $\left(15^{\circ}\right)$ & $\left(6^{\circ}\right)$ & $\left(21^{\circ}\right)$ \\
Minas Gerais & 3.942 & 19,86 & 69,15 & 51,91 & 0,29 \\
& $\left(26^{\circ}\right)$ & $\left(14^{\circ}\right)$ & $\left(6^{\circ}\right)$ & $\left(7^{\circ}\right)$ & $\left(10^{\circ}\right)$ \\
Santa Catarina & 1.827 & 30,19 & 64,76 & 54,24 & 0,47 \\
\multirow{2}{*}{ Rio Grande do Norte } & $\left(22^{\circ}\right)$ & $\left(24^{\circ}\right)$ & $\left(4^{\circ}\right)$ & $\left(8^{\circ}\right)$ & $\left(1^{\circ}\right)$ \\
& 454 & 14,61 & 78,28 & 56,05 & 0,19 \\
Goiás & $\left(7^{\circ}\right)$ & $\left(3^{\circ}\right)$ & $\left(8^{\circ}\right)$ & $\left(9^{\circ}\right)$ & $\left(15^{\circ}\right)$ \\
& 1.587 & 27,15 & 83,23 & 60,69 & 0,33 \\
Bahia & $\left(19^{\circ}\right)$ & $\left(19^{\circ}\right)$ & $\left(9^{\circ}\right)$ & $\left(10^{\circ}\right)$ & $\left(7^{\circ}\right)$ \\
& 1.725 & 11,89 & 97,64 & 62,80 & 0,12 \\
& $\left(21^{\circ}\right)$ & $\left(2^{\circ}\right)$ & $\left(12^{\circ}\right)$ & $\left(11^{\circ}\right)$ & $\left(24^{\circ}\right)$ \\
& & & & & Continua
\end{tabular}


Conclusão

\begin{tabular}{|c|c|c|c|c|c|}
\hline Estados & Mortes & Mortes/100mil hab & Mortes/100mil veíc & Mortes $/ \mathbf{1 0}^{\mathbf{9}} \mathrm{km}$ & Veíc/hab \\
\hline \multirow{2}{*}{ Acre } & 112 & 16,47 & 102,19 & 63,73 & 0,16 \\
\hline & $\left(2^{\mathrm{o}}\right)$ & $\left(7^{\circ}\right)$ & $\left(13^{\circ}\right)$ & $\left(12^{\circ}\right)$ & $\left(17^{\circ}\right)$ \\
\hline \multirow{2}{*}{ Rondônia } & 449 & 30,06 & 107,41 & 63,76 & 0,28 \\
\hline & $\left(6^{\circ}\right)$ & $\left(23^{\circ}\right)$ & $\left(16^{\circ}\right)$ & $\left(13^{\circ}\right)$ & $\left(11^{\circ}\right)$ \\
\hline \multirow{2}{*}{ Mato Grosso do Sul } & 695 & 29,75 & 89,13 & 66,00 & 0,33 \\
\hline & $\left(11^{\circ}\right)$ & $\left(21^{\circ}\right)$ & $\left(10^{\circ}\right)$ & $\left(14^{\mathrm{o}}\right)$ & $\left(6^{\circ}\right)$ \\
\hline \multirow{2}{*}{ Paraná } & 3.166 & 29,90 & 73,61 & 69,44 & 0,41 \\
\hline & $\left(25^{\circ}\right)$ & $\left(22^{\circ}\right)$ & $\left(7^{\circ}\right)$ & $\left(15^{\circ}\right)$ & $\left(3^{\circ}\right)$ \\
\hline \multirow{2}{*}{ Mato Grosso } & 1.033 & 33,97 & 114,74 & 74,24 & 0,30 \\
\hline & $\left(14^{\mathrm{o}}\right)$ & $\left(27^{\circ}\right)$ & $\left(18^{\circ}\right)$ & $\left(16^{\mathrm{o}}\right)$ & $\left(8^{\circ}\right)$ \\
\hline \multirow{2}{*}{ Pará } & 1.103 & 15,07 & 152,71 & 76,12 & 0,10 \\
\hline & $\left(16^{\circ}\right)$ & $\left(5^{\circ}\right)$ & $\left(24^{\circ}\right)$ & $\left(17^{\circ}\right)$ & $\left(26^{\circ}\right)$ \\
\hline \multirow{2}{*}{ Tocantins } & 446 & 34,83 & 145,38 & 77,90 & 0,24 \\
\hline & $\left(5^{\circ}\right)$ & $\left(26^{\circ}\right)$ & $\left(21^{\circ}\right)$ & $\left(18^{\circ}\right)$ & $\left(13^{\circ}\right)$ \\
\hline \multirow{2}{*}{ Pernambuco } & 1.533 & 17,55 & 111,18 & 84,22 & 0,16 \\
\hline & $\left(18^{\circ}\right)$ & $\left(8^{\circ}\right)$ & $\left(17^{\circ}\right)$ & $\left(19^{\circ}\right)$ & $\left(18^{\circ}\right)$ \\
\hline \multirow{2}{*}{ Espirito Santo } & 1.061 & 30,72 & 103,81 & 84,33 & 0,30 \\
\hline & $\left(15^{\circ}\right)$ & $\left(25^{\circ}\right)$ & $\left(14^{\mathrm{o}}\right)$ & $\left(20^{\circ}\right)$ & $\left(9^{\circ}\right)$ \\
\hline \multirow{2}{*}{ Roraima } & 120 & 29,07 & 124,84 & 88,24 & 0,23 \\
\hline & $\left(3^{\circ}\right)$ & $\left(20^{\circ}\right)$ & $\left(19^{\circ}\right)$ & $\left(21^{\circ}\right)$ & $\left(14^{\circ}\right)$ \\
\hline \multirow{2}{*}{ Sergipe } & 475 & 23,76 & 146,78 & 95,61 & 0,16 \\
\hline & $\left(8^{\circ}\right)$ & $\left(16^{\circ}\right)$ & $\left(23^{\circ}\right)$ & $\left(22^{o}\right)$ & $\left(16^{\mathrm{o}}\right)$ \\
\hline \multirow{2}{*}{ Paraíba } & 788 & 21,05 & 146,40 & 97,47 & 0,14 \\
\hline & $\left(12^{\circ}\right)$ & $\left(15^{\circ}\right)$ & $\left(22^{\circ}\right)$ & $\left(23^{\circ}\right)$ & $\left(20^{\circ}\right)$ \\
\hline \multirow{2}{*}{ Ceará } & 1.663 & 19,68 & 127,72 & 100,89 & 0,15 \\
\hline & $\left(20^{\circ}\right)$ & $\left(13^{\circ}\right)$ & $\left(20^{\circ}\right)$ & $\left(24^{\mathrm{o}}\right)$ & $\left(19^{\circ}\right)$ \\
\hline \multirow{2}{*}{ Maranhão } & 1.128 & 17,89 & 202,53 & 119,01 & 0,09 \\
\hline & $\left(17^{\circ}\right)$ & $\left(9^{\circ}\right)$ & $\left(27^{\circ}\right)$ & $\left(25^{\circ}\right)$ & $\left(27^{\circ}\right)$ \\
\hline \multirow{2}{*}{ Alagoas } & 592 & 18,93 & 176,42 & 119,91 & 0,11 \\
\hline & $\left(9^{\circ}\right)$ & $\left(12^{\mathrm{o}}\right)$ & $\left(25^{\circ}\right)$ & $\left(26^{\mathrm{o}}\right)$ & $\left(25^{\circ}\right)$ \\
\hline \multirow{2}{*}{ Piauí } & 829 & 26,57 & 191,60 & 146,02 & 0,14 \\
\hline & $\left(13^{\circ}\right)$ & $\left(18^{\circ}\right)$ & $\left(26^{\circ}\right)$ & $\left(27^{\circ}\right)$ & $\left(22^{\circ}\right)$ \\
\hline \multirow{2}{*}{ Brasil } & \multirow{2}{*}{37.694} & 19,88 & 70,85 & 55,87 & 0,28 \\
\hline & & $\left(14^{\mathrm{o}}-15^{\mathrm{o}}\right)^{*}$ & $\left(6^{o}-7^{o}\right)^{*}$ & $\left(8^{o}-9^{o}\right)^{*}$ & $\left(11^{\circ}\right)^{*}$ \\
\hline
\end{tabular}

*Posição hipotética do Brasil na classificação estadual 
Nas Figuras 5.5 a 5.9 podem ser visualizados os mapas temáticos do índice de mortes por quilômetro percorrido para os anos de 2004, 2005, 2006, 2007 e 2008, respectivamente. Para elaboração desses mapas foi adotado o seguinte procedimento de classificação:

- Grupo A (do $1^{\circ}$ ao $6^{\circ}$ menor índice): Classificação relativa - situação boa no cenário nacional;

- Grupo B (do $7^{\circ}$ ao $13^{\circ}$ menor índice): Classificação relativa - situação regular no cenário nacional;

- Grupo C (do $14^{\circ}$ ao $20^{\circ}$ menor índice): Classificação relativa - situação ruim no cenário nacional;

- Grupo D (do $21^{\circ}$ ao $27^{\circ}$ menor índice): Classificação relativa - situação péssima no cenário nacional;

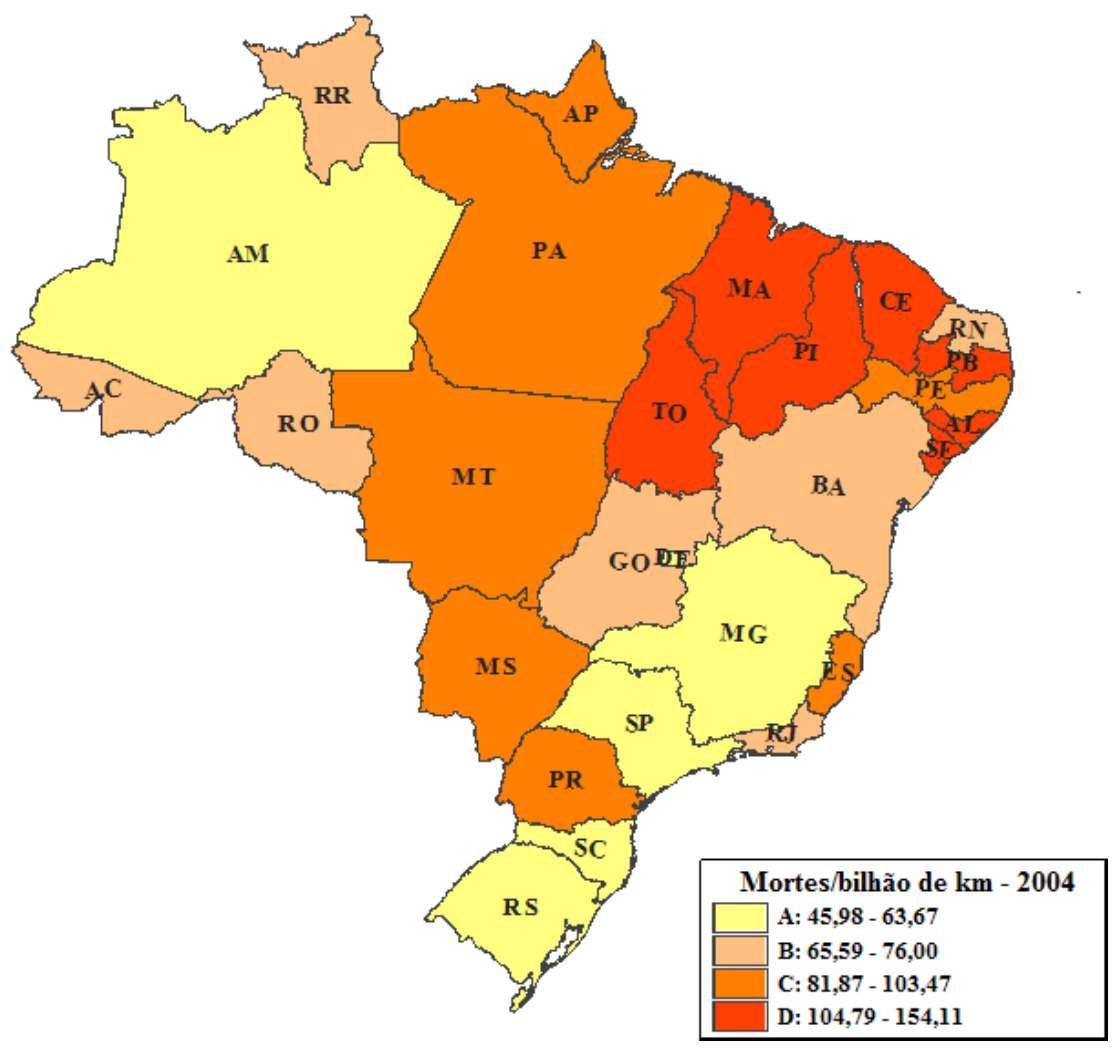

Figura 5.5- Mapa temático do índice de mortes por quilômetro percorrido em 2004 


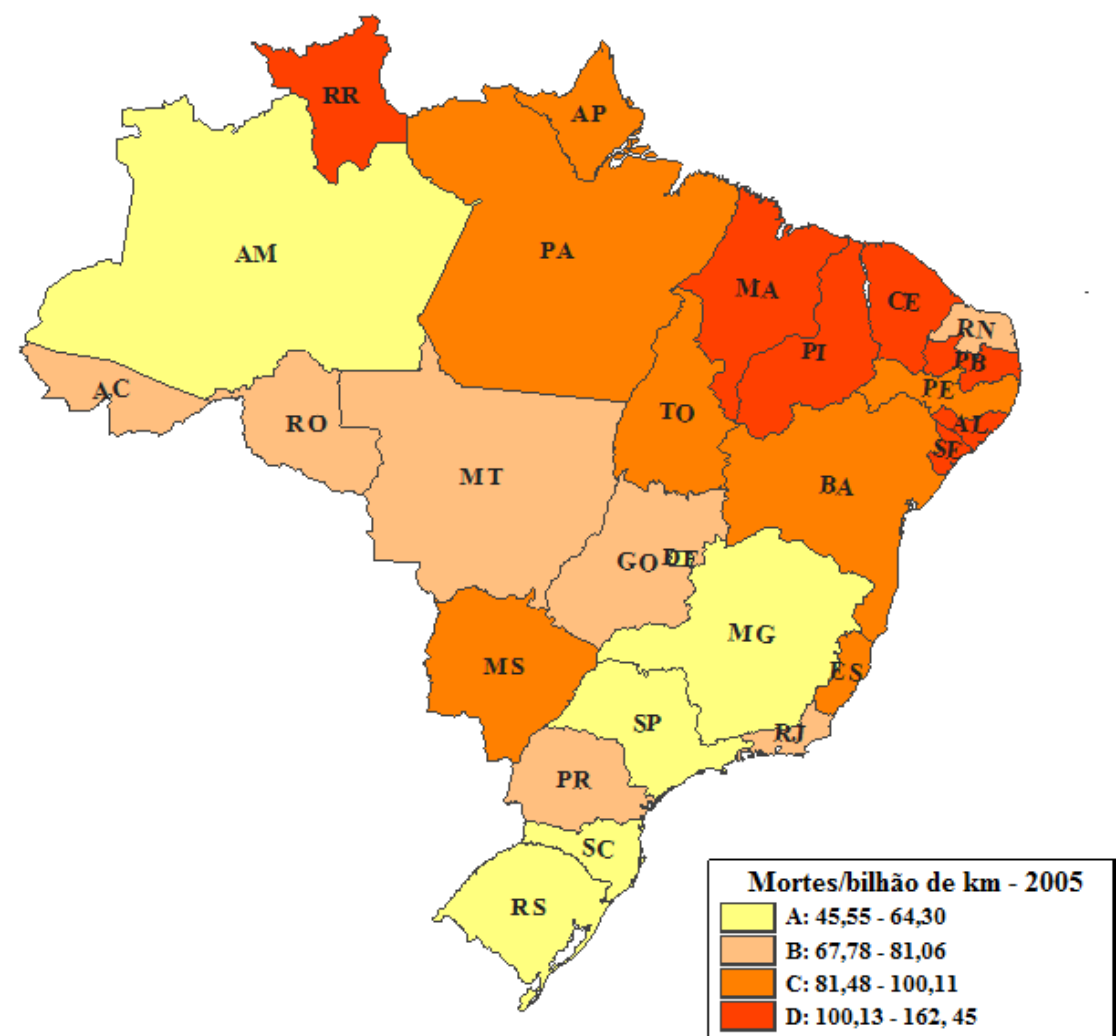

Figura 5.6- Mapa temático do índice de mortes por quilômetro percorrido em 2005

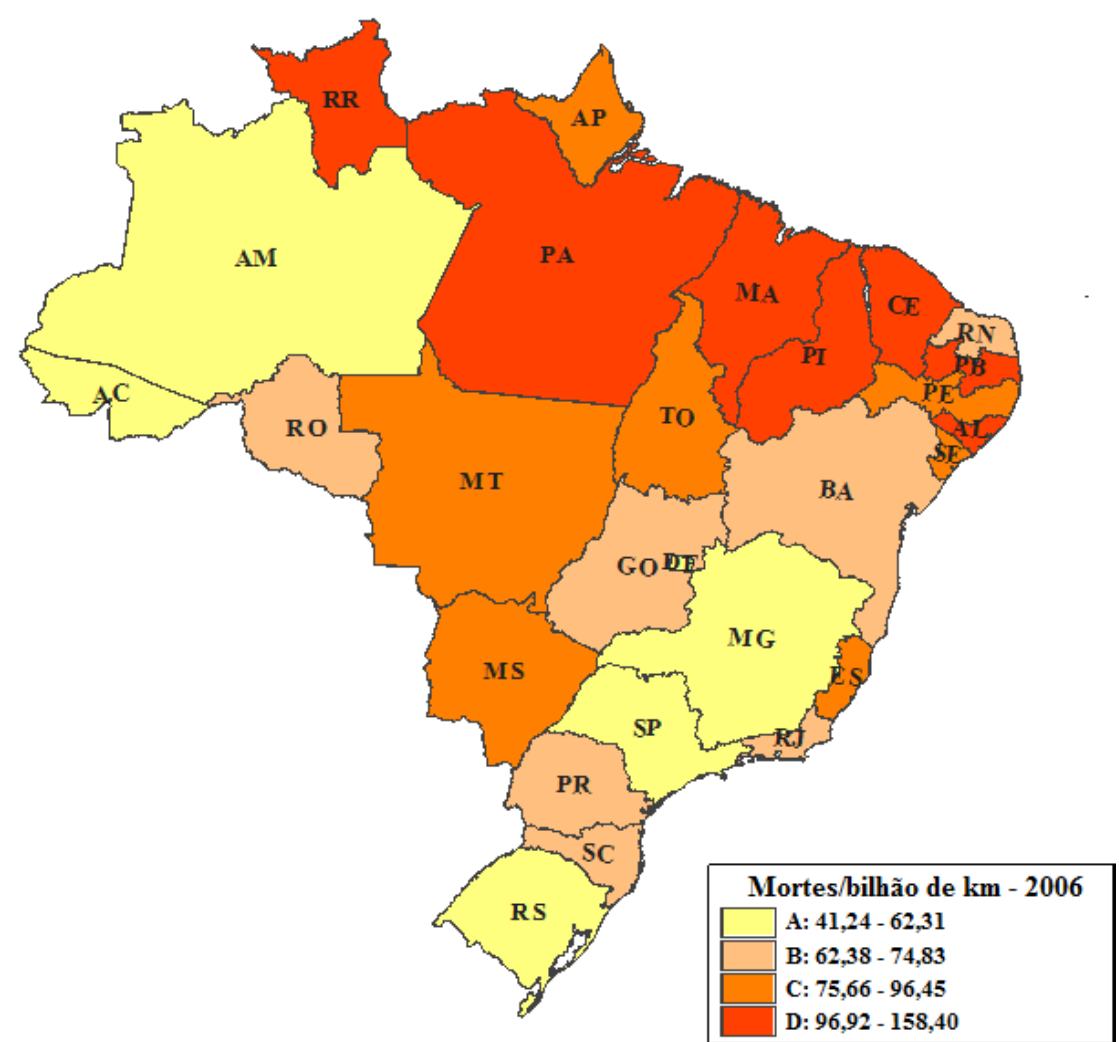

Figura 5.7- Mapa temático do índice de mortes por quilômetro percorrido em 2006 


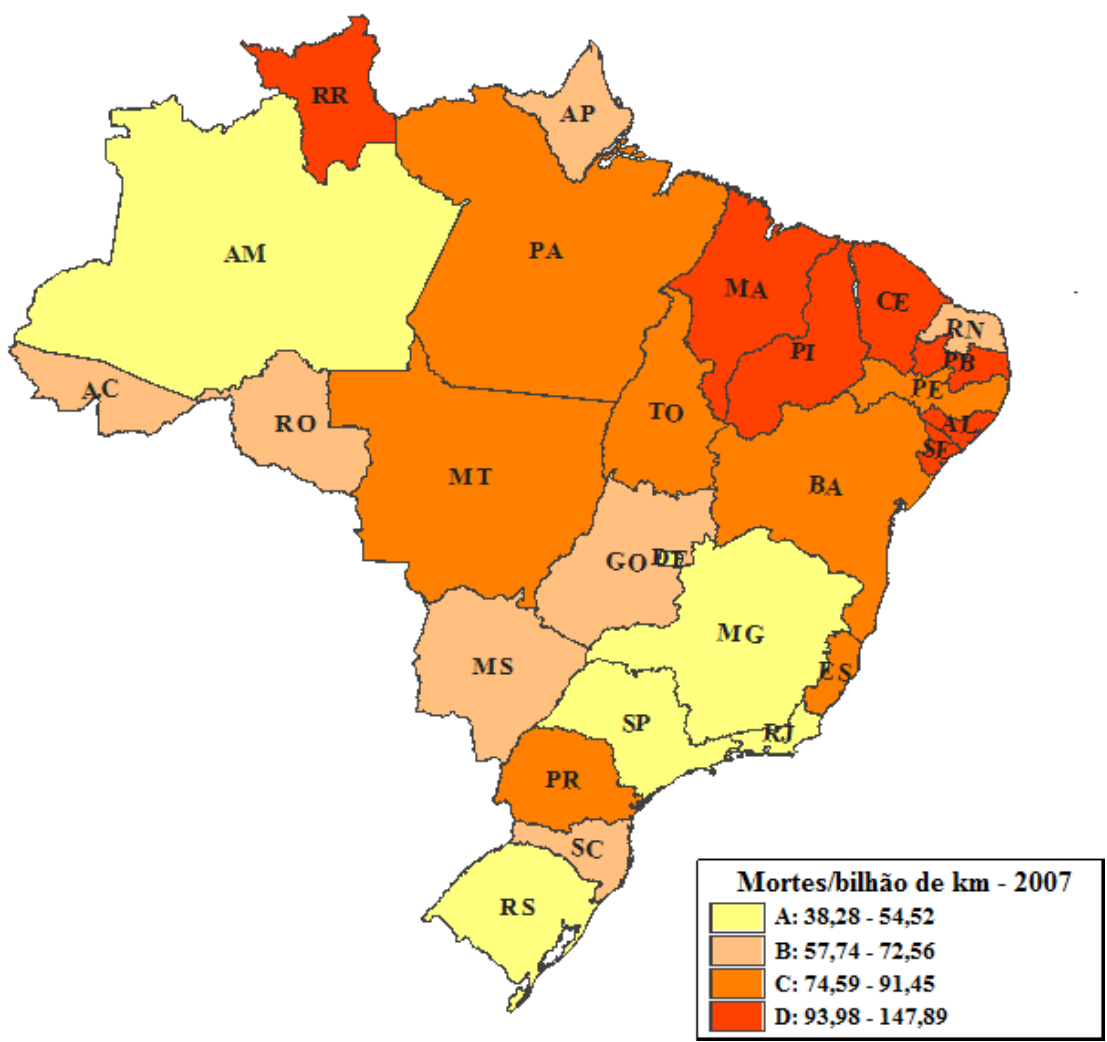

Figura 5.8- Mapa temático do índice de mortes por quilômetro percorrido em 2007

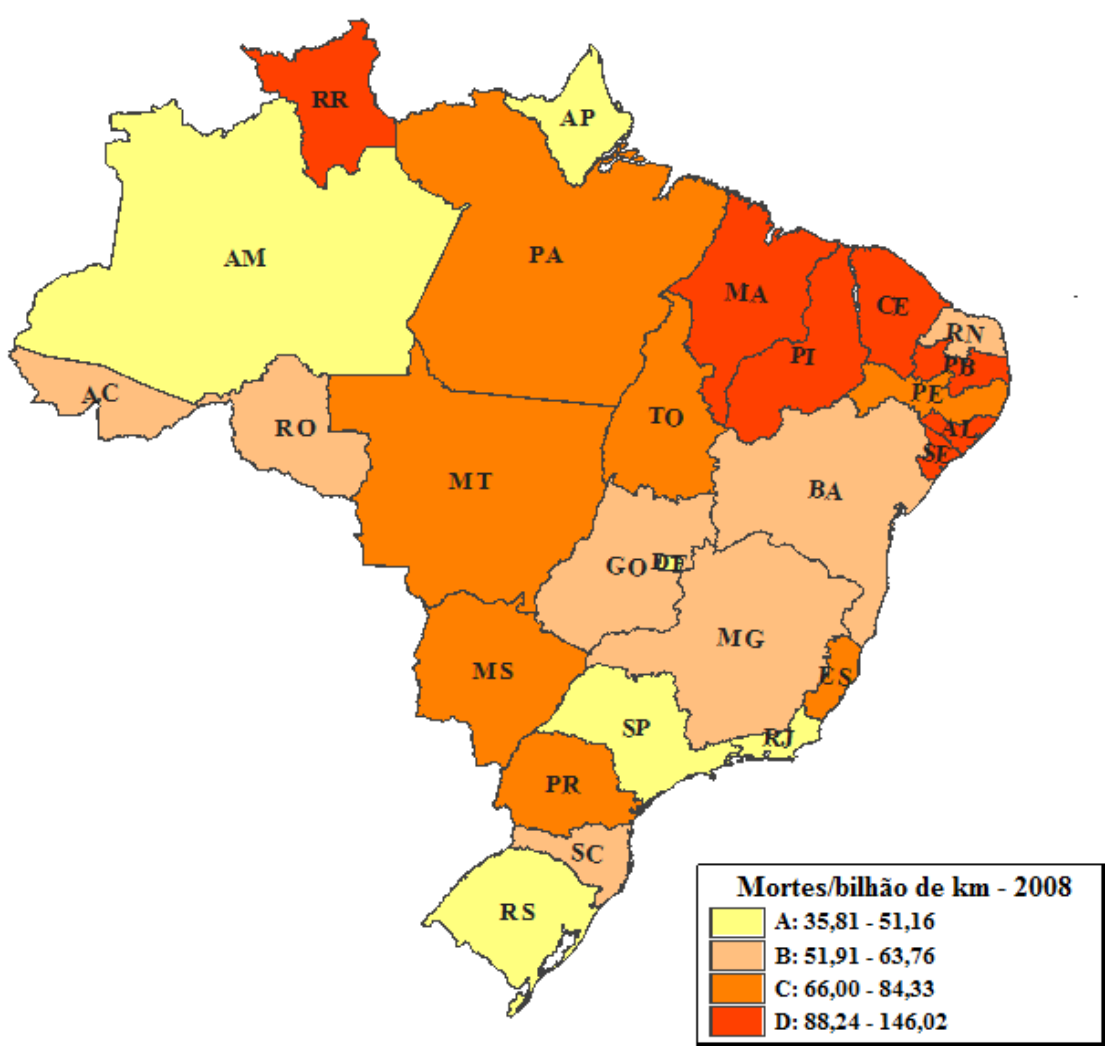

Figura 5.9- Mapa temático do índice de mortes por quilômetro percorrido em 2008 
Os resultados dessa categorização encontram-se relacionados na Tabela 5.7.

Tabela 5. 7 - Classificação dos estados nos Grupos A, B, C e D

\begin{tabular}{|c|c|c|c|c|c|}
\hline & 2004 & 2005 & 2006 & 2007 & 2008 \\
\hline $\mathbf{A}$ & $\begin{array}{c}\text { SP, RS, DF, MG, } \\
\text { AM e SC }\end{array}$ & $\begin{array}{l}\text { SP, RS, MG, DF, } \\
\text { AM e SC }\end{array}$ & $\begin{array}{c}\text { SP, RS, DF, MG, } \\
\text { AC e AM }\end{array}$ & $\begin{array}{l}\text { SP, RS, AM, DF, } \\
\text { MG e RJ }\end{array}$ & $\begin{array}{c}\mathrm{SP}, \mathrm{RJ}, \mathrm{AP}, \mathrm{RS}, \\
\mathrm{AM} \text { e DF }\end{array}$ \\
\hline B & $\begin{array}{c}\text { BA, RJ, RO, RR, } \\
\text { RN, AC e GO }\end{array}$ & $\begin{array}{c}\mathrm{RJ}, \mathrm{RO}, \mathrm{RN}, \mathrm{MT}, \\
\mathrm{PR}, \mathrm{GO} \text { e } \mathrm{AC}\end{array}$ & $\begin{array}{c}\text { SC, GO, RO, RJ, } \\
\text { RN, BA e PR }\end{array}$ & $\begin{array}{c}\mathrm{RO}, \mathrm{SC}, \mathrm{RN}, \mathrm{GO}, \\
\mathrm{AP}, \mathrm{AC} \text { e } \mathrm{MS}\end{array}$ & $\begin{array}{c}\mathrm{MG}, \mathrm{RN}, \mathrm{SC}, \mathrm{GO}, \\
\mathrm{RO}, \mathrm{BA} \text { e AC }\end{array}$ \\
\hline $\mathbf{C}$ & $\begin{array}{c}\text { MS, MT, PR, ES, } \\
\text { AP, PA e PE }\end{array}$ & $\begin{array}{c}\text { AP, BA, ES, MS, } \\
\text { TO, PA e PE }\end{array}$ & $\begin{array}{l}\text { MT, MS, AP, ES, } \\
\text { TO, SE e PE }\end{array}$ & $\begin{array}{l}\text { PR, BA, MT, TO, } \\
\text { ES, PE e PA }\end{array}$ & $\begin{array}{c}\text { PR, MS, MT, PE, } \\
\text { TO, PA e ES }\end{array}$ \\
\hline D & $\begin{array}{c}\text { PB, TO, SE, MA, } \\
\text { CE, AL e PI }\end{array}$ & $\begin{array}{c}\text { SE, PB, RR, MA, } \\
\text { CE, AL e PI }\end{array}$ & $\begin{array}{c}\text { PA, RR, PB, MA, } \\
\text { CE, AL e PI }\end{array}$ & $\begin{array}{c}\text { PB, SE, CE, RR, } \\
\text { MA, AL e PI }\end{array}$ & $\begin{array}{c}\text { RR, SE, PB, CE, } \\
\text { MA, AL e PI }\end{array}$ \\
\hline
\end{tabular}

Com base nas informações sistematizadas nas tabelas e figuras, constata-se o melhor desempenho do estado de São Paulo em todos os anos. Em contraste, têm-se os estados de Alagoas e Piauí com os piores índices em todos os períodos.

Na Figura 5.10 é mostrada a evolução dos diversos valores associados à mortalidade no trânsito para o país nos anos de 2004 a 2008.



Figura 5.10- Índice de mortes por bilhão de quilômetros, por 100mil habitantes, por 100mil veículos e índice de motorização no Brasil no período 2004-2008.

No período de 2004 a 2008, ocorreram as seguintes variações percentuais dos parâmetros associados à acidentalidade:

- $\quad$ Número de mortes $=9,44 \%$

- Índice de mortes por quilômetro $=-18,15 \%$

- Índice de mortes por veículo $=-21,27 \%$ 
- Índice de mortes por habitante $=3,38 \%$

- $\quad$ Índice de motorização $=31,31 \%$

O declínio no número de mortes por quilômetro no período deve ser atribuído ao aumento da quilometragem total percorrida (consequência do aumento da frota e do crescimento econômico) e certa estabilização do número de mortes - certamente em decorrência de ações implementadas pelo governo federal com alcance nacional e, também, de ações específicas levadas a efeito em alguns estados e municípios de grande porte, visando à redução da acidentalidade.

Nas Figuras 5.11 a 5.38 são apresentados os gráficos da evolução do índice de mortes por bilhão de veic.km para todos os estados do país em ordem alfabética.

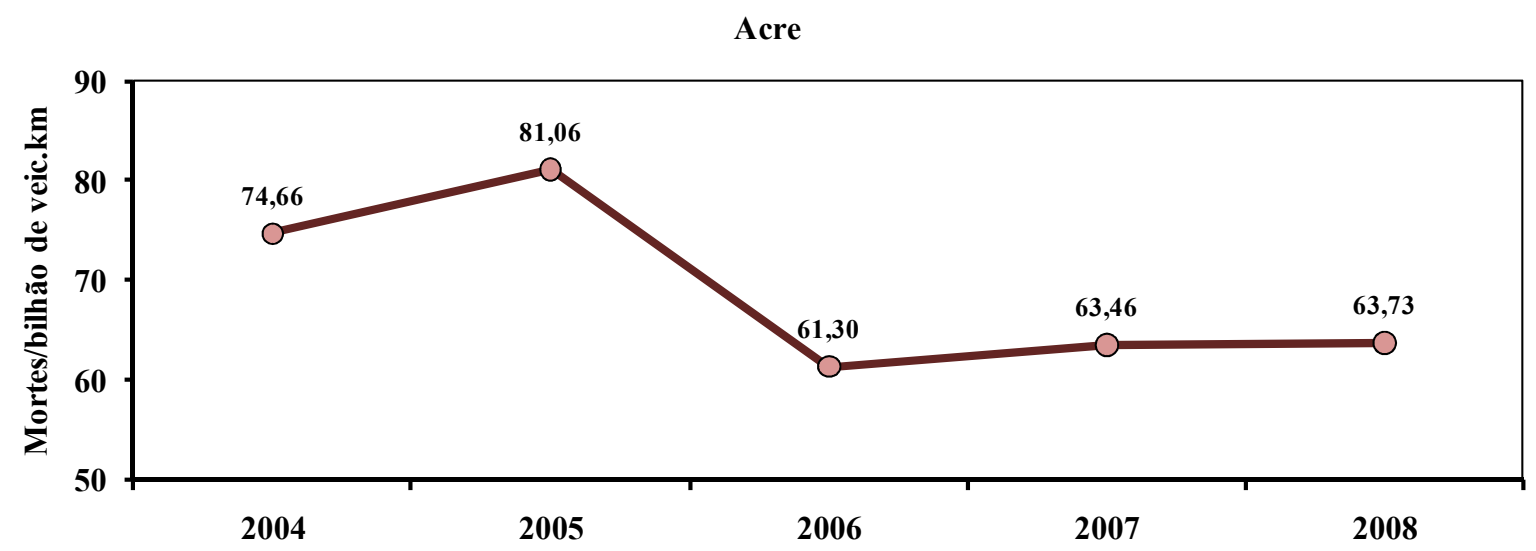

Figura 5.11- Índice de mortes por bilhão de quilômetros no Acre no período 2004-2008

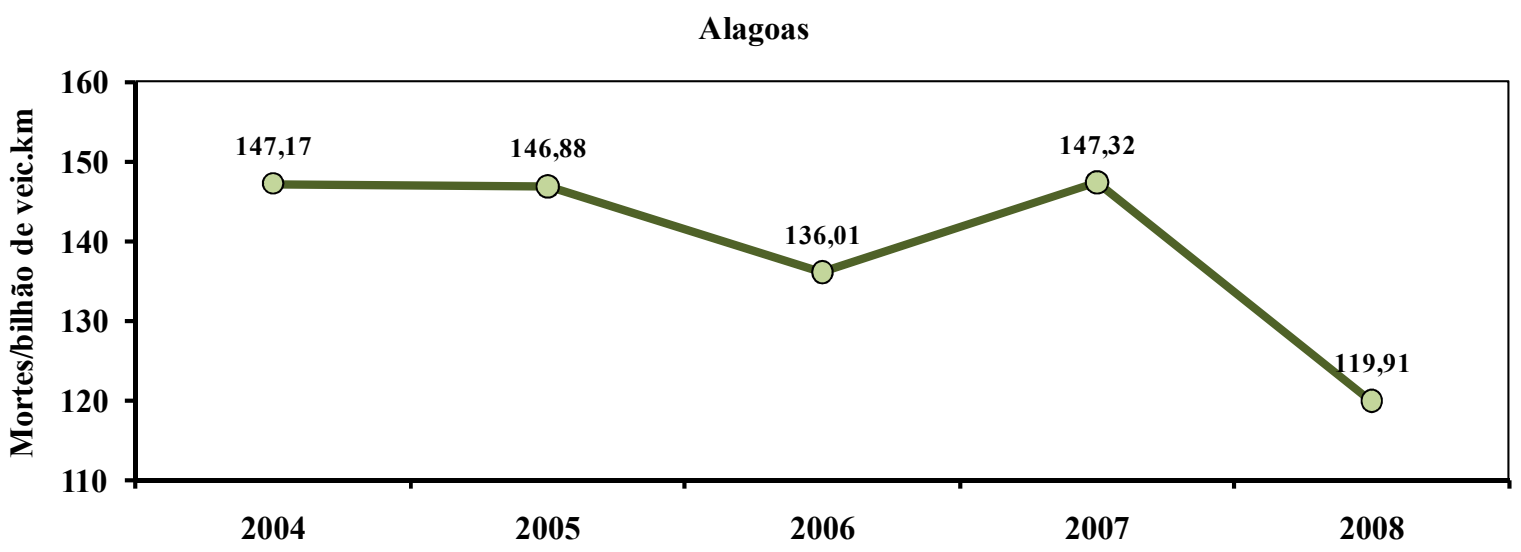

Figura 5.12- Índice de mortes por bilhão de quilômetros em Alagoas no período 2004-2008 


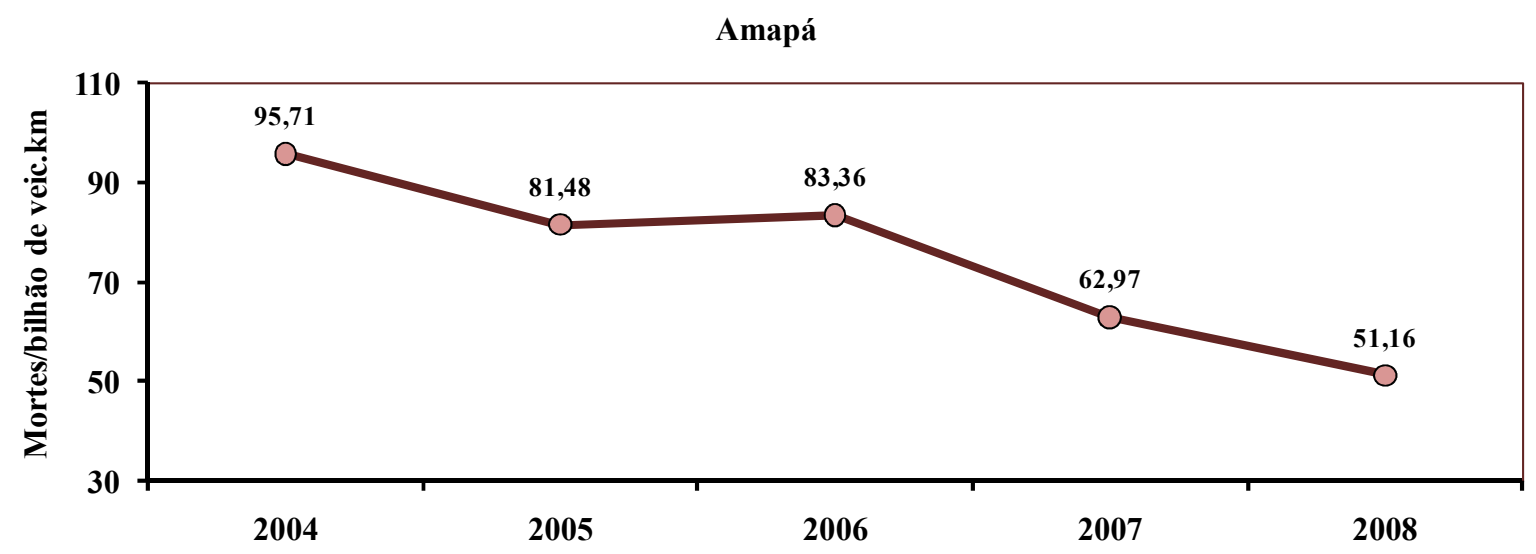

Figura 5.13- Índice de mortes por bilhão de quilômetros no Amapá no período 2004-2008

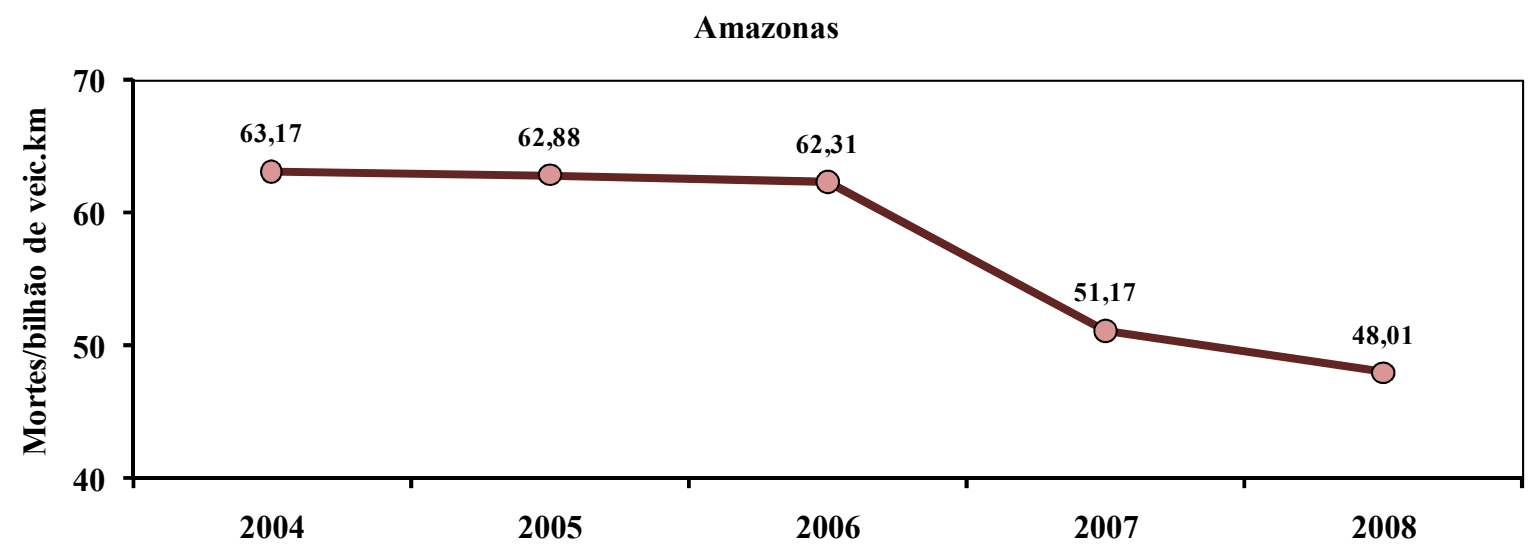

Figura 5.14- Índice de mortes por bilhão de quilômetros no Amazonas no período 2004-2008

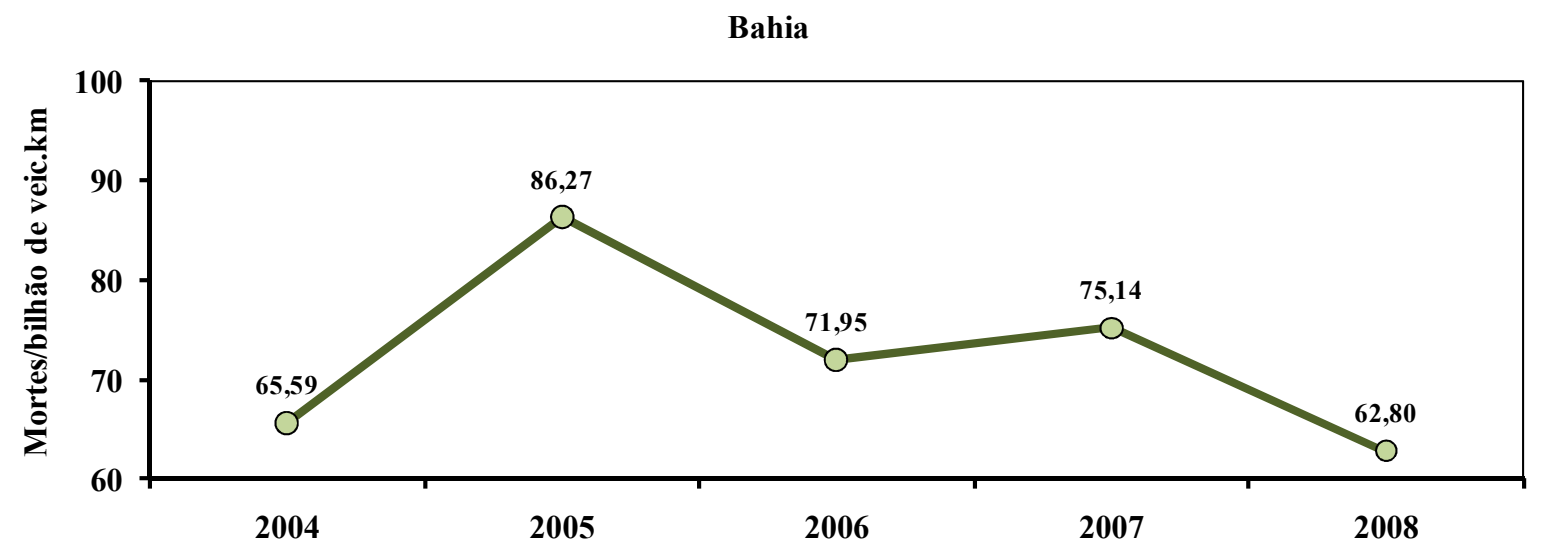

Figura 5.15- Índice de mortes por bilhão de quilômetros na Bahia no período 2004-2008 


\section{Ceará}

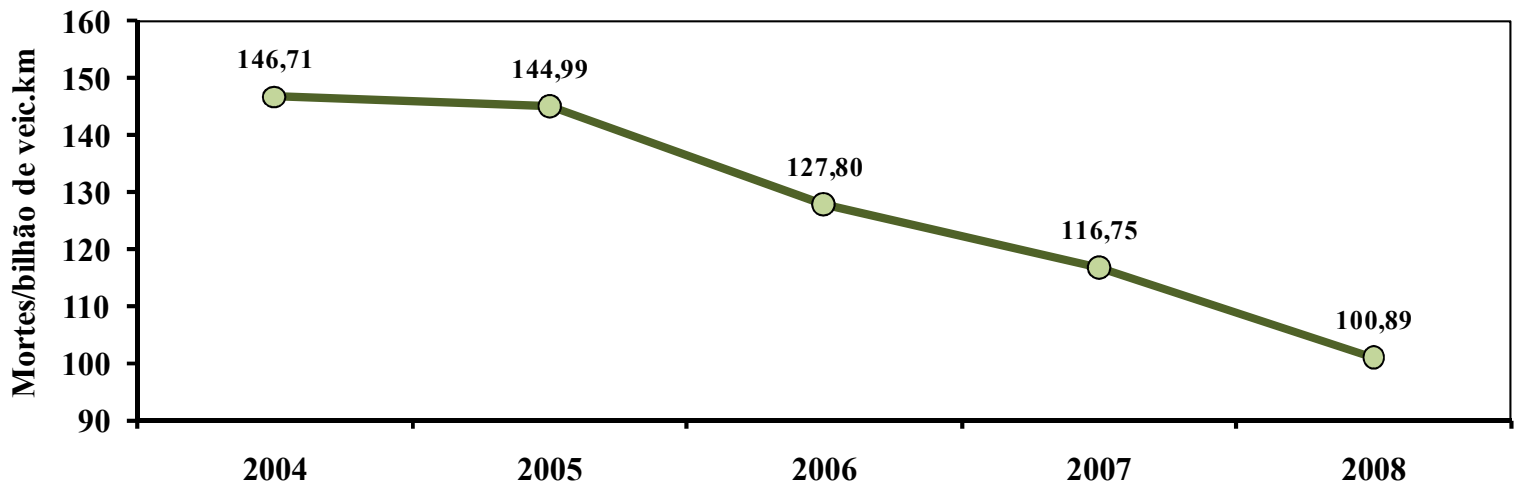

Figura 5.16- Índice de mortes por bilhão de quilômetros no Ceará no período 2004-2008

\section{Distrito Federal}

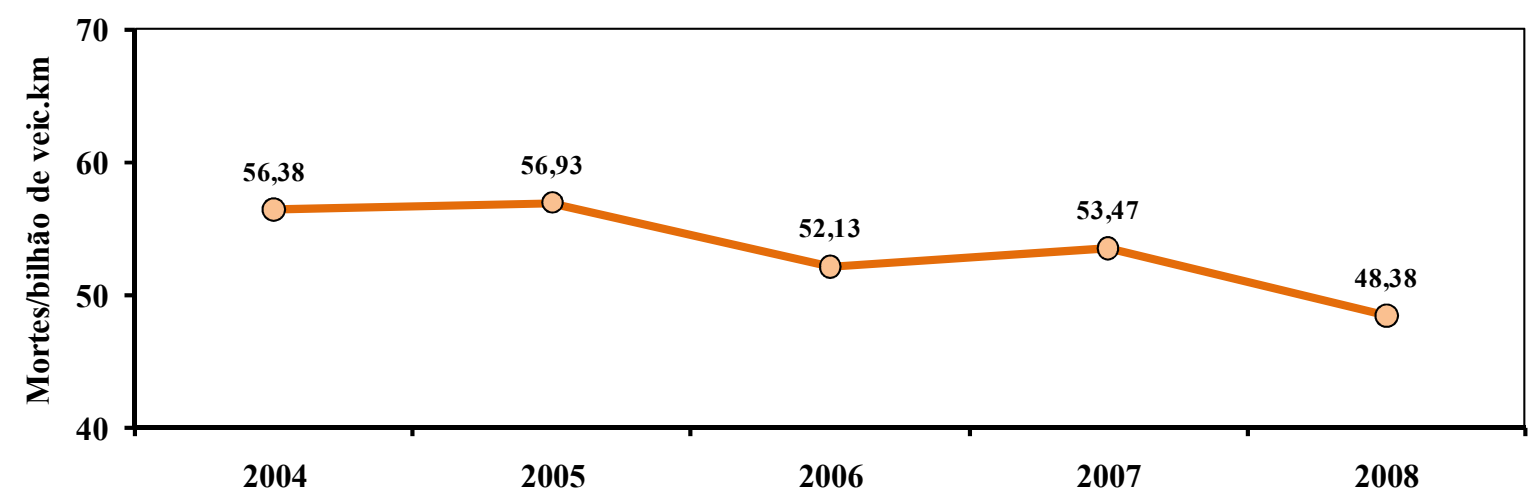

Figura 5.17- Índice de mortes por bilhão de quilômetros no Distrito Federal no período 2004-2008

\section{Espírito Santo}

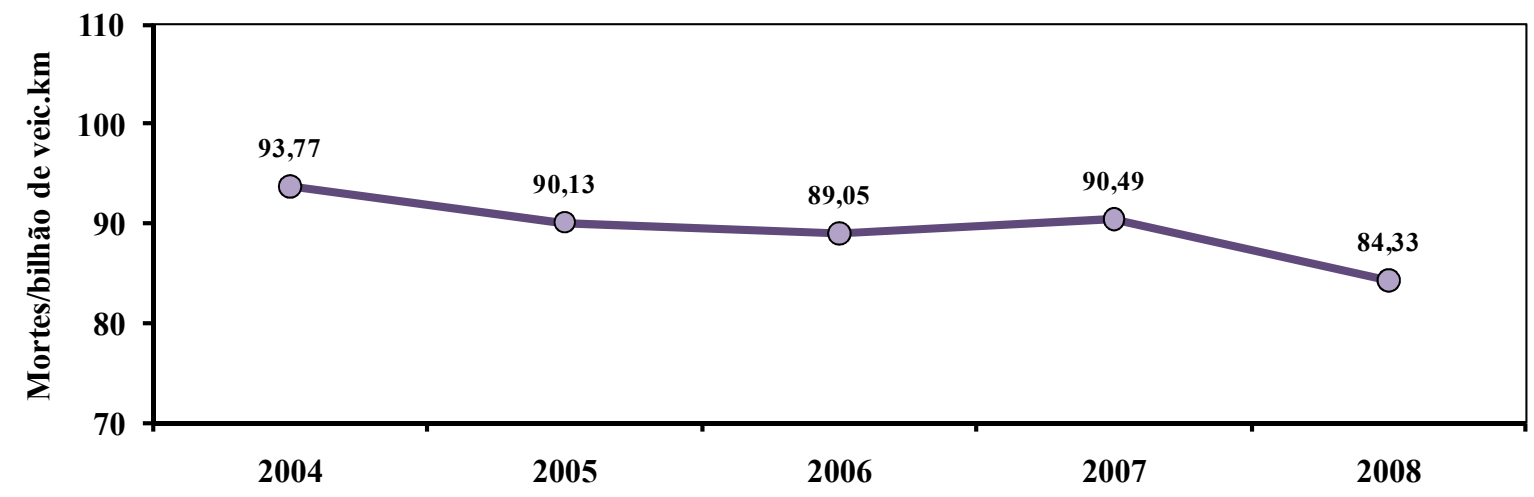

Figura 5.18- Índice de mortes por bilhão de quilômetros no Espírito Santo no período 2004-2008 


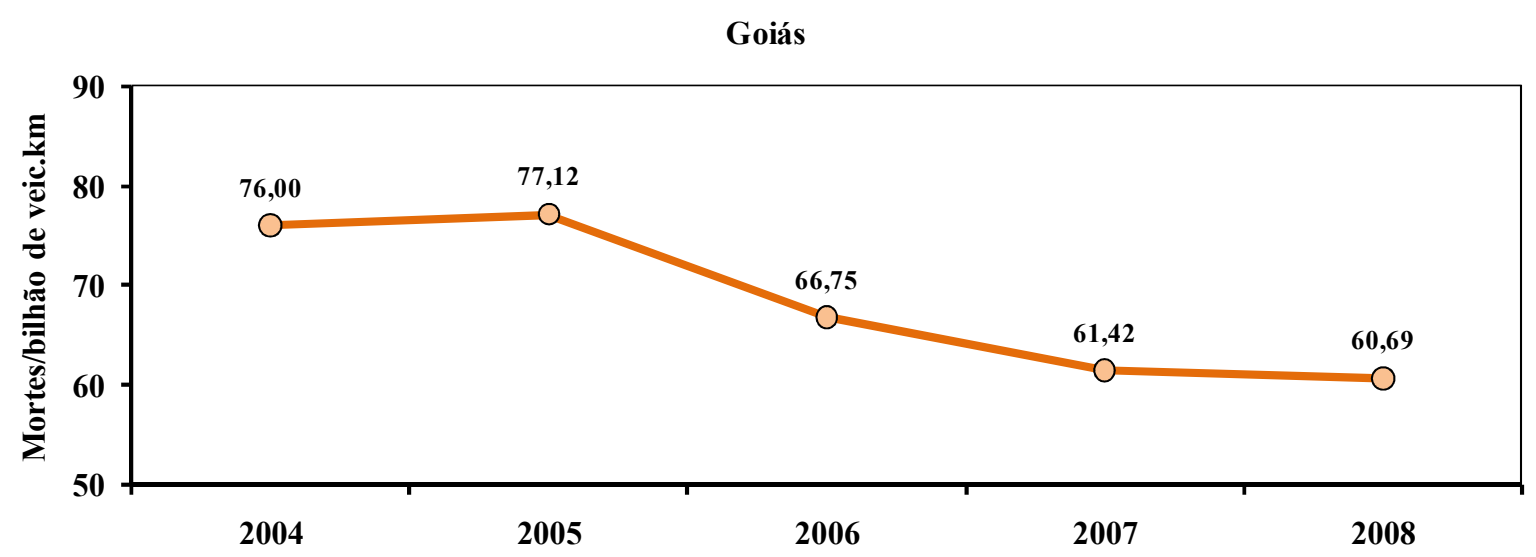

Figura 5.19- Índice de mortes por bilhão de quilômetros em Goiás no período 2004-2008

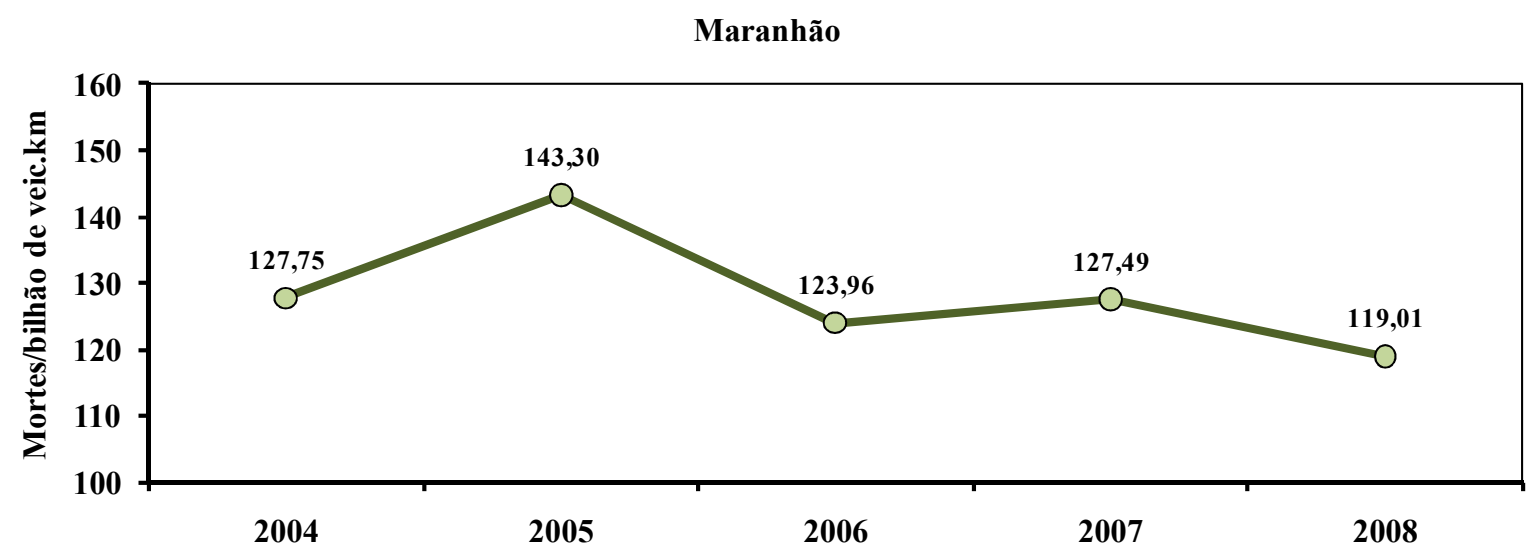

Figura 5.20- Índice de mortes por bilhão de quilômetros no Maranhão no período 2004-2008

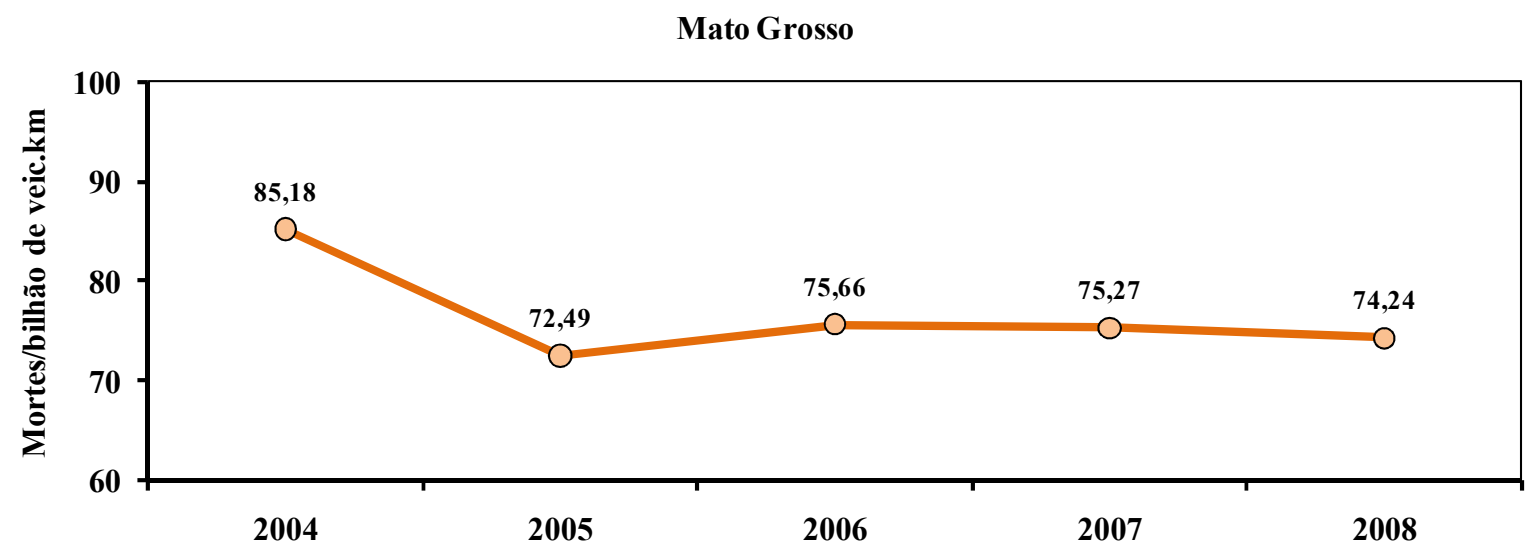

Figura 5.21- Índice de mortes por bilhão de quilômetros no Mato Grosso no período 2004-2008 
Mato Grosso do Sul

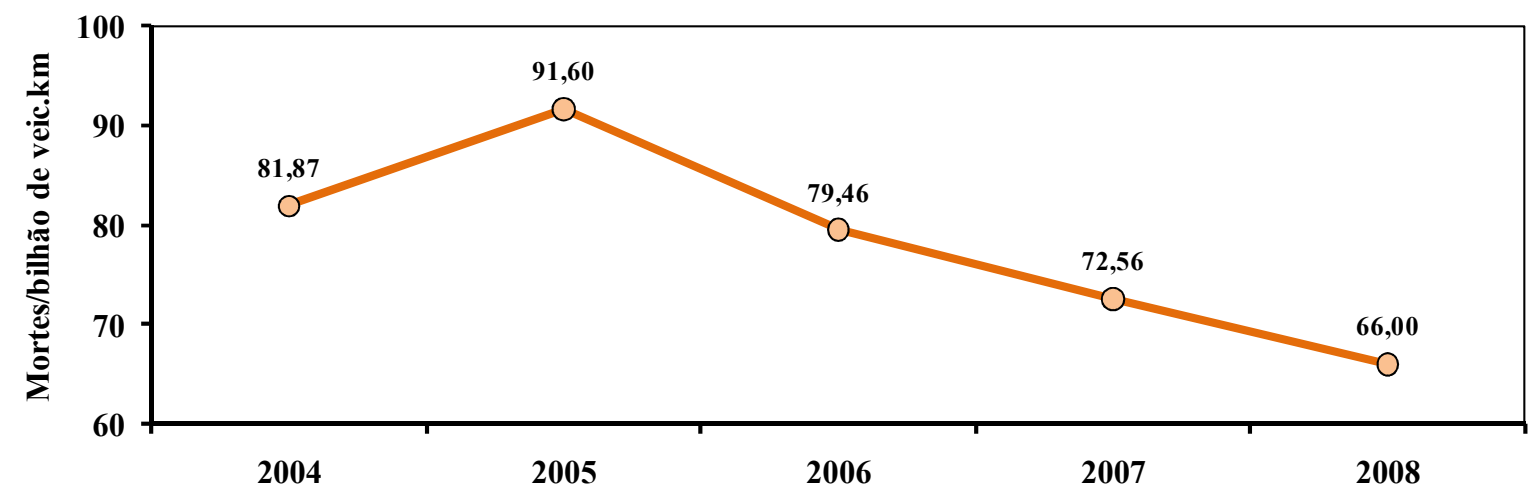

Figura 5.22- Índice de mortes por bilhão de quilômetros no Mato Grosso do Sul no período 2004-2008



Figura 5.23- Índice de mortes por bilhão de quilômetros em Minas Gerais no período 2004-2008

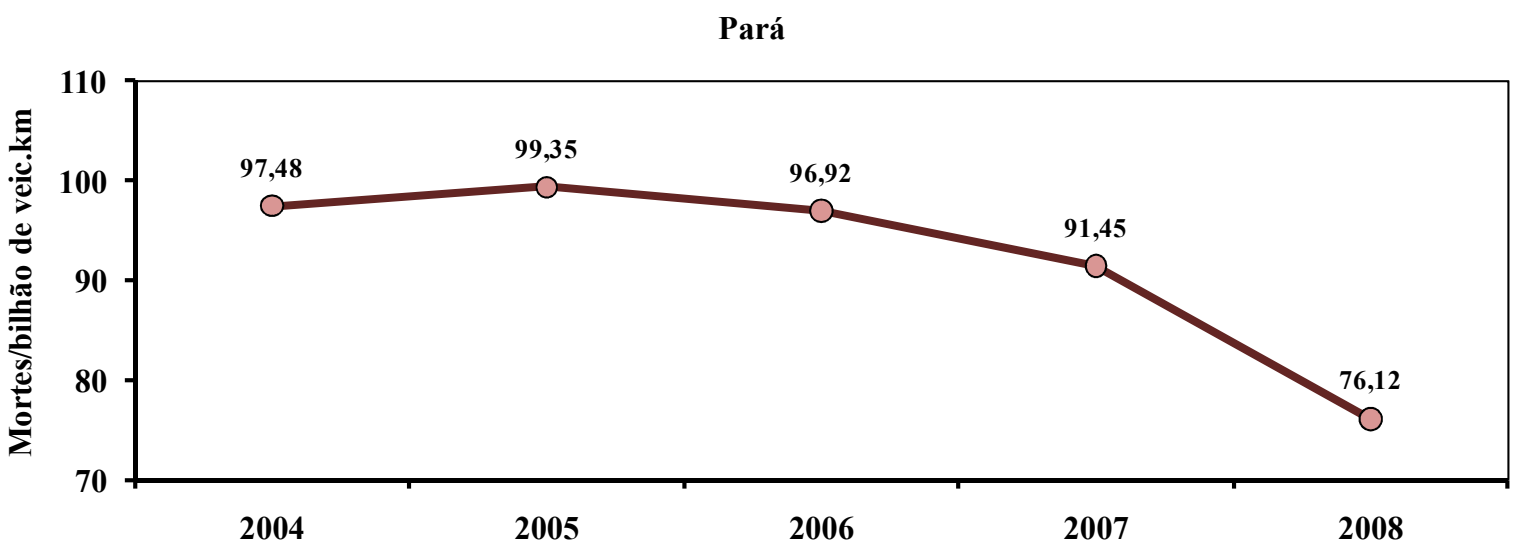

Figura 5.24- Índice de mortes por bilhão de quilômetros no Pará no período 2004-2008 


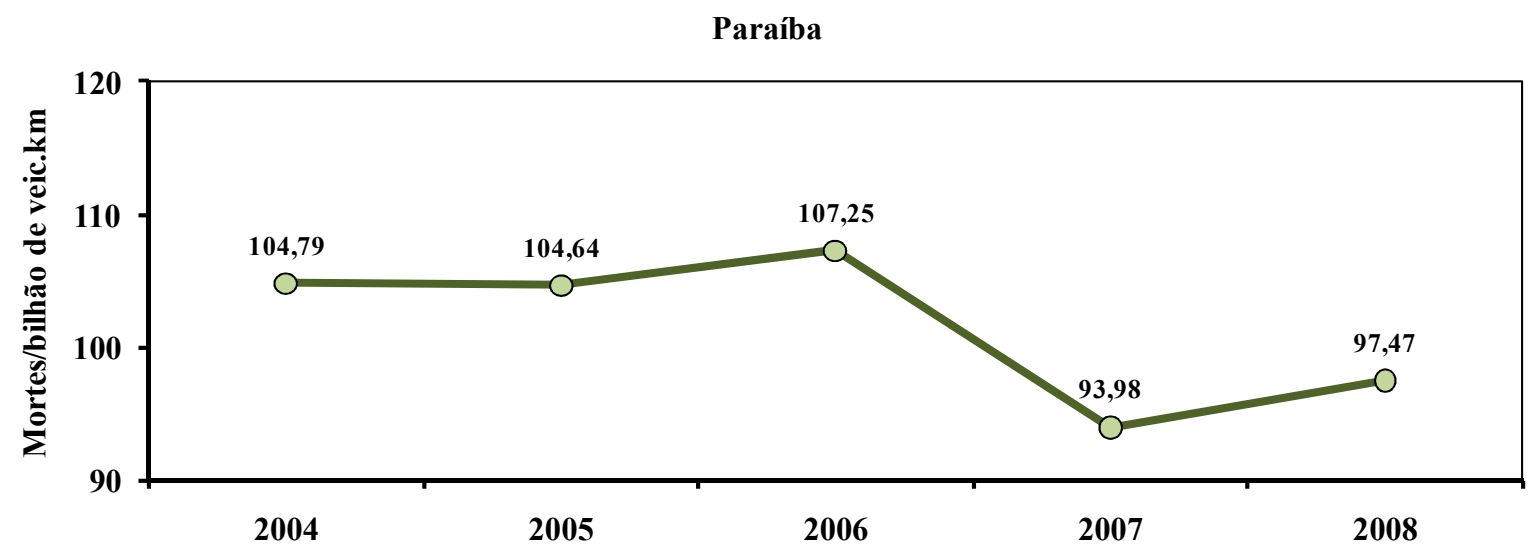

Figura 5.25- Índice de mortes por bilhão de quilômetros na Paraíba no período 2004-2008

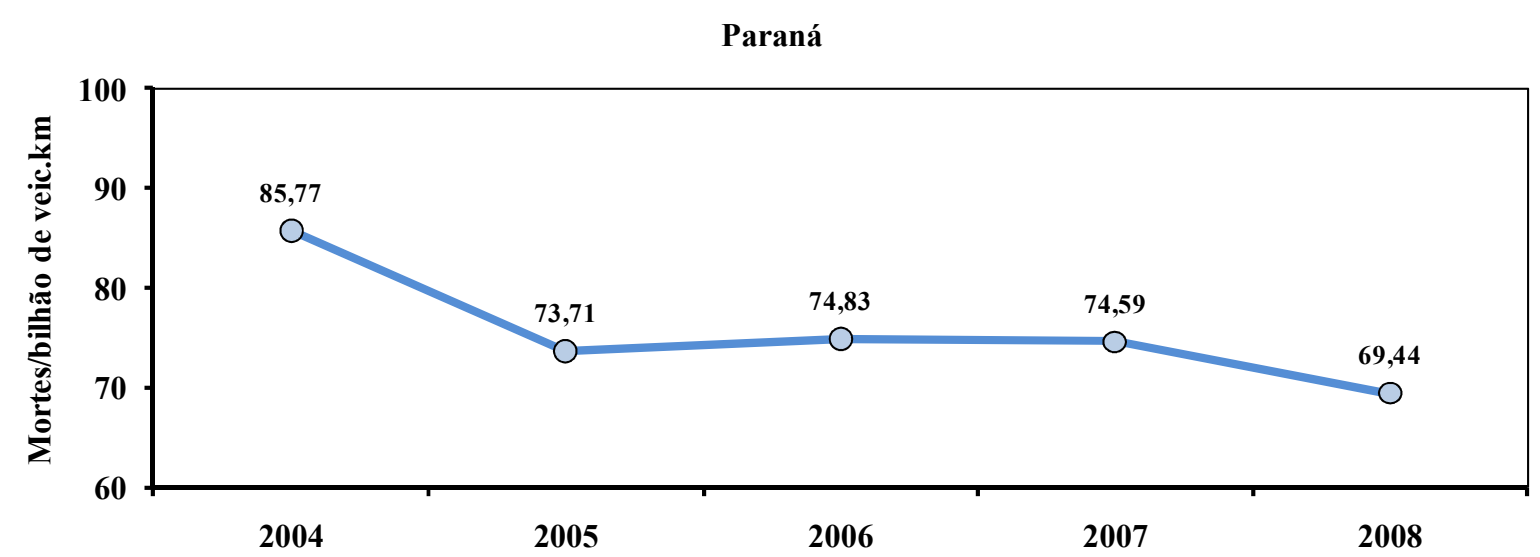

Figura 5.26- Índice de mortes por bilhão de quilômetros no Paraná no período 2004-2008

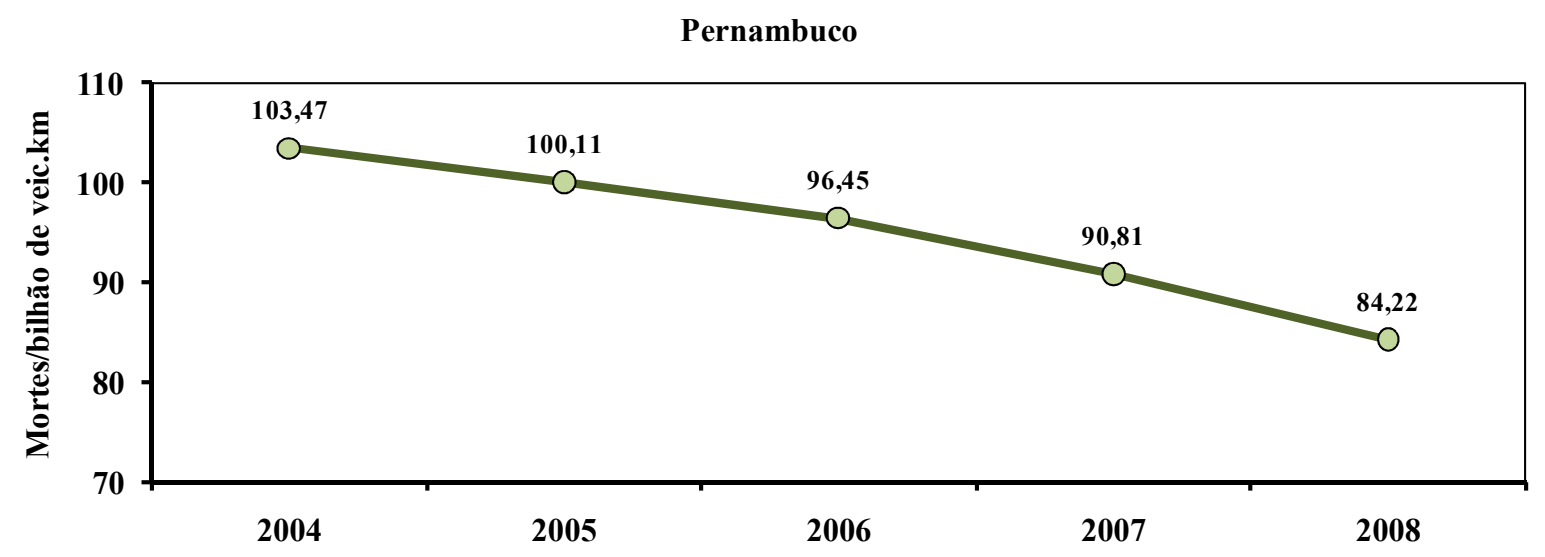

Figura 5.27- Índice de mortes por bilhão de quilômetros em Pernambuco no período 2004-2008 




Figura 5.28- Índice de mortes por bilhão de quilômetros no Piaú no período 2004-2008

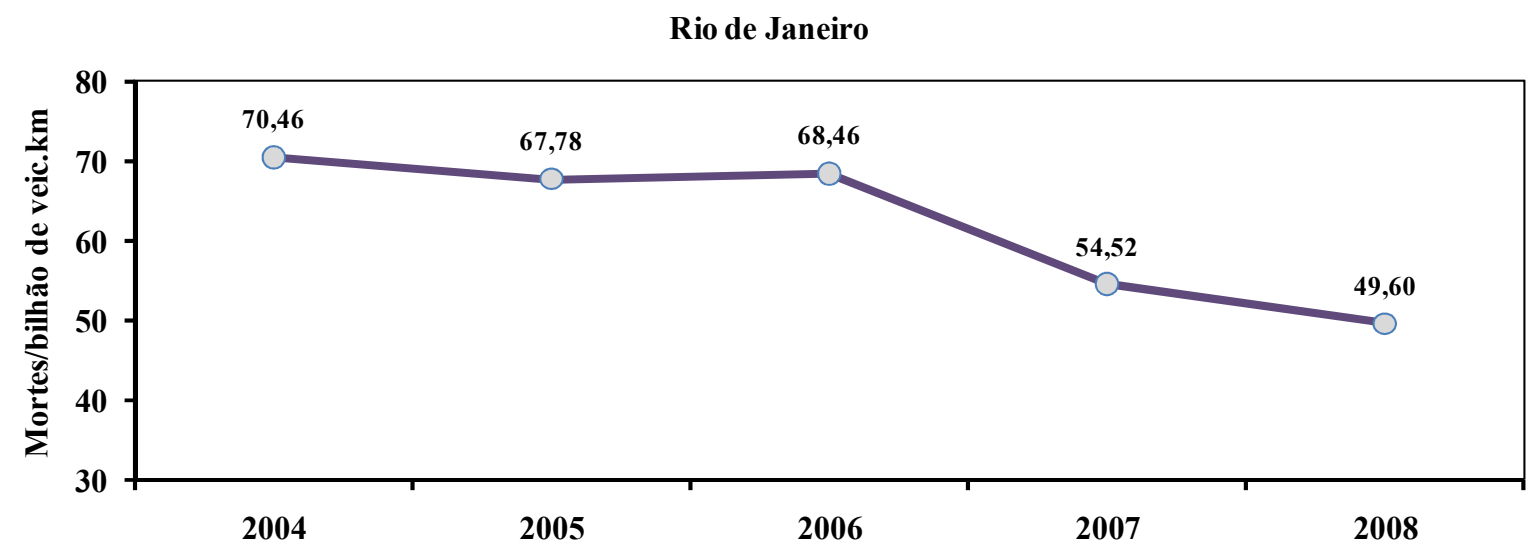

Figura 5.29- Índice de mortes por bilhão de quilômetros no Rio de Janeiro no período 2004-2008

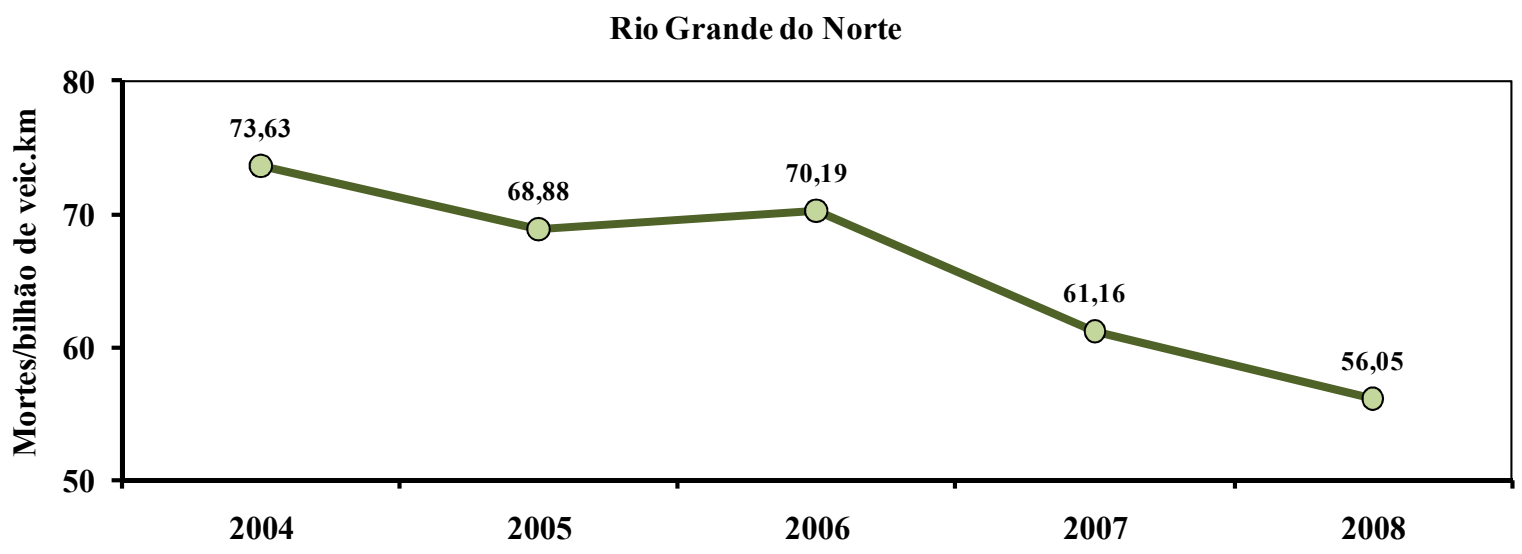

Figura 5.30- Índice de mortes por bilhão de quilômetros no Rio Grande do Norte no período 2004-2008 


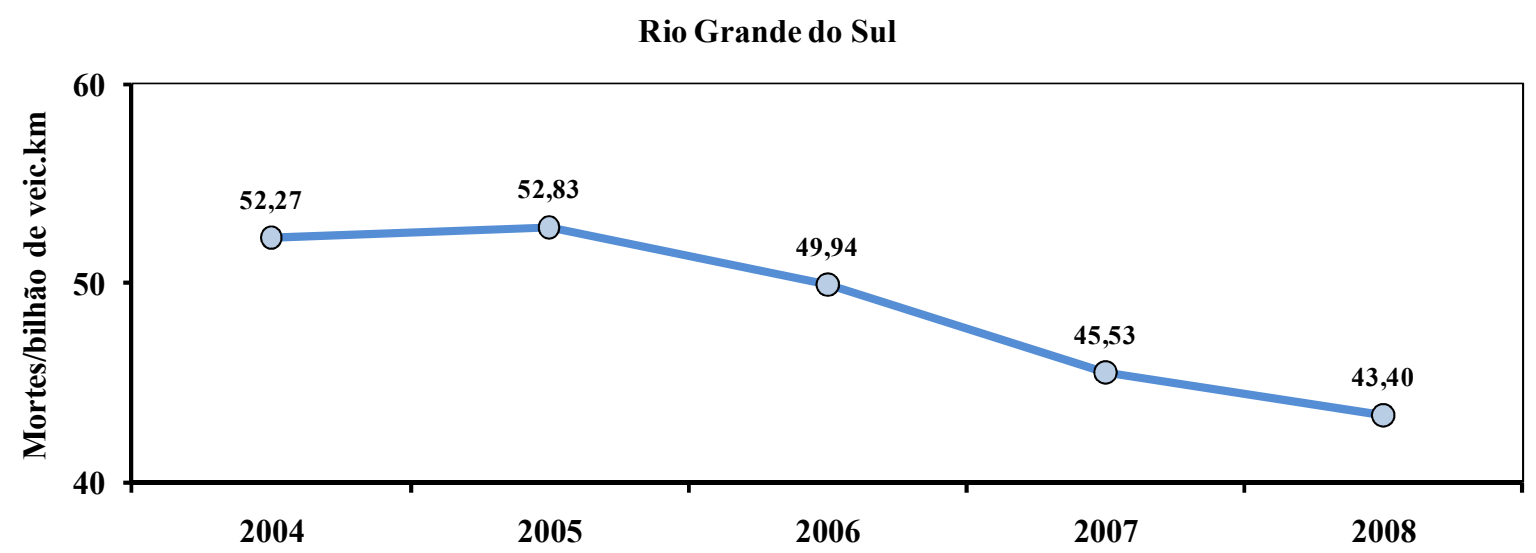

Figura 5.31- Índice de mortes por bilhão de quilômetros no Rio Grande do Sul no período 2004-2008

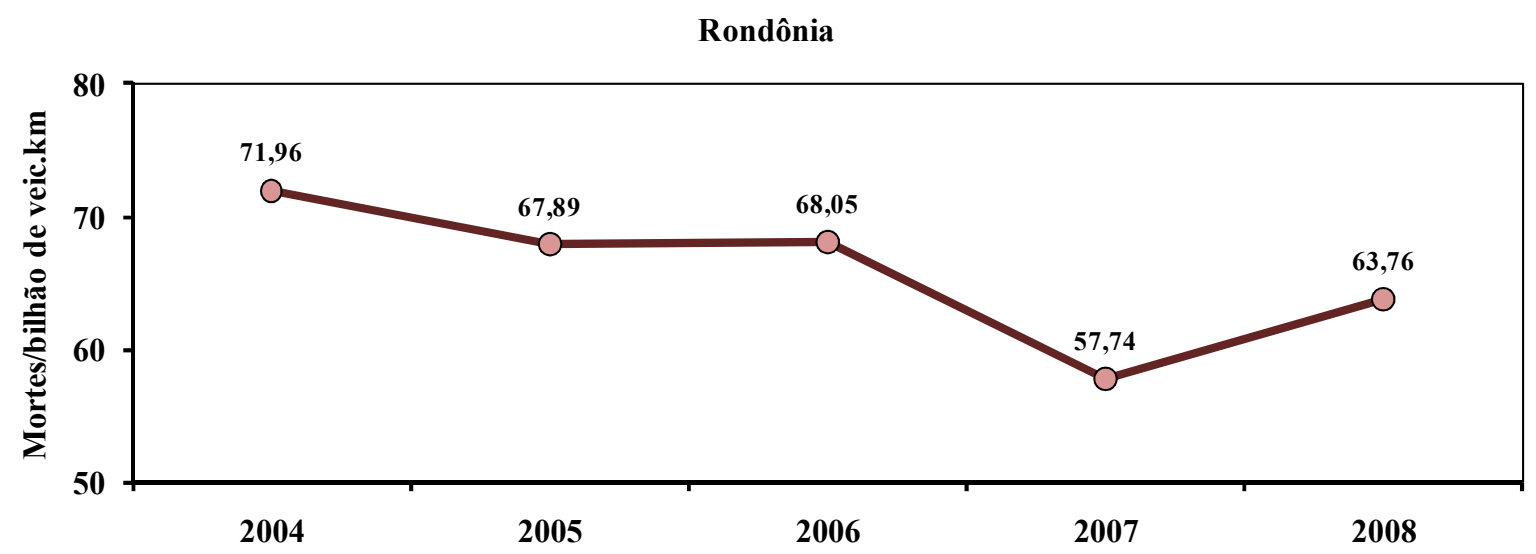

Figura 5.32- Índice de mortes por bilhão de quilômetros em Rondônia no período 2004-2008

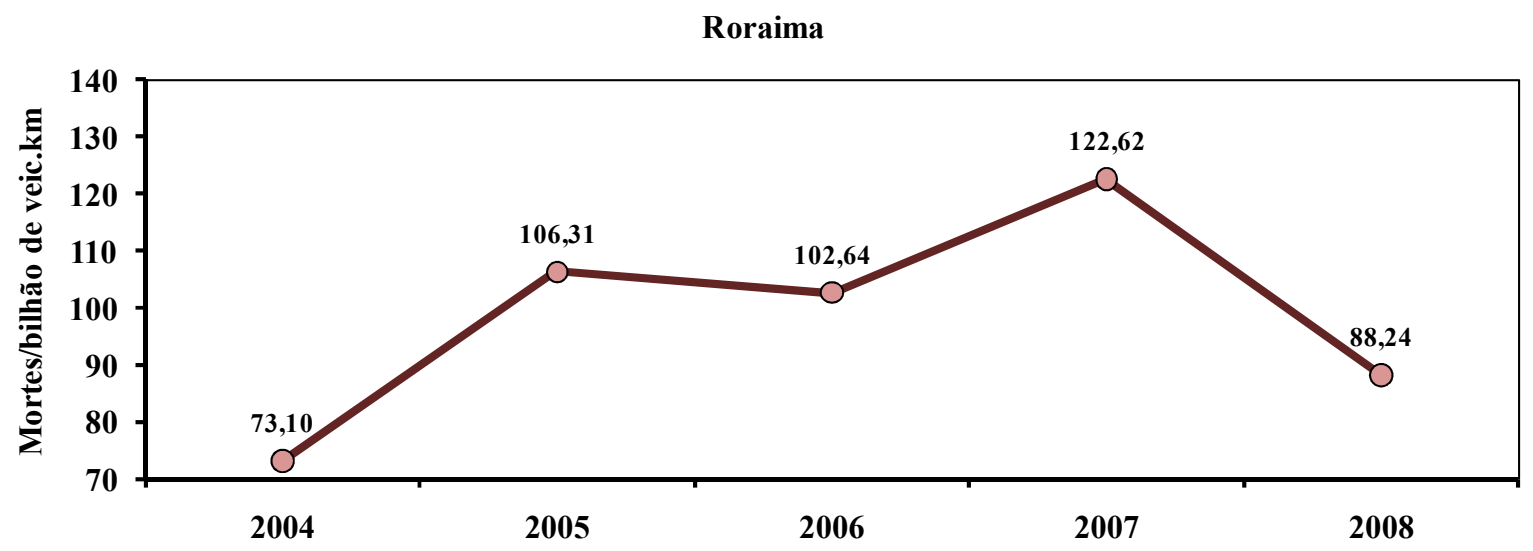

Figura 5.33- Índice de mortes por bilhão de quilômetros em Roraima no período 2004-2008 


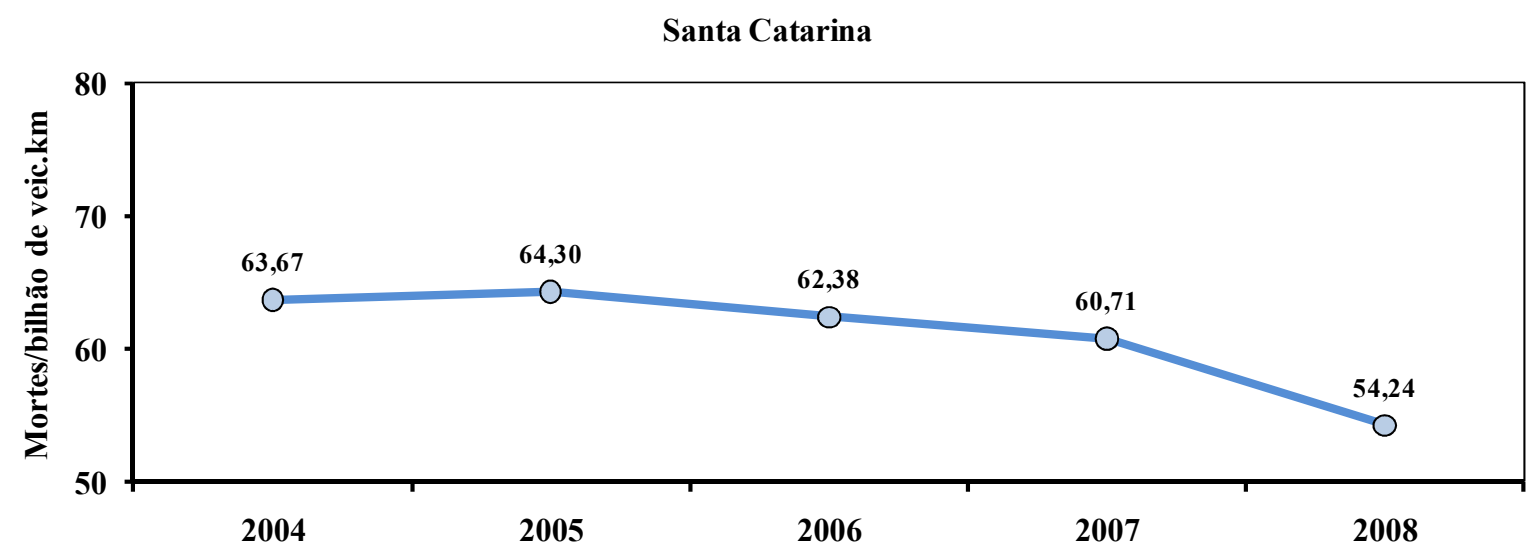

Figura 5.34- Índice de mortes por bilhão de quilômetros em Santa Catarina no período 2004-2008

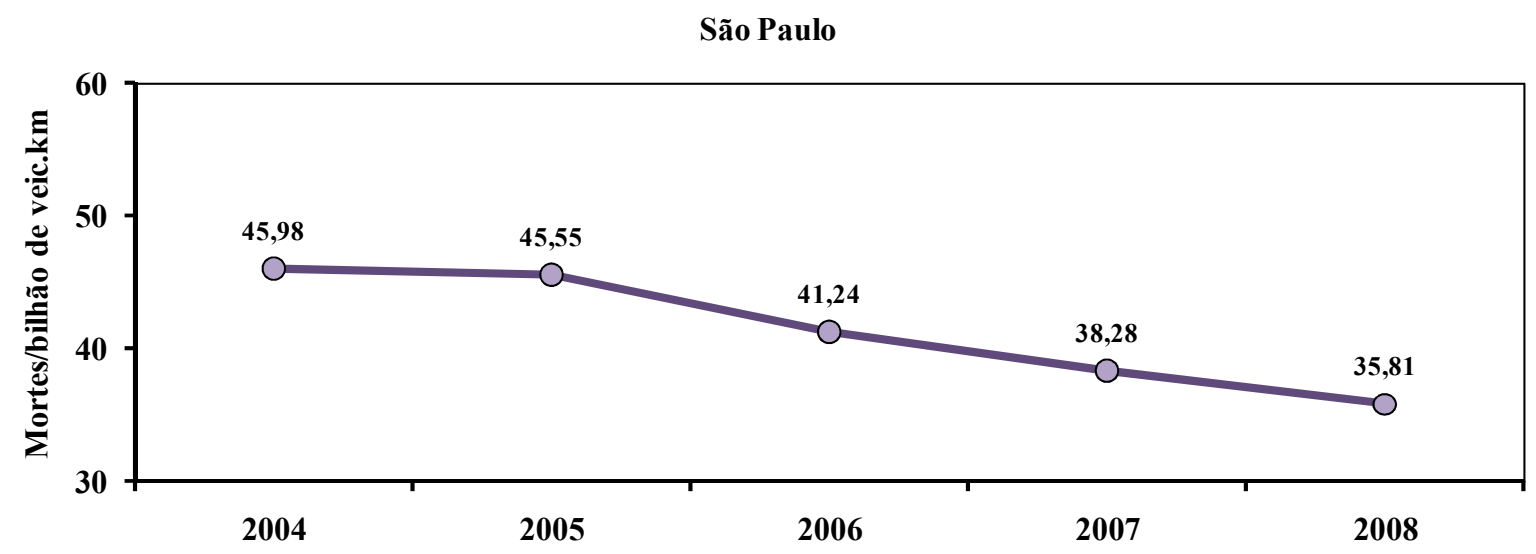

Figura 5.35- Índice de mortes por bilhão de quilômetros em São Paulo no período 2004-2008

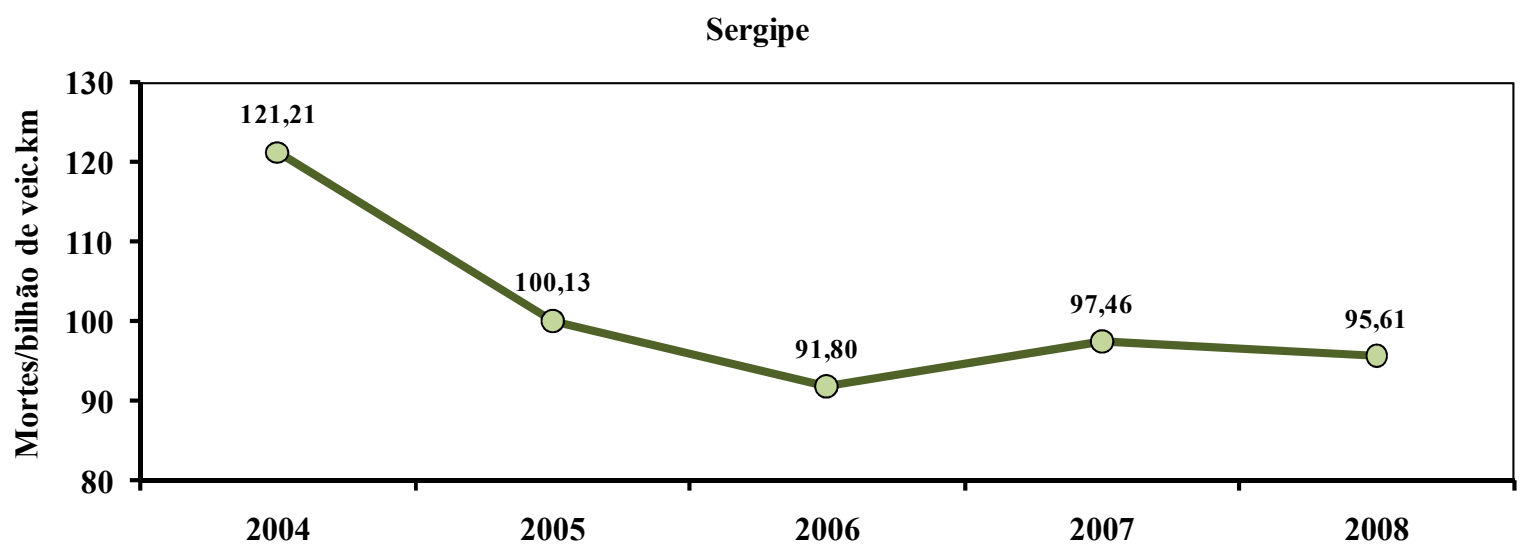

Figura 5.36- Índice de mortes por bilhão de quilômetros em Sergipe no período 2004-2008 


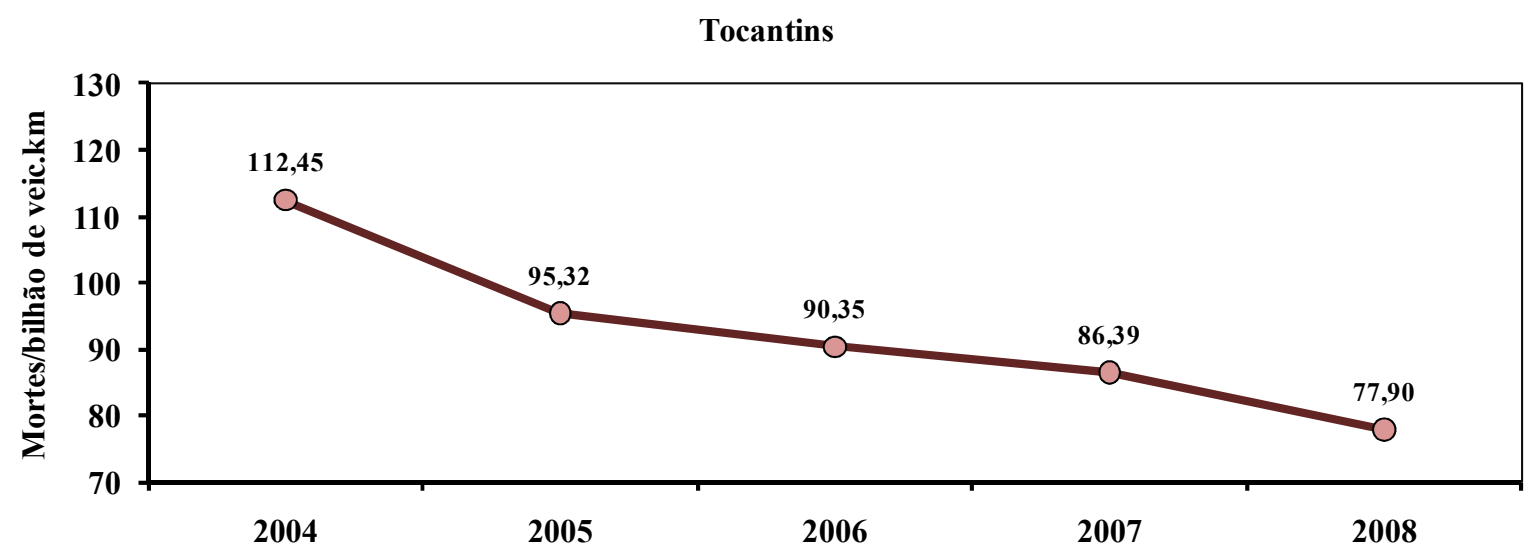

Figura 5.37- Índice de mortes por bilhão de quilômetros em Tocantins no período 2004-2008

A maioria dos estados brasileiros apresentou redução do índice de mortes por quilômetro entre 2004 e 2008, apesar de alguns apresentarem oscilações no decorrer do período.

Visando classificar os desempenhos dos estados no tocante à evolução do índice de mortes por quilômetro, foi adotada a seguinte sistemática:

- Grupo A - estados com redução do índice de mortes por quilômetro acima da média nacional de $18,15 \%$;

- Grupo B - estados com redução do índice de mortes por quilômetro abaixo da média nacional de $18,15 \%$;

- Grupo C - estados com aumento do índice de mortes por quilômetro.

Na Tabela 5.8 estão indicados os estados alocados nas categorias citadas

Tabela 5. 8 - Classificação dos estados nos Grupos A, B e C

\begin{tabular}{cc}
\hline Grupos & Estados \\
\hline A & AP, CE, TO, RJ, AM, RN, SP, PA, SE, GO, MS, PR, PE e AL \\
\hline B & RS, MG, SC, AC, DF, MT, RO, ES, PB, MA, PI e BA \\
\hline C & RR \\
\hline
\end{tabular}

Na Figura 5.38 estão identificados no mapa do país os estados pertencentes às três categorias mencionadas. 




Figura 5.38- Análise da evolução dos índices em relação à redução média nacional

\subsection{Relações entre os índices}

Na Figura 5.39 é mostrada a variação do índice de mortes por quilômetro e do índice de mortes por veículo em todos os Estados no ano de 2008.

Ainda que as linhas de tendência dos dois índices sejam semelhantes, há diferenças pontuais significativas. Isso mostra a necessidade da determinação e do emprego do índice de mortes por quilômetro (o índice mais adequado para mensurar a mortalidade no trânsito), visto que o uso do índice de mortes por veículo pode levar a sensíveis distorções na definição de quais estados devem merecer maior atenção na implementação de ações voltadas para a segurança no trânsito. 


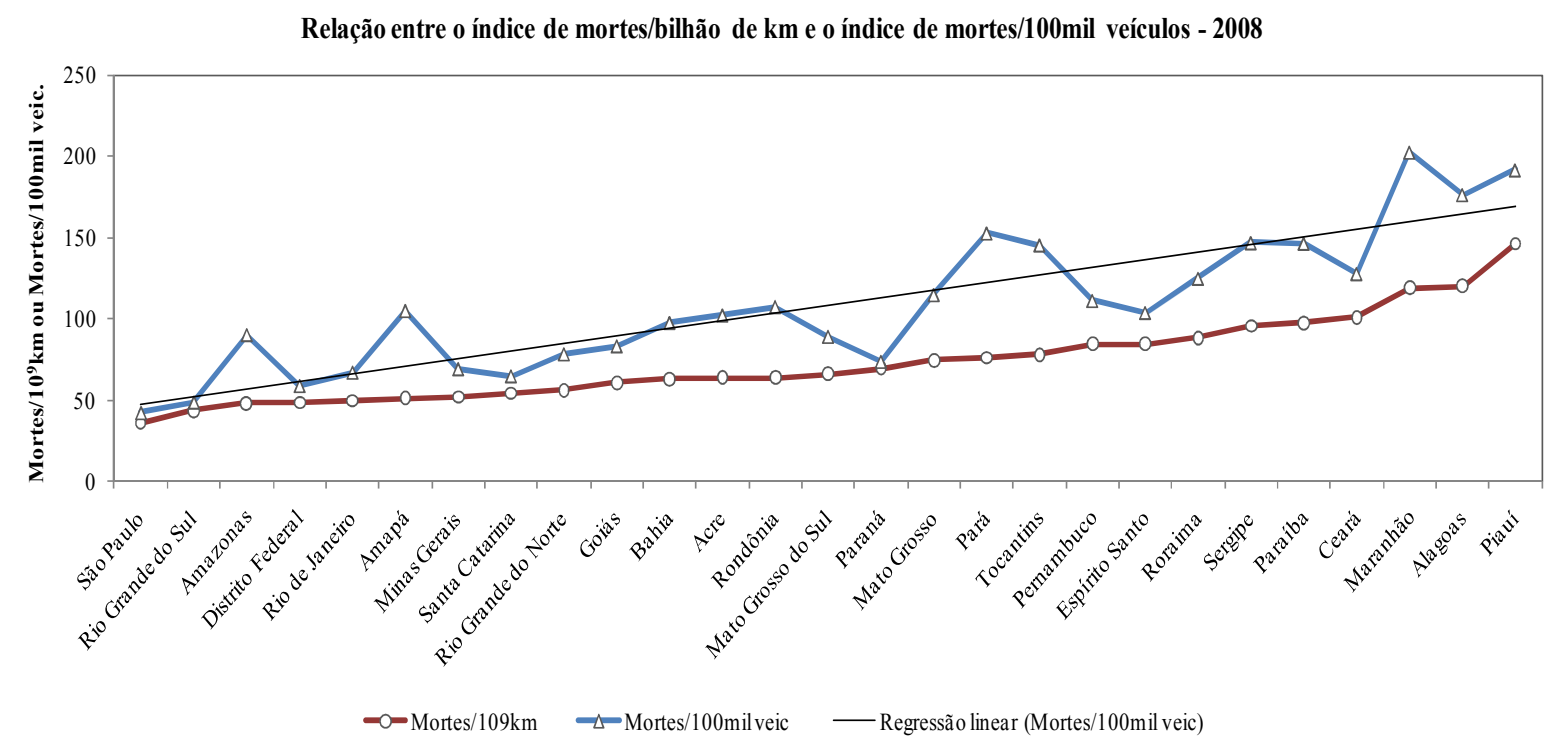

Figura 5.39 - Relação entre o índice de mortes/ bilhão de km e o índice de mortes/100 mil veículos (2008)

Na Figura 5.40 é mostrada a variação do índice de motorização e do PIB per capita por estado para o ano de 2007 (usou-se este ano pelo fato do PIB per capita nos estados ainda não estar disponível para o ano de 2008).

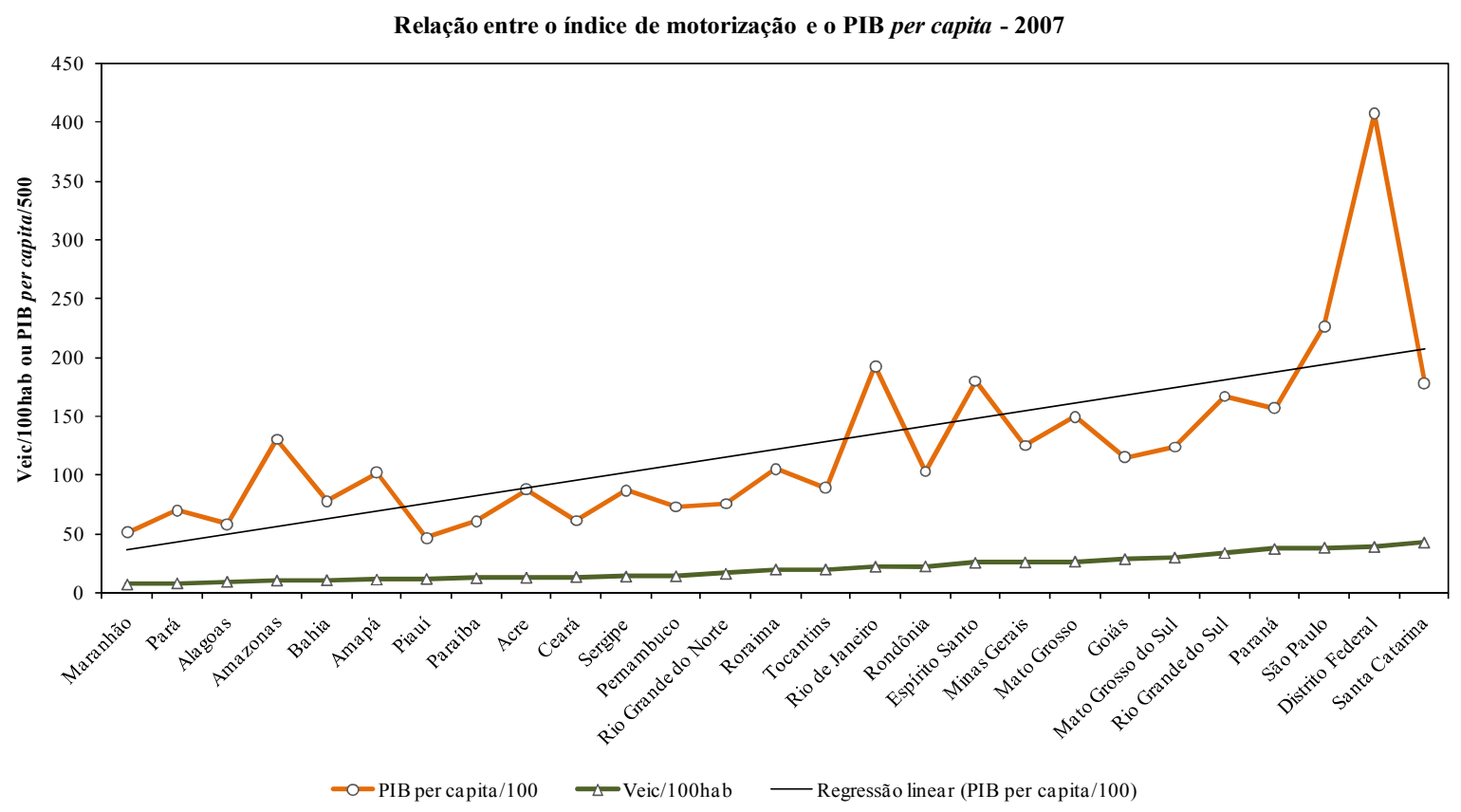

Figura 5.40 - Relação entre o índice de motorização e o PIB per capita em 2007

Como se pode observar, há uma significativa relação entre os dois índices, mostrando que a tendência é o índice de motorização acompanhar o PIB per capita dos estados. 
Nas Figuras 5.41 e 5.42 são mostradas as variações do índice de mortes por quilômetro nos vários estados e relação à variação do índice de motorização e do PIB per capita, respectivamente, para os anos de 2008 e 2007.

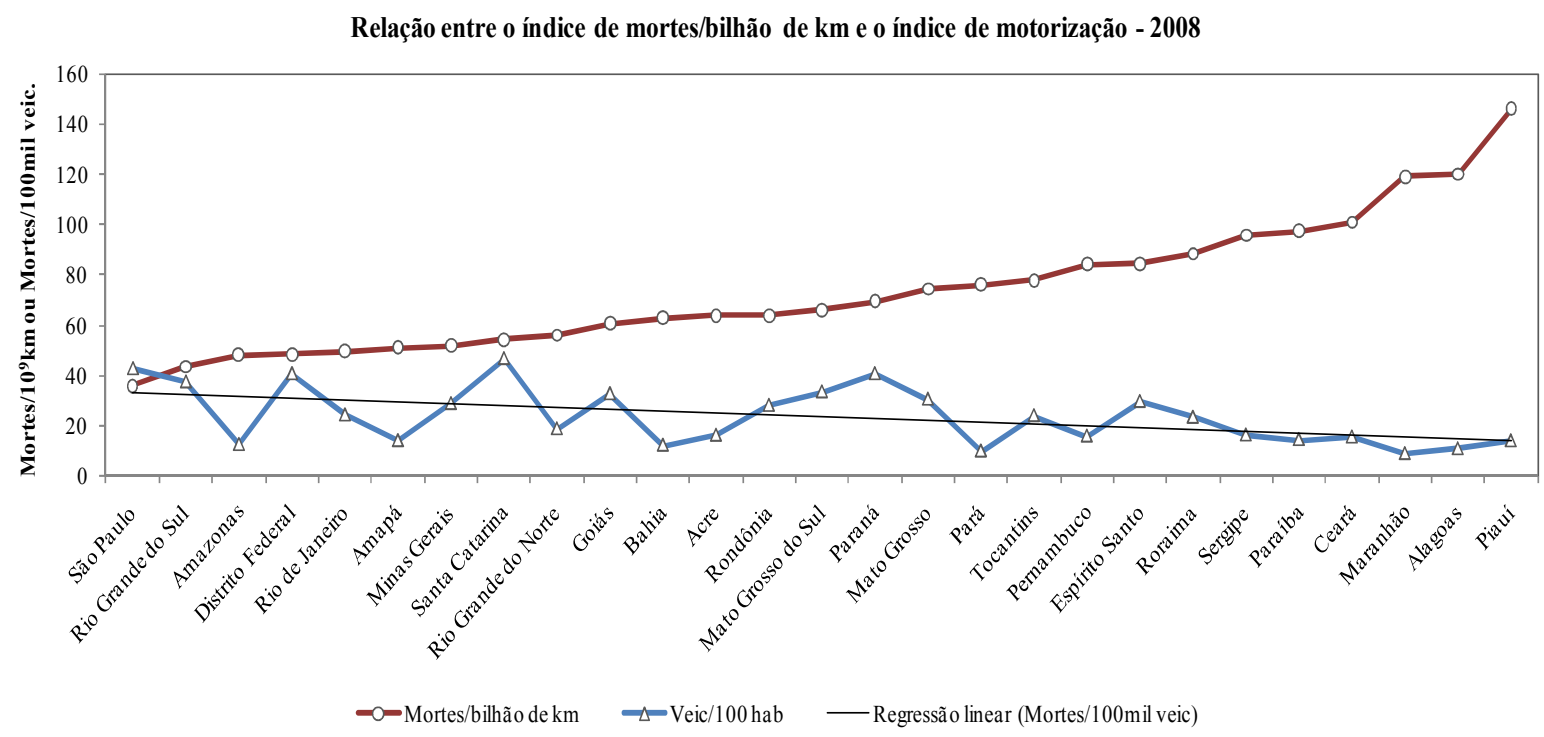

Figura 5.41 - Relação entre o índice de mortes por bilhão de quilômetros e o índice de motorização em 2008

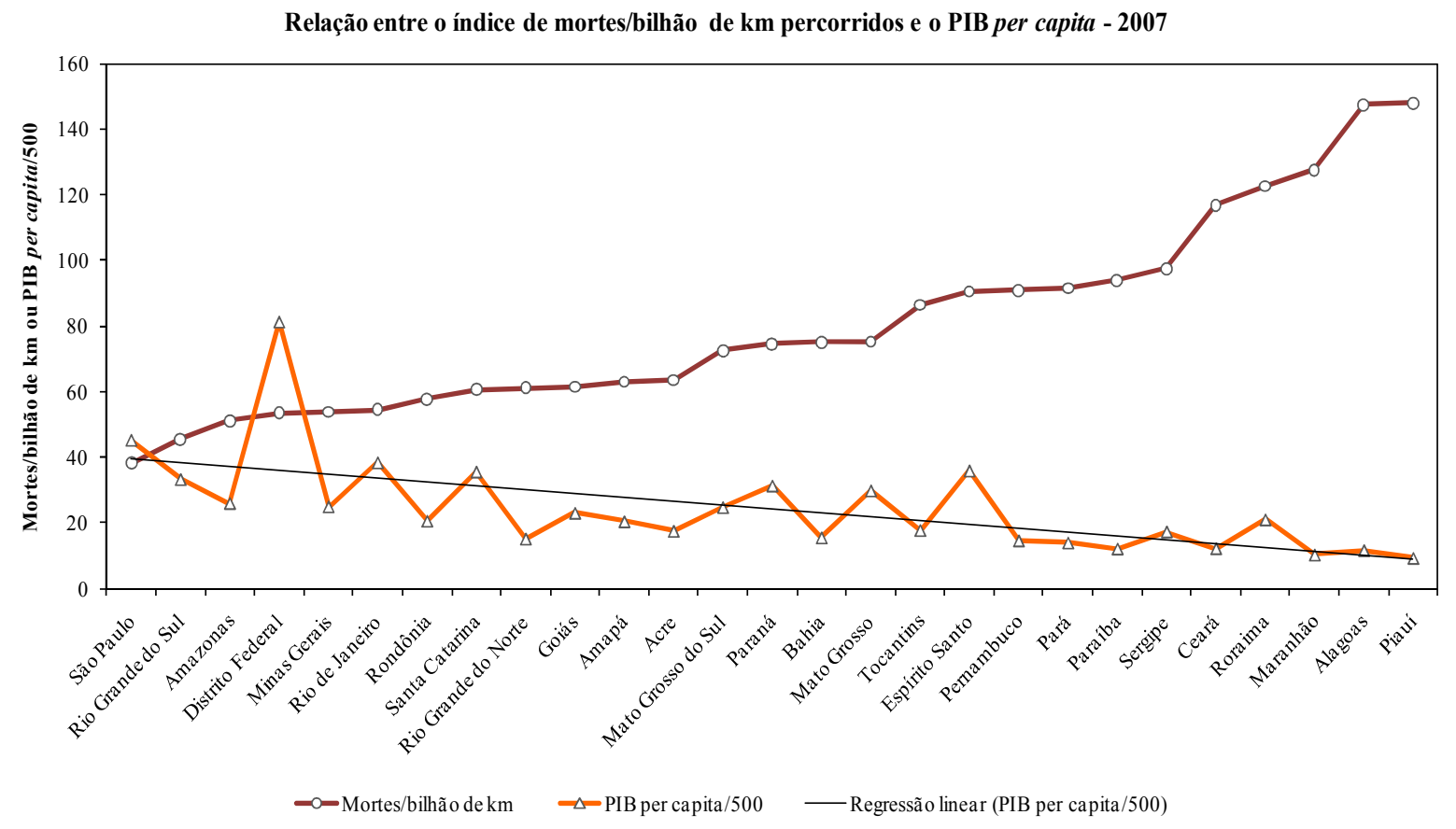

Figura 5.42 - Relação entre o índice de mortes por bilhão de quilômetros e o PIB per capita em 2007

Conforme se observa, a tendência é que nos estados mais ricos (com PIB per capita e taxa de motorização maiores) o índice de mortes por quilômetro seja menor. Esse fato evidencia a 
forte relação entre a segurança no trânsito e o nível de desenvolvimento econômico-social de um país, estado, região ou município, o que, de certa forma, remete à teoria da escala de importância das necessidades humanas propostas por Maslow - a preocupação com a segurança no trânsito aparece somente após a satisfação de necessidades mais básicas da população, como habitação, saúde, educação, mobilidade, emprego, etc..

\subsection{Comparações internacionais}

Para situar o valor estimado da quilometragem anual média percorrida no país dentro do contexto mundial, na Figura 5.43 estão indicados os valores desse parâmetro no Brasil (valor determinado neste trabalho) e em outros países onde se pode obter essa informação. Os valores referem-se ao ano de 2007.

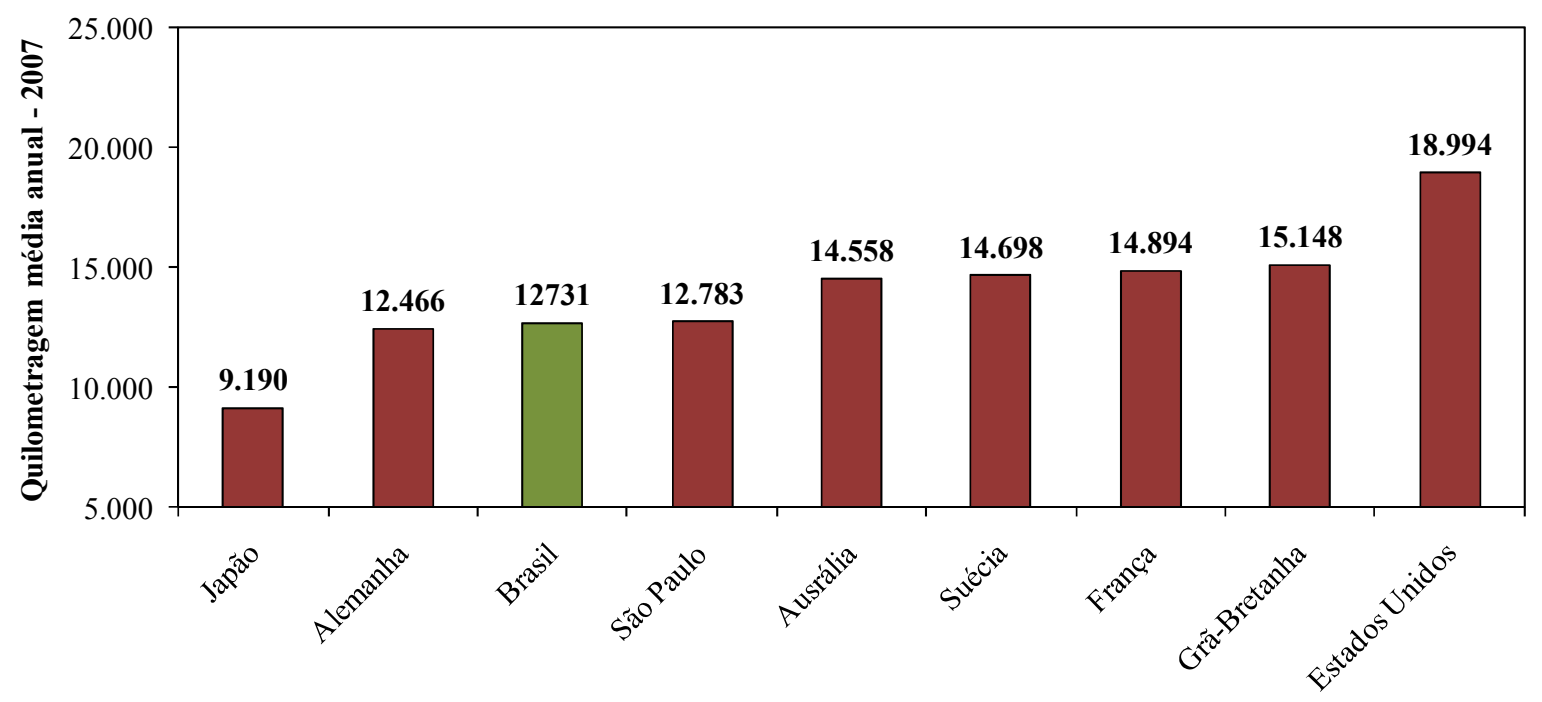

Figura 5.43- Comparação da quilometragem média anual no Brasil e em outros países em 2007 (Fonte: Department of Infrastructure, Transport, Regional Deveolpment and Local Government, 2009)

Como se pode observar, a quilometragem anual média percorrida pelo transporte rodoviário no Brasil é próxima da observada na Alemanha; maior que no Japão; menor que na Austrália, Suécia, França e Grã-Bretanha; e muito menor que nos Estados Unidos e Israel.

Na Figura 5.44 são mostrados os valores do índice de mortes por quilômetro no Brasil (valor determinado neste trabalho) e em outros países onde se pode obter essa informação. O valor 
para o Brasil é referente ao ano de 2008 e para os demais países essa informação corresponde ao ano de 2009.

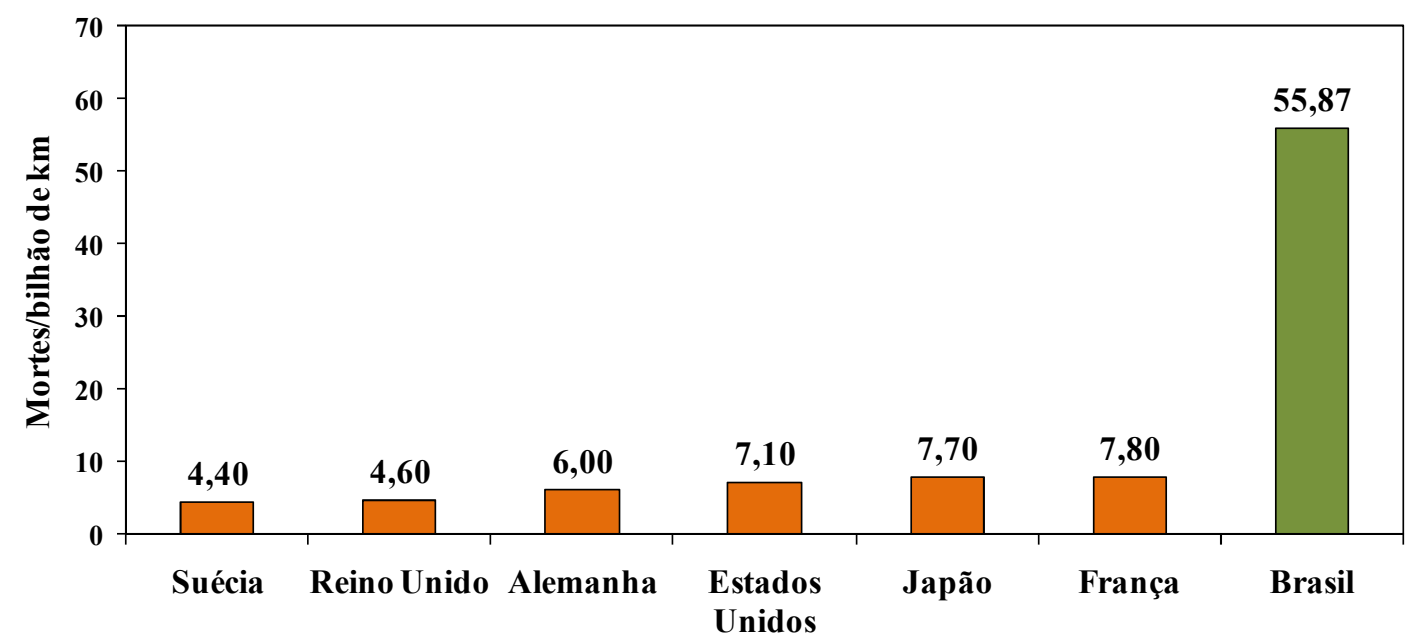

Figura 5.44- Comparação do índice de mortes por bilhão de quilômetros percorridos no Brasil (2008) e em outros países (2009). (Fonte: International Road Traffic and Accident Database - IRTAD, 2010)

Observa-se que o índice brasileiro está bastante acima do valor verificado nos países desenvolvidos, sendo:

- 12,70 vezes maior que o da Suécia;

- 12,15 vezes maior que o da Grã-Bretanha;

- 9,31 vezes maior que o da Alemanha;

- 7,87 vezes maior que o dos Estados Unidos;

- 7,26 vezes maior que o do Japão;

- 7,16 vezes maior que o da França.

Seria interessante a realização dessa comparação com valores de países com nível de desenvolvimento semelhante ao do Brasil, no entanto não se conseguiu obter essa informação por não ser calculada nesses países. 



\section{CONCLUSÕES E RECOMENDAÇÕES}

Os valores associados à mortalidade no trânsito apresentados no Capítulo 5 constituem uma fonte de informações de grande relevância na definição do nível de atenção a ser dado em cada estado do país visando à redução das mortes no trânsito. Essa análise deve ser conduzida considerando o número de mortes e o índice de mortes por quilômetro no ano de 2008 (último ano com dados disponíveis), bem como o comportamento desses valores ao longo dos últimos anos. Maior atenção deve ser dada, sobretudo, aos estados que apresentam maiores índices de mortes por quilômetro, bem como àqueles com valores crescentes desse índice no tempo.

Cabe mencionar, no entanto, que os valores do índice de mortes por quilômetro obtidos no trabalho não são, em absoluto, precisos, mas sim aproximações da realidade. A limitação das informações necessárias e a própria natureza da determinação da quilometragem percorrida por meio do consumo de combustível exigiram a adoção de uma série de hipóteses para se chegar aos valores encontrados - os quais, contudo, têm confiabilidade suficiente para serem usados na prática.

A ausência de informações detalhadas sobre o consumo de óleo diesel nos setores ferroviário e principalmente no hidroviário pode ter prejudicado o cálculo da quilometragem e, em consequência, do índice de mortes por quilômetro, em especial nos estados onde essas atividades são mais intensas. Nesse caso estão a Região Amazônica (com forte atividade hidroviária em relação ao restante do país) e os estados de São Paulo e Minas Gerais (com forte atividade ferroviária se comparados com os demais estados). Todavia, em razão do tamanho da frota ser menor nos estados abrangidos pela Região Amazônica, há indícios do viés contido nas estimativas ser maior na Região Norte.

Outro aspecto que pode ter prejudicado a análise é o desconhecimento da distribuição das frotas estaduais e veículos por tipo de combustível. Em razão disso, recomenda-se, que essas informações sejam mais desagregadas, de modo a permitir a consideração as características da frota de cada unidade da federação.

O índice de mortes por veículo-quilômetro apresentou reduções anuais contínuas no Brasil dentro do período considerado. Tal declínio deve ser atribuído ao aumento da quilometragem 
percorrida (consequência do aumento da frota e do crescimento econômico) e a certa estabilização do número de mortes - provavelmente em decorrência de ações implementadas pelo governo federal com alcance nacional e, também, de ações específicas, com objetivo de redução da acidentalidade viária levadas a efeito em alguns estados.

Por último, cabe dizer da extrema relevância da realização de estudos futuros visando aprimorar a estimativa dos valores do índice de mortes por quilômetro nos estados e no país, por se tratar, efetivamente, do parâmetro considerado o mais adequado para mensurar a mortalidade no trânsito. Tais estudos devem apresentar o índice de mortes em função da distância percorrida em cada modo de transporte, o que auxilia no planejamento de ações mais específicas de redução da acidentalidade. 


\section{REFERÊNCIAS BIBLIOGRÁFICAS}

ASSOCIAÇÃO NACIONAL DOS FABRICANTES DE VEÍCULOS AUTOMOTORES E SINDICATO NACIONAL DA INDÚSTRIA DE COMPONENTES PARA VEÍCULOS AUTOMOTORES. Frota circulante de veículos no período 2004-2009. São Paulo, 2009. Planilha cedida ao autor.

AUTOESPORTE. Ranking Autoesporte: consumo médio. Disponível em: <http:// revist aautoesporte.globo.com/Revista/Autoesporte/0ERT29754-10142,00.html>. Acesso em: 13 maio 2010.

AZUAGA, Denise. Danos ambientais causados por veículos leves no Brasil. 2000. 193 f. Dissertação (Mestre em Ciências em Planejamento Energético) - Universidade Federal do Rio de Janeiro, Rio de Janeiro, 2000.

BORBA, Bruno Soares Moreira Cesar. Metodologia de regionalização do mercado de combustíveis automotivos no Brasil. 2008. 136 f. Dissertação (Mestre em Ciências em Planejamento Energético) Universidade Federal do Rio de Janeiro, Rio de Janeiro, 2008.

BRASIL. Ministério da Ciência e Tecnologia. Secretaria de Políticas Eprogramas de Pesquisa e Desenvolvimento Coordenação Geral de Mudanças Globais de Clima. Emissões de gases de efeito estufa por fontes móveis no setor enegético. Brasília, 2006.

BRASIL. Ministério das Cidades. Departamento Nacional de Trânsito - Denatran. Frota de veículos no período 2004-2008. Disponível em: <http://www.denatran.gov.br/frota.htm>. Acesso em: 5 jan. 2010.

BRASIL. Ministério de Minas e Energia. Agência Nacional do Petróleo Gás Natural e Biocombustíveis. O mercado e a qualidade dos combustíveis automotivos. Brasília, 2004.

BRASIL. Ministério de Minas e Energia. Agência Nacional do Petróleo Gás Natural e Biocombustíveis. Balanço Energético Nacional: Ano base 2008. Brasília, 2009.

BRASIL. Ministério de Minas e Energia. Agência Nacional do Petróleo Gás Natural e Biocombustíveis. Estatísticas de vendas de combustíveis pelas distribuidoras no período 20042008. Disponível em: <http://www.anp.gov.br/?pg=23307\&m=\&t1 $=\& \mathrm{t} 2=\& \mathrm{t} 3=\& \mathrm{t} 4=\& \mathrm{ar}=\& \mathrm{ps}=\&$ cachebust $=1276622345913>$. Acesso em: 30 out. 2010.

BRASIL. Ministério de Minas e Energia. Conpet - Programa Nacional de Racionalização do Uso Dos Derivados do Petróleo e do Gás Natural. Programa Brasileiro de Etiquetagem Veicular. Brasília, 2010. 
BRASIL. Ministério da Saúde. Sistema de Informações de Mortes - Datasus. Mortes por causas externas no período 2004-2008. Disponível em: <http://tabnet.datasus.gov.br/cgi/tabcgi.exe? sim/cnv/extsp.def $>$. Acesso em: 15 mar. 2010.

BRASIL. Ministério do Meio Ambiente (Org.). $1^{0}$ Inventário nacional de emissões atmosféricas por veículos automotores rodoviários: Sumário executivo. Brasília, 2010.

BRASIL. Ministério do Planejamento Orçamento e Gestão. Instituto Brasileiro de Geografia e Estatística - Ibge. Contagens da população no período 2004-2008. Disponível em: $<$ http://www.ibge.gov.br/servidor_arquivos_est/>. Acesso em: 15 dez. 2009.

BRASIL. Ministério Dos Transportes. Agência Nacional Dos Transportes Terrestres. Anuário Estatístico dos Transportes Terrestres - 2009. Brasília, 2009.

CARDOSO, João Lourenço. The use of international data on fuel sales and vehicle fleet for the estimation of yearly national traffic volumes. Accident Analysis And Prevention, Estados Unidos, n. 37, p.207-215, 2005.

DEPARTMENT OF INFRASTRUCTURE, TRANSPORT, REGIONAL DEVELOPMENT AND LOCAL GOVERNMENT (Org.). International road safety comparisons . Camberra, 2009. 19 p. Disponível em: <http://infrastructure.gov.au/roads/safety/publications/publications_list.aspx?sort=type \&meth $=$ ASC\&mode=Road $>$. Acesso em: 20 out. 2010.

ELVIK, Rune et al. The handbook of road safety measures. 2. ed. Bingley: Emerald, 2009. 1124 p.

ELVIK, Rune. Laws of accident causation. Accident Analysis And Prevention, Estados Unidos, v. 38, n. , p.747-752, 2006.

ELVIK, Rune; ERKE, Alena; CHRISTENSEN, Peter. Elementary units of exposure. Transportation Research Record, Washington, n. 2103, p.25-31, 2009.

EVANS, Leonard. Traffic Safety. Bloomfield: Science Serving Society, 2004. 444 p.

FERRAZ, Antonio Clóvis Pinto; RAIA JUNIOR, Archimedes; BEZERRA, Bárbara Stolte. Segurança no Trânsito. São Carlos: Grupo Gráfico São Francisco, 2008. 280 p.

FRIDSTROM, Lasse et al. Measuring the contribution of randomness, exposure, weather, and daylight to the variation in road accident counts. Accident Analysis And Prevention, Estados Unidos, v. 27, n. 1, p.1-20, 1995.

GASNET. Entendendo o GNV. Disponível em: <http://www.gasnet.com.br/novo_gnv/entendendo_ gnv.asp>. Acesso em: 22 jun. 2010. 
GOLOB, Thomas F.; RECKER, Wilfred W.; ALVAREZ, Veronica M.. Freeway safety as a function of traffic flow. Accident Analysis And Prevention, Estados Unidos, n. 36, p.933-946, 2003.

HAUER, Ezra. Observational before-after studies in road safety: estimating the effect of highway and traffic engineering measures on road safety. Reino Unido: Elsevier Science, 1997. 289 p.

HERMANS, Elke; WETS, Geert; BOSSCHE, Filip Van Den. Describing the evolution in the number of highway deaths by decomposition in exposure, accident risk, and fatality risk. Transportation Research Record, Washington, n. 3590, p.1-8, 2006.

INFOPETRO, Provedor de Informações e Análise Econômica do Setor de Petróleo e Gás -. Frota brasileira de veículos leves: difusão dos flexíveis e do GNV. Disponível em: $<$ http://infopetro.wprdpress.com/2010/04/19/frota-brasileira-de-veiculos-leves-difusao-dos-flexiveis-edo-gnv>. Acesso em: 30 abr. 2010.

INTERNATIONAL ROAD TRAFFIC AND ACCIDENT DATABASE - IRTAD (Org.). IRTAD Road Safety 2010: annual report. 2010. 320 p. Disponível em: < http://www.international transportforum.org/irtad/pdf/10IrtadReport.pdf $>$. Acesso em: 5 jan. 2011.

LEDUC, Guillaume. Road traffic data: collection, methods and applications. Espanha: Jrc Technical Notes, 2008. 14 p.

MENSAH, Abraham; HAUER, Ezra. Two problems of averaging arising in the estimation of the relationship between accidents and traffic flow. Transportation Research Record, Washington, $\mathrm{n}$. 1635, p.37-43, 1998.

MOTOESPORTE. Testes de motos. Disponível em: <http://www.motoesporte.com.br /teste.htm>. Acesso em: 1 maio 2010.

ORGANIZAÇÃO MUNDIAL DA SAÚDE (Org.). Informe sobre la situación mundial de la seguridad vial: es hora de pasar a la acción. Genebra, 2009. 227 p. Disponível em: $<$ http://www.who.int/violence_injury_prevention/road_safety_status/2009>. Acesso em: 29 jan. 2010.

PETROBRAS. Gasnet. Vendas de gás natural veicular no período 2004-2008. Disponível em: $<$ http://www.gasnet.com.br/conteudos.asp?tipo=Vendas\&categoria=2\#>. Acesso em: 5 jun. 2010.

PIGNATARO, Louis J. Traffic Engineering: theory and practice. Englewood Clifs: Prentice Hall, 1973. $502 \mathrm{p}$.

SCHAEFFER, Roberto; SZKLO, Alexandre Salem. Matriz energética de Minas Gerais 2007-2030. Brasil: Ppe/Coppe/Ufrj, 2007. 
SEGALLA, Deise Barboza Schiavon. Estudo da frota circulante brasileira. Sindicato Nacional da Indústria de Componentes para Veículos AutomotoresSINDIPEÇAS. Disponível em: <www.sindipecas.org.br/banco_de_imagens/.../FrotaCirculante\%202006.pdf $>$. Acesso em: 30 abr. 2010.

THAGESEN, Bent (Org.). Highway and traffic engineering in developing countries. 485. ed. Grãbretanha: E \& Fn Spon, 1996.

THOMAS, Pete. State of the art report on risk and exposure data. Atenas: National Technical University Of Athens, 2005.

VIEIRA, Heitor. Avaliação de medidas de contenção de acidentes: uma abordagem multidisciplinas. 1999. 1 v. Tese (Doutor em Engenharia de Produção: Ênfase Transportes) Universidade Federal de Santa Catarina, Florianópolis, 1999.

VIEIRA, Heitor et al. A expansão do uso de motocicletas em cenários do Sul do Brasil: uma abordagem analítico retrospectiva. In: CONGRESSO DE PESQUISA E ENSINO EM TRANSPORTES, VIEIRA, Heitor et al. A expansão do uso de motocicletas em cenários do Sul do Brasil: uma abordagem analítico retrospectiva. Anais do XXII ANPET. Fortaleza: Anpet, 2008. p. $964-974$.

WORLD BUSINESS COUNCIL FOR SUSTAINABLE DEVELOPMENT. Mobilidade 2030: Relatório completo. Genebra, 2004. 


\section{APÊNDICE A}

Tabela A.1 - Frota de veículos motorizados por categoria segundo o DENATRAN em 2004

\begin{tabular}{|c|c|c|c|c|c|}
\hline $\begin{array}{c}\text { Grandes Regiões e } \\
\text { Unidades da } \\
\text { Federação }\end{array}$ & Total & $\begin{array}{l}\text { Veículo } \\
\text { leve }\end{array}$ & Motocicleta & Caminhão & Ônibus \\
\hline Brasil & 38.270 .628 & 28.853.746 & 7.039 .675 & 1.883.234 & 493.973 \\
\hline Norte & 1.302 .269 & 719.133 & 484.984 & 78.050 & 20.102 \\
\hline Acre & 64.655 & 35.371 & 25.368 & 3.430 & 486 \\
\hline Amapá & 48.437 & 31.994 & 13.576 & 2.287 & 580 \\
\hline Amazonas & 265.606 & 188.115 & 60.554 & 11.627 & 5.310 \\
\hline Pará & 433.383 & 249.072 & 148.643 & 27.221 & 8.447 \\
\hline Rondônia & 259.473 & 105.005 & 134.596 & 17.417 & 2.455 \\
\hline Roraima & 58.557 & 29.255 & 26.302 & 2.497 & 503 \\
\hline Tocantins & 172.158 & 80.321 & 75.945 & 13.571 & 2.321 \\
\hline Nordeste & 4.746 .822 & 3.033.725 & 1.393 .037 & 242.551 & 77.509 \\
\hline Alagoas & 230.119 & 154.548 & 58.000 & 12.369 & 5.202 \\
\hline Bahia & 1.153 .051 & 796.451 & 267.706 & 64.093 & 24.801 \\
\hline Ceará & 880.375 & 522.359 & 308.695 & 38.418 & 10.903 \\
\hline Maranhão & 314.130 & 159.672 & 134.346 & 15.137 & 4.975 \\
\hline Paraíba & 346.547 & 226.760 & 98.599 & 16.849 & 4.339 \\
\hline Pernambuco & 967.664 & 662.302 & 238.102 & 53.058 & 14.202 \\
\hline Piauí & 262.676 & 134.493 & 111.785 & 13.020 & 3.378 \\
\hline $\begin{array}{c}\text { Rio Grande do } \\
\text { Norte }\end{array}$ & 367.274 & 231.609 & 113.548 & 16.828 & 5.289 \\
\hline Sergipe & 224.986 & 145.531 & 62.256 & 12.779 & 4.420 \\
\hline Sudeste & 20.774.891 & 16.611.992 & 3.009 .666 & 879.469 & 273.764 \\
\hline Espírito Santo & 672.446 & 467.558 & 146.137 & 46.967 & 11.784 \\
\hline Minas Gerais & 4.031 .451 & 2.962 .631 & 800.260 & 214.311 & 54.249 \\
\hline Rio de Janeiro & 3.002 .624 & 2.576 .887 & 280.936 & 95.318 & 49.483 \\
\hline São Paulo & 13.068 .370 & 10.604 .916 & 1.782 .333 & 522.873 & 158.248 \\
\hline Sul & 8.272 .269 & 6.269 .760 & 1.407 .487 & 508.514 & 86.508 \\
\hline Paraná & 3.118 .501 & 2.383 .200 & 490.001 & 213.480 & 31.820 \\
\hline Rio Grande do Sul & 3.161 .333 & 2.442 .032 & 506.334 & 176.215 & 36.752 \\
\hline Santa Catarina & 1.992 .435 & 1.444 .528 & 411.152 & 118.819 & 17.936 \\
\hline Centro-Oeste & 3.174.377 & 2.219 .136 & 744.501 & 174.650 & 36.090 \\
\hline Distrito Federal & 764.274 & 678.815 & 57.990 & 16.398 & 11.071 \\
\hline Goiás & 1.280 .968 & 856.382 & 337.225 & 73.356 & 14.005 \\
\hline Mato Grosso & 581.692 & 317.573 & 210.011 & 48.207 & 5.901 \\
\hline Mato Grosso do Sul & 547.443 & 366.366 & 139.275 & 36.689 & 5.113 \\
\hline
\end{tabular}


Tabela A.2 - Frota de veículos motorizados por categoria segundo o DENATRAN em 2005

\begin{tabular}{|c|c|c|c|c|c|}
\hline $\begin{array}{l}\text { Grandes Regiões e } \\
\text { Unidades da } \\
\text { Federação }\end{array}$ & Total & $\begin{array}{l}\text { Veículo } \\
\text { leve }\end{array}$ & Motocicleta & Caminhão & Ônibus \\
\hline Brasil & 41.035.121 & 30.478 .252 & 8.070 .148 & 1.967 .088 & 519.633 \\
\hline Norte & 1.469 .912 & 790.757 & 572.120 & 85.001 & 22.034 \\
\hline Acre & 72.086 & 38.532 & 29.435 & 3.595 & 524 \\
\hline Amapá & 56.015 & 35.170 & 17.803 & 2.414 & 628 \\
\hline Amazonas & 299.721 & 207.422 & 73.575 & 12.831 & 5.893 \\
\hline Pará & 487.780 & 266.999 & 181.653 & 29.992 & 9.136 \\
\hline Rondônia & 288.956 & 114.889 & 152.750 & 18.627 & 2.690 \\
\hline Roraima & 63.763 & 31.234 & 29.349 & 2.596 & 584 \\
\hline Tocantins & 201.591 & 96.511 & 87.555 & 14.946 & 2.579 \\
\hline Nordeste & 5.177 .562 & 3.233.288 & 1.605 .765 & 255.096 & 83.413 \\
\hline Alagoas & 249.606 & 164.994 & 66.017 & 12.799 & 5.796 \\
\hline Bahia & 1.268 .702 & 857.833 & 315.259 & 68.146 & 27.464 \\
\hline Ceará & 950.233 & 551.421 & 347.286 & 39.992 & 11.534 \\
\hline Maranhão & 358.135 & .780 & 162.926 & 16 & 5.309 \\
\hline Paraíba & 376.059 & 240.975 & 113.199 & 17.332 & 4.553 \\
\hline Pernambuco & 1.036 .195 & 696.683 & 269.122 & 55.813 & 14.577 \\
\hline Piauí & 292.702 & 143.533 & 131.845 & 13.694 & 3.630 \\
\hline $\begin{array}{l}\text { Rio Grande do } \\
\text { Norte }\end{array}$ & 403.790 & 250.190 & 129.933 & 17.945 & 5.722 \\
\hline Sergipe & 242.140 & 153.879 & 70.178 & 13.255 & 4.828 \\
\hline Sudeste & 22.065.437 & 17.444.327 & 3.422.204 & 914.173 & 284.733 \\
\hline Espírito Santo & 731.384 & 504.398 & 164.294 & 50.059 & 12.633 \\
\hline Minas Gerais & 4.320 .622 & 3.130 .585 & 906.804 & 224.950 & 58.283 \\
\hline Rio de Janeiro & 3.152 .302 & 2.684 .845 & 319.078 & 97.576 & 50.803 \\
\hline São Paulo & 13.861 .129 & 11.124 .499 & 2.032 .028 & 541.588 & 163.014 \\
\hline Sul & 8.884.092 & 6.643 .496 & 1.618 .933 & 530.514 & 91.149 \\
\hline Paraná & 3.366 .148 & 2.539 .098 & 569.857 & 223.449 & 33.744 \\
\hline Rio Grande do Sul & 3.343 .251 & 2.551 .233 & 572.040 & 181.518 & 38.460 \\
\hline Santa Catarina & 2.174 .693 & 1.553 .165 & 477.036 & 125.547 & 18.945 \\
\hline Centro-Oeste & 3.438.118 & 2.366.384 & 851.126 & 182.304 & 38.304 \\
\hline Distrito Federal & 810.583 & 717.721 & 64.857 & 16.706 & 11.299 \\
\hline Goiás & 1.388 .620 & 915.652 & 381.700 & 76.218 & 15.050 \\
\hline Mato Grosso & 644.623 & 344.412 & 242.501 & 51.379 & 6.331 \\
\hline Mato Grosso do Sul & 594.292 & 388.599 & 162.068 & 38.001 & 5.624 \\
\hline
\end{tabular}


Tabela A.3 - Frota de veículos motorizados por categoria segundo o DENATRAN em 2006

\begin{tabular}{|c|c|c|c|c|c|}
\hline $\begin{array}{c}\text { Grandes Regiões e } \\
\text { Unidades da } \\
\text { Federação }\end{array}$ & Total & $\begin{array}{l}\text { Veículo } \\
\text { leve }\end{array}$ & Motocicleta & Caminhão & Ônibus \\
\hline Brasil & 44.268 .278 & 32.307.348 & 9.360 .696 & 2.048.258 & 551.976 \\
\hline Norte & 1.659 .231 & 881.189 & 662.383 & 91.329 & 24.330 \\
\hline Acre & 81.508 & 42.439 & 34.633 & 3.875 & 561 \\
\hline Amapá & 64.963 & 40.429 & 21.275 & 2.605 & 654 \\
\hline Amazonas & 333.198 & 229.076 & 83.521 & 13.907 & 6.694 \\
\hline Pará & 543.272 & 288.080 & 213.078 & 32.178 & 9.936 \\
\hline Rondônia & 320.426 & 126.473 & 171.567 & 19.537 & 2.849 \\
\hline Roraima & 71.271 & 33.694 & 34.255 & 2.675 & 647 \\
\hline Tocantins & 244.593 & 120.998 & 104.054 & 16.552 & 2.989 \\
\hline Nordeste & 5.705 .166 & 3.476 .345 & 1.869 .676 & 268.420 & 90.725 \\
\hline Alagoas & 272.474 & 177.668 & 75.133 & 13.366 & 6.307 \\
\hline Bahia & 1.399 .112 & 927.065 & 370.193 & 72.162 & 29.692 \\
\hline Ceará & 1.042 .449 & 587.097 & 401.103 & 41.870 & 12.379 \\
\hline Maranhão & 407.705 & 192.201 & 192.744 & 17.191 & 5.569 \\
\hline Paraíba & 416.173 & 260.434 & 132.757 & 18.071 & 4.911 \\
\hline Pernambuco & 1.123 .353 & 737.099 & 310.978 & 58.515 & 16.761 \\
\hline Piauí & 330.838 & 155.726 & 156.853 & 14.465 & 3.794 \\
\hline $\begin{array}{l}\text { Rio Grande do } \\
\text { Norte }\end{array}$ & 450.342 & 274.402 & 150.773 & 19.044 & 6.123 \\
\hline Sergipe & 262.720 & 164.653 & 79.142 & 13.736 & 5.189 \\
\hline Sudeste & 23.664 .155 & 18.421.699 & 3.989 .615 & 952.318 & 300.523 \\
\hline Espírito Santo & 805.049 & 548.657 & 189.221 & 53.522 & 13.649 \\
\hline Minas Gerais & 4.680 .296 & 3.325 .206 & 1.057 .535 & 234.327 & 63.228 \\
\hline Rio de Janeiro & 3.324 .350 & 2.803 .803 & 366.904 & 100.926 & 52.717 \\
\hline São Paulo & 14.854 .460 & 11.744 .033 & 2.375 .955 & 563.543 & 170.929 \\
\hline Sul & 9.511 .428 & 6.999 .064 & 1.868 .323 & $\mathbf{5 4 7 . 8 5 7}$ & 96.184 \\
\hline Paraná & 3.611 .097 & 2.682 .558 & 662.157 & 230.542 & 35.840 \\
\hline Rio Grande do Sul & 3.533 .971 & 2.656 .412 & 650.398 & 186.690 & 40.471 \\
\hline Santa Catarina & 2.366 .360 & 1.660 .094 & 555.768 & 130.625 & 19.873 \\
\hline Centro-Oeste & 3.728 .298 & 2.529.051 & 970.699 & 188.334 & 40.214 \\
\hline Distrito Federal & 874.233 & 771.161 & 74.416 & 17.198 & 11.458 \\
\hline Goiás & 1.512 .961 & 982.254 & 435.451 & 79.270 & 15.986 \\
\hline Mato Grosso & 699.158 & 365.702 & 273.895 & 52.838 & 6.723 \\
\hline Mato Grosso do Sul & 641.946 & 409.934 & 186.937 & 39.028 & 6.047 \\
\hline
\end{tabular}


Tabela A.4 - Frota de veículos motorizados por categoria segundo o DENATRAN em 2007

\begin{tabular}{|c|c|c|c|c|c|}
\hline $\begin{array}{c}\text { Grandes Regiões e } \\
\text { Unidades da } \\
\text { Federação }\end{array}$ & Total & $\begin{array}{l}\text { Veículo } \\
\text { leve }\end{array}$ & Motocicleta & Caminhão & Ônibus \\
\hline Brasil & 48.453.899 & 34.640 .234 & 11.071.370 & 2.152.143 & 590.152 \\
\hline Norte & 1.881 .953 & 972.940 & 783.885 & 98.340 & 26.788 \\
\hline Acre & 93.934 & 47.738 & 41.407 & 4.197 & 592 \\
\hline Amapá & 74.556 & 46.270 & 24.803 & 2.800 & 683 \\
\hline Amazonas & 371.025 & 251.661 & 97.331 & 14.821 & 7.212 \\
\hline Pará & 622.157 & 319.912 & 255.987 & 35.102 & 11.156 \\
\hline Rondônia & 361.783 & 140.312 & 197.522 & 20.823 & 3.126 \\
\hline Roraima & 83.699 & 39.405 & 40.655 & 2.915 & 724 \\
\hline Tocantins & 274.799 & 127.642 & 126.180 & 17.682 & 3.295 \\
\hline Nordeste & 6.398.883 & 3.782 .499 & 2.232.538 & 284.974 & 98.872 \\
\hline Alagoas & 301.497 & 193.230 & 87.450 & 13.963 & 6.854 \\
\hline Bahia & 1.563 .195 & 1.008 .079 & 445.881 & 76.866 & 32.369 \\
\hline Ceará & 1.165 .708 & 634.778 & 473.299 & 44.290 & 13.341 \\
\hline Maranhão & 476.486 & 216.443 & 235.238 & 18.782 & 6.023 \\
\hline Paraíba & 472.465 & 286.009 & 161.836 & 19.175 & 5.445 \\
\hline Pernambuco & 1.239 .508 & 789.639 & 368.907 & 62.302 & 18.660 \\
\hline Piauí & 375.274 & 170.194 & 185.695 & 15.246 & 4.139 \\
\hline $\begin{array}{l}\text { Rio Grande do } \\
\text { Norte }\end{array}$ & 514.137 & 305.009 & 182.473 & 20.143 & 6.512 \\
\hline Sergipe & 290.613 & 179.118 & 91.759 & 14.207 & 5.529 \\
\hline Sudeste & 25.728 .408 & 19.663 .992 & 4.742 .927 & 1.000 .807 & 320.682 \\
\hline Espírito Santo & 906.439 & 605.677 & 228.428 & 57.590 & 14.744 \\
\hline Minas Gerais & 5.146 .635 & 3.568 .798 & 1.262 .360 & 247.382 & 68.095 \\
\hline Rio de Janeiro & 3.564 .556 & 2.960 .407 & 444.169 & 104.078 & 55.902 \\
\hline São Paulo & 16.110 .778 & 12.529 .110 & 2.807 .970 & 591.757 & 181.941 \\
\hline Sul & 10.306 .789 & 7.475 .094 & 2.161 .178 & 569.456 & 101.061 \\
\hline Paraná & 3.939 .569 & 2.881 .428 & 779.893 & 240.092 & 38.156 \\
\hline Rio Grande do Sul & 3.773 .633 & 2.798 .923 & 739.353 & 193.112 & 42.245 \\
\hline Santa Catarina & 2.593 .587 & 1.794 .743 & 641.932 & 136.252 & 20.660 \\
\hline Centro-Oeste & 4.137 .866 & 2.745 .709 & 1.150 .842 & 198.566 & 42.749 \\
\hline Distrito Federal & 955.939 & 836.616 & 89.464 & 18.093 & 11.766 \\
\hline Goiás & 1.693 .779 & 1.076 .467 & 516.184 & 83.951 & 17.177 \\
\hline Mato Grosso & 782.071 & 395.828 & 323.434 & 55.532 & 7.277 \\
\hline Mato Grosso do Sul & 706.077 & 436.798 & 221.760 & 40.990 & 6.529 \\
\hline
\end{tabular}


Tabela A.5 - Frota de veículos motorizados por categoria segundo o DENATRAN em 2008

\begin{tabular}{|c|c|c|c|c|c|}
\hline $\begin{array}{l}\text { Grandes Regiões e } \\
\text { Unidades da } \\
\text { Federação }\end{array}$ & Total & $\begin{array}{l}\text { Veículo } \\
\text { leve }\end{array}$ & Motocicleta & Caminhão & Ônibus \\
\hline Brasil & 53.206.174 & 37.297.972 & 12.995 .939 & 2.279.141 & 633.122 \\
\hline Norte & 2.154 .280 & 1.074 .760 & 942.860 & 107.030 & 29.630 \\
\hline Acre & 109.604 & 53.745 & 50.570 & 4.657 & 632 \\
\hline Amapá & 85.704 & 52.090 & 29.911 & 2.940 & 763 \\
\hline Amazonas & 415.774 & 277.449 & 114.290 & 16.162 & 7.873 \\
\hline Pará & 722.269 & 356.356 & 315.015 & 38.387 & 12.511 \\
\hline Rondônia & 418.033 & 158.205 & 233.683 & 22.707 & 3.438 \\
\hline Roraima & 96.124 & 44.517 & 47.683 & 3.031 & 893 \\
\hline Tocantins & 306.772 & 132.398 & 151.708 & 19.146 & 3.520 \\
\hline Nordeste & 7.214.830 & 4.109.394 & 2.694 .083 & 303.757 & 107.596 \\
\hline Alagoas & 335.568 & 208.743 & 104.861 & 14.521 & 7.443 \\
\hline Bahia & 1.766 .774 & 1.094 .380 & 554.475 & 82.500 & 35.419 \\
\hline Ceará & 1.302 .108 & 688.067 & 552.370 & 47.158 & 14.513 \\
\hline Maranhão & 556.961 & 243.041 & 286.483 & 20.898 & 6.539 \\
\hline Paraíba & 538.242 & 311.117 & 200.876 & 20.216 & 6.033 \\
\hline Pernambuco & 1.378 .903 & 846.719 & 446.043 & 65.933 & 20.208 \\
\hline Piauí & 432.671 & 187.785 & 224.260 & 16.161 & 4.465 \\
\hline $\begin{array}{c}\text { Rio Grande do } \\
\text { Norte }\end{array}$ & 579.979 & 335.643 & 215.898 & 21.409 & 7.029 \\
\hline Sergipe & 323.624 & 193.899 & 108.817 & 14.961 & 5.947 \\
\hline Sudeste & 28.035.213 & 21.084.102 & 5.546 .436 & 1.060 .343 & 344.332 \\
\hline Espírito Santo & 1.022 .071 & 665.946 & 278.863 & 61.543 & 15.719 \\
\hline Minas Gerais & 5.700 .994 & 3.871 .358 & 1.492 .120 & 263.493 & 74.023 \\
\hline Rio de Janeiro & 3.838 .207 & 3.132 .991 & 537.004 & 108.462 & 59.750 \\
\hline São Paulo & 17.473 .941 & 13.413 .807 & 3.238 .449 & 626.845 & 194.840 \\
\hline Sul & 11.176.724 & 8.030 .587 & 2.445 .193 & 596.155 & 104.789 \\
\hline Paraná & 4.301 .003 & 3.105 .838 & 902.105 & 252.169 & 40.891 \\
\hline Rio Grande do Sul & 4.054 .573 & 2.982 .901 & 828.076 & 201.293 & 42.303 \\
\hline Santa Catarina & 2.821 .148 & 1.941 .848 & 715.012 & 142.693 & 21.595 \\
\hline Centro-Oeste & 4.625.127 & 2.999.129 & $\mathbf{1 . 3 6 7 . 3 6 7}$ & 211.856 & 46.775 \\
\hline Distrito Federal & 1.038 .243 & 899.114 & 107.840 & 19.075 & 12.214 \\
\hline Goiás & 1.906 .778 & 1.187.288 & 610.384 & 89.626 & 19.480 \\
\hline Mato Grosso & 900.311 & 441.230 & 391.643 & 59.605 & 7.833 \\
\hline Mato Grosso do Sul & 779.795 & 471.497 & 257.500 & 43.550 & 7.248 \\
\hline
\end{tabular}





\section{APÊNDICE B}

Tabela B.1 - Frota nacional de veículos leves por categoria e tipo de combustível segundo ANFAVEA/SINDIPEÇAS

\begin{tabular}{cccccc}
\hline Subcategorias de veículos leves & $\mathbf{2 0 0 4}$ & $\mathbf{2 0 0 5}$ & $\mathbf{2 0 0 6}$ & $\mathbf{2 0 0 7}$ & $\mathbf{2 0 0 8}$ \\
\hline Automóvel a gasolina & 12.861 .762 & 13.400 .283 & 13.684 .750 & 13.917 .607 & 14.101 .984 \\
Comercial leve gasolina & 1.484 .275 & 1.560 .402 & 1.610 .209 & 1.668 .404 & 1.792 .496 \\
Automóvel flex & 281.628 & 978.311 & 2.156 .269 & 3.818 .082 & 5.803 .508 \\
Comercial leve flex & 53.486 & 135.272 & 267.371 & 471.470 & 721.022 \\
Automóvel a álcool & 1.514 .225 & 1.539 .369 & 1.539 .941 & 1.539 .948 & 1.539 .948 \\
Comercial leve a álcool & 157.786 & 159.162 & 159.204 & 159.204 & 159.204 \\
Automóvel a diesel & 18.401 & 23.890 & 28.474 & 38.499 & 31.574 \\
Comercial leve a diesel & $\mathbf{7 1 9 . 4 2 1}$ & 795.691 & 879.470 & 976.485 & 1.103 .776 \\
\hline Total & $\mathbf{1 7 . 0 9 0 . 9 8 4}$ & $\mathbf{1 8 . 5 9 2 . 3 8 0}$ & $\mathbf{2 0 . 3 2 5 . 6 8 8}$ & $\mathbf{2 2 . 5 8 9 . 6 9 9}$ & $\mathbf{2 5 . 2 5 3 . 5 1 2}$ \\
\hline
\end{tabular}

Tabela B.2 - Frota nacional de motocicletas por cilindrada segundo ANFAVEA/SINDIPEÇAS

\begin{tabular}{cccccc}
\hline $\begin{array}{c}\text { Subcategorias de } \\
\text { motocicletas }\end{array}$ & $\mathbf{2 0 0 4}$ & $\mathbf{2 0 0 5}$ & $\mathbf{2 0 0 6}$ & $\mathbf{2 0 0 7}$ & $\mathbf{2 0 0 8}$ \\
\hline$\leq 115 \mathrm{CC}$ & 566.604 & 668.154 & 712.159 & 840.998 & 965.940 \\
$>115 \mathrm{e} \leq 250 \mathrm{CC}$ & 2.560 .445 & 3.204 .470 & 4.113 .908 & 5.286 .122 & 6.794 .947 \\
$>250 \mathrm{e} \leq 500 \mathrm{CC}$ & 75.869 & 82.338 & 92.890 & 106.785 & 122.438 \\
$>500 \mathrm{CC}$ & 32.248 & 39.959 & 51.203 & 61.819 & 81.435 \\
\hline Total & $\mathbf{3 . 2 3 5 . 1 6 6}$ & $\mathbf{3 . 9 9 4 . 9 2 1}$ & $\mathbf{4 . 9 7 0 . 1 6 0}$ & $\mathbf{6 . 2 9 5 . 7 2 4}$ & $\mathbf{7 . 9 6 4 . 7 6 0}$ \\
\hline
\end{tabular}

Tabela B.3 - Frota nacional de caminhões por categoria segundo ANFAVEA/SINDIPEÇAS

\begin{tabular}{cccccc}
\hline Subcategorias de caminhões & $\mathbf{2 0 0 4}$ & $\mathbf{2 0 0 5}$ & $\mathbf{2 0 0 6}$ & $\mathbf{2 0 0 7}$ & $\mathbf{2 0 0 8}$ \\
\hline Leve & 305.519 & 328.023 & 348.642 & 374.169 & 403.652 \\
Médio & 252.302 & 260.742 & 270.311 & 280.955 & 293.189 \\
Pesado & 339.204 & 380.844 & 419.218 & 475.260 & 549.734 \\
\hline Total/Média & $\mathbf{8 9 7 . 0 2 5}$ & $\mathbf{9 6 9 . 6 0 9}$ & $\mathbf{1 . 0 3 8 . 1 7 1}$ & $\mathbf{1 . 1 3 0 . 3 8 4}$ & $\mathbf{1 . 2 4 6 . 5 7 5}$ \\
\hline
\end{tabular}

Tabela B.4 - Frota nacional de ônibus por categoria segundo ANFAVEA/SINDIPEÇAS

\begin{tabular}{cccccc}
\hline Subcategorias de ônibus & $\mathbf{2 0 0 4}$ & $\mathbf{2 0 0 5}$ & $\mathbf{2 0 0 6}$ & $\mathbf{2 0 0 7}$ & $\mathbf{2 0 0 8}$ \\
\hline Microônibus & 23.585 & 24.884 & 26.188 & 27.532 & 28.728 \\
Rodoviário & 16.077 & 21.667 & 27.104 & 34.533 & 42.126 \\
Urbano & 164.326 & 172.776 & 186.074 & 201.935 & 221.772 \\
\hline Total/Média & $\mathbf{2 0 3 . 9 8 8}$ & $\mathbf{2 1 9 . 3 2 7}$ & $\mathbf{2 3 9 . 3 6 6}$ & $\mathbf{2 6 4 . 0 0 0}$ & $\mathbf{2 9 2 . 6 2 6}$ \\
\hline
\end{tabular}





\section{APÊNDICE C}

Tabela C.1 - Frota de veículos convertidos para o uso do GNV no período 2004-2008

\begin{tabular}{|c|c|c|c|c|c|}
\hline & 2004 & 2005 & 2006 & 2007 & 2008 \\
\hline Brasil & 825.803 & 1.031 .943 & 1.304 .821 & 1.490 .943 & 1.567 .269 \\
\hline Região Norte & $\mathbf{0}$ & $\mathbf{0}$ & 106 & 164 & 164 \\
\hline Acre & 0 & 0 & 0 & 0 & 0 \\
\hline Amapá & 0 & 0 & 0 & 0 & 0 \\
\hline Amazonas & 0 & 0 & 106 & 164 & 164 \\
\hline Pará & 0 & 0 & 0 & 0 & 0 \\
\hline Rondônia & 0 & 0 & 0 & 0 & 0 \\
\hline Roraima & 0 & 0 & 0 & 0 & 0 \\
\hline Tocantins & 0 & 0 & 0 & 0 & 0 \\
\hline Região Nordeste & 146.567 & 178.891 & 219.388 & 249.791 & 255.400 \\
\hline Alagoas & 9.334 & 13.009 & 16.200 & 18.027 & 18.373 \\
\hline Bahia & 33.640 & 43.558 & 56.998 & 67.498 & 68.659 \\
\hline Ceará & 27.065 & 32.098 & 38.253 & 43.943 & 45.523 \\
\hline Maranhão & 0 & 0 & 0 & 0 & 0 \\
\hline Paraíba & 10.943 & 12.261 & 14.987 & 17.183 & 17.622 \\
\hline Pernambuco & 30.636 & 36.276 & 41.521 & 45.344 & 46.024 \\
\hline Piauí & 144 & 172 & 186 & 203 & 218 \\
\hline Rio Grande do Norte & 25.539 & 28.841 & 33.519 & 36.909 & 38.032 \\
\hline Sergipe & 9.266 & 12.676 & 17.724 & 20.684 & 20.949 \\
\hline Região Sudeste & 618.676 & 768.340 & 971.220 & 1.107 .984 & 1.170 .894 \\
\hline Espírito Santo & 26.450 & 29.592 & 34.782 & 36.784 & 37.246 \\
\hline Minas Gerais & 56.002 & 61.017 & 62.450 & 63.111 & 63.375 \\
\hline Rio de Janeiro & 322.717 & 417.115 & 550.400 & 638.997 & 688.702 \\
\hline São Paulo & 213.507 & 260.616 & 323.588 & 369.092 & 381.571 \\
\hline Região Sul & 57.259 & 79.732 & 107.293 & 125.006 & 132.326 \\
\hline Paraná & 14.594 & 17.441 & 24.018 & 26.878 & 27.292 \\
\hline Rio Grande do Sul & 19.664 & 26.315 & 32.648 & 36.075 & 37.979 \\
\hline Santa Catarina & 23.001 & 35.976 & 50.627 & 62.053 & 67.055 \\
\hline Região Centro-Oeste & 3.301 & 4.980 & 6.814 & 7.998 & 8.485 \\
\hline Distrito Federal & 0 & 0 & 13 & 69 & 309 \\
\hline Goiás & 0 & 0 & 67 & 396 & 497 \\
\hline Mato Grosso & 0 & 180 & 1.208 & 1.587 & 1.659 \\
\hline Mato Grosso do Sul & 3.301 & 4.800 & 5.526 & 5.946 & 6.020 \\
\hline
\end{tabular}





\section{APÊNDICE D}

Tabela D.1 - Volume de gasolina comercializado, por estado, no período 2004-2008 (1)

\begin{tabular}{|c|c|c|c|c|c|}
\hline Gasolina C (I) & 2004 & 2005 & 2006 & 2007 & 2008 \\
\hline Brasil & 23.173.878.602 & 23.553.490.055 & 24.007.633.479 & 24.325.448.632 & 25.174.782.612 \\
\hline Norte & 1.124 .911 .405 & 1.151.779.189 & 1.249.157.463 & 1.381 .765 .535 & 1.547 .662 .086 \\
\hline Acre & 47.175 .557 & 49.531 .644 & 54.125 .469 & 59.986 .728 & 69.961 .945 \\
\hline Amapá & 57.101 .350 & 57.911 .219 & 64.644 .757 & 72.340 .094 & 82.509 .628 \\
\hline Amazonas & 301.378 .183 & 302.865 .598 & 332.061 .528 & 354.301 .334 & 388.553 .260 \\
\hline Pará & 380.819 .049 & 403.298 .983 & 435.939 .377 & 493.385 .978 & 559.079 .289 \\
\hline Rondônia & 161.999 .316 & 166.802 .829 & 180.781 .711 & 192.110 .865 & 211.211 .337 \\
\hline Roraima & 47.178 .234 & 43.405 .650 & 48.344 .950 & 52.591 .944 & 62.254 .191 \\
\hline Tocantins & 129.259 .716 & 127.963 .266 & 133.259 .671 & 157.048 .593 & 174.092 .436 \\
\hline Nordeste & 3.409.559.480 & 3.450.145.022 & 3.564.073.393 & 3.617 .637 .712 & 3.975.416.121 \\
\hline Alagoas & 170.994 .576 & 167.044 .647 & 168.899 .387 & 163.490 .353 & 172.374 .634 \\
\hline Bahia & 995.292 .284 & 992.721 .729 & 1.006 .425 .234 & 988.911 .789 & 1.050 .094 .404 \\
\hline Ceará & 503.268 .744 & 509.174 .840 & 530.568 .079 & 552.584 .758 & 615.539 .660 \\
\hline Maranhão & 275.970 .408 & 289.145 .963 & 306.351 .738 & 327.629 .238 & 371.604 .657 \\
\hline Paraíba & 270.767 .084 & 267.905 .945 & 281.008 .494 & 301.021 .955 & 341.331 .354 \\
\hline Pernambuco & 620.504 .022 & 629.655 .097 & 637.645 .566 & 621.960 .222 & 676.940 .041 \\
\hline Piauí & 164.197 .834 & 173.735 .648 & 195.720 .647 & 213.323 .769 & 246.146 .293 \\
\hline Rio Grande do Norte & 247.737 .609 & 257.801 .126 & 266.639 .721 & 272.333 .341 & 304.051 .807 \\
\hline Sergipe & 160.826 .919 & 162.960 .027 & 170.814 .527 & 176.382 .287 & 197.333.269 \\
\hline Sudeste & 11.485 .625 .428 & 11.685.975.915 & 11.862.159.429 & 12.091.616.225 & 12.046 .910 .226 \\
\hline Espírito Santo & 422.415 .756 & 431.178 .089 & 461.645 .144 & 474.983 .766 & 485.291 .811 \\
\hline Minas Gerais & 2.517 .975 .520 & 2.580 .236 .020 & 2.698 .050 .560 & 2.827 .568 .220 & 2.924 .880 .571 \\
\hline Rio de Janeiro & 1.848 .172 .403 & 1.739 .318 .622 & 1.660 .802 .986 & 1.635 .151 .708 & 1.616 .429 .481 \\
\hline São Paulo & 6.697 .061 .749 & 6.935 .243 .184 & 7.041 .660 .739 & 7.153 .912 .530 & 7.020 .308 .362 \\
\hline Sul & 4.869.763.752 & 4.984.151.220 & 5.022 .524 .770 & 4.945 .657 .366 & 5.197 .528 .369 \\
\hline Paraná & 1.580 .814 .794 & 1.724 .457 .488 & 1.645 .806 .401 & 1.639 .229 .439 & 1.699 .665 .491 \\
\hline Rio Grande do Sul & 1.964 .302 .476 & 1.906 .624 .807 & 1.898 .189 .895 & 1.967 .365 .597 & 2.121 .884 .889 \\
\hline Santa Catarina & 1.324 .646 .482 & 1.353 .068 .925 & 1.478 .528 .474 & 1.339 .062 .329 & 1.375 .977 .988 \\
\hline Centro-Oeste & 2.284.018.537 & 2.281.438.709 & 2.309.718.424 & 2.288.771.794 & 2.407 .265 .811 \\
\hline Distrito Federal & 696.183 .432 & 710.505 .216 & 736.015 .526 & 731.690 .263 & 773.089 .436 \\
\hline Goiás & 880.882 .434 & 879.473 .092 & 890.038 .412 & 880.459 .813 & 921.928 .734 \\
\hline Mato Grosso & 373.215 .236 & 372.597 .065 & 364.957 .357 & 347.660 .395 & 355.889 .155 \\
\hline Mato Grosso do Sul & 333.737 .435 & 318.863 .336 & 318.707 .129 & 328.961 .323 & 356.358 .486 \\
\hline
\end{tabular}

(Fonte: Ministério de Minas e Energia, 2010) 
Tabela D.2 - Volume de álcool comercializado, por estado, no período 2004-2008 (1)

\begin{tabular}{|c|c|c|c|c|c|}
\hline Álcool hidratado (l) & 2004 & 2005 & 2006 & 2007 & 2008 \\
\hline Brasil & 4.512.926.045 & 4.667.222.869 & 6.186.552.816 & 9.366 .835 .702 & 13.290.095.836 \\
\hline Norte & 54.979 .562 & 62.681 .101 & 57.772 .186 & 113.626 .910 & 197.765 .210 \\
\hline Acre & 3.753 .053 & 3.999 .534 & 4.135 .926 & 6.373 .692 & 9.511 .650 \\
\hline Amapá & 770.200 & 890.750 & 925.300 & 1.452 .374 & 2.771 .449 \\
\hline Amazonas & 13.533 .434 & 19.016 .005 & 16.265 .730 & 32.504 .389 & 54.703 .033 \\
\hline Pará & 10.513 .644 & 10.808 .935 & 10.367 .000 & 17.748 .832 & 31.548 .272 \\
\hline Rondônia & 12.738 .751 & 13.629 .467 & 10.618 .080 & 21.534 .123 & 40.583 .801 \\
\hline Roraima & 578.100 & 736.200 & 1.299 .000 & 2.256 .270 & 2.865 .817 \\
\hline Tocantins & 13.092 .380 & 13.600 .210 & 14.161 .150 & 31.757 .231 & 55.781 .187 \\
\hline Nordeste & 282.558 .630 & 328.328.118 & 417.410 .299 & 712.957 .607 & 1.235 .696 .040 \\
\hline Alagoas & 23.517 .710 & 26.897 .096 & 34.903 .254 & 51.462 .021 & 83.104 .322 \\
\hline Bahia & 59.552 .908 & 67.113 .703 & 95.525 .759 & 173.953 .492 & 369.506 .458 \\
\hline Ceará & 35.623 .651 & 40.502 .867 & 66.099 .393 & 107.878.077 & 152.940 .754 \\
\hline Maranhão & 8.255 .586 & 11.272 .908 & 16.591 .652 & 49.095 .935 & 107.358 .397 \\
\hline Paraíba & 32.053 .766 & 34.027 .545 & 36.596 .954 & 63.588 .610 & 89.659 .659 \\
\hline Pernambuco & 69.219 .461 & 93.531 .437 & 107.508 .489 & 163.306 .061 & 280.705 .414 \\
\hline Piauí & 16.216 .389 & 14.966 .761 & 14.037 .543 & 19.439 .832 & 28.274 .624 \\
\hline Rio Grande do Norte & 23.355 .553 & 26.500 .186 & 33.372 .572 & 67.384 .434 & 94.711 .927 \\
\hline Sergipe & 14.763 .606 & 13.515 .615 & 12.774 .683 & 16.849 .144 & 29.434 .484 \\
\hline Sudeste & 2.893.982.940 & 3.023.306.530 & 4.381.774.396 & 6.578.099.455 & 9.022.759.069 \\
\hline Espírito Santo & 36.720 .930 & 50.545 .069 & 42.426 .781 & 70.831 .092 & 137.246 .765 \\
\hline Minas Gerais & 420.904 .595 & 391.481 .332 & 371.414 .323 & 602.743 .948 & 957.199 .811 \\
\hline Rio de Janeiro & 109.816 .563 & 180.528 .029 & 224.254 .942 & 359.404 .270 & 677.059 .602 \\
\hline São Paulo & 2.326 .540 .852 & 2.400 .752 .100 & 3.743 .678 .350 & 5.545 .120 .145 & 7.251 .252 .892 \\
\hline Sul & 904.645 .786 & 883.409 .181 & 872.401 .175 & 1.163 .947 .980 & 1.605 .379 .172 \\
\hline Paraná & 538.763 .390 & 518.236 .505 & 520.583 .657 & 701.253 .418 & 904.330 .300 \\
\hline Rio Grande do Sul & 192.009 .777 & 189.898 .238 & 158.758 .981 & 220.297 .421 & 324.890 .395 \\
\hline Santa Catarina & 173.872 .619 & 175.274 .438 & 193.058 .537 & 242.397 .140 & 376.158 .477 \\
\hline Centro-Oeste & 376.759.127 & 369.497 .939 & 457.194 .760 & 798.203 .750 & 1.228 .496 .345 \\
\hline Distrito Federal & 76.198 .795 & 77.559 .279 & 80.855 .558 & 150.221 .381 & 174.775 .869 \\
\hline Goiás & 170.095 .266 & 149.375 .883 & 238.581 .380 & 435.305 .538 & 610.591 .291 \\
\hline Mato Grosso & 59.251 .839 & 70.976 .925 & 72.465 .484 & 107.203 .414 & 276.849 .038 \\
\hline Mato Grosso do Sul & 71.213 .227 & 71.585 .852 & 65.292 .338 & 105.473 .418 & 166.280 .147 \\
\hline
\end{tabular}

(Fonte: Ministério de Minas e Energia, 2010) 
Tabela D.3 - Volume de óleo diesel comercializado, por estado, no período 2004-2008 (1)

\begin{tabular}{|c|c|c|c|c|c|}
\hline Óleo diesel (l) & 2004 & 2005 & 2006 & 2007 & 2008 \\
\hline Brasil & 39.225 .674 .616 & 39.167 .154 .702 & 39.008.397.496 & 41.558.179.590 & 44.763.952.307 \\
\hline Norte & 3.421.509.798 & 3.711.084.101 & 3.601.275.658 & 3.765.621.377 & 3.950.522.270 \\
\hline Acre & 158.901 .966 & 169.085 .830 & 131.981 .482 & 123.674 .458 & 128.170 .735 \\
\hline Amapá & 194.657 .562 & 224.430 .124 & 209.450 .619 & 231.801 .377 & 245.168 .852 \\
\hline Amazonas & 698.141 .062 & 830.160 .400 & 714.176 .548 & 703.212 .089 & 740.401 .067 \\
\hline Pará & 1.297.287.179 & 1.332 .128 .271 & 1.387 .972 .406 & 1.481 .449 .841 & 1.509 .833 .347 \\
\hline Rondônia & 591.767 .246 & 663.267 .463 & 654.631 .320 & 631.352 .105 & 666.985 .832 \\
\hline Roraima & 54.011 .900 & 52.236 .054 & 52.656 .071 & 55.765 .645 & 68.044 .680 \\
\hline Tocantins & 426.742 .883 & 439.775 .959 & 450.407 .212 & 538.365 .862 & 591.917 .756 \\
\hline Nordeste & 5.621.937.033 & 5.700 .396 .493 & 5.818.493.307 & 6.214 .428 .480 & 7.089.165.781 \\
\hline Alagoas & 317.896 .412 & 308.918 .589 & 313.508 .561 & 315.257 .150 & 325.839 .037 \\
\hline Bahia & 2.053 .940 .335 & 2.058 .622 .223 & 2.060 .100 .475 & 2.206 .097 .779 & 2.619 .163 .838 \\
\hline Ceará & 529.996 .413 & 565.180 .776 & 613.766 .916 & 660.767 .023 & 765.014 .632 \\
\hline Maranhão & 654.635 .558 & 701.662 .736 & 714.793 .333 & 779.812 .274 & 908.193 .574 \\
\hline Paraíba & 339.806 .710 & 334.305 .415 & 335.808 .188 & 354.242 .405 & 368.078 .009 \\
\hline Pernambuco & 819.972 .100 & 828.809 .338 & 861.111 .469 & 918.209 .095 & 1.023 .506 .776 \\
\hline Piauí & 312.132 .953 & 318.895 .253 & 323.647 .288 & 334.862 .765 & 396.861 .764 \\
\hline Rio Grande do Norte & 354.106 .584 & 339.102 .433 & 358.685 .423 & 358.009 .715 & 377.230 .910 \\
\hline Sergipe & 239.449 .968 & 244.899 .730 & 237.071 .654 & 287.170 .275 & 305.277 .241 \\
\hline Sudeste & 17.155.710.906 & 17.395.452.653 & 17.542.164.110 & 18.739.569.353 & 19.840.469.352 \\
\hline Espírito Santo & 702.013 .629 & 741.141 .033 & 843.909 .269 & 872.670 .209 & 935.896 .723 \\
\hline Minas Gerais & 5.015 .728 .659 & 5.175 .074 .765 & 5.307 .947 .163 & 5.720 .685 .731 & 5.910 .221 .727 \\
\hline Rio de Janeiro & 2.139.262.194 & 2.188 .716 .304 & 2.185.277.206 & 2.355 .824 .070 & 2.437.017.428 \\
\hline São Paulo & 9.298 .706 .424 & 9.290 .520 .551 & 9.205 .030 .472 & 9.790 .389 .342 & 10.557 .333 .474 \\
\hline Sul & 8.121.003.910 & 7.828.606.982 & 7.752.178.417 & 8.166.044.556 & 8.689.112.324 \\
\hline Paraná & 3.601 .696 .384 & 3.541 .790 .791 & 3.511 .476 .939 & 3.705 .978 .749 & 3.930 .213 .421 \\
\hline Rio Grande do Sul & 2.741 .196 .046 & 2.480 .833 .636 & 2.477.786.770 & 2.592 .199 .167 & 2.756.189.801 \\
\hline Santa Catarina & 1.778 .111 .480 & 1.805 .982 .555 & 1.762 .914 .708 & 1.867 .866 .640 & 2.002 .709 .103 \\
\hline Centro-Oeste & 4.905.512.969 & 4.531.614.473 & 4.294.286.004 & 4.672.515.824 & 5.194.682.581 \\
\hline Distrito Federal & 362.568 .560 & 368.530 .055 & 361.398 .931 & 368.313 .233 & 369.895 .173 \\
\hline Goiás & 1.523 .507 .096 & 1.552 .097 .892 & 1.570 .136 .628 & 1.732 .371 .775 & 1.961 .883 .397 \\
\hline Mato Grosso & 2.006 .859 .045 & 1.706 .815 .433 & 1.524 .971 .715 & 1.663 .248 .877 & 1.843 .744 .528 \\
\hline Mato Grosso do Sul & 1.012 .578 .268 & 904.171 .093 & 837.778 .730 & 908.581 .939 & 1.019 .159 .483 \\
\hline
\end{tabular}

(Fonte: Ministério de Minas e Energia, 2010) 
Tabela D.4 - Volume de GNV comercializado, por estado, no período 2004-2008 (m³)

\begin{tabular}{|c|c|c|c|c|c|}
\hline GNV $\left(\mathrm{m}^{3}\right)$ & 2004 & 2005 & 2006 & 2007 & 2008 \\
\hline Brasil & 1.585 .637 .700 & 1.935 .630 .120 & 2.315.194.640 & 2.558.266.740 & 2.424.887.308 \\
\hline Norte & $\mathbf{0}$ & $\mathbf{0}$ & $\mathbf{0}$ & $\mathbf{0}$ & 839.000 \\
\hline Acre & 0 & 0 & 0 & 0 & 0 \\
\hline Amapá & 0 & 0 & 0 & 0 & 0 \\
\hline Amazonas & 0 & 0 & 0 & 0 & 839.000 \\
\hline Pará & 0 & 0 & 0 & 0 & 0 \\
\hline Rondônia & 0 & 0 & 0 & 0 & 0 \\
\hline Roraima & 0 & 0 & 0 & 0 & 0 \\
\hline Tocantins & 0 & 0 & 0 & 0 & 0 \\
\hline Nordeste & 317.392 .440 & 380.650 .570 & 447.587 .440 & 477.143.080 & 449.285.218 \\
\hline Alagoas & 25.632 .010 & 32.336 .510 & 38.860 .400 & 43.443 .010 & 40.702 .140 \\
\hline Bahia & 68.636 .000 & 84.906 .470 & 101.892 .000 & 113.981 .000 & 102.032 .270 \\
\hline Ceará & 57.803 .260 & 66.281 .600 & 72.762 .400 & 79.143 .690 & 76.246 .265 \\
\hline Maranhão & 0 & 0 & 0 & 0 & 0 \\
\hline Paraíba & 28.109 .640 & 32.817 .340 & 41.556 .000 & 40.996 .000 & 41.161 .500 \\
\hline Pernambuco & 57.249 .780 & 68.968 .790 & 76.035 .300 & 73.117 .340 & 72.438 .155 \\
\hline Piauí & 0 & 68.200 & 8.643 .100 & 2.893 .810 & 706.410 \\
\hline Rio Grande do Norte & 58.132 .730 & 66.180 .940 & 70.698 .950 & 79.652 .740 & 72.661 .400 \\
\hline Sergipe & 21.829 .020 & 29.090 .720 & 37.139 .290 & 43.915 .490 & 43.337 .078 \\
\hline Sudeste & 1.164 .998 .070 & 1.387 .504 .770 & 1.646 .015 .690 & 1.825.533.300 & 1.720 .568 .505 \\
\hline Espírito Santo & 37.011 .480 & 41.476 .250 & 47.280 .000 & 50.449 .000 & 46.355 .860 \\
\hline Minas Gerais & 93.699 .130 & 98.842 .100 & 94.052 .500 & 91.331 .280 & 72.636 .965 \\
\hline Rio de Janeiro & 620.579 .450 & 762.768 .400 & 930.907 .000 & 1.059 .217 .000 & 1.033 .845 .750 \\
\hline São Paulo & 413.708 .010 & 484.418 .020 & 573.776 .190 & 624.536 .020 & 567.729 .930 \\
\hline Sul & 97.568 .860 & 157.373 .380 & 208.064 .910 & 240.827 .720 & 236.700 .610 \\
\hline Paraná & 19.781 .640 & 23.661 .320 & 29.219 .410 & 33.194 .560 & 33.684 .175 \\
\hline Rio Grande do Sul & 37.558 .250 & 53.857 .010 & 68.487 .300 & 78.256 .480 & 73.518 .105 \\
\hline Santa Catarina & 40.228 .970 & 79.855 .050 & 110.358 .200 & 129.376 .680 & 129.498 .330 \\
\hline Centro-Oeste & 5.678 .330 & 10.101 .400 & 13.526.600 & 14.762 .640 & 17.493 .975 \\
\hline Distrito Federal & 0 & 0 & 0 & 0 & 1.890 .830 \\
\hline Goiás & 0 & 0 & 0 & 151.940 & 1.089 .345 \\
\hline Mato Grosso & 0 & 0 & 2.218 .400 & 3.893 .780 & 3.033 .785 \\
\hline Mato Grosso do Sul & 5.678 .330 & 10.101 .400 & 11.308 .200 & 10.716 .920 & 11.480 .015 \\
\hline
\end{tabular}




\section{APÊNDICE E}

Tabela E.1 - Preços do álcool e gasolina no período 2004-2008, segundo ANP (2010)

\begin{tabular}{|c|c|c|c|c|c|c|c|c|c|c|}
\hline \multirow[b]{2}{*}{$\begin{array}{l}\text { Preços médios da } \\
\text { gasolina e do álcool } \\
\text { (R\$) }\end{array}$} & \multicolumn{2}{|c|}{2004} & \multicolumn{2}{|c|}{2005} & \multicolumn{2}{|c|}{2006} & \multicolumn{2}{|c|}{2007} & \multicolumn{2}{|c|}{2008} \\
\hline & 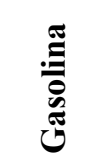 & $\frac{\overline{8}}{8}$ & 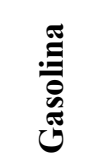 & $\frac{\overline{0}}{8}$ & 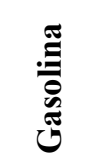 & $\frac{\overline{8}}{8}$ & 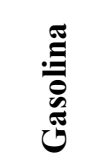 & $\frac{\overline{8}}{4}$ &  & $\frac{\overline{8}}{\frac{e}{4}}$ \\
\hline Brasil & 2,082 & 1,212 & 2,312 & 1,377 & 2,541 & 1,676 & 2,504 & 1,492 & 2,501 & 1,484 \\
\hline Norte & 2,259 & 1,644 & 2,553 & 2,553 & 2,691 & 2,152 & 2,655 & 1,927 & 2,708 & 1,925 \\
\hline Acre & 2,433 & 1,769 & 2,649 & 1,932 & 2,919 & 2,239 & 2,893 & 2,043 & 2,938 & 2,079 \\
\hline Amapá & 2,238 & 1,873 & 2,446 & 2,017 & 2,553 & 2,182 & 2,397 & 1,995 & 2,592 & 2,137 \\
\hline Amazonas & 2,112 & 1,497 & 2,574 & 1,827 & 2,549 & 2,042 & 2,452 & 1,765 & 2,426 & 1,775 \\
\hline Pará & 2,299 & 1,877 & 2,429 & 1,536 & 2,589 & 2,288 & 2,556 & 2,062 & 2,719 & 2,118 \\
\hline Rondônia & 2,368 & 1,585 & 2,553 & 1,802 & 2,678 & 2,111 & 2,618 & 1,871 & 2,662 & 1,837 \\
\hline Roraima & 2,083 & 1,624 & 2,601 & 2,041 & 2,852 & 2,233 & 2,622 & 2,057 & 2,683 & 2,140 \\
\hline Tocantins & 2,202 & 1,373 & 2,525 & 1,621 & 2,754 & 2,013 & 2,733 & 1,732 & 2,747 & 1,748 \\
\hline Nordeste & 2,133 & 1,435 & 2,409 & 2,409 & 2,670 & 1,904 & 2,632 & 1,714 & 2,629 & 1,755 \\
\hline Alagoas & 2,204 & 1,330 & 2,596 & 1,669 & 2,670 & 1,943 & 2,824 & 1,759 & 2,773 & 1,798 \\
\hline Bahia & 2,143 & 1,491 & 2,345 & 1,657 & 2,610 & 1,813 & 2,587 & 1,635 & 2,594 & 1,677 \\
\hline Ceará & 2,202 & 1,426 & 2,446 & 1,631 & 2,687 & 1,880 & 2,586 & 1,682 & 2,540 & 1,777 \\
\hline Maranhão & 2,065 & 1,624 & 2,358 & 1,790 & 2,728 & 2,025 & 2,720 & 1,802 & 2,633 & 1,722 \\
\hline Paraíba & 2,063 & 1,400 & 2,358 & 1,644 & 2,608 & 1,905 & 2,535 & 1,738 & 2,440 & 1,765 \\
\hline Pernambuco & 2,101 & 1,332 & 2,380 & 1,563 & 2,641 & 1,819 & 2,596 & 1,577 & 2,586 & 1,656 \\
\hline Piauí & 2,175 & 1,634 & 2,409 & 1,906 & 2,479 & 2,100 & 2,533 & 1,875 & 2,588 & 1,886 \\
\hline Rio Grande do Norte & 2,097 & 1,401 & 2,355 & 1,648 & 2,632 & 1,873 & 2,541 & 1,639 & 2,586 & 1,812 \\
\hline Sergipe & 2,047 & 1,424 & 2,337 & 1,740 & 2,542 & 2,044 & 2,508 & 1,889 & 2,513 & 1,837 \\
\hline Sudeste & 2,023 & 1,087 & 2,259 & 2,259 & 2,483 & 1,481 & 2,452 & 1,320 & 2,446 & 1,318 \\
\hline Espírito Santo & 2,113 & 1,235 & 2,372 & 1,530 & 2,612 & 1,965 & 2,610 & 1,790 & 2,618 & 1,761 \\
\hline Minas Gerais & 2,040 & 1,333 & 2,209 & 1,536 & 2,412 & 1,875 & 2,393 & 1,642 & 2,381 & 1,592 \\
\hline Rio de Janeiro & 2,095 & 1,281 & 2,329 & 1,534 & 2,525 & 1,834 & 2,494 & 1,641 & 2,516 & 1,648 \\
\hline São Paulo & 1,986 & 0,972 & 2,237 & 1,177 & 2,418 & 1,412 & 2,396 & 1,274 & 2,387 & 1,279 \\
\hline Sul & 2,163 & 1,302 & 2,459 & 2,459 & 2,641 & 1,793 & 2,539 & 1,546 & 2,527 & 1,530 \\
\hline Paraná & 2,063 & 1,156 & 2,467 & 1,377 & 2,282 & 1,641 & 2,416 & 1,450 & 2,395 & 1,407 \\
\hline Rio Grande do Sul & 2,231 & 1,425 & 2,697 & 1,794 & 2,570 & 2,148 & 2,528 & 1,743 & 2,534 & 1,759 \\
\hline Santa Catarina & 2,173 & 1,375 & 2,562 & 1,610 & 2,443 & 1,804 & 2,541 & 1,701 & 2,537 & 1,691 \\
\hline Centro-Oeste & 2,18 & 1,373 & 2,431 & 2,431 & 2,655 & 1,819 & 2,626 & 1,567 & 2,598 & 1,638 \\
\hline Distrito Federal & 2,091 & 1,481 & 2,364 & 1,665 & 2,596 & 1,905 & 2,572 & 1,695 & 2,554 & 1,829 \\
\hline Goiás & 2,075 & 1,255 & 2,341 & 1,395 & 2,547 & 1,630 & 2,494 & 1,421 & 2,477 & 1,505 \\
\hline Mato Grosso & 2,453 & 1,507 & 2,749 & 1,715 & 2,941 & 1,979 & 2,881 & 1,456 & 2,712 & 1,371 \\
\hline Mato Grosso do Sul & 2,245 & 1,435 & 2,570 & 1,633 & 2,737 & 1,915 & 2,684 & 1,699 & 2,673 & 1,708 \\
\hline
\end{tabular}





\section{APÊNDICE F}

Tabela F.1 - Volume de álcool corrigido, por estado, no período 2004-2008 (1)

\begin{tabular}{|c|c|c|c|c|c|}
\hline Álcool hidratado (l) & 2004 & 2005 & 2006 & 2007 & 2008 \\
\hline Brasil & 4.833 .600 .000 & 5.654 .740 .000 & 7.093.275.000 & 10.365 .732 .000 & 14.660 .780 .000 \\
\hline Norte & 58.886 .232 & 75.943.519 & 66.239 .474 & 125.744 .290 & 218.161.875 \\
\hline Acre & 4.019 .733 & 4.845 .778 & 4.742 .101 & 7.053 .394 & 10.492 .642 \\
\hline Amapá & 824.928 & 1.079 .220 & 1.060 .915 & 1.607 .258 & 3.057 .285 \\
\hline Amazonas & 14.495 .076 & 23.039 .518 & 18.649 .691 & 35.970 .716 & 60.344 .872 \\
\hline Pará & 11.260 .710 & 13.095 .950 & 11.886 .423 & 19.641 .599 & 34.802 .027 \\
\hline Rondônia & 13.643 .926 & 16.513 .266 & 12.174 .302 & 23.830 .561 & 44.769 .442 \\
\hline Roraima & 619.178 & 891.969 & 1.489 .386 & 2.496 .882 & 3.161 .386 \\
\hline Tocantins & 14.022 .682 & 16.477 .819 & 16.236 .656 & 35.143 .880 & 61.534 .222 \\
\hline Nordeste & 302.636 .334 & 397.797 .618 & 478.587.370 & 788.988.696 & 1.363.140.493 \\
\hline Alagoas & 25.188 .803 & 32.588 .134 & 40.018 .793 & 56.950 .024 & 91.675 .350 \\
\hline Bahia & 63.784 .545 & 81.313 .996 & 109.526 .339 & 192.504 .207 & 407.615 .789 \\
\hline Ceará & 38.154 .953 & 49.072 .690 & 75.787 .144 & 119.382 .390 & 168.714 .415 \\
\hline Maranhão & 8.842 .201 & 13.658 .093 & 19.023 .381 & 54.331 .614 & 118.430 .887 \\
\hline Paraíba & 34.331 .403 & 41.227 .283 & 41.960 .728 & 70.369 .815 & 98.906 .777 \\
\hline Pernambuco & 74.137 .972 & 113.321 .342 & 123.265 .298 & 180.721 .314 & 309.656 .181 \\
\hline Piauí & 17.368 .673 & 18.133 .512 & 16.094 .933 & 21.512 .931 & 31.190 .749 \\
\hline Rio Grande do Norte & 25.015 .123 & 32.107 .244 & 38.263 .769 & 74.570 .432 & 104.480 .114 \\
\hline Sergipe & 15.812 .660 & 16.375 .324 & 14.646 .984 & 18.645 .968 & 32.470 .232 \\
\hline Sudeste & 3.099 .620 .025 & 3.662.994.643 & 5.023.982.128 & 7.279 .599 .876 & 9.953.328.203 \\
\hline Espírito Santo & 39.330 .201 & 61.239 .678 & 48.644 .994 & 78.384 .647 & 151.401 .815 \\
\hline Minas Gerais & 450.812 .717 & 474.313 .143 & 425.850 .067 & 667.021 .652 & 1.055 .921 .343 \\
\hline Rio de Janeiro & 117.619 .773 & 218.725 .160 & 257.122 .508 & 397.731 .791 & 746.888 .660 \\
\hline São Paulo & 2.491 .857 .334 & 2.908 .716 .663 & 4.292.364.559 & 6.136 .461 .785 & 7.999 .116 .386 \\
\hline Sul & 968.926 .995 & 1.070.325.839 & 1.000 .263 .253 & 1.288.073.497 & 1.770.951.177 \\
\hline Paraná & 577.046 .177 & 627.887 .885 & 596.882 .165 & 776.036 .351 & 997.599 .095 \\
\hline Rio Grande do Sul & 205.653 .372 & 230.077 .970 & 182.027 .236 & 243.790 .337 & 358.398 .214 \\
\hline Santa Catarina & 186.227 .446 & 212.359 .984 & 221.353 .852 & 268.246 .809 & 414.953 .868 \\
\hline Centro-Oeste & 403.530.414 & 447.678.381 & 524.202 .776 & 883.325.641 & 1.355.198.252 \\
\hline Distrito Federal & 81.613 .235 & 93.969 .705 & 92.706 .023 & 166.241 .260 & 192.801 .511 \\
\hline Goiás & 182.181 .686 & 180.981 .668 & 273.548 .677 & 481.727 .308 & 673.565 .089 \\
\hline Mato Grosso & 63.462 .083 & 85.994 .620 & 83.086 .271 & 118.635 .780 & 305.402 .075 \\
\hline Mato Grosso do Sul & 76.273 .409 & 86.732 .387 & 74.861 .805 & 116.721 .294 & 183.429 .577 \\
\hline
\end{tabular}





\section{APÊNDICE G}

Tabela G.1 - Fator de correção 7 do óleo diesel (uso agropecuário)

\begin{tabular}{cccccc}
\hline $\begin{array}{c}\text { Fator de correção 7- } \\
\text { diesel agropecuário }\end{array}$ & $\mathbf{2 0 0 4}$ & $\mathbf{2 0 0 5}$ & $\mathbf{2 0 0 6}$ & $\mathbf{2 0 0 7}$ & $\mathbf{2 0 0 8}$ \\
\hline Acre & 0,996 & 0,963 & 0,952 & 0,946 & 0,941 \\
Amapá & 0,999 & 0,995 & 0,995 & 0,995 & 0,995 \\
Amazonas & 0,999 & 0,988 & 0,986 & 0,985 & 0,984 \\
Pará & 0,992 & 0,918 & 0,921 & 0,921 & 0,914 \\
Rondônia & 0,993 & 0,941 & 0,939 & 0,933 & 0,930 \\
Roraima & 0,995 & 0,947 & 0,947 & 0,947 & 0,951 \\
Tocantins & 0,983 & 0,836 & 0,837 & 0,855 & 0,853 \\
\hline Alagoas & 0,977 & 0,767 & 0,767 & 0,754 & 0,734 \\
Bahia & 0,989 & 0,891 & 0,890 & 0,891 & 0,897 \\
Ceará & 0,995 & 0,949 & 0,952 & 0,953 & 0,955 \\
Maranhão & 0,991 & 0,916 & 0,916 & 0,919 & 0,922 \\
Paraíba & 0,996 & 0,955 & 0,954 & 0,954 & 0,950 \\
Pernambuco & 0,994 & 0,939 & 0,941 & 0,941 & 0,941 \\
Piauí & 0,991 & 0,911 & 0,911 & 0,909 & 0,914 \\
Rio Grande do Norte & 0,996 & 0,953 & 0,955 & 0,952 & 0,950 \\
Sergipe & 0,994 & 0,942 & 0,939 & 0,947 & 0,944 \\
\hline Espírito Santo & 0,992 & 0,929 & 0,936 & 0,935 & 0,932 \\
Minas Gerais & 0,989 & 0,898 & 0,899 & 0,901 & 0,893 \\
Rio de Janeiro & 0,998 & 0,983 & 0,983 & 0,983 & 0,982 \\
São Paulo & 0,986 & 0,866 & 0,862 & 0,863 & 0,858 \\
\hline Paraná & 0,980 & 0,798 & 0,793 & 0,792 & 0,781 \\
Rio Grande do Sul & 0,971 & 0,684 & 0,679 & 0,674 & 0,658 \\
Santa Catarina & 0,986 & 0,859 & 0,853 & 0,853 & 0,847 \\
\hline Distrito Federal & 0,995 & 0,953 & 0,951 & 0,949 & 0,944 \\
Goiás & 0,976 & 0,766 & 0,766 & 0,775 & 0,778 \\
Mato Grosso & 0,975 & 0,705 & 0,665 & 0,674 & 0,672 \\
Mato Grosso do Sul & 0,967 & 0,635 & 0,601 & 0,609 & 0,612 \\
\hline & & & & &
\end{tabular}





\section{APÊNDICE H}

Tabela H.1 - Fator de correção 8 do óleo diesel (uso ferroviário)

\begin{tabular}{cccccc}
\hline $\begin{array}{c}\text { Fator de correção 8- } \\
\text { diesel ferroviário }\end{array}$ & $\mathbf{2 0 0 4}$ & $\mathbf{2 0 0 5}$ & $\mathbf{2 0 0 6}$ & $\mathbf{2 0 0 7}$ & $\mathbf{2 0 0 8}$ \\
\hline Acre & 1,000 & 1,000 & 1,000 & 1,000 & 1,000 \\
Amapá & 1,000 & 1,000 & 1,000 & 1,000 & 1,000 \\
Amazonas & 1,000 & 1,000 & 1,000 & 1,000 & 1,000 \\
Pará & 0,974 & 0,971 & 0,968 & 0,967 & 0,966 \\
Rondônia & 1,000 & 1,000 & 1,000 & 1,000 & 1,000 \\
Roraima & 1,000 & 1,000 & 1,000 & 1,000 & 1,000 \\
Tocantins & 1,000 & 1,000 & 1,000 & 1,000 & 1,000 \\
\hline Alagoas & 0,995 & 0,995 & 0,996 & 0,995 & 0,995 \\
Bahia & 0,987 & 0,989 & 0,990 & 0,987 & 0,990 \\
Ceará & 0,994 & 0,994 & 0,995 & 0,994 & 0,995 \\
Maranhão & 0,857 & 0,844 & 0,825 & 0,823 & 0,842 \\
Paraíba & 0,993 & 0,993 & 0,994 & 0,993 & 0,993 \\
Pernambuco & 0,996 & 0,996 & 0,997 & 0,996 & 0,997 \\
Piauí & 0,998 & 0,998 & 0,998 & 0,998 & 0,998 \\
Rio Grande do Norte & 0,995 & 0,995 & 0,996 & 0,995 & 0,995 \\
Sergipe & 0,980 & 0,983 & 0,984 & 0,982 & 0,984 \\
\hline Espírito Santo & 0,910 & 0,914 & 0,924 & 0,922 & 0,930 \\
Minas Gerais & 0,934 & 0,935 & 0,936 & 0,934 & 0,938 \\
Rio de Janeiro & 0,966 & 0,966 & 0,964 & 0,963 & 0,964 \\
São Paulo & 0,988 & 0,986 & 0,984 & 0,986 & 0,985 \\
\hline Paraná & 0,990 & 0,990 & 0,984 & 0,986 & 0,988 \\
Rio Grande do Sul & 0,981 & 0,980 & 0,969 & 0,972 & 0,976 \\
Santa Catarina & 0,988 & 0,989 & 0,983 & 0,985 & 0,987 \\
\hline Distrito Federal & 0,998 & 0,998 & 0,998 & 0,998 & 0,998 \\
Goiás & 0,993 & 0,994 & 0,994 & 0,993 & 0,994 \\
Mato Grosso & 1,000 & 0,999 & 0,992 & 0,991 & 0,990 \\
Mato Grosso do Sul & 0,983 & 0,985 & 0,928 & 0,923 & 0,921 \\
\hline & & & & & \\
\hline & & & \\
\hline
\end{tabular}





\section{APÊNDICE I}

Tabela I.1 - Fator de correção 9 do óleo diesel (uso aquaviário)

\begin{tabular}{cccccc}
\hline $\begin{array}{c}\text { Fator de correção 9- } \\
\text { diesel aquaviário }\end{array}$ & $\mathbf{2 0 0 4}$ & $\mathbf{2 0 0 5}$ & $\mathbf{2 0 0 6}$ & $\mathbf{2 0 0 7}$ & $\mathbf{2 0 0 8}$ \\
\hline Acre & 0,981 & 0,982 & 0,974 & 0,969 & 0,969 \\
Amapá & 0,994 & 0,995 & 0,994 & 0,994 & 0,994 \\
Amazonas & 0,798 & 0,828 & 0,777 & 0,740 & 0,749 \\
Pará & 0,970 & 0,971 & 0,969 & 0,966 & 0,966 \\
Rondônia & 0,989 & 0,990 & 0,989 & 0,987 & 0,987 \\
Roraima & 0,809 & 0,800 & 0,779 & 0,760 & 0,800 \\
Tocantins & 0,962 & 0,963 & 0,960 & 0,961 & 0,964 \\
\hline Alagoas & 0,992 & 0,991 & 0,991 & 0,989 & 0,989 \\
Bahia & 0,991 & 0,991 & 0,990 & 0,989 & 0,990 \\
Ceará & 1,000 & 1,000 & 1,000 & 1,000 & 1,000 \\
Maranhão & 0,978 & 0,980 & 0,978 & 0,976 & 0,979 \\
Paraíba & 1,000 & 1,000 & 1,000 & 1,000 & 1,000 \\
Pernambuco & 0,997 & 0,997 & 0,997 & 0,996 & 0,997 \\
Piauí & 0,963 & 0,963 & 0,960 & 0,955 & 0,962 \\
Rio Grande do Norte & 1,000 & 1,000 & 1,000 & 1,000 & 1,000 \\
Sergipe & 0,996 & 0,996 & 0,996 & 0,996 & 0,996 \\
\hline Espírito Santo & 1,000 & 1,000 & 1,000 & 1,000 & 1,000 \\
Minas Gerais & 0,997 & 0,997 & 0,997 & 0,996 & 0,996 \\
Rio de Janeiro & 0,997 & 0,997 & 0,997 & 0,997 & 0,997 \\
São Paulo & 0,998 & 0,998 & 0,997 & 0,997 & 0,997 \\
\hline Paraná & 0,998 & 0,998 & 0,998 & 0,998 & 0,998 \\
Rio Grande do Sul & 0,993 & 0,992 & 0,991 & 0,990 & 0,991 \\
Santa Catarina & 1,000 & 1,000 & 1,000 & 1,000 & 1,000 \\
\hline Distrito Federal & 1,000 & 1,000 & 1,000 & 1,000 & 1,000 \\
Goiás & 0,998 & 0,998 & 0,998 & 0,998 & 0,998 \\
Mato Grosso & 0,991 & 0,989 & 0,986 & 0,986 & 0,987 \\
Mato Grosso do Sul & 0,987 & 0,986 & 0,983 & 0,982 & 0,983 \\
\hline & & & & & \\
\hline & & &
\end{tabular}





\section{APÊNDICE J}

Tabela J.1 - Volume de óleo diesel corrigido, por estado, no período 2004-2008 (1)

\begin{tabular}{|c|c|c|c|c|c|}
\hline Óleo diesel (I) & 2004 & 2005 & 2006 & 2007 & 2008 \\
\hline Brasil & 35.485.139.050 & 30.651.113.372 & 30.866 .224 .610 & 32.729.009.262 & 35.064 .781 .443 \\
\hline Norte & 2.985.995.384 & 3.048.838.352 & 2.970.293.374 & 3.064.098.673 & 3.201.424.988 \\
\hline Acre & 147.252 .605 & 151.144 .413 & 117.914 .582 & 108.666 .144 & 111.972 .166 \\
\hline Amapá & 183.443 .704 & 210.033 .173 & 199.473 .612 & 219.882 .461 & 232.092 .198 \\
\hline Amazonas & 527.429 .746 & 642.051 .569 & 526.856 .610 & 491.538 .088 & 522.288 .725 \\
\hline Pará & 1.152 .600 .399 & 1.089 .638 .148 & 1.154 .402 .563 & 1.223 .128 .712 & 1.233 .192 .702 \\
\hline Rondônia & 551.288 .191 & 584.060 .872 & 585.674 .954 & 557.719 .651 & 586.001 .496 \\
\hline Roraima & 41.216 .971 & 37.426 .788 & 37.395 .151 & 38.498 .134 & 49.589 .919 \\
\hline Tocantins & 382.763 .768 & 334.483 .390 & 348.575 .902 & 424.665 .483 & 466.287 .783 \\
\hline Nordeste & 5.108.457.187 & 4.736.597.327 & 4.919.533.907 & 5.219 .445 .216 & 5.982.067.958 \\
\hline Alagoas & 290.807 .701 & 220.808 .888 & 228.420 .611 & 224.311 .527 & 225.560 .663 \\
\hline Bahia & 1.884 .058 .262 & 1.698 .211 .431 & 1.729 .146 .839 & 1.839 .336 .060 & 2.205 .841 .529 \\
\hline Ceará & 496.567 .572 & 503.743 .215 & 560.347 .911 & 600.576 .066 & 695.931 .399 \\
\hline Maranhão & 515.930 .991 & 502.449 .481 & 508.936 .208 & 552.137 .379 & 660.803 .970 \\
\hline Paraíba & 318.648 .101 & 299.444 .307 & 306.747 .164 & 321.769 .529 & 332.683 .200 \\
\hline Pernambuco & 767.469 .522 & 730.635 .716 & 775.204 .655 & 822.751 .986 & 916.052 .930 \\
\hline Piauí & 281.765 .554 & 263.917 .364 & 272.060 .672 & 278.202 .938 & 333.374 .767 \\
\hline Rio Grande do Norte & 332.718 .267 & 303.889 .485 & 328.531 .907 & 325.305 .633 & 341.256 .321 \\
\hline Sergipe & 220.491 .216 & 213.497 .440 & 210.137 .939 & 255.054 .099 & 270.563 .178 \\
\hline Sudeste & 15.506.744.317 & 14.121.359.785 & 14.484.627.239 & 15.415 .169 .275 & 16.217.346.584 \\
\hline Espírito Santo & 601.470 .306 & 594.394 .593 & 703.403 .220 & 721.503 .880 & 776.805 .886 \\
\hline Minas Gerais & 4.380 .093 .832 & 4.091 .933 .714 & 4.285 .145 .016 & 4.597 .818 .283 & 4.718 .525 .252 \\
\hline Rio de Janeiro & 1.951 .005 .482 & 1.958 .739 .840 & 1.988 .622 .087 & 2.132 .468 .801 & 2.201 .882 .641 \\
\hline São Paulo & 8.574 .174 .697 & 7.476 .291 .637 & 7.507 .456 .917 & 7.963 .378 .311 & 8.520 .132 .805 \\
\hline Sul & 7.406.516.908 & 5.647.468.245 & 5.613.834.646 & 5.889.055.374 & 6.181.098.629 \\
\hline Paraná & 3.307 .133 .760 & 2.639 .027 .928 & 2.634 .357 .455 & 2.771 .742 .685 & 2.899 .615 .910 \\
\hline Rio Grande do Sul & 2.457 .836 .562 & 1.558 .723 .432 & 1.555 .708 .644 & 1.612 .682 .203 & 1.678 .838 .407 \\
\hline Santa Catarina & 1.641 .546 .587 & 1.449 .716 .885 & 1.423 .768 .547 & 1.504 .630 .486 & 1.602 .644 .312 \\
\hline Centro-Oeste & 4.477.425.253 & 3.096 .849 .664 & 2.877.935.443 & 3.141.240.724 & 3.482.843.285 \\
\hline Distrito Federal & 341.415 .647 & 331.267 .748 & 330.547 .496 & 334.606 .605 & 333.465 .231 \\
\hline Goiás & 1.397 .210 .898 & 1.114 .857 .837 & 1.149 .102 .749 & 1.275 .275 .988 & 1.450 .100 .575 \\
\hline Mato Grosso & 1.837 .405 .101 & 1.123 .654 .025 & 955.984 .479 & 1.050 .186 .637 & 1.159 .147 .365 \\
\hline Mato Grosso do Sul & 901.393 .607 & 527.070 .054 & 442.300 .720 & 481.171 .494 & 540.130 .115 \\
\hline
\end{tabular}





\section{APÊNDICE K}

Tabela K.1- Valores de $k$

\begin{tabular}{cccccc}
\hline $\begin{array}{c}\text { Fator de correção 9 - } \\
\text { diesel aquaviário }\end{array}$ & $\mathbf{2 0 0 4}$ & $\mathbf{2 0 0 5}$ & $\mathbf{2 0 0 6}$ & $\mathbf{2 0 0 7}$ & $\mathbf{2 0 0 8}$ \\
\hline Acre & 0,500 & 0,500 & 0,700 & 1,000 & 1,000 \\
Amapá & 0,500 & 0,500 & 0,500 & 0,500 & 0,500 \\
Amazonas & 0,700 & 0,700 & 1,000 & 1,000 & 1,000 \\
Pará & 0,600 & 0,700 & 0,700 & 0,700 & 1,000 \\
Rondônia & 0,700 & 0,700 & 1,000 & 1,000 & 1,000 \\
Roraima & 1,000 & 1,500 & 1,500 & 1,500 & 1,400 \\
Tocantins & 1,000 & 1,000 & 1,000 & 1,000 & 1,000 \\
\hline Alagoas & 0,700 & 1,000 & 1,000 & 1,000 & 1,000 \\
Bahia & 0,600 & 0,700 & 1,000 & 1,000 & 0,700 \\
Ceará & 1,000 & 1,000 & 1,000 & 1,000 & 1,000 \\
Maranhão & 0,500 & 0,500 & 0,500 & 0,500 & 0,500 \\
Paraíba & 1,000 & 1,000 & 1,000 & 1,000 & 1,000 \\
Pernambuco & 1,000 & 1,000 & 1,000 & 1,000 & 1,000 \\
Piauí & 0,700 & 0,700 & 1,000 & 1,000 & 0,700 \\
Rio Grande do Norte & 0,700 & 1,000 & 1,000 & 1,000 & 1,000 \\
Sergipe & 1,000 & 1,000 & 1,000 & 1,000 & 1,000 \\
\hline Espírito Santo & 1,000 & 1,000 & 1,000 & 1,000 & 1,000 \\
Minas Gerais & 0,700 & 1,000 & 1,000 & 1,000 & 1,000 \\
Rio de Janeiro & 1,000 & 1,000 & 1,000 & 1,000 & 1,000 \\
São Paulo & 1,000 & 1,000 & 1,000 & 1,000 & 1,000 \\
\hline Paraná & 0,700 & 1,000 & 1,000 & 1,000 & 1,000 \\
Rio Grande do Sul & 1,000 & 1,300 & 1,400 & 1,400 & 1,400 \\
Santa Catarina & 1,000 & 1,000 & 1,000 & 1,000 & 1,000 \\
\hline Distrito Federal & 1,000 & 1,000 & 1,000 & 1,000 & 1,300 \\
Goiás & 1,000 & 1,000 & 1,000 & 1,000 & 1,000 \\
Mato Grosso & 0,500 & 1,000 & 1,000 & 1,000 & 1,000 \\
Mato Grosso do Sul & 0,700 & 1,000 & 1,400 & 1,400 & 1,300 \\
\hline & & & & & \\
\hline & & &
\end{tabular}





\section{APÊNDICE L}

Tabela L.1- Quilometragens médias anuais correspondentes ao ano de 2004

\begin{tabular}{|c|c|c|c|c|c|}
\hline $\begin{array}{c}\text { Grandes Regiões e } \\
\text { Unidades da } \\
\text { Federação }\end{array}$ & Todos & $\begin{array}{l}\text { Veículo } \\
\text { leve }\end{array}$ & Motocicleta & Caminhão & Ônibus \\
\hline Brasil & 13.183 & 10.036 & 14.533 & 42.994 & 64.115 \\
\hline Norte & 20.332 & 15.107 & 14.358 & 88.745 & 85.766 \\
\hline Acre & 17.193 & 13.292 & 12.102 & 85.253 & 86.529 \\
\hline Amapá & 25.239 & 18.483 & 18.112 & 134.543 & 133.773 \\
\hline Amazonas & 20.980 & 16.862 & 16.436 & 83.632 & 81.504 \\
\hline Pará & 20.120 & 14.660 & 14.415 & 82.617 & 80.094 \\
\hline Rondônia & 18.209 & 13.230 & 12.181 & 85.238 & 86.058 \\
\hline Roraima & 16.354 & 13.916 & 14.056 & 61.191 & 55.708 \\
\hline Tocantins & 23.503 & 15.794 & 13.487 & 111.922 & 100.986 \\
\hline Nordeste & 15.451 & 12.557 & 15.277 & 35.690 & 68.546 \\
\hline Alagoas & 16.565 & 14.003 & 15.785 & 33.607 & 60.860 \\
\hline Bahia & 17.190 & 13.899 & 17.897 & 35.456 & 68.041 \\
\hline Ceará & 12.697 & 10.479 & 12.534 & 30.977 & 59.218 \\
\hline Maranhão & 18.390 & 14.482 & 18.752 & 37.989 & 74.451 \\
\hline Paraíba & 17.320 & 14.104 & 16.489 & 46.098 & 92.528 \\
\hline Pernambuco & 13.863 & 11.061 & 13.492 & 35.668 & 69.273 \\
\hline Piauí & 14.229 & 11.176 & 13.397 & 37.467 & 73.748 \\
\hline Rio Grande do Norte & 15.790 & 13.814 & 15.145 & 33.205 & 60.801 \\
\hline Sergipe & 16.391 & 13.101 & 15.278 & 38.981 & 75.087 \\
\hline Sudeste & 12.152 & 9.479 & 14.399 & 38.730 & 64.261 \\
\hline Espírito Santo & 13.623 & 10.510 & 15.413 & 23.923 & 73.888 \\
\hline Minas Gerais & 13.252 & 9.841 & 15.130 & 43.694 & 51.603 \\
\hline Rio de Janeiro & 13.390 & 11.284 & 17.098 & 27.316 & 75.183 \\
\hline São Paulo & 11.442 & 8.921 & 13.454 & 39.313 & 65.632 \\
\hline Sul & 12.392 & 9.174 & 14.542 & 37.768 & 61.472 \\
\hline Paraná & 11.436 & 8.685 & 12.404 & 33.470 & 54.807 \\
\hline Rio Grande do Sul & 12.350 & 9.003 & 15.352 & 39.203 & 64.683 \\
\hline Santa Catarina & 14.024 & 10.211 & 16.653 & 43.136 & 68.075 \\
\hline Centro-Oeste & 15.729 & 11.552 & 14.320 & 67.094 & 53.098 \\
\hline Distrito Federal & 13.460 & 11.838 & 16.652 & 51.987 & 39.140 \\
\hline Goiás & 16.014 & 11.545 & 14.055 & 69.139 & 58.227 \\
\hline Mato Grosso & 18.246 & 12.036 & 14.229 & 71.984 & 56.386 \\
\hline Mato Grosso do Sul & 15.351 & 10.752 & 12.737 & 65.819 & 53.974 \\
\hline
\end{tabular}


Tabela L.2- Quilometragens médias anuais correspondentes ao ano de 2005

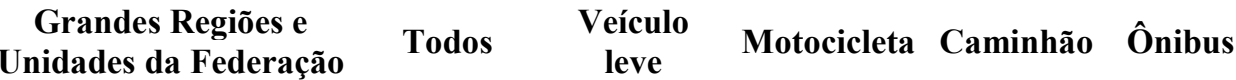

\begin{tabular}{|c|c|c|c|c|c|}
\hline Brasil & 12.819 & 9.837 & 14.271 & 40.373 & 60.857 \\
\hline Norte & 19.092 & 14.059 & 13.363 & 87.460 & 84.736 \\
\hline Acre & 16.258 & 12.793 & 11.501 & 82.455 & 84.224 \\
\hline Amapá & 23.664 & 17.032 & 16.126 & 144.749 & 143.351 \\
\hline Amazonas & 20.215 & 15.723 & 14.725 & 92.468 & 89.569 \\
\hline Pará & 19.768 & 14.067 & 14.572 & 83.289 & 81.179 \\
\hline Rondônia & 17.077 & 12.662 & 11.089 & 83.613 & 84.967 \\
\hline Roraima & 15.342 & 12.382 & 11.903 & 77.160 & 71.623 \\
\hline Tocantins & 18.839 & 13.114 & 11.528 & 88.092 & 79.988 \\
\hline Nordeste & 14.853 & 12.194 & 14.510 & 34.023 & 65.909 \\
\hline Alagoas & 16.148 & 13.626 & 15.062 & 33.820 & 61.266 \\
\hline Bahia & 16.181 & 13.201 & 16.070 & 34.080 & 66.124 \\
\hline Ceará & 12.324 & 10.166 & 12.249 & 29.711 & 57.477 \\
\hline Maranhão & 17.128 & 13.683 & 17.383 & 34.794 & 68.438 \\
\hline Paraíba & 16.213 & 13.375 & 15.624 & 41.750 & 83.889 \\
\hline Pernambuco & 13.563 & 11.060 & 13.381 & 32.576 & 63.785 \\
\hline Piauí & 13.375 & 10.719 & 12.802 & 32.961 & 65.328 \\
\hline Rio Grande do Norte & 16.178 & 13.775 & 14.968 & 39.980 & 74.087 \\
\hline Sergipe & 15.756 & 13.067 & 14.358 & 35.149 & 68.524 \\
\hline Sudeste & 12.022 & 9.437 & 14.432 & 36.806 & 61.822 \\
\hline Espírito Santo & 13.107 & 10.211 & 15.017 & 22.068 & 68.405 \\
\hline Minas Gerais & 13.880 & 9.651 & 15.009 & 54.796 & 65.554 \\
\hline Rio de Janeiro & 13.358 & 11.341 & 16.647 & 26.634 & 73.829 \\
\hline São Paulo & 11.076 & 8.882 & 13.695 & 32.853 & 55.804 \\
\hline Sul & 11.906 & 8.914 & 14.359 & 34.233 & 56.432 \\
\hline Paraná & 11.866 & 8.845 & 12.955 & 36.161 & 59.876 \\
\hline Rio Grande do Sul & 11.154 & 8.346 & 14.627 & 31.028 & 51.976 \\
\hline Santa Catarina & 13.194 & 9.910 & 16.175 & 35.848 & 57.235 \\
\hline Centro-Oeste & 14.510 & 10.821 & 13.534 & 59.860 & 48.244 \\
\hline Distrito Federal & 13.002 & 11.510 & 15.973 & 49.136 & 37.302 \\
\hline Goiás & 13.931 & 10.460 & 13.391 & 52.283 & 44.621 \\
\hline Mato Grosso & 18.383 & 11.629 & 13.251 & 82.010 & 66.017 \\
\hline Mato Grosso do Sul & 13.356 & 9.819 & 11.651 & 52.233 & 44.169 \\
\hline
\end{tabular}


Tabela L.3- Quilometragens médias anuais correspondentes ao ano de 2006

\begin{tabular}{|c|c|c|c|c|c|}
\hline $\begin{array}{c}\text { Grandes Regiões e } \\
\text { Unidades da } \\
\text { Federação }\end{array}$ & Todos & $\begin{array}{l}\text { Veículo } \\
\text { leve }\end{array}$ & Motocicleta & Caminhão & Ônibus \\
\hline Brasil & 12.650 & 9.824 & 13.491 & 40.303 & 61.150 \\
\hline Norte & 18.614 & 13.658 & 12.481 & 92.153 & 89.009 \\
\hline Acre & 15.810 & 12.480 & 11.195 & 83.395 & 85.733 \\
\hline Amapá & 21.605 & 16.241 & 15.406 & 128.986 & 127.124 \\
\hline Amazonas & 20.231 & 15.452 & 14.470 & 97.833 & 94.419 \\
\hline Pará & 19.012 & 14.014 & 13.471 & 81.744 & 79.583 \\
\hline Rondônia & 18.711 & 12.628 & 10.766 & 113.748 & 115.447 \\
\hline Roraima & 15.037 & 12.567 & 11.944 & 73.141 & 67.229 \\
\hline Tocantins & 15.837 & 11.209 & 9.088 & 81.672 & 73.589 \\
\hline Nordeste & 14.914 & 11.948 & 14.229 & 38.217 & 73.747 \\
\hline Alagoas & 15.489 & 13.604 & 13.197 & 32.658 & 59.506 \\
\hline Bahia & 17.204 & 12.769 & 16.829 & 46.176 & 89.978 \\
\hline Ceará & 12.393 & 10.073 & 12.350 & 31.156 & 60.298 \\
\hline Maranhão & 16.106 & 13.060 & 16.165 & 33.456 & 65.642 \\
\hline Paraíba & 15.526 & 13.325 & 14.010 & 40.551 & 81.093 \\
\hline Pernambuco & 13.226 & 10.568 & 13.317 & 32.427 & 61.377 \\
\hline Piauí & 14.712 & 11.847 & 12.797 & 46.157 & 91.594 \\
\hline Rio Grande do Norte & 15.249 & 13.350 & 13.101 & 40.307 & 75.304 \\
\hline Sergipe & 15.424 & 13.086 & 14.132 & 32.609 & 63.825 \\
\hline Sudeste & 12.065 & 9.653 & 13.878 & 35.796 & 60.660 \\
\hline Espírito Santo & 12.944 & 10.038 & 13.700 & 24.228 & 75.025 \\
\hline Minas Gerais & 13.291 & 9.310 & 13.612 & 54.336 & 65.165 \\
\hline Rio de Janeiro & 13.231 & 11.487 & 14.608 & 25.836 & 72.268 \\
\hline São Paulo & 11.361 & 9.293 & 13.793 & 31.323 & 53.818 \\
\hline Sul & 11.268 & 8.556 & 12.654 & 33.404 & 55.601 \\
\hline Paraná & 10.733 & 8.049 & 10.775 & 34.532 & 57.746 \\
\hline Rio Grande do Sul & 10.681 & 7.974 & 12.913 & 32.000 & 54.136 \\
\hline Santa Catarina & 13.061 & 10.230 & 15.238 & 33.545 & 54.048 \\
\hline Centro-Oeste & 13.764 & 10.322 & 13.059 & 56.676 & 46.282 \\
\hline Distrito Federal & 12.440 & 11.033 & 15.217 & 47.593 & 36.335 \\
\hline Goiás & 13.635 & 10.346 & 13.068 & 51.329 & 44.255 \\
\hline Mato Grosso & 15.956 & 10.348 & 12.561 & 67.362 & 55.311 \\
\hline Mato Grosso do Sul & 13.175 & 9.091 & 11.358 & 58.981 & 50.575 \\
\hline
\end{tabular}


Tabela L.4- Quilometragens médias anuais correspondentes ao ano de 2007

\begin{tabular}{|c|c|c|c|c|c|}
\hline $\begin{array}{c}\text { Grandes Regiões e } \\
\text { Unidades da } \\
\text { Federação }\end{array}$ & Todos & $\begin{array}{c}\text { Veículo } \\
\text { leve }\end{array}$ & Motocicleta & Caminhão & Ônibus \\
\hline Brasil & 12.731 & 9.742 & 14.138 & 40.236 & 61.458 \\
\hline Norte & 18.122 & 13.742 & 12.471 & 88.236 & 85.178 \\
\hline Acre & 16.440 & 12.691 & 10.815 & 102.031 & 105.424 \\
\hline Amapá & 21.087 & 15.962 & 14.872 & 133.629 & 132.544 \\
\hline Amazonas & 18.961 & 15.211 & 13.838 & 85.294 & 82.644 \\
\hline Pará & 18.595 & 14.144 & 13.379 & 78.853 & 76.280 \\
\hline Rondônia & 16.946 & 12.343 & 10.106 & 100.098 & 101.809 \\
\hline Roraima & 13.835 & 11.846 & 11.015 & 67.963 & 62.561 \\
\hline Tocantins & $\mathbf{1 7 . 9 8 6}$ & 12.469 & 11.497 & 91.882 & 83.633 \\
\hline Nordeste & 14.474 & 11.390 & 14.151 & 37.733 & 72.714 \\
\hline Alagoas & 14.859 & 12.692 & 14.055 & 30.232 & 54.923 \\
\hline Bahia & 16.405 & 12.028 & 16.020 & 45.552 & 88.818 \\
\hline Ceará & 12.256 & 9.872 & 12.307 & 31.332 & 60.546 \\
\hline Maranhão & 16.215 & 12.377 & 17.113 & 33.250 & 65.980 \\
\hline Paraíba & 15.653 & 12.704 & 15.907 & 39.629 & 78.570 \\
\hline Pernambuco & 12.580 & 9.893 & 12.661 & 32.029 & 59.766 \\
\hline Piauí & 13.910 & 11.141 & 12.330 & 43.980 & 87.946 \\
\hline Rio Grande do Norte & 14.948 & 12.736 & 14.187 & 37.451 & 70.270 \\
\hline Sergipe & 15.394 & 12.991 & 13.173 & 37.323 & 73.775 \\
\hline Sudeste & 12.413 & 9.863 & 14.760 & 35.770 & 61.170 \\
\hline Espírito Santo & 12.607 & 9.286 & 15.001 & 23.036 & 71.203 \\
\hline Minas Gerais & 13.586 & 9.052 & 15.532 & 54.640 & 66.020 \\
\hline Rio de Janeiro & 13.647 & 11.440 & 17.834 & 26.242 & 73.795 \\
\hline São Paulo & 11.753 & 9.740 & 13.892 & 31.157 & 54.268 \\
\hline Sul & 11.069 & 7.970 & 13.808 & 33.374 & 56.043 \\
\hline Paraná & 10.642 & 7.701 & 11.838 & 34.516 & 58.045 \\
\hline Rio Grande do Sul & 10.908 & 7.709 & 15.086 & 31.777 & 54.330 \\
\hline Santa Catarina & 12.004 & 8.770 & 15.039 & 33.782 & 55.029 \\
\hline Centro-Oeste & 13.592 & 10.115 & 12.936 & 57.985 & 48.378 \\
\hline Distrito Federal & 12.129 & 10.562 & 17.026 & 44.966 & 35.881 \\
\hline Goiás & 13.564 & 10.551 & 12.295 & 53.287 & 46.364 \\
\hline Mato Grosso & 15.068 & 9.677 & 11.345 & 69.523 & 58.233 \\
\hline Mato Grosso do Sul & 13.234 & 9.159 & 11.383 & 60.392 & 52.581 \\
\hline
\end{tabular}

